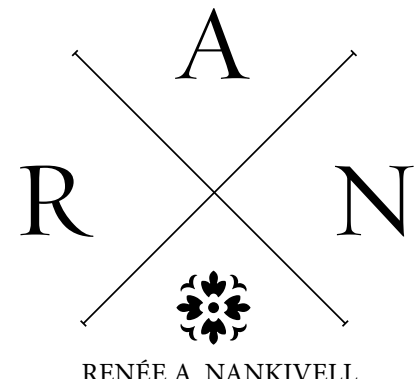

RENÉE A. NANKIVELL 


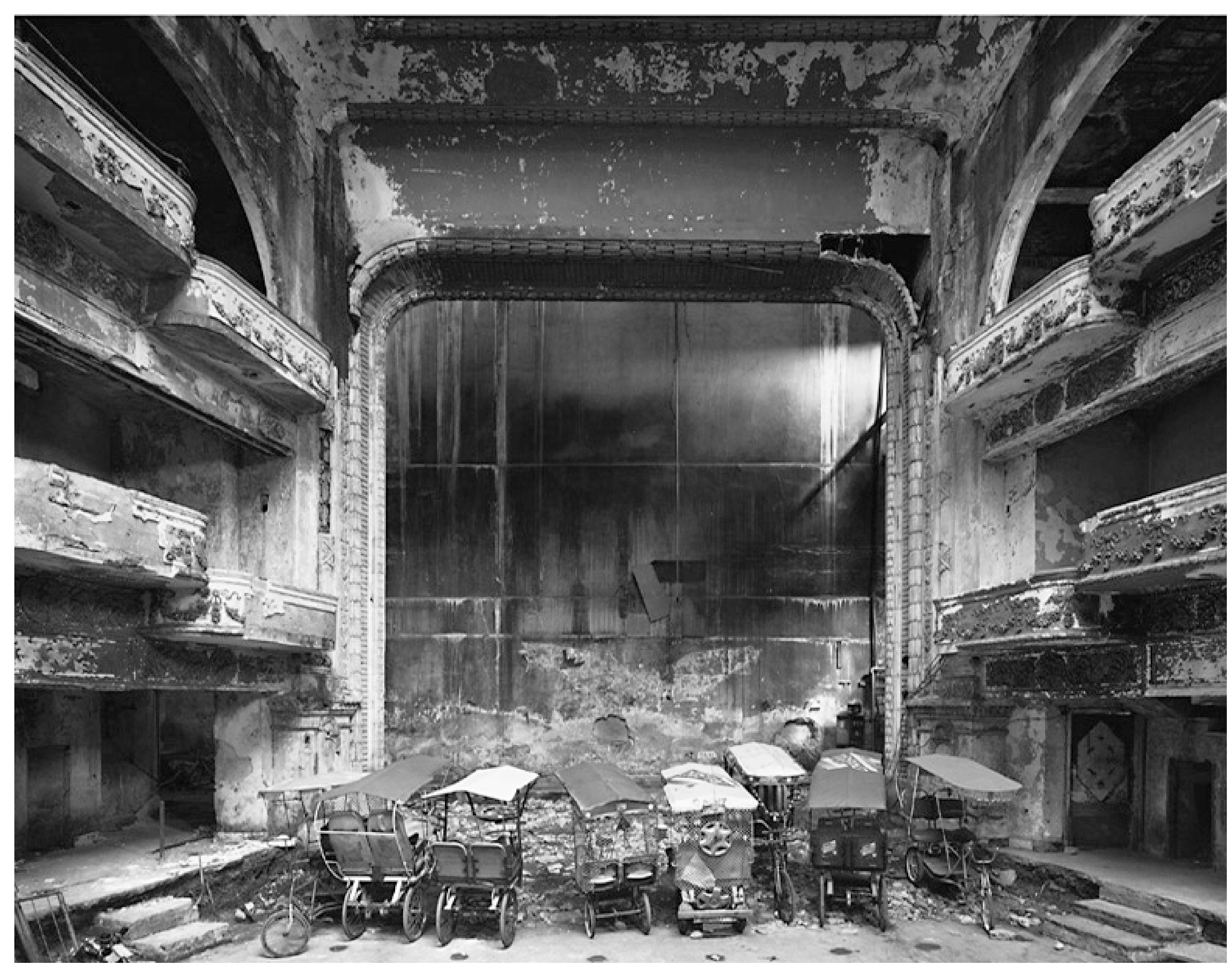


Burrianka WEE $D^{\circ}$ for
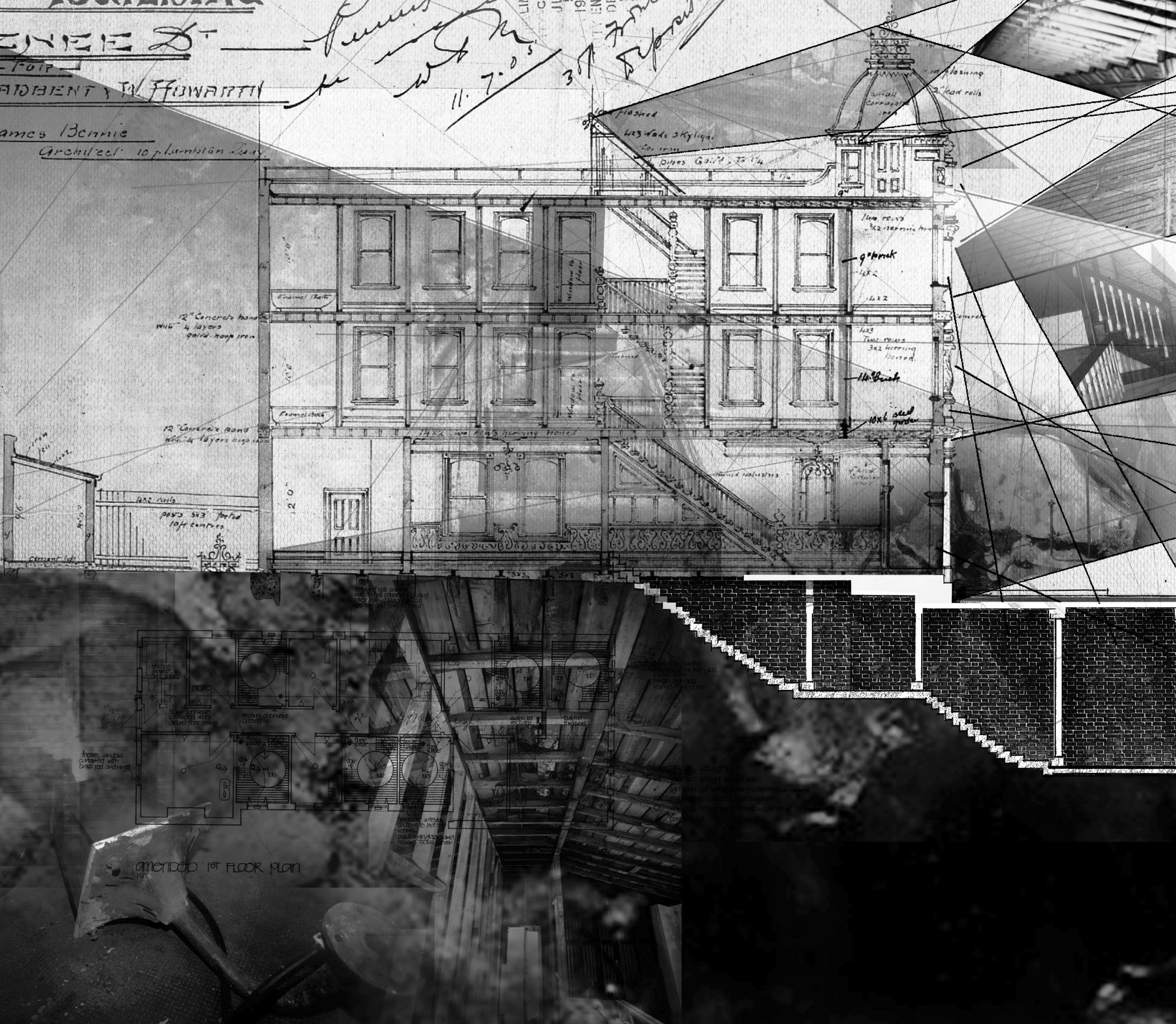

.

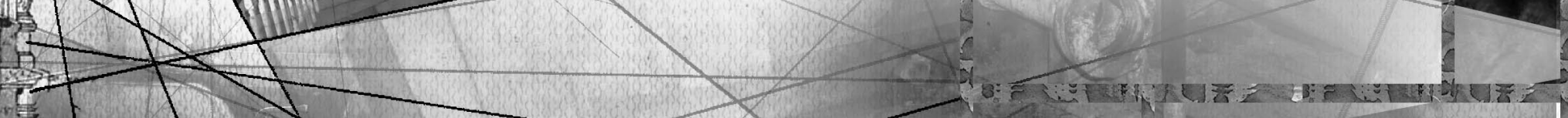




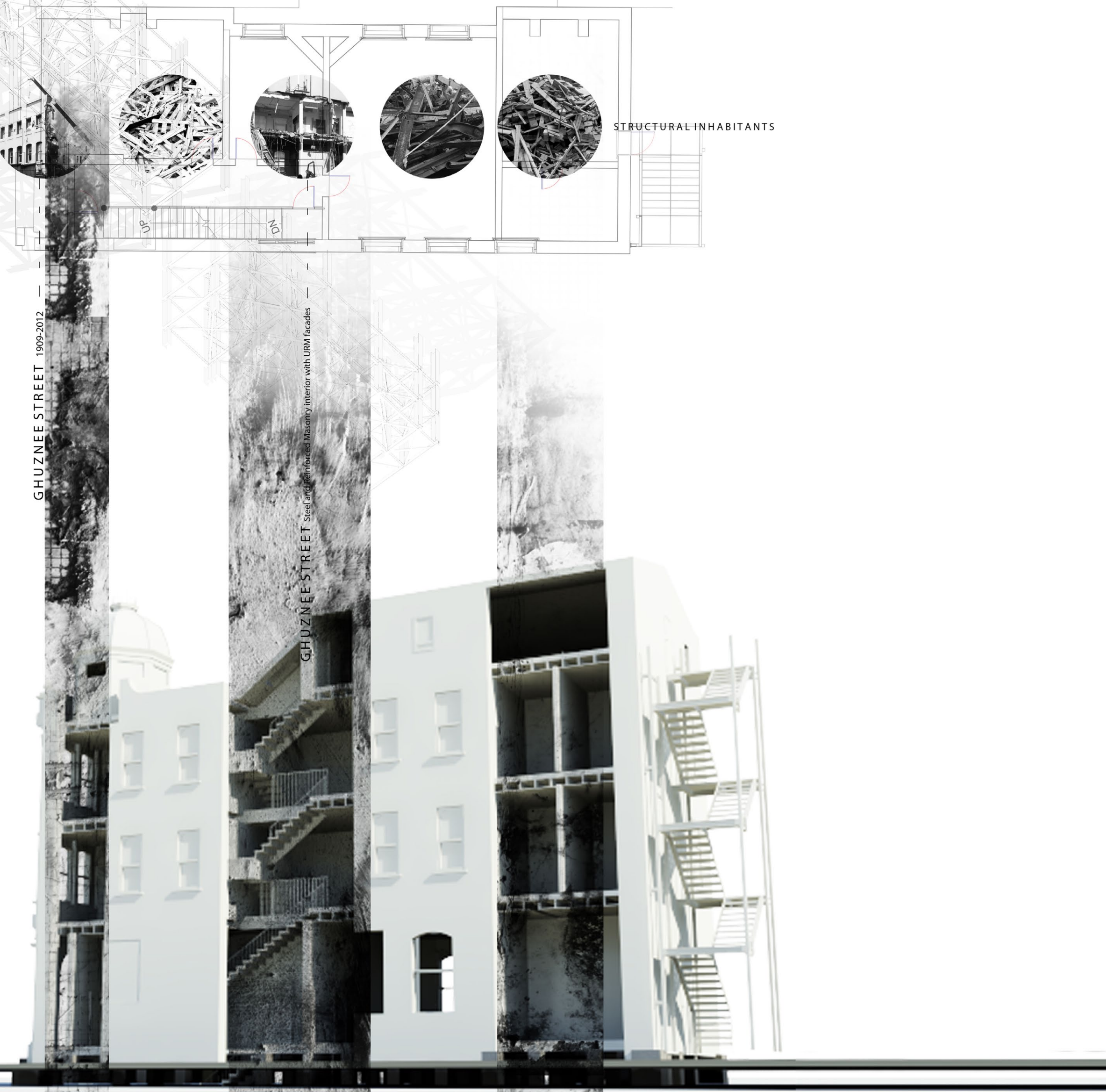




\section{Time Passes}

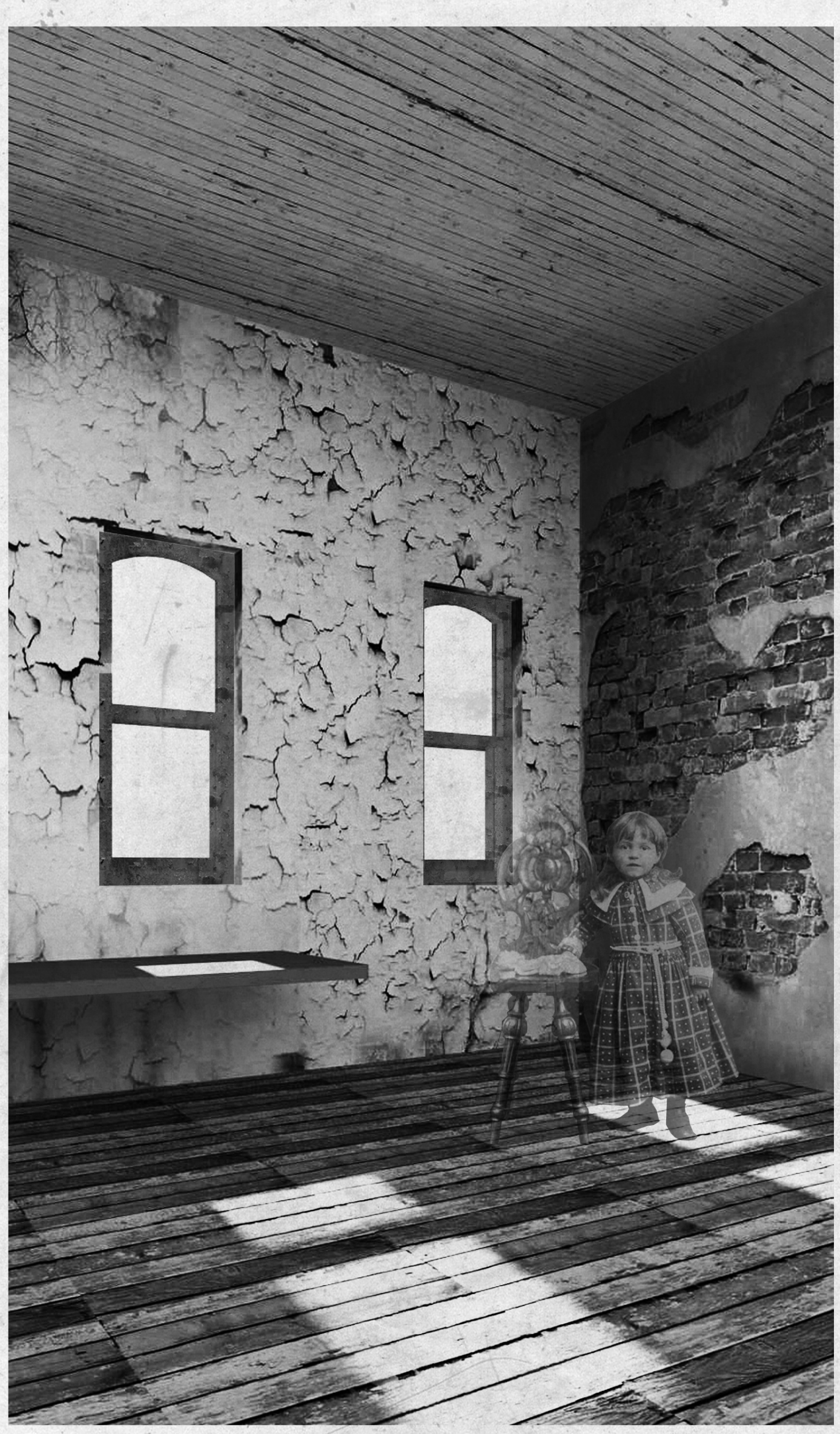

No material within this thesis may be used without permission of the copyright owner. 


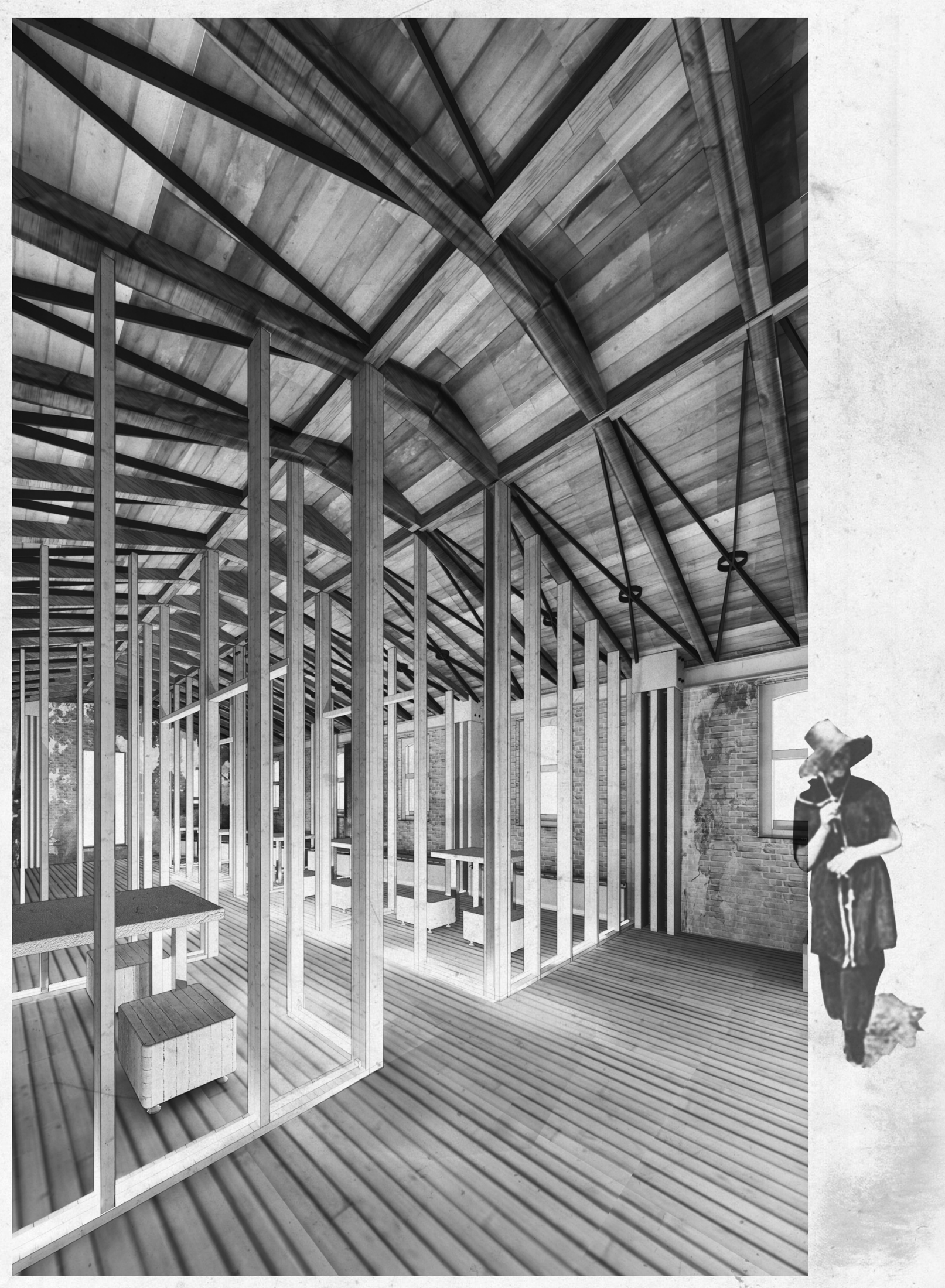

\section{ACKNOWLEDGEMENTS}

Through this thesis and accumulative five years of study, I have been taken on an eventful and unexpected journey much like a rollercoaster, if it wasn't for those who sat by my side, with words of wisdom and a hand to hold, the ride would not have been the same. I would like to like to thank all those who held my hand along the journey and willingly shared in the screams of fear, anxiety and joy.

To my family, close friends and fellow classmates who have provided many kind words of encouragement. Thank-you.

To my parents Jan and Peter Nankivell who are my drivers and my inspiration. Thank-you.

Joshua M. Noon whose friendship over the last ten years has been on par with his infallible advice for the graphic design of this document. Thank-you.

Shea M. Treacy whose kindness and attention to detail cannot go without mention. Thank-you.

I would also like to thank Sean Gledhill for his structural engineering council, design guidance and friendship throughout the production of this thesis.

And I would particularly like to thank my supervisor Daniel k. Brown who soon became a mentor and close friend. Thank-you for all the wisdom and words of encouragement you have given me at times when I thought i'd never make it to the end of the ride, and thank-you for teaching me that.

The hardest part is having the faith to trust in yourself. 


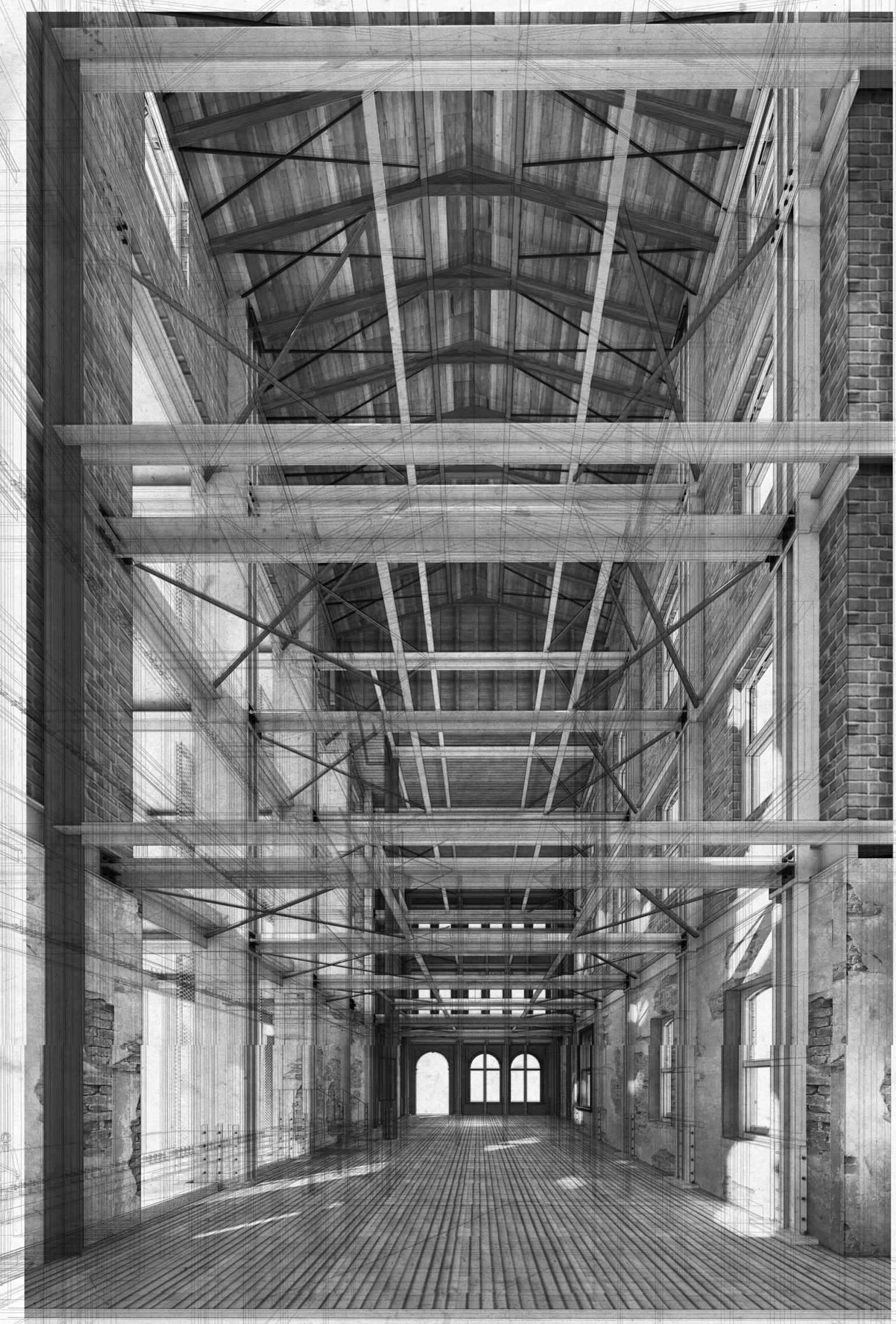

\section{CONTENTS}

To Introduce

An introduction to the theories and ideas addressed by this thesis

Layer 01:History theory \& poetic stratification An exploration of layering theories as a means to address New Zealand's lateral bracing requirements.

Layer 02: Assimilating architecture \& installation art Contextual heritage An exploration of both architectural and installation art projects to explore An exploration of both architectural and installation art projects to explore
methods of engaging with aging historic buildings as a means of protecting the layers of history within historic sites.

Layer 03: Contextual heritage

An exploration of the contextual conditions within Wellington an within the design research vehicle the Albemarle Hotel.

Layer 04: Programmatic explorations

An exploration of the New Zealand Historic Places Trust as a viable contemporary program to re-inhabit the Albemarle.

Layer 05: An exploration of contemporary layers A contemporary exploration of lateral bracing methods that both provides seismic resistance and create habitable spatial definitions within the historic Albemarle Hotel.

Peeling Back: A retrospective view of the last layer This chapter provides a retrospective summary of the research imperative of this thesis, whilst also proposing future methods of improving seismic historic materials.

References \& Figures

A complete list of text references and figures for this thesis.
OI 


\section{ABSTRACT}

$\mathrm{T}$ he demand for a new approach to safeguarding New Zealand's endangered historic buildings was identified as a result of the recent increase in building code and strengthening requirements following the Christchurch earthquakes of 2010-2011. The Wellington City Council identified 266 heritage buildings in the city that must be either strengthened or demolished to address these increased requirements. This thesis explores this threat as an opportunity for researching how contemporary design interventions can be challenged to both strengthen and become active participants in the ongoing history of New Zealand's potentially endangered historic buildings. This thesis challenges the current approach of completely 'restoring' 19th-20th century historic buildings in New Zealand, to develop techniques that structurally reinforce historic buildings while inviting the progressive weathering of a building to remain as a testament to its history.

This thesis proposes a structural intervention that is responsive to the progressive history of historic buildings, simultaneously introducing a contemporary structural intervention that both participates in and compliments the progressive historic transformations of the vehicle. This thesis argues that current historic buildings in semi-decayed states in fact enable visitors to witness multiple stages in the life of a building, while fully restored buildings only enable visitors to witness the original form of the building. This thesis proposes a model for contemporary intervention within historic buildings that draws a design intervention from seismic strengthening.

Fig. i (PG. II) Campoamor, Vista Este (19982002) BY ANDREW MONI

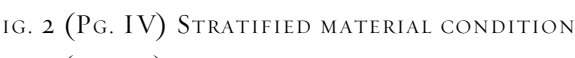
1G. 3 (PG. VI) IDENTIFYING the weak points IN

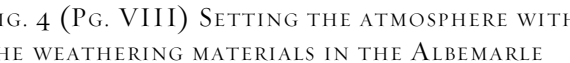
HOTEL

Fig. 5 (PG. X) Existing Roof top conditions Fig. 6 (PG. XII) EXPLoRING LATERAL BRACING WITHIN THE ALBEM MRLE HOTEL WiTHOUT FLoO
The notion of layering is explored as a design approach to incorporate the contemporary with the historic as an additional layer of exposed on-going history, thereby further exposing the layers of history evident within New Zealand's historic buildings. This thesis combines layering theories of architects Louis Kahn and Carlo Scarpa with related theories of installation artist Mary Miss. The theoretical imperatives of Scarpa and Kahn are explored as a tool of engagement for the junction between the contemporary and historic building materials, and the work of Marry Miss is explored as a design approach for developing a contemporary intervention that references the layered historic building while inviting new means of occupancy between layers. The selected vehicle for the design research investigation is the Albemarle Hotel on Ghuznee Street in Wellington. The techniques proposed in this thesis to strengthen the Albemarle Hotel suggest an approach that might be applied to New Zealand's wider body of historic buildings that constitute New Zealand's heritage fabric, ultimately protecting them from demolition while preserving additional layers of their historic narratives.

Over all the design research experiments suggest that contemporary interventions derived from structural strengthening may be a viable and cost-effective method of re-inhabiting New Zealand's endangered heritage buildings, avoiding demolition and securing New Zealand's heritage for future generations.

\section{Research Questions:}

This thesis challenges the current economically unsustainable approach of laterally reinforcing and completely 'restoring' 19th-20th century historic buildings in New Zealand. This thesis argues that current historic buildings in semi-decayed states in fact enable visitors to witness multiple stages in the on-going life of a building.

Can the weathered state of New Zealand's heritage buildings be proactively retained and celebrated as witnesses to their history? Can new lateral reinforcing requirements be conceived as active participants in revealing the on-going history of New Zealand's historic buildings? 
"Nothing STIRRED IN THE DRAWING-ROOM OR IN THE DINING-ROOM OR ON THE STAIRCASE. ONLY THROUGH THE RUSTY HINGES AND SWOLLEN SEAMOISTENED WOODWORK CERTAIN AIRS, DETACHED FROM THE BODY OF THE WIND (THE HOUSE WAS RAMSHACKLE AFTER ALL) CREPT ROUND CORNERS AND Ventured indoors. Almost one might imagine THEM, AS THEY ENTERED THE DRAWING-ROOM QUESTIONING AND WONDERING, TOYING WITH THE FLAP OF HANGING WALL-PAPER, ASKING, WOULD IT HANG MUCH LONGER, WhEN WOUlD IT FALL? THEN SMOOTHLY BRUSHING THE WALLS, THEY PASSED ON MUSINGLY AS IF ASKING THE RED AND YELLOW ROSES ON THE WALL-PAPER WHETHER THEY HAD TIME AT THEIR DISPOSAL) THE TORN LETTERS IN THE WASTEPAPER BASKET, THE FLOWERS, THE BOOKS, ALL OF WHICH WERE NOW OPEN TO THEM AND ASKING, Were they allies? Were ther enemies? How long WOULD THEY ENDURE."
THE YOUNG WOMAN

I always knew I would work in heritage architecture, mainly because I have never been drawn to the impressive facets, oblique angles, organic curves, or the shiny new nature of contemporary design; for some reason I have become enchanted by quiet old historic buildings, the grandmothers and grandfathers to the young contemporary buildings. These are the structures that have earned their place in history, creating the foundation upon which the contemporary child builds; and with the dilemma of choosing a thesis topic that represents the pinnacle of five years of study towards my Master of Architecture (Prof) looming over my head like a storm cloud, I visited one of my favourite buildings in Wellington, the Albemarle Hotel, 59 Ghuznee Street. Upon visiting the Albemarle Hotel or 'Heaven, Hell and Petticoat Junction' as it has previously been dubbed, I discovered that the Category II historic building was half 'renovated' and deserted; a partial demolition had taken place on the interior before it was abandoned by its owners and put up for sale. Ironically I saw that the contractors had revealed an extraordinary quality of beauty in the exposed layers and peeling paint; I was able to see the history of the building, as I never thought possible. The layers of wallpaper from its days as a brothel peeled away from the layers of paint from the days as a sauna: all was exposed, and I felt a sudden connection to the people who had occupied this space before me. I then discovered that the building was likely to face demolition, due to the high cost of reinforcing and prevention of earthquake damage; the building owners could not find a buyer who was willing to invest in the historic hotel in order to save it from demolition. This set the stage for my realization that this was a critical contemporary architectural problem needing new design approaches to resolve it....my search was over. 
INTRODUCTION

New Zealand's settlement dates back over 200 years to the British colonization and over 700 years to the Polynesian settlement believed to be around $1300 \mathrm{AD}$ (Geoff 2009, Ministry for Culture and Heritage 2011). New Zealand's 700 years of cultural history in comparison to 2000-5000 years in more ancient civilizations of the world is considered a 'recent' or a 'young history' on the world scale; however this thesis argues that New Zealand's historic sites should be treated with the same veneration as the more ancients examples. New Zealand's 19th-20th Century historic buildings that inhabit the 21st Century have been exposed to the threat of either damage from an earthquake or demolition as a preventative measure to protect the population from harm in the event of an earthquake.

The structural inadequacy of New Zealand's building code with regards to both historic and contemporary buildings was revealed following the Christchurch earthquakes of 2010-2011. The earthquakes resulted in the destruction of over $85 \%$ of Christchurch's unreinforced masonry (URM) buildings and the death of 185 people (Dizhur et al. 280). This series of natural disasters has exposed the need for a re-evaluation of New Zealand's building code with particular regards to historic buildings and the techniques involved in structurally retrofitting URM buildings. The increased lateral reinforcing requirements have increased resulted in the preventative demolition of some of Wellington's historic buildings including the future demolition of the Riddiford Building atWellington Hospital, Erskine College in Island Bay and the Harcourts Building on Lambton Quay (McBride 23.03.12, McBride 2.09.12, Torrie).

The Harcourts building, a Category I heritage building is one of Wellington's firs heritage buildings to be potentially demolished due to the cost of earthquake bracing.The Dominion Post published an article on the 30th of November 2012 that explained: "The cost of earthquake-strengthening work on the category 1 listed building has been put at $\$ 10.8$ million, which Mr Dunajtschik has described as not economically viable”(Easton). This is now the situation for many owners of heritage buildings in Wellington; the alternative to a costly strengthening project is unfortunately elective demolition.
"Wellington City Council planners said the earthquake-prone building, on the corner of Lambton Quay and Grey St, was a risk to public safety. It recommended its owner, Wellington developer Mark Dunajtschik, be granted consent to demolish it. Mr Dunajtschik has applied to the council for a demolition permit, and wants to put up a 25-storey building to match the adjoining HSBC Tower" (Easton).

The challenge now is to test approaches to improving the lateral bracing of historic buildings in cost effective ways that address the complex issues of degrees of historic renovation versus opportunities for the exposure of contemporary elements, addressing the very real threat facing Wellington's built heritage.

This thesis attempts to develop an approach to some of the multiplicity of problems facing New Zealand's 19th-20th century historic buildings that inhabit the 21 st century. It identifies methods that may produce a cost effective approach to introducing lateral bracing to New Zealand's vulnerable historic buildings. This thesis argues that the 'restoration' process can often be expensive, and when added to the recent increase in lateral bracing requirements of the building code, owners of historic sites may not be able to afford to upgrade their dilapidated heritage buildings, in which case the Wellington City Council has identified that these buildings will be demolished as a means of preventing earthquake damage and loss of life. The full 'restoration' of heritage sites including the introduction of concealed lateral bracing is a cost prohibitive approach. It involves the costly restoration of the original historic elements by removing 'subsequently deposited ' (i.e. newer) historic elements or features that can be viewed as having their own equal historic value and place in the ongoing history of the building. The concealment of the required new contemporary elements ignores the fact that today is a viable reflection of tomorrow's history as a part of the theory that historic buildings can build a multiplicity of layers over time that evidences the history within the historic site. This thesis argues that the full 'restoration' of historic buildings also ignores the potential problem that their original program may be obsolete and thus their configurations may need to be readdressed to enable viable new programs to sustain the use of heritage structures in the 21 st century. 
The design research imperatives of this thesis propose viable solutions to these issues that are intended to vary with the context of each historic site to which they are applied. This thesis proposes that the on-going changes in many historic buildings can be retained as important reflections of history, thus reducing the need for costly renovation. It proposes that new lateral bracing can be exposed to reduce the cost of concealing large structural elements; and furthermore it argues that internal configurations of historic buildings can be changed to enable the accommodation of new and more viable programs.

The intertwined issues involved in the design research problem require a response that is equally complex and multifaceted; this thesis proposes an approach that enables this multiplicity of issues to be addressed by: celebrating the layers of progressive weathering and transformation, exposing new contemporary structural elements to act in combination with the aging heritage site, allowing the reconfiguration of the historic interior planning where appropriate, and designing the new lateral bracing intervention to not only achieve the building code requirements but to also become a framework for the new planning opportunities.

This thesis explores theories of layering or stratification as a potential means to engage with the semi-decayed or semi-demolished heritage sites in New Zealand. It recognises that each heritage site evidences differing degrees of weathering and therefore should engage this new approach in ways that are appropriate to its unique circumstances, while safeguarding the semi-decayed state and preserves its exposed layers. This thesis argues that historic value is in fact added to a heritage building by safeguarding each layer of its history; this thesis proposes that it is in the decay and layering of materials that historic buildings find additional meaning and beauty, permitting materials to tell a historical story of their life or the lives they have witnessed. Jeremy Gibbs (aka RomanyWG) an urban explorer and photographer argues that it is recognition of the history behind decay that allows us to feel an intimate connection to those who have occupied the space before us; he discusses the visible layers revealed by decay as an expression of life (RomanyWG).
This thesis argues that exposing the layers of such life evidences the existence of the ranges of history within a given space, and the expression of such layers allows the beauty of time to be witnessed. This thesis explores theories of stratification or layering explored by architects and theorists Louis Kahn and Carlo Scarpa, as a tool to engage with the endangered heritage buildings in New Zealand.

This thesis applies theoretical imperatives of installation artist Mary Miss to theories of Scarpa and Kahn to enable the intervention to test historical narratives through contemporary design interventions; enabling the seismic design intervention to not only provide lateral bracing but to also give the historic building a layer that represents today as a viable reflection of tomorrow's history. These ideas explore the ephemeral quality or tension created in the 'in-between' or the 'grey' zone between layers, enabling the viewer to experience the effects of time on a heritage building, effectively producing an ephemeral gallery of materials accumulated over time. According to author Anne-Catrin Schultz the zone between the old and new creates a dynamic dialogue by delicately touching the old with the new, penetrating the old with the new and/or placing contemporary elements beside the historic, thereby exploring the notions of proximity, degree of separation or disengagement (10)

CONCLUSION

This thesis argues that with the increase in lateral bracing requirements in the New Zealand building code, the current approach to completely 'restoring' heritage buildings may no longer be economically viable. A more effective approach would be to engage with semi-demolished and semi-decayed heritage structures in a way that celebrates their continual metamorphosis over time. This is especially apparent in Wellington where heritage buildings are under threat from demolition, or in Christchurch where historic buildings are now partially demolished due to earthquake damage; this thesis argues that this requirement to laterally brace vulnerable heritage buildings can potentially become a new additional story to be told through a contemporary intervention as a part of the building's on-going history. This thesis proposes that seismic design and methods of layering or stratification can provide the necessary elements to bring the historic buildings up to code and facilitate their re-use in the 21st century. This thesis tests this approach to contemporary intervention as a means of preventing demolition by inviting 
contemporary design to be derived from seismic strengthening requirements; and by retaining the exposed layers of history the intervention will enable visitors to understand the continued and evolving story of New Zealand's historic buildings.

Following the Christchurch earthquakes of 2010-2011 the New Zealand building code requirements increased, particularly with regards to strengthening heritage buildings. Locally, the Wellington City Council has identified 266 endangered buildings in the city and presented them with the ultimatum: to upgrade to meet the new seismic requirements or succumb to a mandatory demolition. It has become apparent that many owners of heritage sites cannot afford to undertake a seismic strengthening project; and as a result New Zealand's heritage may be lost to the forced hand of demolition for fear of potential earthquake damage rather than from the natural disaster itself. Thus, this thesis explores theories of architectural layering and stratification, incorporating seismic strengthening techniques as additional exposed layers. The resulting design research experiment acts as a case study to explore the research imperatives of this thesis: a shift in thinking to re-evaluate the approach to completely 'restoring' 19th-20th century historic buildings in New Zealand, and the development of techniques that structurally reinforce historic buildings more economically (i.e without concealment) while inviting the progressive weathering of the buildings to remain as a testament to their history.

The intention of this thesis is to develop a model for contemporary intervention within New Zealand's heritage fabric which enables heritage buildings to avoid demolition due to the costs of increased lateral bracing requirements.

'Layer One: History, Theory and Poetic Stratification' integrates theoretical approaches to architectural design, installation art, and structural seismic design to formulate and ground the argument for this thesis. 'Layer One' (Chapter 1) begins with a discussion of the current threat to New Zealand's built fabric, identifying the costly rise in building code requirements for both historic and contemporary buildings. It discusses the current legislation drawn from the New Zealand ICOMOS Charter and its resulting application on the Category I Historic Shed 13 in Wellington. 'Layer One' then discusses the notion of weathering and decay within heritage buildings as a celebrated process that evidences the effect of humans and the environment on the built fabric; it argues that the process of weathering or decay is one that enables the metamorphic qualities of a historic building to be witnessed through the exposed layers of time. It then explores the appropriateness of intervention versus 'restoration' in New Zealand's built heritage, identifying the need to recognise the difference between historic buildings in good condition that should continue the process of maintenance, and historic buildings that have fallen into disrepair or have been damaged in some way; this thesis argues that these historic buildings should be permitted to celebrate their decay as a part of their progressive history. 'Layer One' then moves into a discussion of architectural theories by Louis Kahn and Carlo Scarpa, exploring their notions of layering, stratification, and ruins, employed as methods to engage with heritage buildings. It then builds upon theories of Kahn and Scarpa by exploring related theoretical imperatives behind the work of installation artist Mary Miss, incorporating Miss's technique of employing structural form to imply architectural space. Finally 'Layer One' concludes exploring the theoretical side of seismic design discussing the application of seismic structure as a form of expressed contemporary ornament, to reduce the cost impact of lateral bracing by exposing it as a layer of history.

'Layer Two: Assimilating Architecture and Installation Art' discusses the theoretical imperatives and methods behind three contemporary interventions within historic buildings: the Castelvecchio in Verona, Warehouse 17C in Madrid, and the Mint in Sydney. In addition to architectural examples, this chapter explores relevant theoretical imperatives behind installation artists Mary Miss and Ann Hamilton, exploring how these artists employ architectural vocabularies to invite the viewer to occupy the art as habitable space, employing techniques that suggest space that is not bound by the pragmatic and functional nature of 'rooms'. The notion of stratified architectural elements or the process of layering is investigated across both the architectural and installation art disciplines establishing parameters for the evaluation of the design research case study in 'Layer Five'. 
'Layer Three: Contextual Heritage'. In order to establish the critical architectural problem addressed by this thesis, 'Layer Three: Contextual heritage' (Chapter 3) presents diagrams and mapping tools that investigate the threat of earthquakes on Wellington's built heritage. This chapter provides evidence for the research imperatives of this thesis through the evaluation Wellington's wider heritage fabric; it then evaluates the specific conditions within the site chosen for the design case study, the Albemarle Hotel. An evaluation of the heritage qualities and existing conditions of the Albemarle is conveyed through drawings and photographs.

'Layer Four: Programmatic Explorations' identifies the relocation of the New Zealand Historic Places Trust (NZHPT) regional office to the Albemarle Hotel as an appropriate new program to inhabit the historic site and design intervention within the context of the research imperatives. This chapter includes a spatial analysis of the existing program and identifies the need for more public interaction with the staff and the historic building. 'Layer Four' (Chapter 4) then analyses how the existing conditions and material qualities within the Albemarle might be integrated with the design research experiments to facilitate the new program.

'Layer Five: An Exploration of Contemporary Layers' discusses the design research experiment for this thesis. It is intended as an exemplar for contemporary structural intervention within New Zealand's heritage fabric, as an example of a design intervention derived from a seismic strengthening project that provides important additions to the existing building that were not previously there. In the case of this thesis the design research case study provides seismic resistance for the Albemarle Hotel whilst simultaneously providing a new façade for its blighted west elevation facing Glover Park and disabled access to all levels of the historic hotel. This chapter reinforces the argument that each heritage site should be evaluated for the qualities evident within the specific site and the intervention approach should be strategized around those conditions; it argues for the celebration of decay within appropriately weathered historic sites, and design interventions drawn from seismic requirements that facilitate the celebration of that decay and the witnessing of the past.
'Peeling Back:A RetrospectiveView of the Last Layer' discusses how well the theoretical research and design case study experiments have achieved the goal of developing a model for design interventions drawn from structural requirements that are responsive to the decay and weathering evident within the site, and how well they reflect the histories that have passed through the site boundaries as Time Passes. This chapter also discusses the challenges and limitations of the design experiments identifying where future research may be conducted. To further the design research experiment this chapter introduces an exploration into junctions point between the old and the new. It explores the standard steel section to consider future alternative steel profiles and detailing methods that are more sympathetic to the weathering nature of some of New Zealand's heritage buildings.

A Note on Economics

This thesis does not attempt to provide a cost analysis comparison of the proposed seismic intervention against the existing method of seismic strengthening, but refers to the economic 'cost-benefit' of deriving a design intervention from the seismic strengthening required to bring New Zealand's endangered heritage buildings up to the new building code requirements. This thesis argues that the new design intervention method provides the owner of a dilapidated heritage site with a habitable structural intervention that gives something to the building that was not provided for previously, as a means of increasing the cost-benefit of seismic strengthening. In the case of the chosen vehicle for this thesis, the design intervention derived from the structural system provides a new façade for the blighted west elevation of the hotel, opening the building to visitors and park dwellers, providing more natural light to the interior and replacing the scarred and frequently graffitied west façade of the historic hotel. These improvements are referred to in this thesis in terms of 'cost-benefit' and 'economic advantages. 


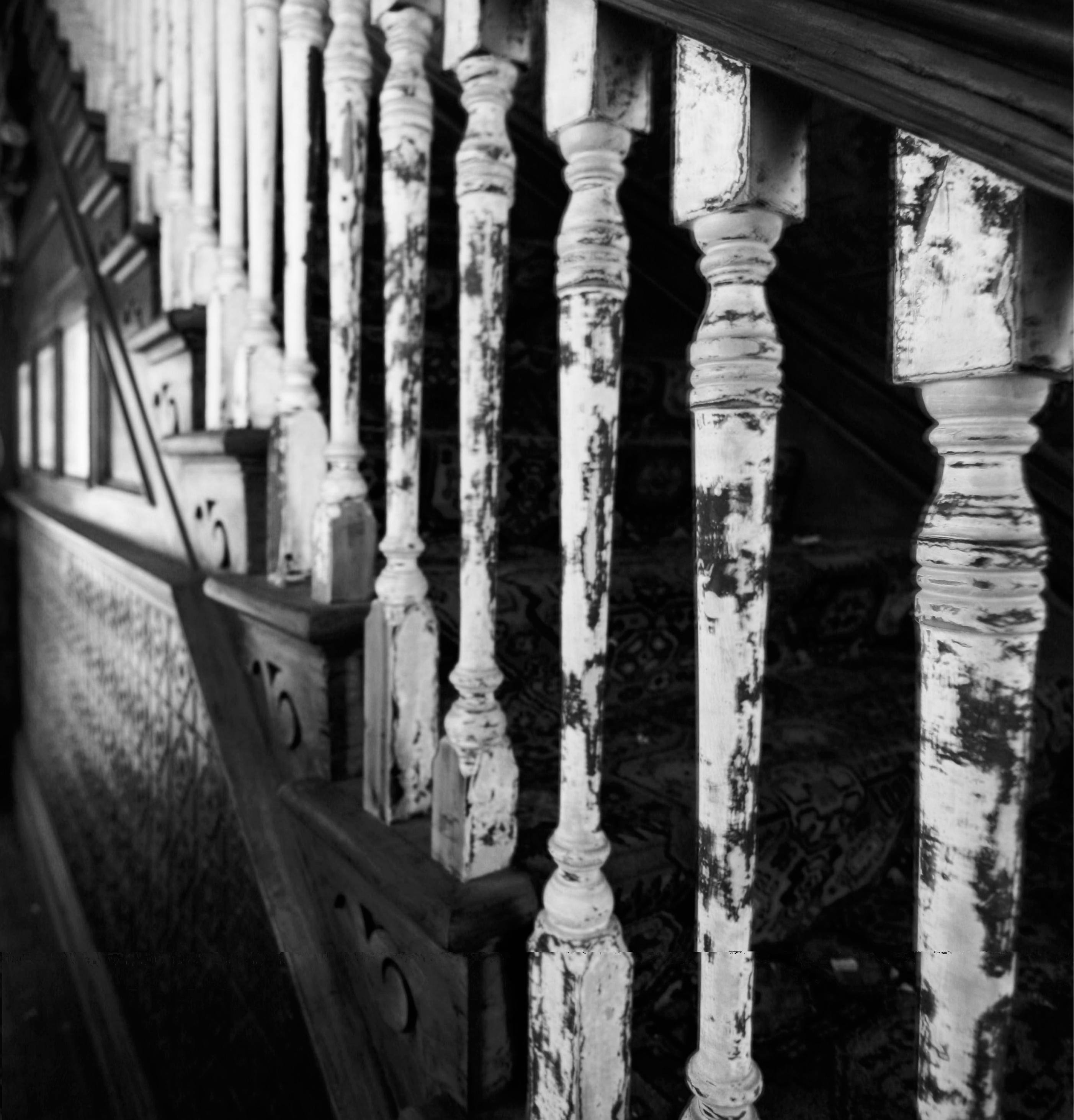

HISTORY THEORY \& POETIC STRATIFICATION

Introduction

\section{History}

Heritage Authorities and the ICOMOS New Zealand Charter

Evaluating the appropriateness of design interventions

Case Study: Shed 13,

37 Customhouse Quay, Wellington

Theory and Poetic Stratification

Decay, Weathering and Wear

Historical layering or stratification

Habitable Installation art

Structural design as a layer

Conclusion
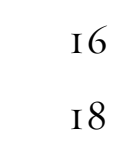

I8

2 I

23

25

25

32

35

37

38 
"WHATEVER ELSE MAY PERISH AND DISAPPEAR, WHAT LIES HERE IS STEADFAST. HERE ONE MIGHT SAY TO

THOSE SLIDING LIGHTS, THOSE FUMBLING AIRS THAT BREATHE AND BEND OVER THE BED ITSELF, HERE YOU CAN NEITHER TOUCH NOR DESTROY."
Tn order to establish an appropriate approach to the design research question 1 this chapter explores theoretical opportunities for integrating contemporary structural reinforcing elements within earthquake-prone historic buildings in ways that enhance the viability of the building, while inviting the new additions and the progressive weathering of a building to both remain visible as a testament to its history. Reflections on theories by Carlo Scarpa, Louis Kahn and installation artist Mary Miss enable this thesis to formulate an approach to the complex problems facing New Zealand's Historic buildings that is equally multifaceted and improves the economic viability of restoring these buildings. 
INTRODUCTION

This chapter explores theoretical imperatives that might guide the seemingly contradictory requirements of heritage restoration and contemporary intervention in order to establish an appropriate and integrated approach to interventions within New Zealand's historic buildings. This thesis challenges the current approaches to renovating 19th-20th century historic buildings in New Zealand, which typically take a costly approach of fully restoring them to their original condition. This traditional attitude towards historic 'restoration' makes it extremely difficult to effectively integrate the additional structural elements necessary for earthquake bracing. This thesis explores techniques that structurally reinforce historic buildings in ways that reflect the layering of both historic and contemporary building materials. 'Layering' is explored as a design approach to incorporate the contemporary with the historic as an additional layer of exposed history, thereby further exposing the layers of history evident within New Zealand's historic buildings. This chapter begins with the evaluation of the current approach to historic buildings and sites in New Zealand, introducing the newfound threat faced by historic buildings due to the rise in building code requirements. This chapter then explores a case study of a seismic intervention and interior spatial design intervention within the Category I historic Shed 13 in Wellington as an example of a new approach to heritage buildings in New Zealand that effectively enables the addition of exposed earthquake strengthening elements.

In order to establish alternative methods of viably incorporating new elements into New Zealand's historic sites, the related work of Louis Kahn, Carlo Scarpa and Mary Miss are reviewed to explore approaches that engage with the notion of layering and the celebration of the 'ruin' or the decaying nature of architectural sites. It considers the work of these three theorists in developing a foundation for the hypothesis that architecture can be enhanced by revealing its levels of decay, rather than requiring expensive methods to remove the decay. Kahn and Scarpa' methods are investigated as a means of considering approaches to such sites that avoid simply restoring them to the original condition and to establish methods of creating contemporary space that reflects and implicates historical meaning; similarly the methods of installation artist Mary Miss are investigated to explore the relationship between the viewer and the ephemeral nature of the weathered heritage site.
This thesis contributes to the discourse of heritage architecture and theory in New Zealand through the recognition that:

1. Weathering, remnants of decay, and signs of a building's on-going evolution can be retained as important layers signifying the history of the building

2. Lateral bracing is yet another layer of historic relevance, inviting exposure and celebration, and

3. Lateral bracing can encourage cost-effective contemporary open planning capabilities in the interiors, thereby facilitating new use and ultimately further protecting New Zealand's built heritage from demolition. 
HISTORY

Due to New Zealand's increase in earthquake awareness, many of our earthquakeprone heritage buildings are in danger of being demolished because the owners cannot afford to re-strengthen their heritage properties. In May 2012 Wellington's buildings were examined using the Wellington City Council's Initial Evaluation Process (IEP); the findings of this process concluded that Wellington has 266 commercial, public and large multi-storey residential properties that are earthquake prone. Under the Wellington City Council's Earthquake Prone Buildings Policy of 2009 these properties must be strengthened in an assigned timeframe between 1-20 years, the most vulnerable of which have already been evacuated until this process has been completed. It has become evident that we no longer have the option of keeping our heritage buildings maintained with just fresh plaster and paint; the Building Act (2004) now requires contemporary lateral bracing interventions to be added to our historic buildings in order to protect them and their occupants in the event of an earthquake (Wellington City Council 'Earthquake-prone Buildings').

This thesis explores more cost effective types of structural interventions that can achieve the legislated goals, by exposing the new structure along with the exposed layers of weathering, thereby portraying the on-going metamorphosis of New Zealand's historic sites. It investigates contemporary structural interventions that have the ability to strengthen our historic sites, inviting the structural interventions to provide a new programmatic planning capability that might enhance the historic buildings' capacities to become a profitable asset once more. The aim of this thesis is to explore seismic interventions that will balance the cost-benefit dilemma faced by historic building owners, by allowing the historic sites to expose their historic evolution and transformations over time.

Heritage Authorities and the ICOMOS New Zealand Charter

This section analyses the ICOMOS (International Council On Monuments and Sites) New Zealand Charter, a set of guidelines for engaging with buildings and sites of cultural and heritage significance. This section discusses the sections of the New Zealand Charter that relate to contemporary adaption and intervention, identifying the fact that the Charter's ideal approach to conservation is not always affordable for all New Zealand's historic sites. This section explores the recent addition to the Charter for 'Risk Mitigation', highlighting the opportunity this provides for contemporary design interventions within New Zealand's heritage buildings.

In 1964, the Second International Congress of Architects and Specialists of Historic Buildings adopted 15 resolutions of which the first resolution was the Venice Charter and the second was the creation of the ICOMOS, a nongovernmental organization responsible for the preservation of the world's heritage sites. ICOMOS New Zealand was established in 1987, and in 1992 the ICOMOS New Zealand Charter was developed and most recently revised in 2010 to include 'Risk Mitigation'. The ICOMOS New Zealand Charter is a set of guidelines for the practice of cultural and heritage conservation, produced specifically for New Zealand's sites of historic value. These include places of significance to Tangata Whenua and Maori, cities of built heritage, cultural landscapes, buildings and structures and significant heritage notable trees. The New Zealand Historic Places Trust (NZHPT), the Ministry of Culture and Heritage, and the Department of Conservation reinforce the Charter, and local district plans reflect principles from within the Charter to ensure the preservation of New Zealand's heritage. These organizations have established the importance of heritage conservation as a means of preserving our cultural heritage value (ICOMOS New Zealand).

The ICOMOS New Zealand Charter establishes guidelines designed to protect New Zealand's heritage for the appreciation of generations to come. The Charter is designed as a benchmark for those working with heritage sites and is written to allow for flexibility. The Charter understands that in some cases change, intervention or adaption is appropriate in places of historic value. In most sections the Charter suggests the ideal situation, but acknowledges that it is not always possible and offers alternatives to allow for the incorporation of things such as structure, contemporary design and change of use, without compromising the heritage value. For example Section Six of the Charter is concerned with heritage intervention; Section Six's first suggestion is that "Intervention[s] should be the minimum necessary to ensure the retention of tangible and intangible values and the continuation of uses integral to those values"(ICOMOS NZ, 'ICOMOS New Zealand Charter' 3). The second recommendation is that "The removal of fabric or the alteration of features and spaces that have cultural heritage value should be avoided" (ICOMOS NZ, 'ICOMOS New Zealand Charter' 3), however the Charter understands that intervention is sometimes inevitable and does not strictly prevent it. 
Section Eight describes the use of heritage sites and the importance of maintaining the original use: "Where the use of a place is integral to its cultural heritage value, that use should be retained" (ICOMOS NZ, 'ICOMOS New Zealand Charter' 3). Again the option to work with adaption is facilitated; the charter states, "Where a change of use is proposed, the new use should be compatible with the cultural heritage value of the place, and should have little or no adverse effect on the cultural heritage value" (ICOMOS NZ, 'ICOMOS New Zealand Charter 3'). Section Eight is particularly important to this thesis as it aims to enable history to be observed within the context of a new use. Section Twenty-one details the guidelines of adaptations in heritage spaces. The Charter states that adaptations are permitted; however adaptations should be minimal and must be reversible, leaving no permanent trace on the heritage element.

"Any alterations or adaptations should be compatible with the original form and fabric of the place, and should avoid inappropriate or incompatible contrasts of form, scale, mass, colour, and material. Adaptation should not dominate or substantially obscure the original form and fabric, and should not adversely affect the setting of a place of cultural heritage value. New work should complement the original form and fabric"(ICOMOS NZ, 'ICOMOS New Zealand Charter' 7).

On the 4th of September 2010, the Charter was amended to include 'risk mitigation' to safeguard against natural disasters; however these revisions are subject to the previous guidelines such as minimal impact (ICOMOS NZ, 'ICOMOS New Zealand Charter'). The Charter provides guidelines for every aspect of adaption and intervention, potentially restricting the prospect of contemporary design within some heritage sites. The Carter does not see adaptation, change of use, or intervention as positive contributors to the history of heritage sites in New Zealand; however it does allow for such changes provided that they can be achieved without destroying the heritage value of the site (Jahn). This thesis argues that with the vast destruction of historic sites in the Christchurch earthquakes of 2010-11, a vitally important opportunity has arisen to allow contemporary architects to engage with the vulnerable heritage sites. The increase in strengthening requirements of the revised building code, now requires that these sites be structurally engaged to secure their survival and the protection of those who occupy them.
Evaluating the Appropriateness of Design Interventions Within Wellington

This section acknowledges that the most appropriate response to a site of cultural and heritage value should be directly related to the history and conditions evident within the unique site. As New Zealand's places of cultural and heritage value are young on a world scale, this thesis explores theorists from Australia who have recently voiced their opinions against the 'Burra Charter', the Australian version of the ICOMOS Charter. This thesis evaluates these concerns in relation to the New Zealand ICOMOS Charter.

The Burra Charter for places of cultural significance in Australia is similar to the New Zealand ICOMOS Charter; both charters relate to the unique nature of each country, and both Charters have adopted a philosophy of pertaining to places not just of heritage value but also places of significance to 'cultural heritage value'. The Barra Charter identifies "all types of places of cultural significance including natural, indigenous and historic places with cultural values" (Australia ICOMOS 1) and the New Zealand ICOMOS Charter identifies itself as relating to "cultural landscapes and features, buildings and structures, gardens and archaeological sites, traditional sites, monuments and sacred places" (ICOMOS New Zealand, ICOMOS New Zealand Charter). It can be assumed that the issues and theoretical responses to the Barra Charter in Australia are potentially relevant to the places of cultural heritage value in New Zealand.

Many owners of heritage buildings have begun to consider demolition over restoration because of the cost-benefit disjunction. For example, the Dominion Post published an article on the 15th of October 2012 which detailed the decision to demolish the Riddiford Building at Wellington Hospital rather than upgrading the complex; this decision was made because the 4 million dollar cost of restrengthening the building is not expected to be returned within the 5 years it would be available as housing (its new program); this is also the case for Erskine College in Island Bay and the Harcourts Building in Wellington (McBride 23.03.12, McBride 02.09.12, Torrie). The 266 earthquake-prone buildings identified under Wellington City Council's IEP process are also facing this decision. 
In some cases architects and heritage building owners are forced to balance the ethical commitment to retaining new Zealand's heritage and the economical dilemma of structurally reinforcing vulnerable historic buildings to resist earthquake damage. Figure 9 \& 10 show the Bresolini's Building on Tory Street in Wellington that has been partially demolished leaving only the street façade as a representative of the historic building that used to occupy the site. Jennifer Hill, heritage consultant and member of the RAIA Heritage Committee, argues that this move to retain only the street façade is morally and ethically questionable.

\begin{abstract}
She writes: "The recent trend to retain remnants of representative public buildings under the guise of heritage protection, when really they act as no more than a base for highrise development, can be revealed as intellectually and conceptually questionable" (65).
\end{abstract}

This thesis proposes that it is not only the façade of New Zealand's heritage buildings that provides its connection to history; the connection also lies in the ability to witness the exposed layers within our historic sites that enable us to have a tangible relationship with history, the building's on-going changes, and the people who have gone before us.

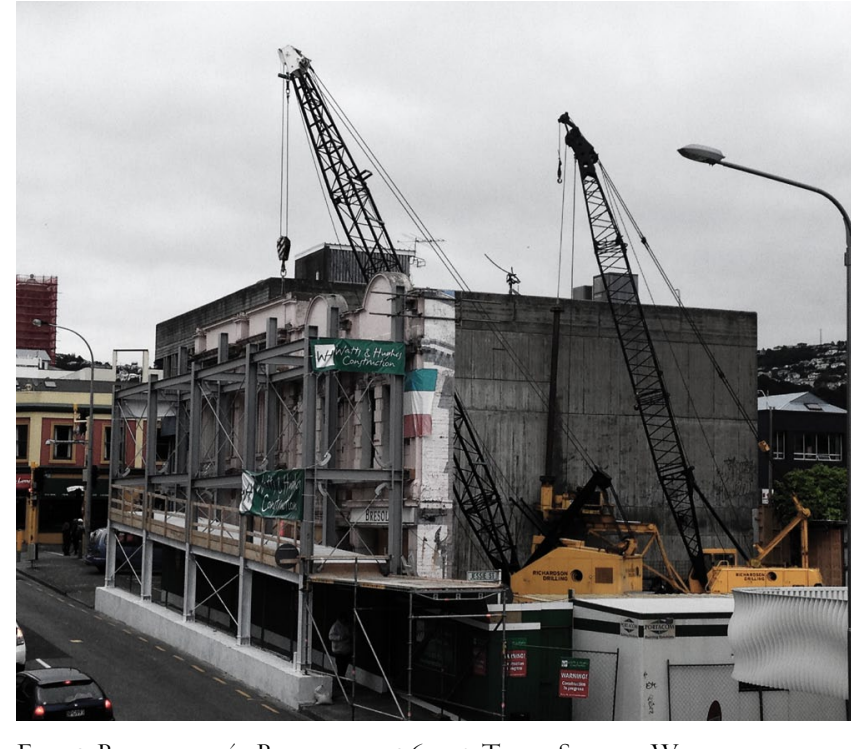

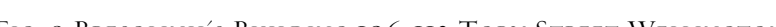

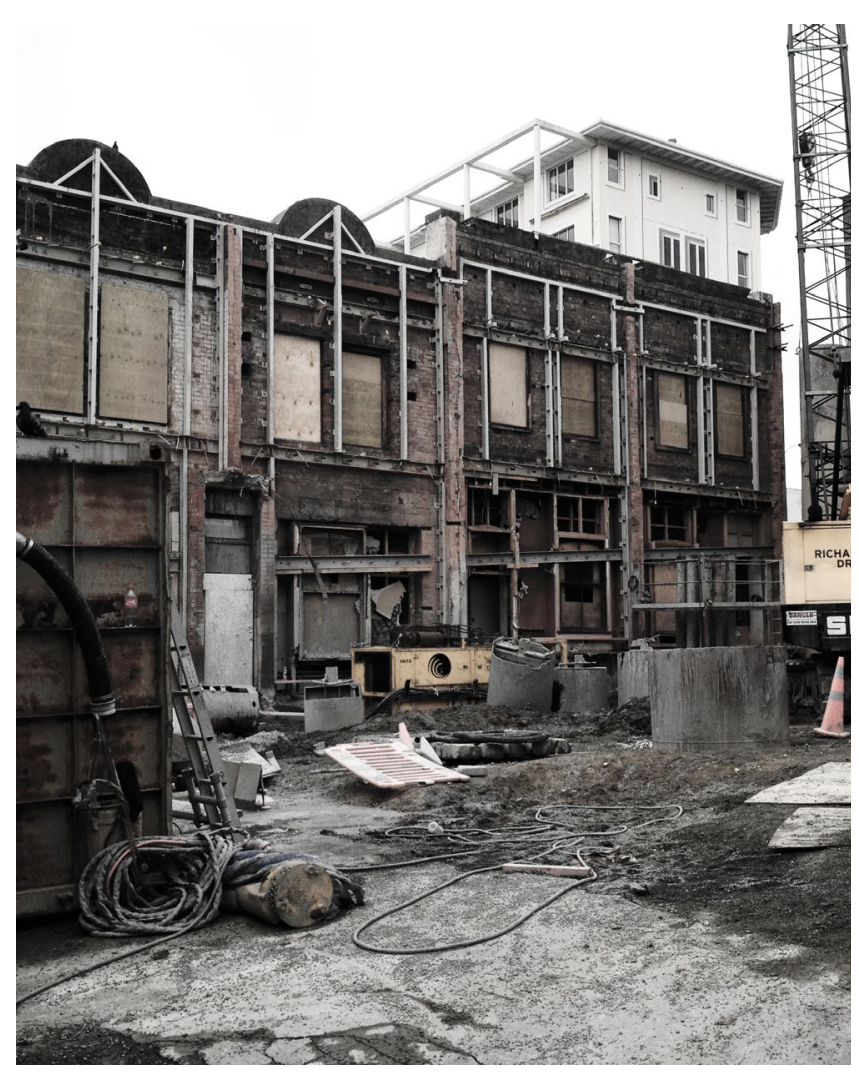

Fig. IO Bresoliniı's Bullding Retaining the facade
CAse STUdr: SHed I3, 37

Customhouse Quar, Wellington

This section explores the seismic and spatial intervention within the Category I historic Shed 13 at 37 Customhouse Quay, which successfully exposes the new seismic structure as well as using that structure to enable new programming (See Fig. 11). This section analyses the methods used to strengthen the potentially vulnerable shed by CCM Architect and Ian Bowman, and the methods used to create a new design and spatial intervention within the existing space by Alistar Cox Architects.

This example identifies the problem that many of Wellington's historic buildings have become programmatically obsolete, and their restoration to the original program may not provide an economical return for the building owner; this section argues that one solution to the cost-benefit issue lies in the introduction of a structural intervention that has the ability to engage a contemporary program within the historic site, thereby economically using one new requirement to resolve another.

Shed 13 houses one of Wellington's most recent contemporary interventions. The historic shed was built in 1904 along with Shed 11; the twin sheds were designed as storage units running parallel to the shoreline in a characteristic Dutch Colonial style. In the early 2000s the Wellington City Council made the decision to re-strengthen Shed 13, in preparation for its reuse (New Zealand Historic Places
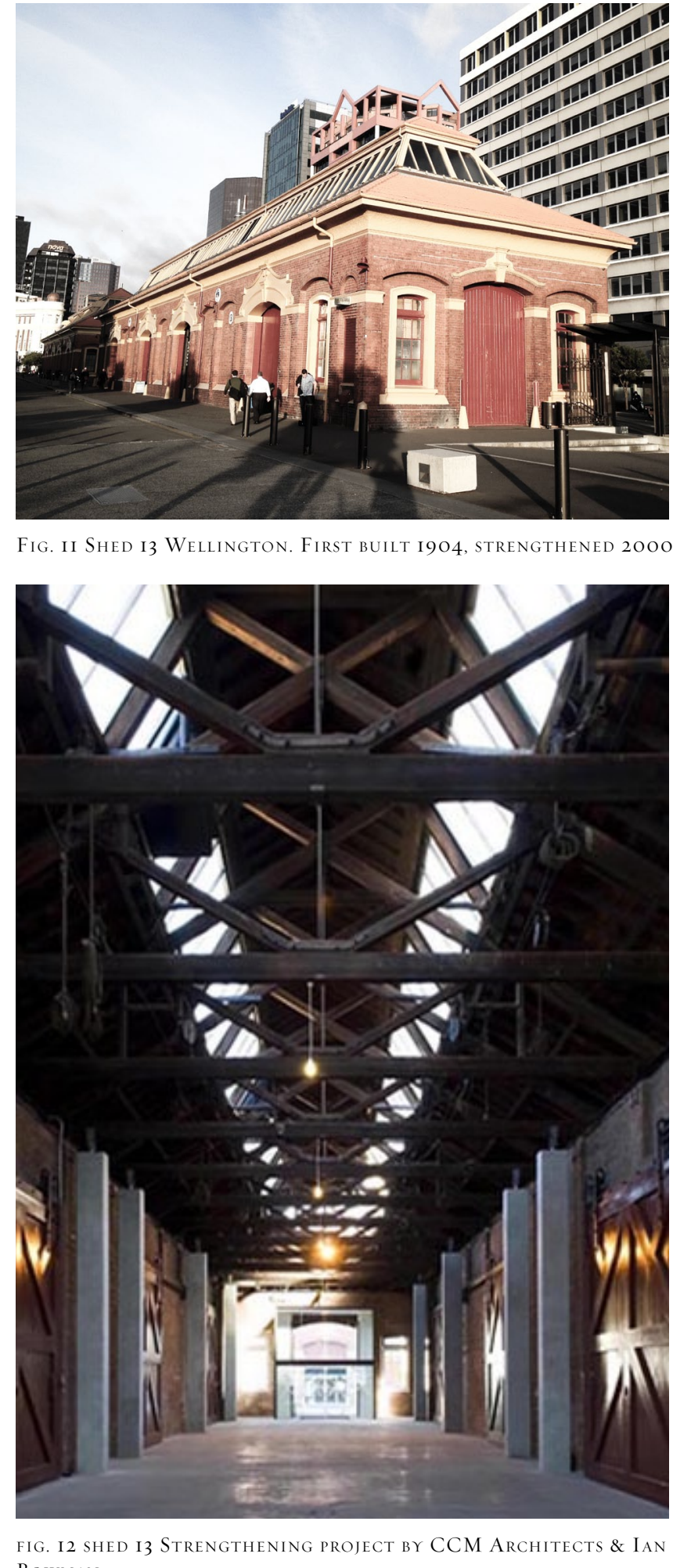

FIG. I2 SH
BOWMAN 
Trust Pouhere Taonga). CCM Architects in collaboration with Conservation Architect Ian Bowman were commissioned for the structural refurbishment (CCM Architects). The strengthening project includes six primary frames with post tensioned concrete column cantilevering from the concrete foundation below; in addition capping trusses were placed running along the top of the exterior walls, running the perimeter of the building. The existing roof truss system was left in its original condition as it displayed sufficient connection strength to resist lateral load. The restrengthening project is an effective and subtle intervention; the concrete columns clearly identify themselves as new from the historic brick, and the additional capping truss disguises itself amongst the resilient timber roof truss system, allowing the historic shed's interior aesthetic to remain dominant (Cattanach et al. 8) (See Fig. 13).

The new design intervention within the historic shed, completed in early 2012, by Alistar Cox Architects, returns Shed 13 to its use as a storage shed and the headquarters for the Mojo Coffee cartel (Gorrie). In accordance with the requirements by the Wellington City Council, the Mojo factory remains open to the public whilst simultaneously roasting and storing coffee beans. The contemporary intervention consists of two white 'boxes' suspended above the factory (See Fig. 12) housing the offices and boardrooms for the Mojo organisation.

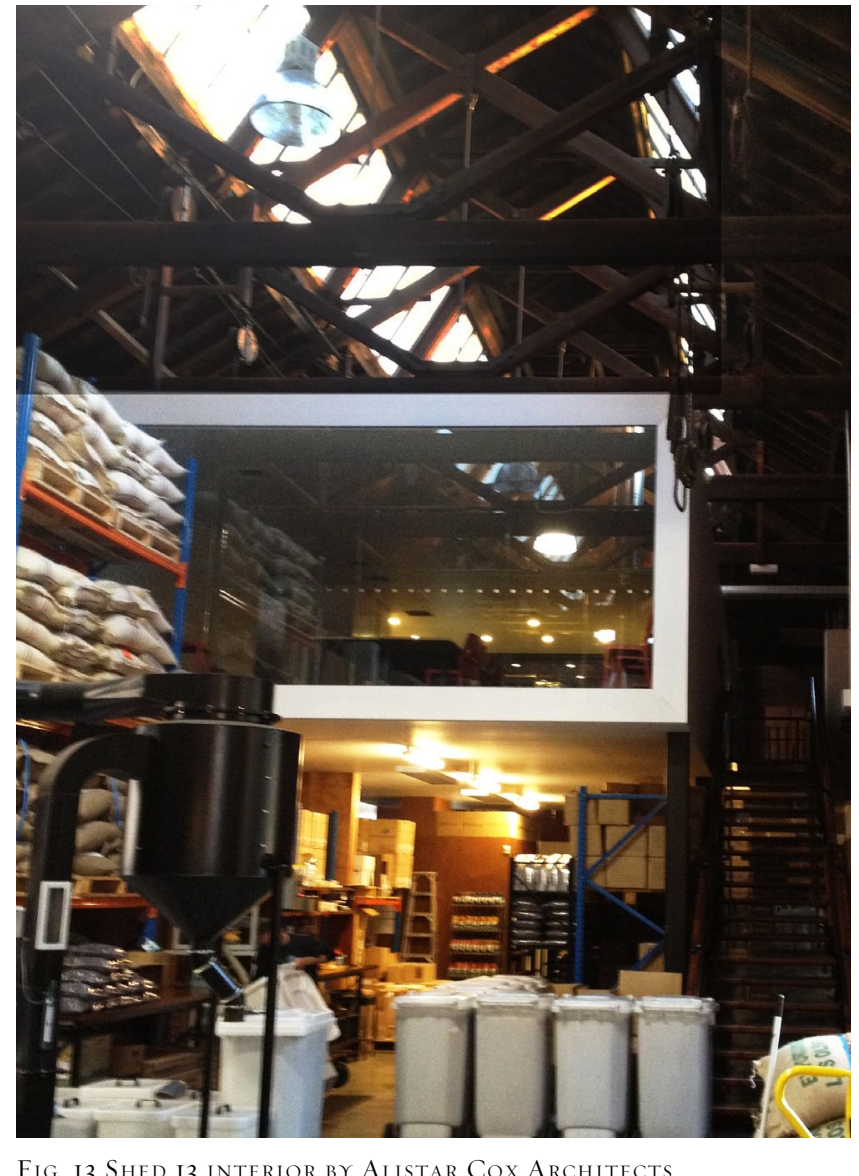

FiG. I3 SHed I3 INTErior br Alistar COX Architects
The intervention praised by the New Zealand Institute of Architects (NZIA) and NZHPT for returning the shed to its original use, also subtly introduces new contemporary office space that appears to float above the factory floor, with access via a single timber stair running down the heritage brick wall (Gorrie). The intervention enables the original program to be retained while the new earthquake structure is invited to suspend the new program above. This validates the idea of revealing the bracing, and using the bracing to enable new program.

\section{Theorr \& Poetic Stratification}

This section explores the 'beauty of decay' or the weathering of a building as a positive process that evidences a building's life over time. It explores the concept that in some cases the imprints of the environment and human presence on a building's surface can be a positive attribute. This section investigates how the decay or weathering of a historic building can become a tool used to reveal the activities a building or surface has witnessed.

Decar, Weathering \& Wear

This thesis argues that the weathering or the aging of a building should not be hidden or removed, but revealed and celebrated; this movement to celebrate the effects of time challenges the traditional subjective notion of beauty. According to urban explorer Jeremy Gibbs (aka RomanyWG), beauty need not always be concerned with pristine, contemporary and elegant spaces, but something that recognizes eternal beauty over a singular and preserved moment in time (RomanyWG). He argues in his book Beauty of Decay that this decay we find beautiful is a means of revealing the soul of a building, expressing its life over time. Gibbs quotes author and photographer Julie Shiel, "I find beauty in decay. I like to see nature conquering what man has left. I believe that old buildings have a soul, and when I photograph these places I try to capture a piece of that soul" (RomanyWG). Gibbs's discussion of the beauty of decay is supported by Mostafavi and Leatherbarrow, authors of On Weathering, who argue that the traditional negative connotation associated with decay is removed when the word decay is substituted with 'weathering'. They call for the celebration of weathering, claiming that weathering is a part of a building's continual metamorphosis, evidencing the effect of the environment on a building's surface. 
Mostafavi and Leatherbarrow describe this process as one that should be recognized and exploited; they describe the weathering of a building as inevitable, and a process that should be witnessed by the public not hidden. Mostafavi and Leatherbarrow refer largely to the exterior of a building when they write about weathering, maintaining that 'In the process of subtracting the 'finish' of construction, weathering adds the 'finish' of the environment" (5). Their argument for the exploitation of decay, allows for the pragmatics of maintenance (required for safety and climatic comfort for those occupying historic sites), but argues that surface decay should be celebrated.

The notion of positive attributes of decay and weathering is not limited to the architecture discipline; Ross Stevens, lecturer at Victoria University of Wellington School of Design, argues in his Master's thesis Worn Out or Worn In?, for the evidencing of the human presence in industrial design. And although Stevens's argument is founded in a different discipline the same ideas can be applied to architecture. Stevens claims that weathering is the process of wearing-in an object rather than wearing-out.

Stevens argues, "These human powered wear patterns form evidence of a person's relationship with the physical world and tangible proof of the person's existence. By denying the environment the chance to add a site-specific finish to a building an opportunity is lost. By denying people the right and ability to leave evidence created by wear in their products, the very meaning and value of a person's existence is put to question" (10).

In the 2010 Venice Architecture Biennale, the Belgian Pavilion exhibition designed by the group Rotor was devoted to architectural 'wear' as art, exploring similar notions to that discussed by Stevens in his thesis Worn Out or Worn In?. The Rotor exhibition titled Usus/Usures (Use/Wear) argues that 'wear' is a reflection of 'use' and should be expressed both in architecture and on 'goods' or products; the Usus/Usures catalogue explains: "As a trace of use, wear reminds us that most of the time other users have gone before us, and still more will follow. In some cases, wear even provides a valuable clue as to the nature of these users. In this sense, traces of wear play a vital part in our ability to read our environment and, by extension, appreciate it" (Boniver et al. 17).
The catalogue draws our attention to the connections of the French words for user, use and wear.

In her article, "Six Degrees of Intervention", Jennifer Hill builds upon the notion of weathering, both man-made and environmental, when she argues for the protection of the layers of history evident in spaces of heritage value. Hill describes this evidencing of weathering or impressions of life as an integral part of a building's historical evolution. She postulates that historic buildings should be permitted to evidence the history they have witnessed over time, employing an architectural layering system as a descriptive tool. She writes, "The history of most buildings is a process of metamorphosis in which every transformation alters our historical interpretation and those transformations of their period also become parts of the history of the building" (64).

This thesis argues that Rotor's theories on wear and use, Stevens's theory of evidencing human presence as 'wear', Hill's advocacy for weathering and layering, and the concepts of environmental weathering explored by Mostafavi and Leatherbarrow, are all ideas capable of adding a positive imprint to some historical sites within New Zealand. This thesis explores the ideas of layering, wear, weathering and the notion of the 'beauty of decay', as viable alternatives to New Zealand's current approach to fully 'restoring' 19th-20th century buildings to their original condition.

Authors such as Jennifer Hill, Susan Macdonald (Assistant Director of the New South Wales Heritage Office), Graham Jahn (architect and former chairman of the City of Sydney Planning Committee) and several practicing architects in Australia have voiced their opinions on the need for an evaluation of the approach to places of heritage value. Their articles in The Double Dimension: Heritage and Innovation argue that the Charter is not the only way to protect heritage sites. Jahn describes the loose-fitting Charter in his article 'Making Room for Tomorrow's Heritage' as a hindrance to contemporary design (201) Jahn argues that heritage authorities are not only preventing contemporary design for the appreciation of the public in this generation, but also depriving the future generations of their heritage (Jahn 211) (Clare). 
"There is evidence that current assessment practice is ensuring that tomorrow's landmarks, unique designs, and exceptional projects cannot be built, depriving future generations of the heritage possibilities of this generation" (Jahn 211).

His position is that the evolving history of a site is just as important as the original history, and unless we recognize this factor, we risk the loss of significant heritage elements from within our built environment. This thesis argues that this position invites significant new approaches incorporating the addition of new elements as contemporary requirements for heritage sites in New Zealand such as lateral bracing, disabled access ways, and secondary fire escapes.

Jennifer Hill, author of the article 'Six Degrees of Intervention' agrees with Jahn's stance that contemporary intervention is a positive move for historic places. She writes, "Every transformation alters our historical interpretation and those transformations of their period also become parts of the history of the building" (64). Hill is a strong advocate for intervention over restoration; she discusses the layering of buildings as a positive metamorphosis, which adds to the history of the site and community. Hill discusses this process with reference to the Female Orphan School at Rydalmere, Sydney:

"While continuity of use was no longer achievable, the 190-year history of the building was easily discernible in the remaining fabric.

There was an active decision to allow 190 years of layers to co-exist and not to return to a particular point in time therefore requiring a degree of judgment in presentation. The appearance of a multiplicity of

layers involved both the demolition and reconstruction of these layers Later additions, which obscured part of the original 1813 building and showed no appreciation of the building's significance were removed The northeast wall was reconstructed with carefully matched brick and mortar to the original specifications. Wall finishes revealed the variety of paint schemes from 1813 to the 2920s" (67).
Hill further deliberates that by permitting the layers of history to remain in heritage sites such as the Female Orphan School, the intervention becomes more cost-effective than complete 'restoration'. She writes, 'The completed project enjoys an archaeological richness of layering not achievable through the veneer of the more costly restoration option" (67).

Both Jahn and Hill argue that the events of today will be the history of the next generation. Although, the heritage authorities are acting according to their guidelines to "support the on-going meanings and functions of places of cultural heritage value, in the interests of present and future generations" (ICOMOS New Zealand, ICOMOS New Zealand Charter 3), Jahn and Hill are showcasing the contradiction - that the restrictions of the heritage authorities are altering the representation of built heritage, preventing future generations from the opportunity to appreciate the adaptive and collaborative architectural move of this generation, which will in turn become our history. This thesis aligns with Hill's argument that the complete 'restoration' of a heritage site is not only a more expensive approach but also actively eradicates layers of history evident within some heritage sites.

The ICOMOS NZ Charter and the Barra Charter of Australia state that a close relation to history/heritage gives a community the ability to learn from the past and compare its current achievements to those which have gone before (ICOMOS New Zealand, 'About ICOMOS'). Jahn and Hill are united in their opinion that heritage authorities are creating an idealistic representation of historic sites, describing it as a "fake history" (Hill 65). Restoration and reconstruction of a heritage building is identified in both the charters as important, to ensure that the built heritage is maintained and continued for appreciation in the future. In Jahn and Hill's opinion, the charter fails to see that in some cases restoring buildings as they age is actively extracting layers of history that contribute positively to the architectural aging of that building. Hill describes deterioration of the built form as an integral part of its history; she quotes Laura Lilli stating, 
"Time does not diminish the sensitivity of the lines on the works of the past, in the same way as the wrinkles on the face of an ageing human being do not destroy the intensity of the expression. Restoration means adding a deadly veneer; a senseless face lift; at most, a death mask" (Hill $65)$.

This thesis argues that neither restoration nor intervention is an inappropriate approach to heritage buildings; but suggests that there needs to be an in-depth evaluation of each heritage site before a contemporary intervention can be made. It argues that different degrees of restoration and contemporary intervention can both be appropriately implicated within New Zealand's heritage sites as a means of witnessing and expressing their history. This thesis proposes an approach that identifies three contemporary forms of 'renovation', each of which may be applied to varying degrees as relevant to a particular building: full restoration of original historic conditions, retention of transforming layered conditions i.e the integration of historic and new, and the transformation into completely new / contemporary space.

- $\quad$ Approach 01 suggests that if the heritage site (or zone within a heritage site) is in a very good condition, then that site should continue to be maintained and restored for the appropriate use. Where the building code requires a structural intervention or secondary strengthening, the structural intervention has the potential to identify itself without adversely disrupting the cultural heritage value of the space.

- $\quad$ Approach 02 identifies heritage sites (or zones within a heritage site) that have fallen into costly disrepair or evidence multiple layers of relevan history; these should be seen as having opportunities to engage with the decay and weathered elements as a means of revealing the stories that the site has witnessed over time, enabling the decay to be celebrated as a beautiful aspect of that building's history.
Approach 03- identifies zones within heritage sites that have little or no heritage value or have been damaged beyond repair such as through significant water infiltration or partial demolition due to previous alterations.

Within these three approaches, the level of intervention should also be evaluated depending on the site, determining which elements should be preserved and which areas of decay should be celebrated so that the historic nature of the site is not lost to the intervention; but both contemporary and historic elements can work together to support the physical and ephemeral journey of the historical site. This thesis grounds itself in the call for this new integration of maintenance, restoration and additional contemporary elements, and the celebration of weathering and decay evident within some of New Zealand's dilapidated heritage sites. Design opportunities are explored by structural interventions that enable and enhance the habitability of New Zealand's historic sites, allowing them to become economically and programmatically viable in the 21 st century.

This thesis maintains that the degrees and types of weathering and decay suggest the appropriateness of the type of 'renovation' to be applied. The chart below suggests a method of defining an appropriate response to New Zealand's heritage buildings.

\begin{tabular}{|l|l|l|}
\hline Classification & Degree and Type of Weathering / Decay & Type of Restoration \\
\hline C1 & $\begin{array}{l}\text { Little or no weathering or decay. } \\
\text { Cull restoration of the original historic } \\
\text { conditions. }\end{array}$ \\
\hline C2 & $\begin{array}{l}\text { Mankind-related decay from partial } \\
\text { demolition; and / or } \\
\text { History-related decay from exposure of of } \\
\text { overlapping conditions. }\end{array}$ & $\begin{array}{l}\text { Retention of the transforming, layered } \\
\text { conditions; } \\
\text { integration of historic and new. }\end{array}$ \\
\hline C3 & $\begin{array}{l}\text { Weather-related decay from water infiltration } \\
\text { or previous alterations. }\end{array}$ & $\begin{array}{l}\text { Transformation into completely new / } \\
\text { contemporary. }\end{array}$ \\
\hline
\end{tabular}

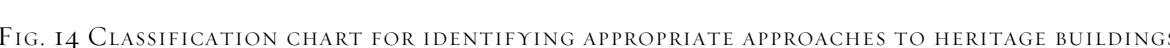


Historical Layering or Stratification

This section explores theories of layering or stratification as a tool to evidence the evolving life of a historic building or site. It explores the opportunity that contemporary intervention holds to brace and protect the multiplicity of layers evident within some historical sites. This section explores the theoretical imperatives behind the works of architects and theorists who clearly identify and engage the collaboration of historical and contemporary layers as an approach that establishes an important discourse between the elements on a site both old and new. Layering or stratification as a tool can be implicated within the design experiments of this thesis to evidence past and present history and enable a contemporary program within the historic hotel, as well as means of resolving contemporary problems buildings and occupiers face.

"So therefore I thought of the beauty of ruins, of things which nothing leaves behind, and so I thought of wrapping ruins around buildings; you might say encasing a building in a ruin so that you look through the wall which has its apertures as if by accident. I felt this would be an answer

to the glare problem" (Lois Kahn as quoted in Larson et al. 38).

Louis Kahn's body of work and theoretical imperatives clearly engage with the notion of layering; his work integrates design techniques with formal gestures taken from the ancient precedents he witnessed, particularly the ruins of Italy, Greece, and India. Throughout his life Kahn explored many related theories including the notion of 'wrapping ruins around buildings', which was initially explored in his unbuilt project for the U.S. Consulate in Luanda, Angola (Larson et al. 67). One of Kahn's many applications of this theory of adding new layers was as a mechanism to solve the problem of sun glare which he observed in Africa; Kahn designed sixteen detached wall segments or 'ruins' to wrap around the building, approximately eight feet from the consulate offices, creating a 'grey zone' or the 'in-between' space that separates the 'ruin' and the building.

"Kahn intended light to enter this intermediate exterior zone between building and 'ruin', where it would reflect, soften, and scatter. Between black and white, this grey zone would allow the eyes to make a comfortable transition from the relatively dark interior to the brilliant light of the arid land beyond" (Larson et al. 41).
It was not until Kahn's exploration of the Salk Institute for Biological Studies in San Diego, California, that he fully developed the independent nature of the exterior 'ruin':

"Although Kahn spoke of Luanda as 'ruins wrapped around buildings', it was at the Salk that he truly accomplished this: fully exterior and independent cylindrical ruins wrap around cubic inhabitable space, and cubic ruins wrap around cylindrical inhabited space. These are the perfect geometries of square within circle and circle within square, repeated thousands of times from Vitruvius through the Middle Ages and the Renaissance" (Larson et al. 67).

Drawing from the geometries of circles and squares, Kahn recreated these ideals with formal design intentions; his work clearly identifies with the notion of 'ruins' without reproducing them. Kahn represents his love for the great Roman ruins by emulating the plans and formal geometries, but translates them into thinner materials. One of the most interesting aspects of Kahn's work is the fact that he was predominantly interested in the 'grey' zone between the ruin and the building, a common theme explored by other theorists and installation artists discussed in this thesis who engage layering as a means of exposing history.

"Stratification is a system which, by means of two-dimensional, add-on elements, conveys a multi-layered complexity that allows narrative (memorative) or formal subject matter to become operative simultaneously. This principle of layering informs the aesthetics of many 20th and 21st century architects" ( Schultz 7).

Architect and theorist, Carlo Scarpa used the approach of stratification or layering as a means of integrating contemporary interventions into historic sites. Scarpa's work visibly exposes the sedimentation and layering of materials through this process; he divulges the layers of time and meaning within space. Scarpa's renovation of the Castelvecchio Museum in Verona is an example how an intervention can be stratified to reveal the layers of time and history; Scarpa adds new layers to the existing historic site in such a way, that whilst in the space you become aware that each layer of history is a contributor to the holistic experience of the space. 
Scarpa's work explores spatial layering which defines the space between layers, and material layering whereby layers directly touch each other to make one complex, but are still recognized as individual layers or strata (Schultz 10). Scarpa reconfigures the existing space so that it reveals the layers applied at different periods of time to formulate a link between the past and present, revealing the chronological events of time that have occurred in that space; Scarpa lays bare the development and rich history of the Castelvecchio through stratification (Schultz 16). Scarpa's drawings embody his idea of stratification: "Often ground planes, cross sections, and elevations are found on a plan sketched above and inside each other. The complexity of the drawings is emphasized by the use of differentcolored pencils. As though on a palimpsest, erased, earlier versions often exist one on top of the other, making it possible to see the formative process" (Schultz 18) leaving traces of "nervous marks" and "deep incised marks" to make the drawing a descriptive process of thought (Schultz 18).

Examples of 'structure as a layer' can be found in Scarpa's renovation of the Castelvecchio, Scarpa uses the joint or connection to express his stratified architecture. To accentuate the junction point of the original beams, Scarpa placed news beams below the existing beams, which signal the absence of a column that was removed to allow for circulation within the space (Frampton 309).

"By establishing the point of the absent column, the cylindrical hinged joint between the concrete and steel, ostensibly introduced in order to allow for differential movement, [this] was as crucial to the articulation of the space as the built-up character of the steel joist" (Frampton 309).

Scarpa exposes the steel beams as an integrated part of the design; he suggests that by using the structure as a part of a system of stratum that articulates the space, it tells the story of the absent column and the difference between the historic and contemporary structural systems, using the architectural layers to communicate the history of the site.
Although Scarpa's renovation of the Castelvecchio (1956-1964) occurred nearly 50 years ago, his method of stratification is being called upon in a contemporary sense by Jennifer Hill. Hill argues for architects and heritage authorities to return to methods of design and practice that allow historic architecture to have its own voice, and speak of the histories it has witnessed rather than removing layers or strata that evidence history, to preserve the architecture and memories associated with a particular period of time (Hill 63).

Habitable Installation Art

To develop new approaches to contemporary spatial design that is reflective of the histories evident within a site, the theoretical imperatives and methods employed by installation artist Mary Miss are explored in this section; this section discusses Mary Miss's use of architecture as a medium from which she creates sculptural installations that blur the boundary between the habitable and uninhabitable, and the new and the historic; it discusses how Miss's sculptural approach to layering and ephemeral space can be tested in the design chapter of this thesis as a method to engage the structural intervention as a space-defining tool.

Mary Miss builds upon the theories of Kahn and Scarpa by starting with the notion of the layer, the broken, and the ephemeral nature of space; she does not work with existing historic structures but implicates historical meaning through her installations by suggesting the notion of habitation. Miss is interested in the interaction between the viewer and the constructed form; to her art is no longer about a singular object caged in the architectural vehicle of the gallery, where one stares at the object in order to find meaning. Her work creates its own 'canvas' or means of presenting itself, using landscape and architectural vocabularies, Miss creates an envelope that the viewer enters as a part of the emotional and physical experience of unveiling her work to the viewer. She creates the notion of being 'inside' the installation both physically and emotionally (Zapatka and Miss 8). 
"Miss is less interested in the cerebral than in the emotional and physical experience, which she precipitates through mixtures of forms that work subliminally. Because she has walked through these places, but she then turns them slowly in her imagination, because they are built in materials that themselves have strong associations, the results ring with the authenticity of their antecedent - they are not a style-orientated amalgamation of thin, facile references lifted from the faces of other buildings" (Boyarsky and Miss 99).

Her work "provoke[s] curiosity in the viewer" (Boyarsky and Miss 99), by assimilating multiple references into one suggestive sculpture, making the experience of viewing her work about the discovery of a multitude of meanings married together in her work, rather than just a singular reference to history. Miss's principle objective is to reveal something about the site to the viewer that would have previously gone unnoticed; to achieve this she combines different forms and the associated meanings to create a collective emotional and physical experience for the viewer.

She takes architectural structures, memories and materials she has seen on her exploratory travels and combines them; through the use of memories of the site context, and the references stimulated by the multiple forms and materials, Miss creates a holistic experience for the viewer that is rich in meaning. The reason the viewer is drawn to Miss' work may be subconscious but still equally appreciated (Boyarsky and Miss 99). She responds to the physical nature of the site in which her work sits. By employing a myriad of memories and associations hinted at by the elements within her work, Miss creates a sensation of intrigue and understanding in the viewer that cannot be fully comprehended but appreciated. The multitude of associated memories embedded within her work enables Miss's work to be appreciated by the broad public as well as those educated in the arts (Zapatka and Miss).

This thesis will test potential applications of Miss's installation art within the realm of architecture, investigating how her methods can be employed to create, enable and enhance habitable space within the context of an existing historic built environment. Methods employed by Mary Miss to create layered and nonprogrammed spatial installations will be tested in the design experiments of this thesis to explore how the physical experience of Miss's installations, can be achieved along with a function that both structurally and pragmatically engages with New Zealand's endangered historic buildings. Both Miss and Scarpa's related works are further explored in 'Layer Two: Assimilating Architecture and Installation Art'.

Structural design as a Layer

In order to establish how lateral seismic bracing might become another exposed layer of contemporary history openly expressed within New Zealand's weathering heritage buildings, this section analyses structure as an integral part of a stratified system of layers employed by architects to enrich historical sites as a protective and space-defining tool. This section explores the application of seismic resisting structure within a historic building as a form of contemporary 'ornamentation'. As a case study, it evaluates methods proposed by engineers in collaboration with theorists to strengthen the historic Turnbull House at 11 Bowen Street in Wellington, whilst simultaneously inviting the structural layer to act as a current layer, or layer of the present in the timeline of history.

Structural engineer and Associate Professor Andrew Charleson argues that structure is often employed as an after-thought when achieving an architectural concept (Charleson 9). In his book Seismic Design for Architects Charleson argues that structure can posses design merit as well as structural resistance. He argues that structure has the ability to enrich architecture as a space-defining tool, and should be employed as a mechanism to contribute to the architectural concept, not purely act as a support system (Charleson 9). He claims, "Structure no longer remains silent but has a voice to be heard" (Charleson 15). The collaborative book Moments of Resistance by Taylor, Preston, Hartoonian, Ostwald, and Charleson takes seismic strengthening to an emotive and theoretical level, contributing to Charleson's argument that structure can be concerned with more than purely seismic or gravity loading. The authors change the discourse on seismic structure to be centred on the facilitation of lateral bracing as a narrative tool (Taylor et al.). Moments of Resistance focuses on two projects, the first of which is of particular interest to this thesis. The theoretical project looks to structurally reinforce the Turnbull House in Wellington, a Revivalist building from the early 19th Century, a similar vehicle as the one chosen for this thesis. 
The authors discuss methods that expose rather than conceal seismic reinforcing, in order to engage the structural elements as active participants of the space. Methods such as steel panels that 'hover' parallel to shear walls and steel sections that are 'fleshed out' with timber and decorative steel tie interpretations were explored to integrate the lateral bracing with the notion of dressing walls and surfaces with exposed seismic resisting structure.

"Regularly spaced ties were inserted into the brick exterior wall. Polished stainless steel studs over these ties, their shiny surfaces reflective in sunlight. As a visible sign of the strengthening they act as decorative embellishment that does not attempt to revive the past but again critically evaluates the role of the boss or disk as a covering and marker for a junction or fixing point" (Taylor et al 66).

Moments of Resistance is an important study for its theoretical stance on secondary structure which explores applications to a similar building to that being examined in this thesis. The authors conclude that secondary seismic resistance can include an ornamental aspect, as it is not always active and therefore must remain a positive contributor to space even when not acting under force from and earthquake or lateral loading.

CONCLUSION

The seismic inadequacy of New Zealand's 19th and 20th century historic buildings provides a window of opportunity to test the theory that contemporary lateral bracing elements can be exposed in order to express the current stage of metamorphosis in a heritage building. It is argued above that structure can act as a stratum or layer that remains exposed within the heritage building; this structural insertion can also be explored in ways that functionally and programmatically enable the historic building to become habitable and profitable once again.

The goal of New Zealand's heritage authorities is to protect our built heritage; however, the theories discussed above suggest in some cases that restoration is actively scraping a layer of history from our heritage, postulating that weathering represents a layered metamorphosis of a building through time.
The ICOMOS NZ Charter maintains its position that contemporary interventions and adaptations should maintain the historical significance, involve the least degree of intervention possible and use reversible techniques to execute all interventions. However, this thesis argues for a more intimate evaluation process that identifies historic buildings that have fallen into disrepair as sites that are able to engage decay and weathering as a part of their history. It is argued that the evidencing of man-made and environmental impressions signals our tangible existence and relationship to the built environment. This thesis argues that the historic / contemporary collaborative projects are the architectural representation of our time.

The analysis conducted in this chapter is employed to provide a theoretical grounding from which the design experiments conducted in, 'Layer Five: An exploration of contemporary layers' (Chapter Five) can be initiated. This chapter identifies the threat now facing New Zealand's historic buildings, due to the rise in building code and earthquake strengthening requirements. It establishes that a new evaluation system is required that identifies the difference between zones within heritage sites that can easily be maintained and zones or sites that have fallen into disrepair; acknowledging that decaying heritage sites provide an opportunity to engage with the decay or weathering of elements as a means of creating a timeline of history through the impressions and imprints left by mankind and the environment.

This chapter explored theoretical imperatives behind the notion of layering and stratification in both architecture and installation art, to formulate an argument for the application of a system of stratified architectural elements that can be employed as a tool to resolve new problems facing our heritage buildings and protect our heritage sites from demolition. The Albemarle Hotel, for example is a dilapidated historic building in Wellington in need of a seismic resisting structural intervention, but the cost is considered prohibitively high. The design chapter will use the Albemarle Hotel as a design research case study to test applications of the methods of Kahn, Scarpa and Miss in ways that create a multiplicity of integrated viable responses to New Zealand's vulnerable sites. 


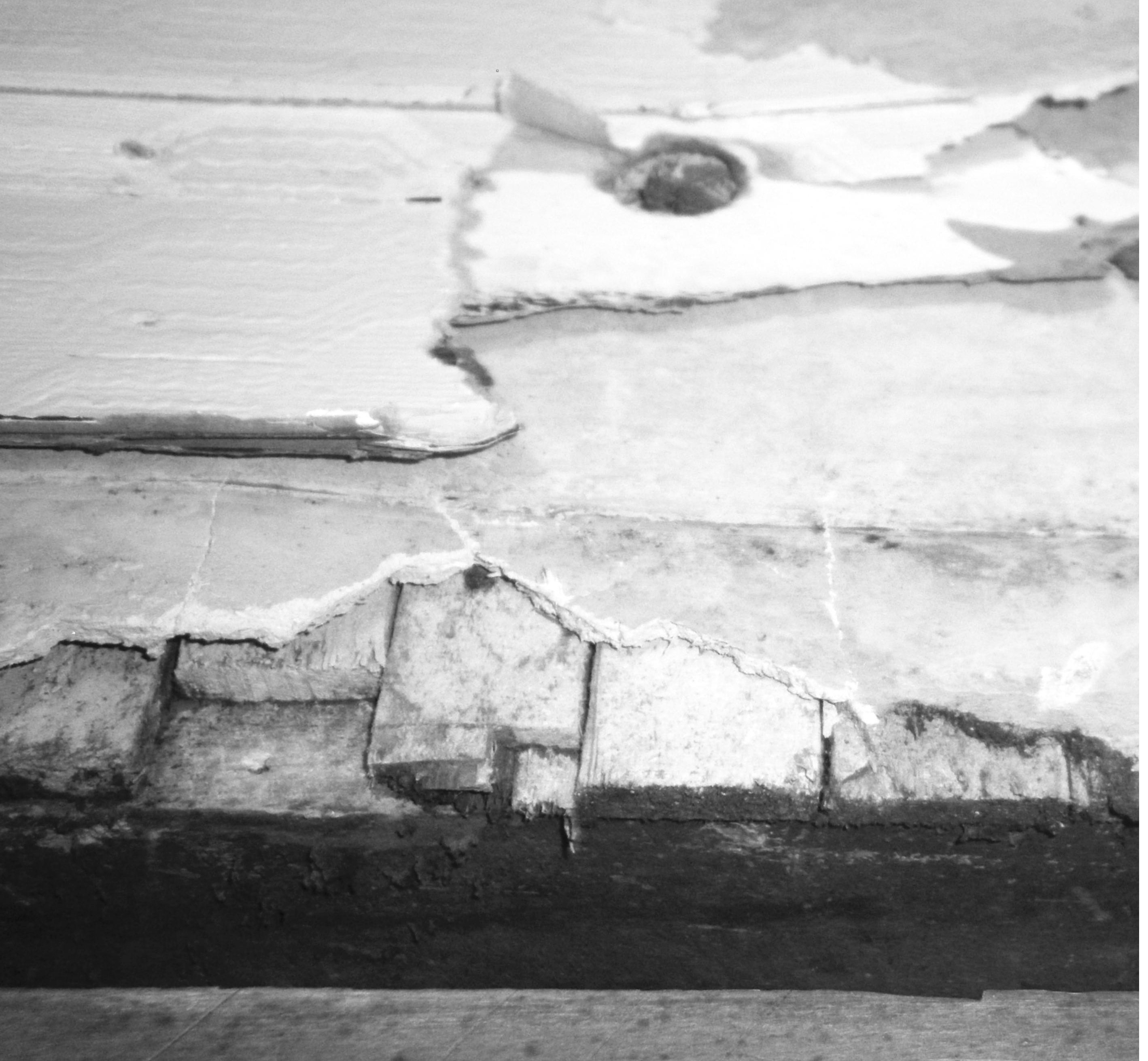

Assimilating

ARCHITECTURE \&

INSTALLATION ART

Castelvecchio

Warehouse 17C

The Mint

Collaboration of Case Studies

Mary Miss

Summary of Habitable Installation Art

53 
"SO With THE HOUSE EMPTY AND THE DOORS LOCKED AND THE MATTRESSES ROLLED ROUND, THOSE STRAY AIRS, ADVANCE GUARDS OF GREAT ARMIES, BLUSTERED IN, BRUSHED BARE BOARDS, NIBBLED AND FANNED, MET NOTHING IN BEDROOM OR DRAWING-ROOM THAT WHOLLY RESISTED THEM BUT ONLY HANGINGS THAT FLAPPED, WOOD THAT CREAKED, THE BARE LEGS OF TABLES, SAUCEPANS AND CHINA ALREADY FURRED, TARNISHED, CRACKED. WHAT PEOPLE HAD SHED AND LEFT Ó A PAIR OF SHOES, A SHOOTING CAP, SOME FADED SKIRTS AND COATS IN WARDROBES Ó THOSE ALONE KEPT THE HUMAN SHAPE AND IN THE EMPTINESS INDICATED HOW ONCE THEY WERE FILLED AND ANIMATED; HOW ONCE HANDS WERE BUSY WITH HOOKS AND BUTTONS; HOW ONCE THE LOOKINGGLASS HAD HELD A FACE; HAD HELD A WORLD HOLLOWED OUT IN WHICH A FIGURE TURNED, A HAND FLASHED, THE DOOR OPENED, IN CAME CHILDREN RUSHING AND TUMBLING; AND WENT OUT AGAIN."
A

s discussed previously this thesis explores theories of layering and tratification as a potential approach to the design research problem; this approach was initially developed in response to the weathering and peeling paint witnessed in some of New Zealand's historic sites. The notion of architectural layering as a method of evidencing history is supported in this chapter by case studies whose techniques are recognised as a celebration of weathering; this chapter explores the Castelvecchio in Verona by Carlo Scarpa, Warehouse 17C in Madrid by the Arturo Franco Office, and The Mint in Sydney by FJMT Architects. All three projects apply notions of layering in very different ways to achieve a celebration of decay and weathering within a historic building. This chapter investigates the methods and theoretical imperatives employed by each project; it critiques the approach each intervention has taken to engage with an aging structure in order to create spatial experiences appropriate to the building and its new program, as well as further understanding and appreciation of the historic ruin. This chapter then analyses case studies by two contemporary installation artists who engage with architecture as a vehicle of expression. Mary Miss and Ann Hamilton integrate architecture, art, and sculptural design to change the state of the viewer so that aspects of a site that were previously unnoticed can be understood in new ways. This chapter explores how each artist's work differs from the practice of architecture, but could in fact be applied to habitable architecture as an approach to exploring the design research imperatives of this thesis. 
CAstelvecchio

According to Anne-Catrin Schultz, author of Carlo Scarpalayers:

"Architectonic layering goes beyond merely fulfilling technical requirements the, principle of layering may be used as a formative method that allows elements of different origins to be combined into a non-hierarchal whole. Layering exists in a realm of complexity and implies a capacity of being interpreted that goes beyond itself and creates references to the world at large" (Schultz 17).

Carlo Scapra was commissioned to transform the ruins of the Old Castle of Verona into a museum of art. His intervention in the Castelvecchio lays bare the notion of stratification or layering, unveiling a chronological timeline of history within the complex. Through his intervention, Scarpa transforms the Castelvecchio into a museum incorporating time-related sedimentation of materials, abrasions and meaning by visibly exposing layers of time and history. The intervention originally designed by Scarpa as a vehicle to convert the complex into a museum has become in itself a museum of architecture over time. Scarpa stratifies both old and new materials in a way that encourages the visitor to become aware that each layer is a contributor to the success of the space, formulating a time line of history embedded within the walls (Schultz 9). "Interventions in the existing context are integrated as additional layers leaving the visible sign of their time and referring to the conceptual essence of their cultural belonging" (Schultz 7).

Scarpa's intervention in the Castelvecchio is disengaged from the existing historic building; it never sits directly on the existing but appears to hover above, below or next to the existing allowing the negative threshold between the new and the old to speak louder than the materials themselves (Schultz 10).
SPECS

Project: Castelvecchio

Location: Verona, Italy

Date of Completion: 1957

1964, 1967-1970, 1974

Architect: Carlo Scarpa

Original Use: Castle of the

Scala family built 1354-1376
He used contemporary elements to frame the historic, as well as to place it onto a particular axis so that it achieves a type of sacred positioning. Figure 16 shows how Scarpa's intervention frames the historic brick wall opening in the centre of the wall, on the central spatial axis, even though the original vaulted door opening was off axis. He uses the addition of the contemporary screen to enable the original vaulted opening to remain visible while also placing the historic brick wall onto a centre axis; Scarpa employed disengagement and reorientation as methods of transitioning the viewer to see the desired aspect of the existing building to experientially lead the viewer through the space to witness the decay. The decay itself becomes an element being displayed by Scarpa in the museum as museum artefacts.

"He layered history, allowing each historical moment to come alive and take its place next to others and interspersed new ones. He was able to achieve this while setting up a dialogue between old and new, provoking the older elements into conversation with wholly invented new forms, surfaces, textures, and motifs" (Guidi, Olsberg, and Scarpa 70).

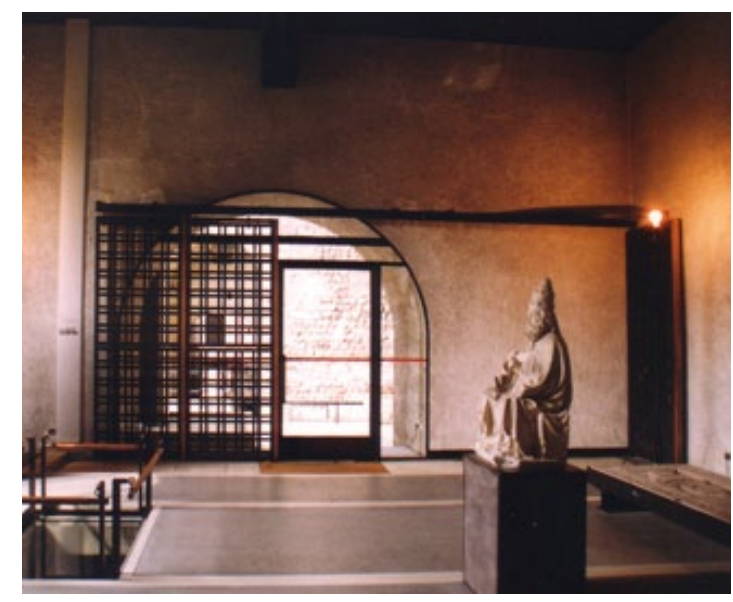

Fig. I6 CASTELVECCHIO INTERIOR DOOR PORTAL

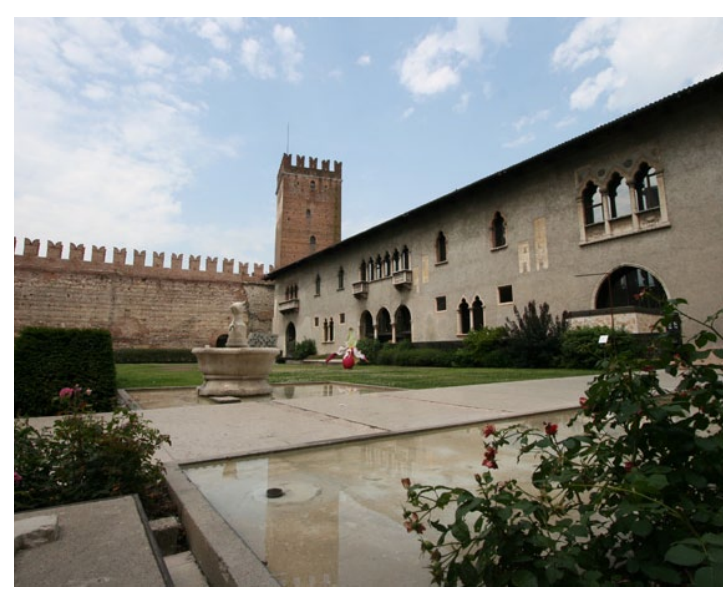

Fig. I7 Castelvecchio courtyard by Carlo Scarpa

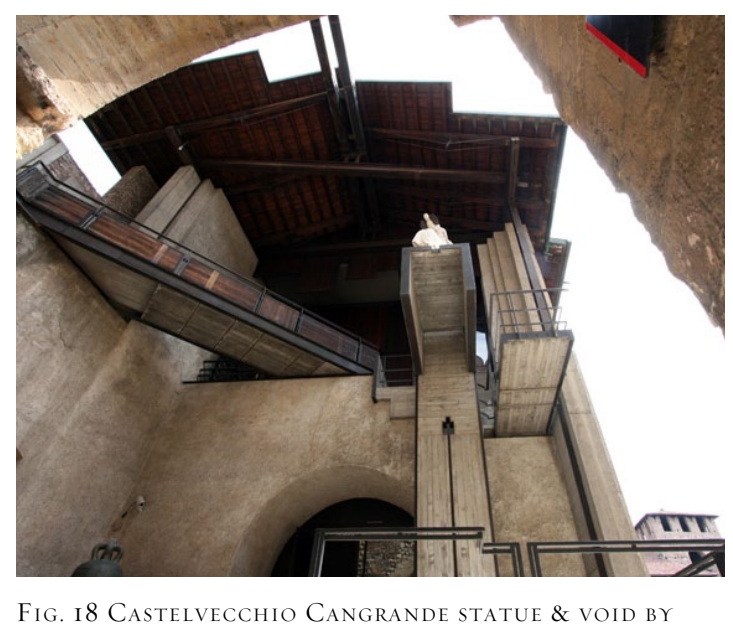

Fig. 18 CastelleEcchio Cangrande statue \& void by
Carlo Scarpa (1958-64) 
This thesis proposes that Scarpa's method of re-orientating the viewer to face and recognise the beauty of the decaying elements can be tested in the historic Albemarle Hotel to allow viewers to see the spaces in new and more robust ways. The previous internal layout of the hotel was spatially organized around enclosed rooms and corridors that did not attempt to establish any orientation to historic elements. It was designed to maximise the profitability of small hotel rooms, not celebrate the facade or structure or spatial relationships. The design research case study argues that since walls have already been semi-demolished over time, a stronger recognition of the history of the building already occurs; the new intervention can further enhance our reading of the history bby applying lessons learned from Scarpa in the Castelvecchio. Similarly to Scarpa the new design will test inserting a new raised floor that is disengaged from the existing floor and aligned with the central window on the heritage façade. The occupier would then actively step up onto the new floor identifying the space where corridor was previously located; the new floor, without the visual disruption of rooms and doors would invite the occupier to look through the space out of the façade to the street. The occupier will then be orientated facing the historic front façade and be able to witness the structural intervention integrated with the decaying façade, similarly to how Scarpa approached the same issues in the Castelvecchio. This builds further upon Scrapa by challenging the new lateral bracing to become an active participant in achieving these goals under the new contemporary conditions.
WAREHOUSE I7C

The Arturo Franco Office was commissioned to transform the ruins of a historic slaughterhouse in Madrid into a restaurant (See Fig. 19). The contemporary intervention within the historic slaughterhouse by Arturo Franco Office explores the notion of 'non-intervention', reducing the intervention to enable the heritage warehouse to reveal the decay of the existing structure and the beauty of the contemporary against the historic (Arturo Franco). The project does not attempt to refurbish or preserve the warehouse in its original condition, but allows the aging of materials to speak of the history embedded within the walls

“A constant dialog has been established between the new and the old, without mixing them up, together but not blended. These two languages look close to each other. The new boosts the value of the old and vice versa. Two viewpoints face to face, both revealed with maximum rawness" (Arturo Franco).

The contemporary materials face off with the historic, creating a dynamic tension in the buffer zone that separates the old and the new. The Arturo Franco Office employed industrial inspired steel and glass as a method of presenting the historic warehouse, framing the peeling paint and crumbling brick, and enabling it to become sanctioned as art on the walls; by hovering glass in front of crumbling brick, the intervention acts as a stage that presents and preserves decay (See Fig. 20). While Scarpa had framed elements of decay that were robust, this method allows Arturo Franco to frame elements of decay that are fragile even to the point of allowing the decay to continue.
SPECS Project: The Warehouse 17C Location: Madrid, Spain Date of Completion: 2006 Architects: Arturo Franco Office

Original Use: Slaughterhouse by Luis Bellido 1907 
The intervention does not seek to touch or penetrate the decaying structure in any way but sits next to or on top of the decaying surfaces. The contemporary intervention guards the warehouse without sheltering it; the intervention celebrates and facilitates the process of decay to continue as an on-going historical illustration. This thesis argues that the Warehouse intervention is extremely successful, although a potential weakness of the project is that it is not dealing with the same multiplicity of issues as those facing New Zealand's heritage fabric (i.e the need for new lateral bracing) but is dealing with the issue of decay alone.

The architectural techniques employed by the $17 \mathrm{C}$ Warehouse intervention supports the notion of layering in a contemporary sense as a method to celebrate the decay of heritage sites. To introduce these techniques to the context of New Zealand's semi-demolished and semi-decayed heritage sites would establish a foundation by which the argument for the framing of decay as art on the walls can be supported. The design experiments will employ this method of sanctifying decay by presenting it as a positive aesthetic, but could further the research imperatives of Arturo Franco by inviting the glass that frames the decay to also frame the space between the rhythmic structural elements required as lateral bracing. The glass could act as a celebrator of decay, protecting it from further debilitation, whilst also defining the space proposed as an office or spatial bay for the NZHPT office.

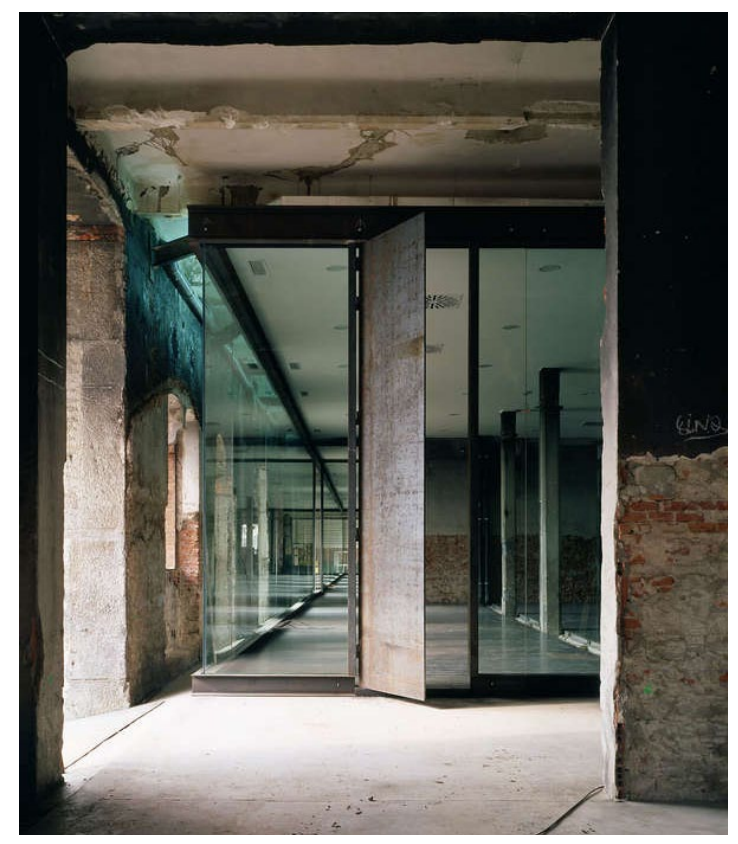

Fig. I9 Warehouse 17 C bY Arturo Franco Office -
INTErior Space defined bY GLaSS partitions (2006)

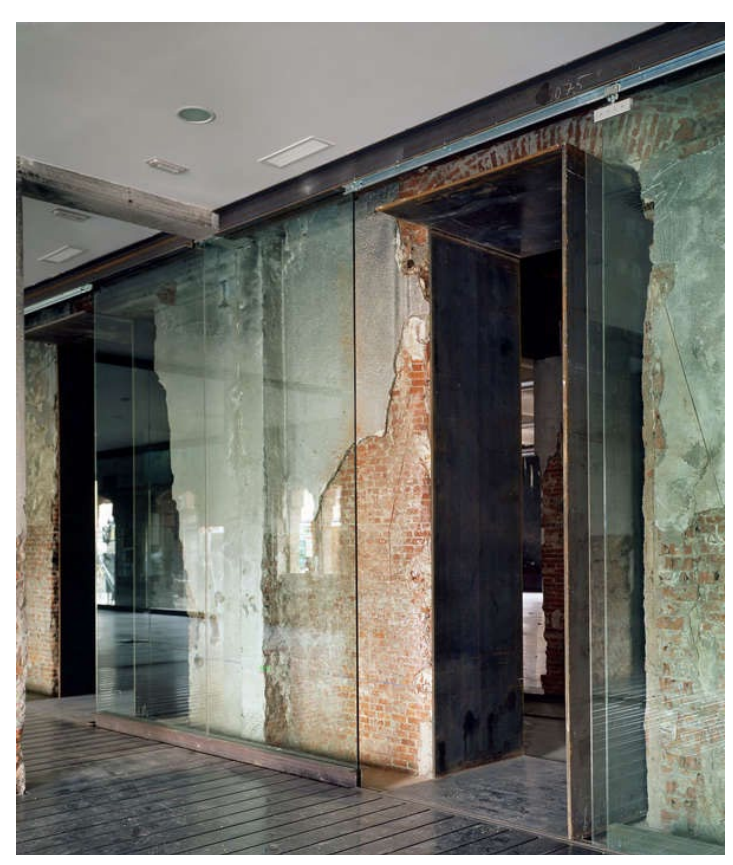

Fig. 20 Warehouse i7C br arturo Franco Office -
The Mint

FJMT Architects were commissioned to transform the ruins of a historic coin factory into an office interior. The Mint is central Sydney's oldest building originally a coin factory and now the headquarters for the New South Wales Historic Houses Trust (HHT). The historic coin factory and surviving archaeological elements are integrated into the new contemporary complex designed by FJMT Architects in 2004 (Historic Houses Trust of NSW) (See Fig. 21). The additional complex compliments the historic factory in terms of proportions and continuing datum lines, but contrasts the historic structure through materiality.

The intervention within the historic coin factory achieves the celebrating decay and weathering of historic buildings through the incision of structural elements. This case study enables the design experiments of this thesis to go beyond the works of Scarpa and Arturo Franco by successfully exposing structural elements. The new visible structure penetrates the historic without 'restoring' it, permitting exposed structural incisions into the existing heritage fabric, the incisions to become the next layer in the evidencing of the coin factory's history. The contemporary intervention braces the aging stone factory using steel and glass; where the weathering does not affect the structural capacity of the building, the flaking paint is permitted to continue flaking and the stone permitted to crumble around the HHT offices. The new Mint complex invites the public to wander through the historic and contemporary structures in a museum-like fashion; this notion of engaging the public with aging structures is something that this thesis looks to apply to the Albemarle in Wellington: the Mint programmatically establishes an important precedent for the NZHPT to be house within the Albemarle and to actively encourage the public to participate in the building as a means of witnessing and further understanding the imperatives of historic preservation.
SPECS Project: The Mint

Location: Sydney, Australia Date of Completion: 2005 Architects: FJMT Architects Original Use: Coin Factory 1855 
New floors were introduced into the factory, but disengaged in places creating view shafts down to the ruin-like original foundations, celebrating the decay and weathering of the historic factory and allowing it to be witnessed by the public. The Mint frames and sanctifies decay much like the $17 \mathrm{C}$ Warehouse, but takes the concept further by inviting the contemporary new structural elements to visibly slice into the historic, penetrating the material and allowing visitors to see the contemporary structural elements penetrating the aging historic material; the design experiments of this thesis also employ structural elements to slice through the historic elements.

The interior could have become a stronger spatial experience if it considered how the design could have encouraged spatial and planning orientation in relation to the historic conditions evident within the site. For example the interior layout including the disengaged floor disregards the placement of the windows in the heritage façade, cutting off the spatial experience of the existing windows by terminating halfway along a window (See Fig. 23).

This thesis will test the Mint's approach by inviting the structural intervention to slice into the existing heritage fabric where necessary; and in other locations the structural intervention will sit disengaged from the existing adopting more of a respectable and sympathetic relationship with the existing historic materials.

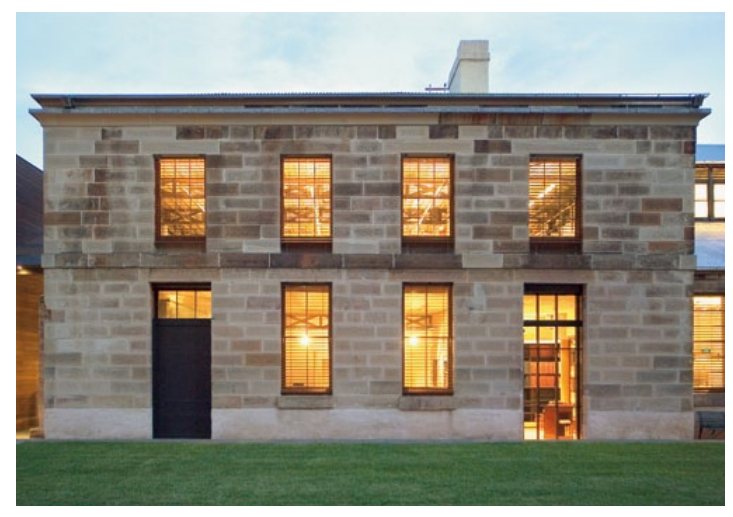

Fig. 2I The Mint SYdneY Ñ historic CoIn factory (1855)

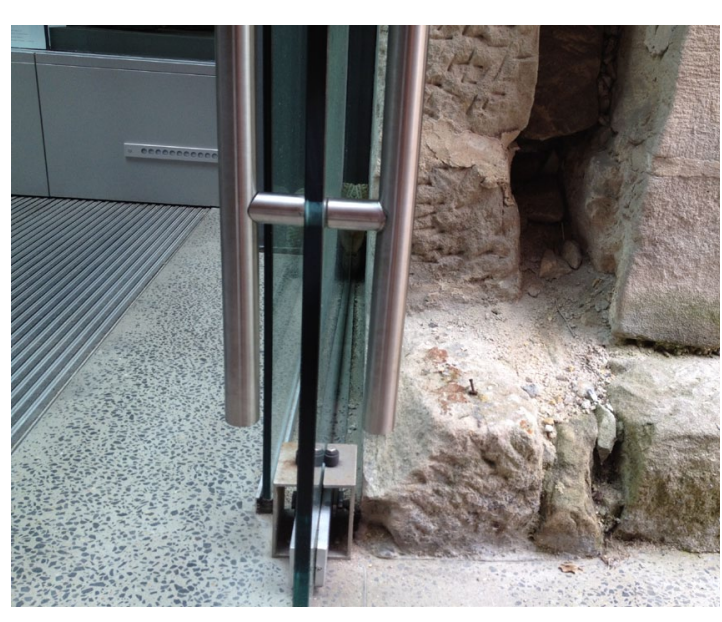

ig. 22 The Mint Sydney - contemporary entranc

Fig. 22 The MinT SYDNeY - CONTEM
ADDition FJMT ARChiteCTS (2005)

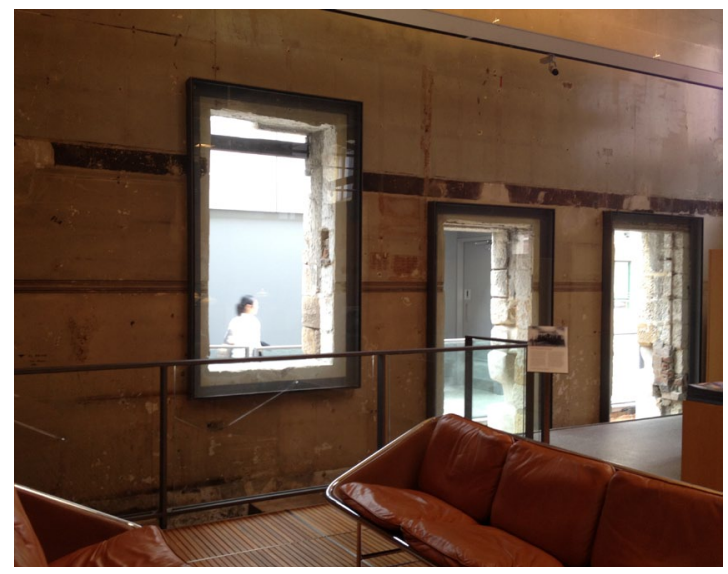

FiG. 23 The MiNT SYDNEY - RECEPTION FOR THE HHT b
FIMT ARCHITFCTS (2005)
Collaboration of Case Studies

Castelvecchio \& Carlo Scarpa: Disengages new and old layers to respect their identity, and treats the decayed as positive visual elements.

The Warehouse 17C: Guards the history of fragile types of decay that may be vulnerable. The Mint: Exposes the raw new structure that may be required in a public space as a positive addition to its history

This thesis combines strengths and examines the weaknesses of all three different case studies and invites their strengths to inform the design research experiment within the Albemarle Hotel. The Castelvecchio explores the notion of disengagement and reorientation, transforming the intervention within the Castelvecchio into a museum of materials and historical layers. Warehouse 17C explores the active retention and protection of decaying elements as elements of beauty and history by presenting crumbling brick, fire-damaged ceilings and peeling paint, in a way that allows the weathering to be protected and perceived as art not deterioration. The Mint explores the incision of new structural elements within historic buildings and integration of the public within the ministry of historic trusts. 
Using these three architectural case studies, the design research experiment will explore opportunities to:

Concepts identified in the Castelvecchio:

- $\quad$ Disengage floor planes as a means of celebrating the relationship between the old and the new.

- Employ the negative space between the old and new as a means of engaging a discourse between the two elements.

- $\quad$ Re-orientate the viewer to align with the axis of the historic weathering elements.

Concepts identified in the Warehouse $17 \mathrm{C}$

- Sanction the celebration of decay using glass to protect and frame the peeling of paint it in a unique way, as art.

- Invite the design intervention, such as hovering glass or structural members to become a space defining tool.

- Invite new floors to orientate the viewer towards the historic aging façade.

Concepts identified in The Mint:

- Expose the raw nature of contemporary earthquake strengthening as a part of the hotel's history.

- Employ structural elements to slice through heritage elements as a means of engaging them in a dialogue while providing seismic protection.

- Take precedents from the Mint to permit public space within the hotel to encourage public involvement and opinion on the debate for the celebration of decay.

The design research experiment will also explore opportunities using two installation art case studies by May Miss and Ann Hamilton.
MarY Miss

Mary Miss is an installation artist whose work explores physical spaces that achieve architectural meaning; her work differs from architecture in the fact that her installations are not defined by programmatic function. Many of Miss's works such as Untitled (1976) (See Fig. 24 \& 25) and Field Rotation (1981) (See Fig. 26) imply architectural space and function, they succeed in instigating architectural space and make reference to architectural structures with the intention of drawing the viewer past the preconception of architectural form (Zapatka and Miss 20). One of her repeating interest is in the implication of structural form. Miss works with a multiplicity of theories and ideas; she employs this multiplicity to create a reference system that does not become explicit to one reference but suggestive of many.

"Miss layers her work in associations, and the layering starts with materials. She is interested in expanding the meaning of form: 'I don't want to deny any association or content. want to take the implications of a material and elaborate upon it, whether a grid of steel or railroad ties'” (Miss quotes by Boyarsky and Miss 99).

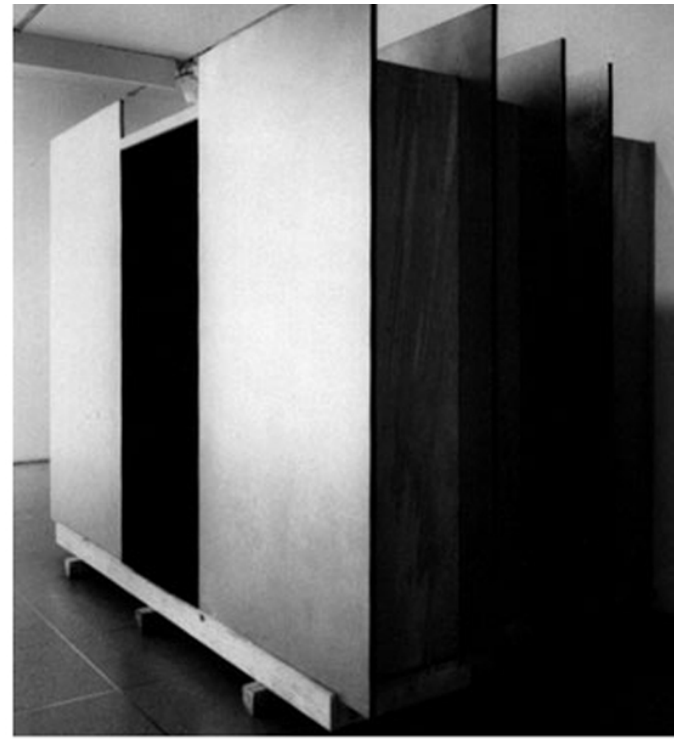

Fig. 24 UntitLed (1976) br Marr Miss

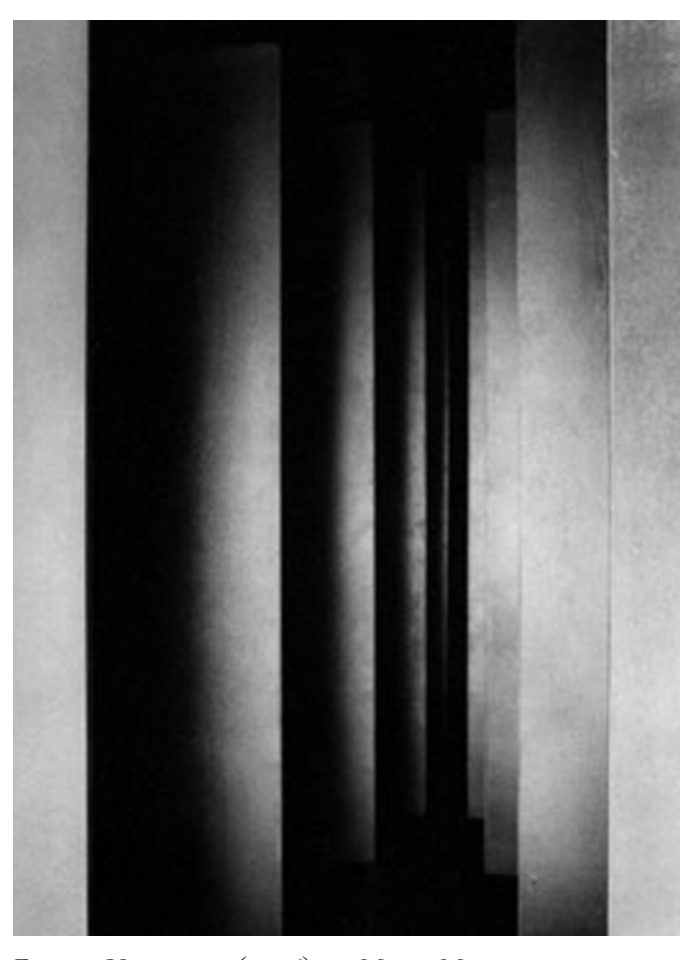

Fig. 25 UntitLed (1976) BY MARY Miss 
Miss has a strong interest in structural form and the implications of material choice. For example in her project Veiled Landscape (1979) (See Fig. 27) she employs structural grid to frame the landscape, providing physical barriers between the viewer and the landscape, abstracting the sky and surrounding foliage to become part of the installation. Through the use of screens and a curtain of posts, Miss creates a rhythmic procession whereby the viewer must pass through each barrier one at a time to reach the pathway that continues through the landscape (Zapatka and Miss).

Each architectural layer unveils the layer beyond, establishing new spatial qualities as the number of layers is progressively reduced. This method will be tested in the design research experiment as an additional means of engaging history while responding to new contemporary programmatic and spatial requirements.

Miss integrates new architectural elements to redirect the viewer toward a greater awareness of her objects and their context. She uses structure to create a rhythmic procession will be applied to the lateral bracing structural system of the design research intervention; this is explored in detail in 'Layer Five: An exploration of contemporary layers'. The bracing system will be used to create a rhythm through the existing historic hotel so that the new structural grid lines establish spatial ordering systems within the open plan nature of the interior.

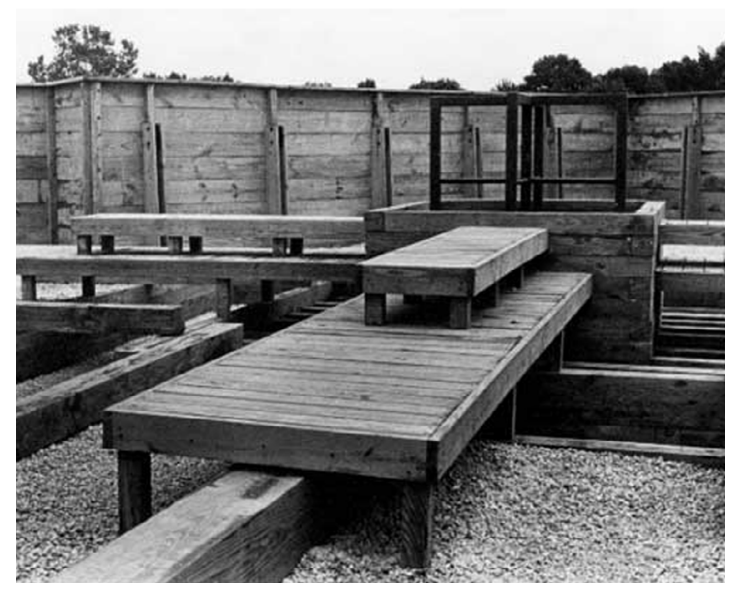

Fig. 26 Field Rotation (1980-8I) br Marr Miss

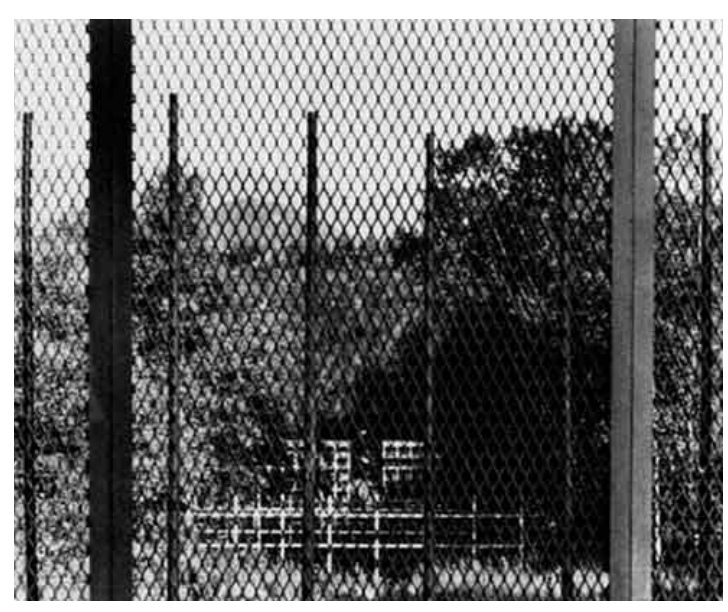

Fig. 27 Fifld Rotation (1980-8I) br Marr Miss
Ann Hamilton

Ann Hamilton is an installation artist whose work focuses on multisensory experience, incorporating sight, sound, smell, touch and emotion. Like Mary Miss, Ann Hamilton is interested in the relationship between visitor and object; however Hamilton's work differs in the fact that it is largely focused upon creating installations within prescribed 'rooms', each room igniting the senses of the visitor and giving them the perception of being alone. Hamilton often works with multiple rooms, taking the visitor on a narrative journey of their own senses, such as her work in The Capacity of Absorption at the Temporary Contemporary of Los Angeles Museum of Contemporary Art (1988-1989) where Hamilton's installation took the visitor through three rooms of overwhelming sensory experiences (Simon and Hamilton) (See Fig. 28, 29, \& 30)

“Hamilton's installations are wit nessed by visitors who occupy the same space with any number of others but who, it seems, find themselves distinctly alone. In part, it is heightened self-consciousness amid odd sounds, smells, and materials (live insects or birds for example or organic matter in the process of growing or decaying) and in the face of a distanced figure, the live performer working in self-contained isolation at a repetitive task" (Simon and Hamilton 63).

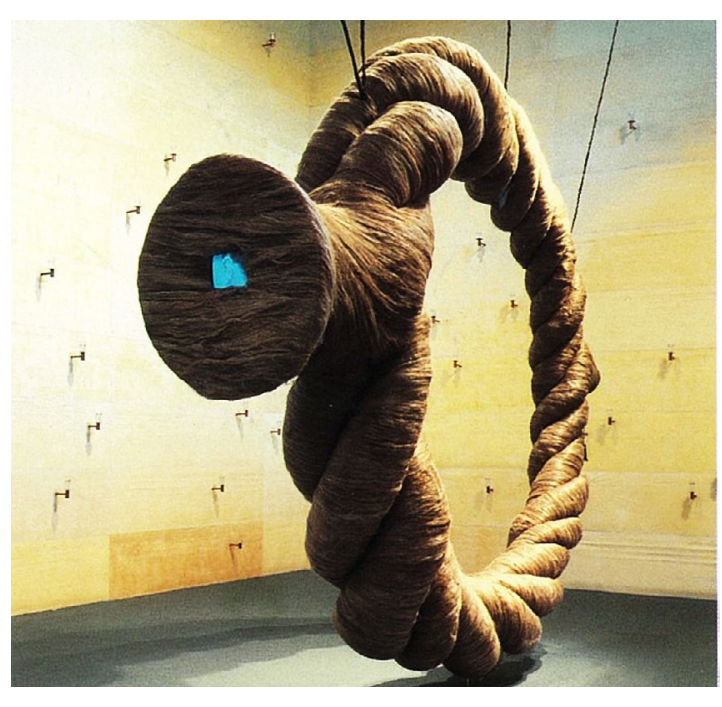

Fig. 28 CapactTrof Absorption (1988) room onf ol threE bY ANN HAMLLTon

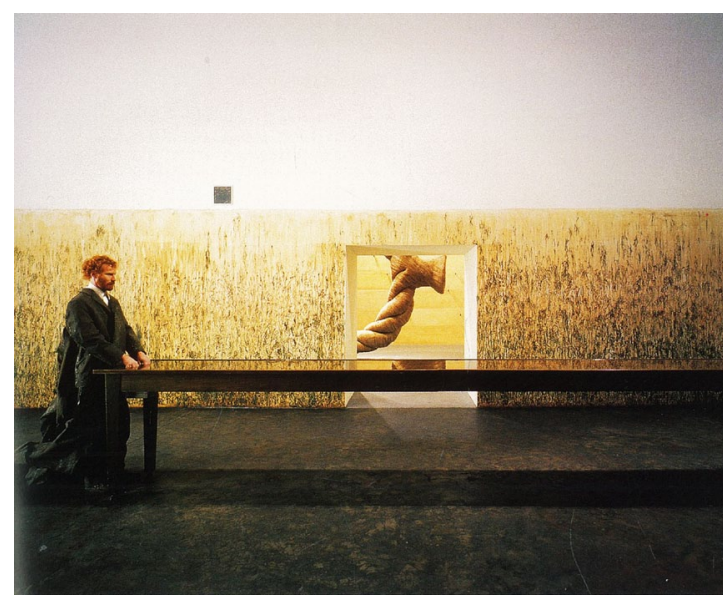

Fig. 29 Capacity of Absorption (1988) room two of three br ANN Hamilton

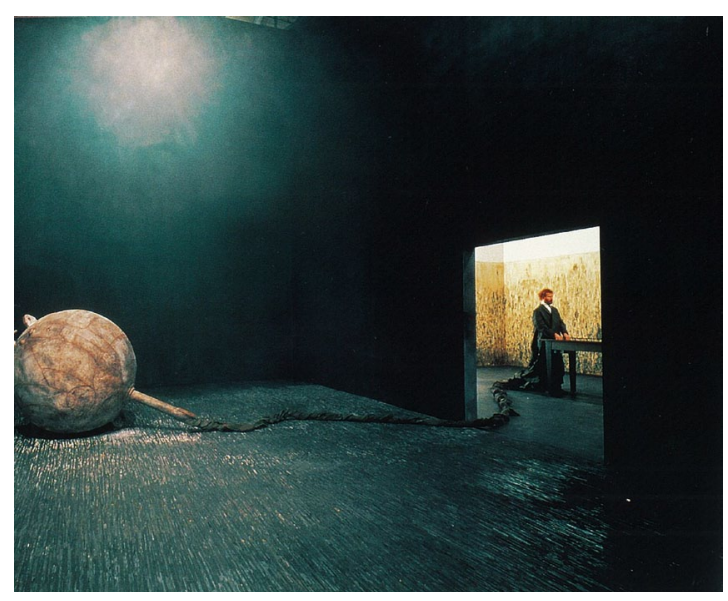
Fig. 30 Capacitr of Absorption (1988) room three of 
Hamilton's project The Spell (1997) (See Fig. $31 \&$ 32) as a part of the 1997 Venice Biennale explores the notion of 'rooms' within 'rooms'. The installation was housed in a 1303 warehouse factory originally used for making rope; the installation was placed between a row of columns and the brick masonry exterior wall.

"Twin curtains were suspended from the ceiling on motorized mounts, swirling, billowing, and lifting like tents taking flight in a windstorm" (Simon and Hamilton 185).

The twin black-over-white curtains had a vertical opening running the full height of the curtain, inviting viewers to enter the installation; from within the revolving translucent curtain the viewer could see glimpses of figures moving inside the twin curtain and moving past the installation, creating the sensation of being alone within a 'room' but aware of others in the neighbouring 'rooms'.

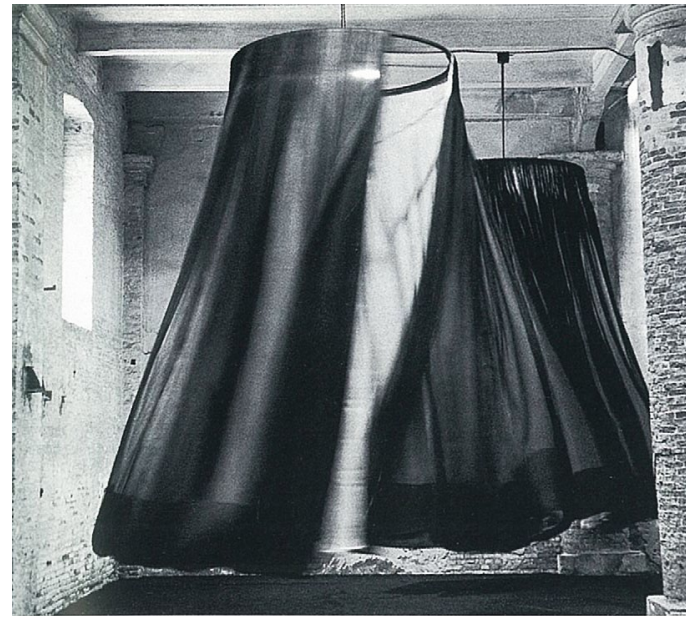

Fig. 3I The Spell (1997) br Ann Hamilton

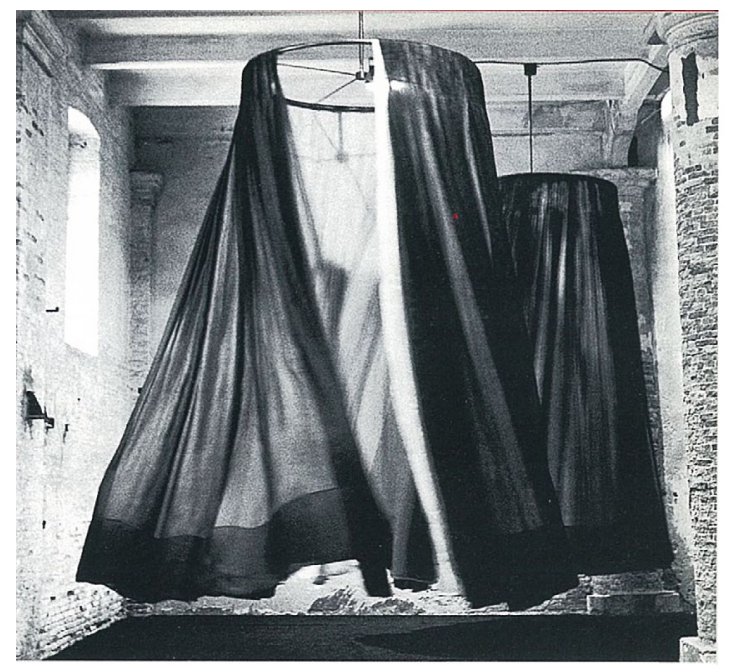

Fig. 32 The Spell (1997) Br AnN Hamilton
Hamilton's installation work, while architectural, differs from the traditional goals of architecture through her focus on the relationship of the viewer to the object, she is not concerned with holistic form or external relationships. Hamilton's creation of 'rooms' within 'rooms' is a notion that this thesis looks to translate through the medium of architecture. Investigating how spaces can be created in the zone between layers, inviting the structure to implement a rhythmic system of partitions of varying translucency to create the sense of rooms within rooms without solid separation. This will enable the office workers to feel like they achieve spatial separation even within an open space, occupying a small 'room' within the open plan office. 
Summarr of Habitable Installation Art

Mary Miss and Ann Hamilton conduct their installation art within the blurring media of art, sculpture, and architecture; the multidisciplinary and multisensory nature of their work enables the wider public to engage with their work, finding meaning in their changing spatial hierarchies and formal configurations. By inviting the viewer into the installation and changing their state in some way, each artist transcends the boundaries of more than one creative discipline through both the theoretical imperatives and the physical installations.

This thesis draws upon Miss and Hamilton's ability to engage architectural vocabularies without being hampered by pragmatic and functional limitations. This enables the artists to inform spaces purely in terms of the relationships between viewer and space, and space and viewer. The resulting spaces have a high level of beauty and theoretical insight. While this thesis argues that they also have potential to be highly pragmatic and functional, the ambiguity of the installation allows the viewer to explore the space without functional prejudice. This thesis looks to use spatial installation art to critically evaluate and advance the viewer/ occupants' relationships to the object/space, to use these relationships to inform the architecture and the thesis imperatives. This thesis tests the processes and underlying concepts behind such sculptural installation approaches and engages similar methods within the functionality of architectural practice. Explorations will be conducted within the design research vehicle for this thesis (Albemarle Hotel) to test these concepts derived from sculptural installation art against the pragmatics of function
Concepts identified in the Mary Miss case studies:

- Employing structural members to create a rhythmic ordering system.

- Applying multiple translucent partitions as layers to establish spatial qualities that can potentially become habitable.

- Inviting multiple layers of varying materials to create a holistic space.

Concepts identified in the Ann Hamilton case studies:

- Employing transparent scenes to create 'rooms within rooms' and implicate smaller spatial definitions within a wider open-plan space.

- Recreating the viewer's relationship to the space through sensory environments.

- Implicating the zone between layers as habitable space.

The translation of the three architectural case studies and the case studies of Mary Miss and Ann Hamilton's habitable installation art are explored in the following section 'Layer Five', which tests the approaches discussed in the 'Layer One' and 'Layer Two' within the Albemarle. The aim of 'Layer Five' is to test the methods explored by the architects and installation artists discussed in this chapter. It explores how all of these approaches can be integrated in varying ways depending on specific conditions, while also engaging the exposed lateral bracing to act as spatial definers for contemporary new programs, similarly to Mary Miss and Ann Hamilton's installation experiments but applied within habitable architecture. 

"LOVELINESS AND STILLNESS CLASPED HANDS IN THE BEDROOM, AND AMONG THE SHROUDED JUGS AND SHEETED CHAIRS EVEN THE PRYING OF THE WIND, AND THE SOFT NOSE OF THE CLAMMY SEA AIRS, RUBBING, SNUFFLING, ITERATING, AND REITERATING THEIR QUESTIONS ÓîWILl YOU FADE? WILL YOU PERISH?ŶÓ SCARCELY DISTURBED THE PEACE, THE INDIFFERENCE, THE AIR OF PURE INTEGRITY, AS IF THE QUESTION THEY ASKED SCARCELY NEEDED THAT THEY SHOULD ANSWER: WE REMAIN."

Virginia Woolf, To the Lighthouse (Time PAsses, 4)
$\mathrm{T}$ his chapter introduces the Category II historic Albemarle Hotel, as the chosen vehicle for design research experimentation. The Albemarle Hotel is employed as a mechanism to expose the common threat faced by Wellington's historic buildings; many of our historic sites may be lost to damage in an earthquake, or purposefully demolished to prevent the loss of life in the event of an earthquake. To set the foundation for the design research problem this section discusses the seismic and historic contexts of Wellington, in particular the Te Aro region where the Albemarle is located. 


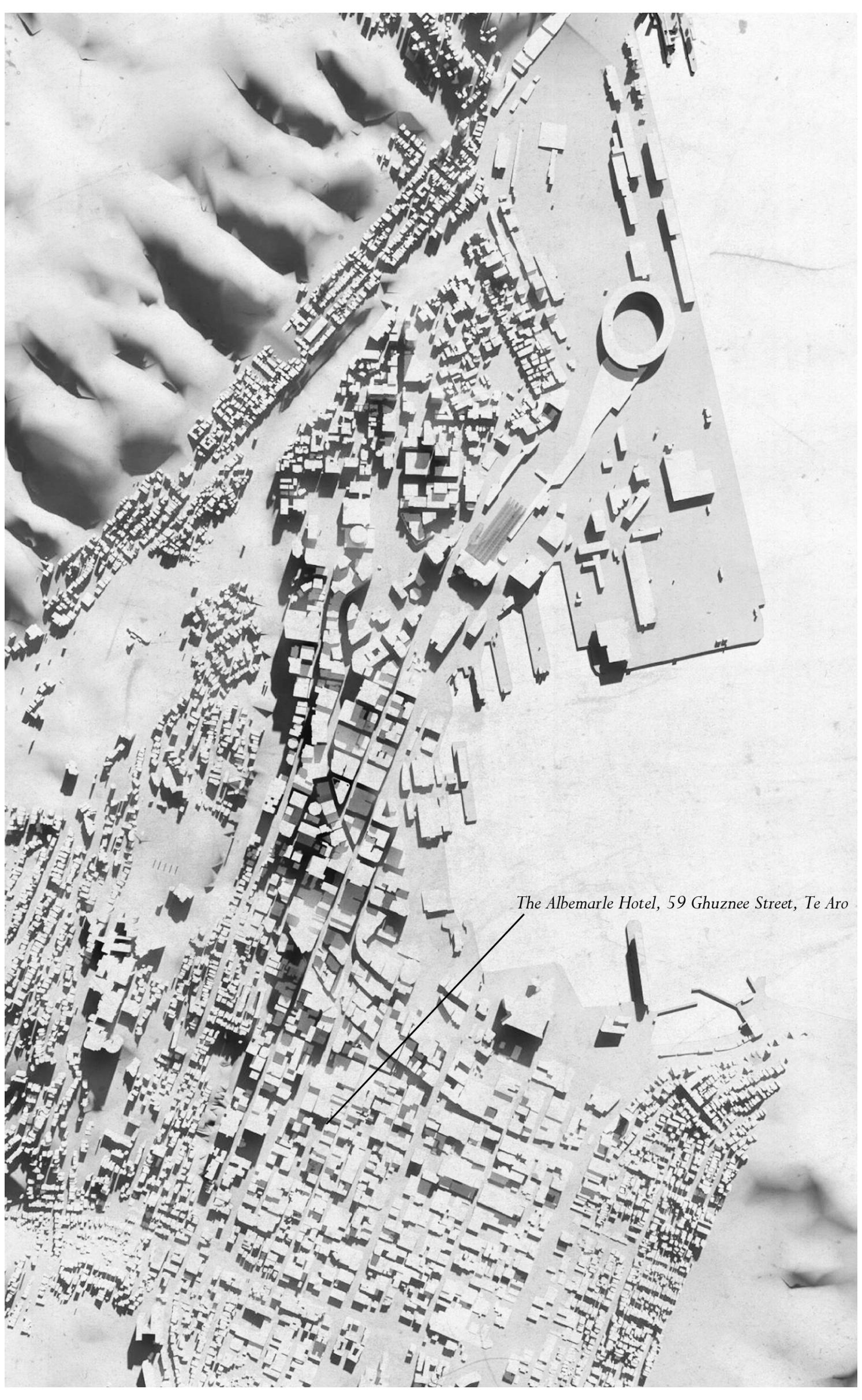

Fig. 34 Aerial view of Wellington central

INTRODUCTION

This chapter discusses the potential threat to Wellington's historic buildings, highlighting the vast number of buildings affected by the recent amendments to the Building Act (2004) and the IEP (Initial Evaluation Process) conducted in May 2012 which identified 266 EQP (Earthquake Prone) buildings in Wellington which now require additional costly lateral bracing in order to structurally protect them and their occupants from potential earthquake damage (Department of Building and Housing). Because of the logistical and economical difficulties this incurs, this thesis suggests that a change of attitude towards heritage intervention is pivotal to the survival of Wellington's built heritage. This chapter exposes the positive potentials that the Building Act revisions have provided; by passing legislation that requires contemporary elements to engage with historic sites, the Building Act has provided an opportunity for contemporary design to engage with historic buildings. The fact that heritage buildings must now incorporate contemporary bracing elements reinforces the argument that the potential transformation of heritage buildings could potentially form a built time line, a means of recording and evidencing of the layers of history as 'Time Passes'.

The Albemarle Hotel was selected as the design research vehicle for this thesis to test the proposed approach to New Zealand's historic buildings in response to the recent increase in lateral bracing requirements. The Albemarle strongly evidences the recurring issues recently thrust upon Wellington's historic buildings. The earthquake-prone (EQP) historic buildings of Wellington are a prominent part of our cityscape, the destruction of which would be a huge loss to Wellington's character, as it was to Christchurch's. However, the extensive work required by the Wellington City Council's Earthquake-prone Buildings Policy (2009) and reinforced by the IEP (2012) is expensive and many owners cannot afford to complete the work. This may result in the elective destruction of some or even a large amount of our built heritage (Schouten). This thesis argues that this new set of restrictions is in fact an opportunity to re-evaluate the way New Zealand approaches heritage buildings, from conservation and literal restoration to the celebration of aging and weathering as a means of chronicling the history and natural transformations of our buildings. 


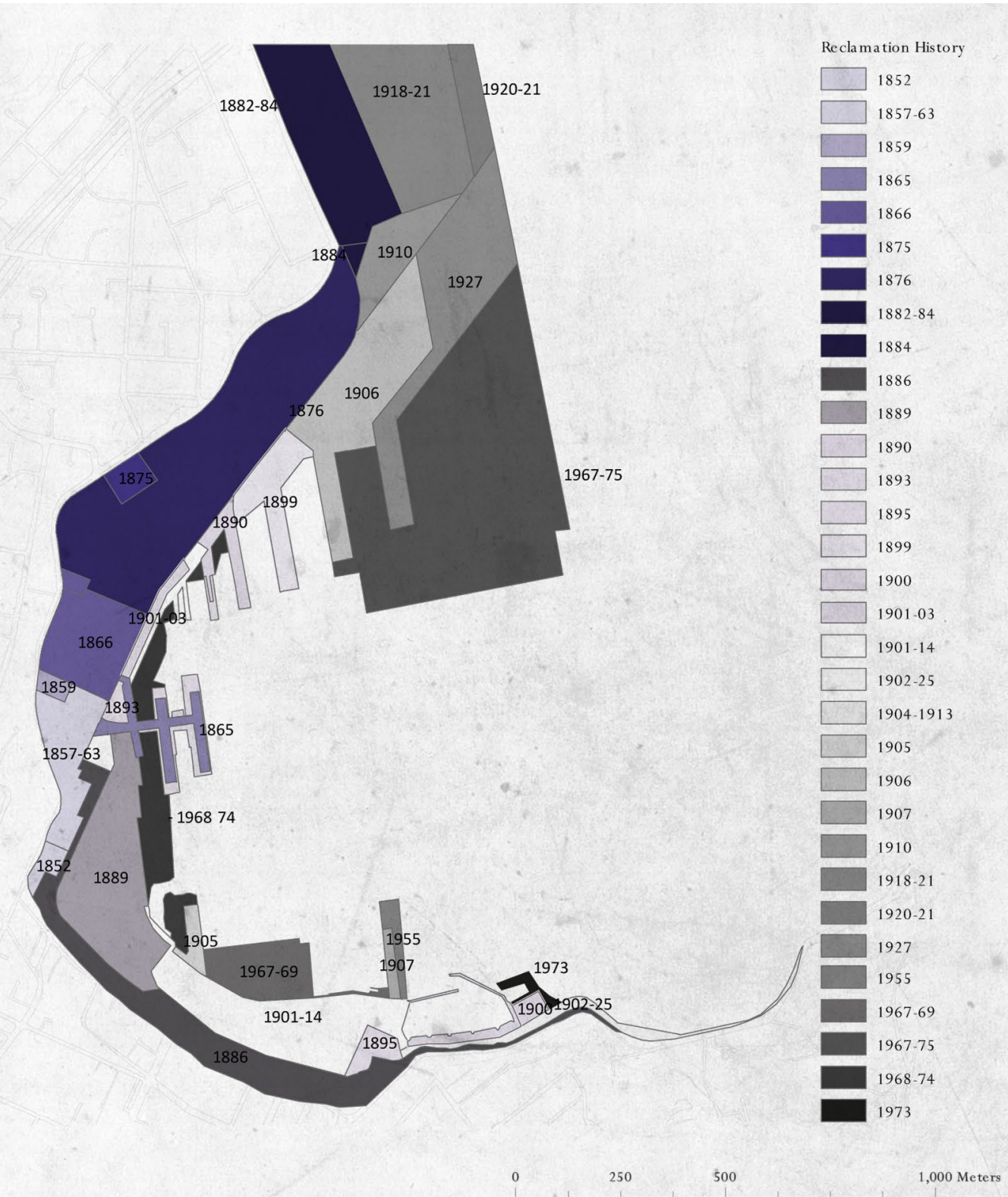

This site analysis explores the neighbourhood of the Albemarle Hotel (Te Aro) and more importantly the intimate conditions within the Albemarle itself. The chapter evaluates the dominant heritage areas within the hotel and the echelon of decay in order to surmise how it can simultaneously retain the dominant heritage zones as well as the weathered conditions, while establishing opportunities for newer contemporary programs to thrive within.

Reclamation of Wellington Harbour

Nestled between two hillsides, Wellington is the compact and culture filled capital city of New Zealand. Known for its picturesque qualities, Wellington has undergone many large-scale reclamation projects. Between 1842-1973 a total of 1.854 square kilometres was reclaimed giving the city more space to accommodate for expansion including an expanded port and industrial area, and an expanded beach along Oriental Parade (Maclean). Buildings on reclaimed land can be particularly vulnerable to earthquake damage.
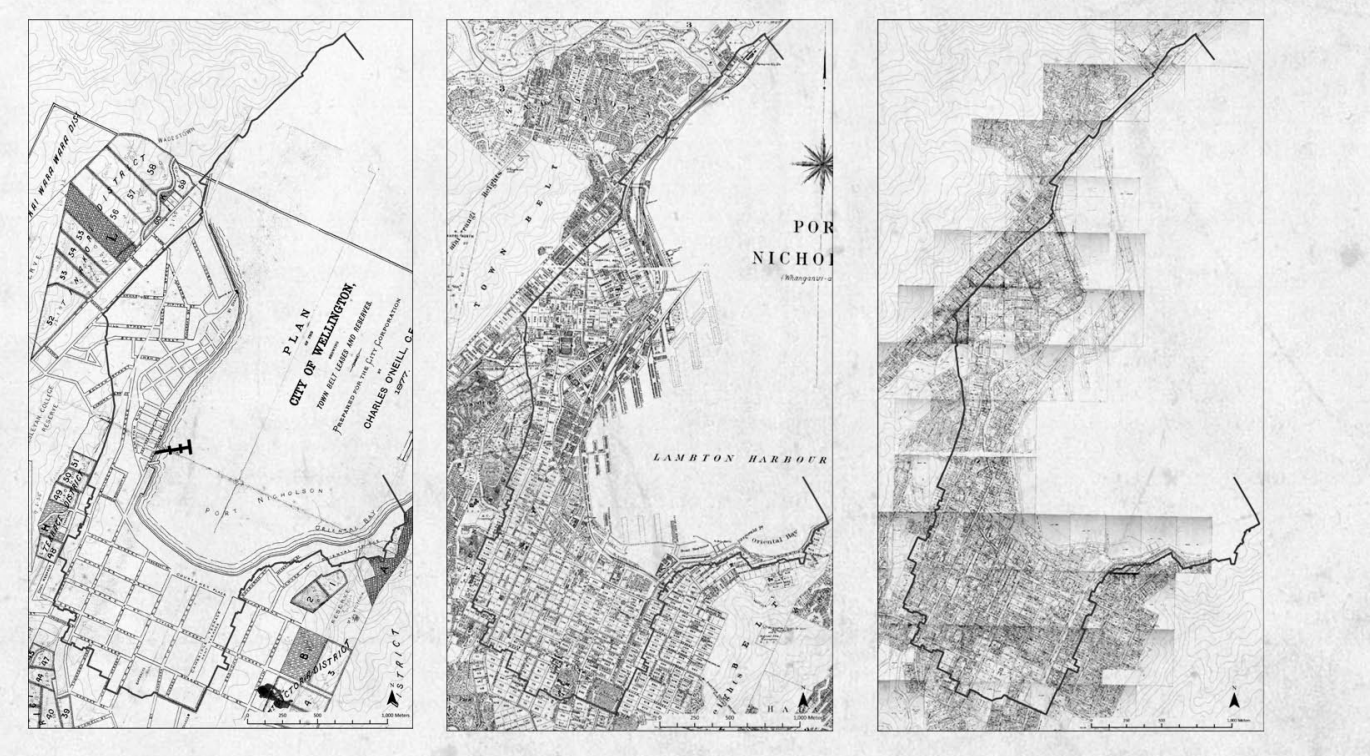

Fig. 35 Reclamation of Wellington Harbour 


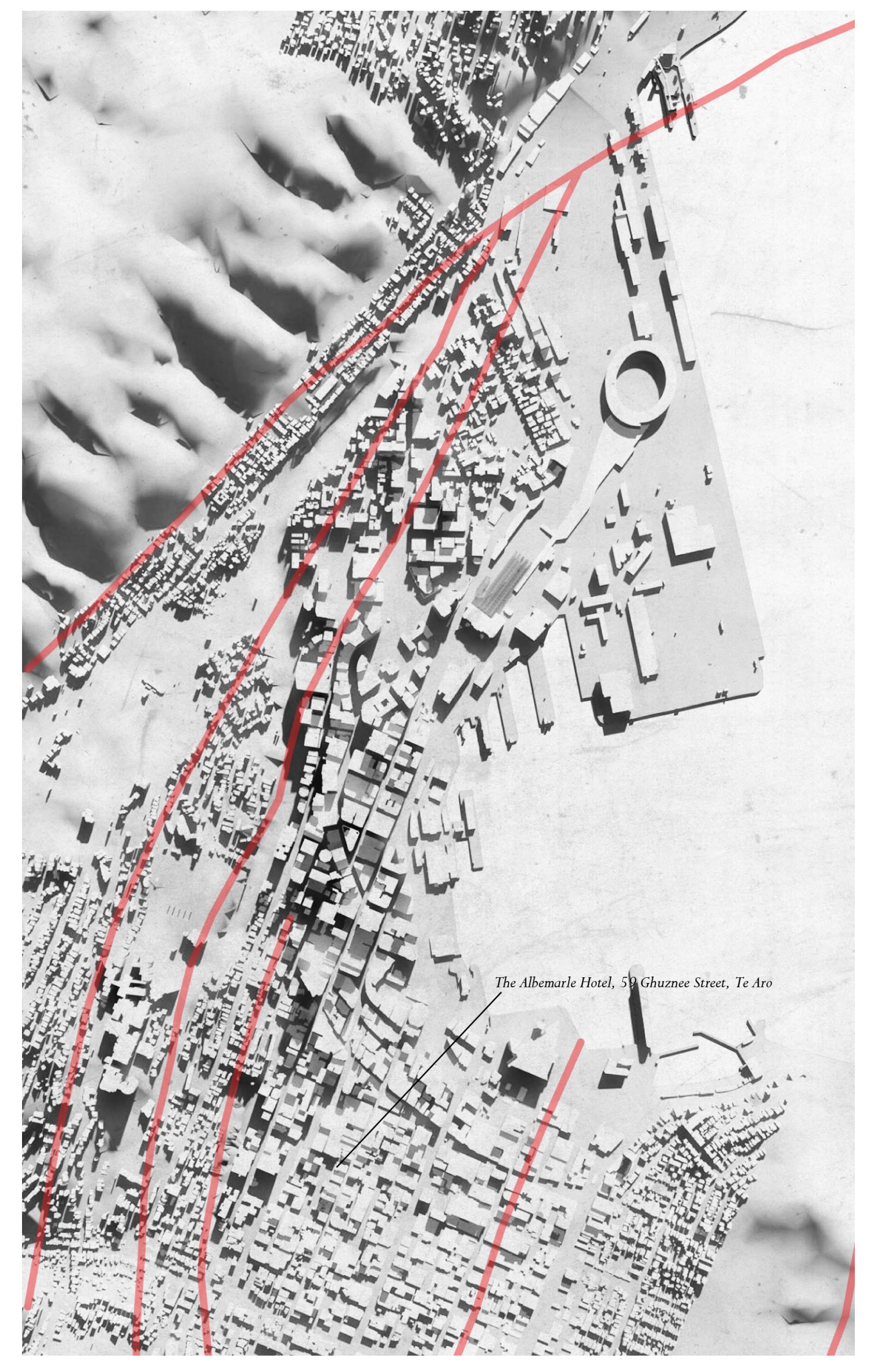

Fig. 36 Wellington's fault lines
Wellington's Fault Lines

Wellington sits along the collision zone between two of the world's great tectonic plates. The Australian and Pacific Plates lie 20-30km below the earth's surface (Maclean). The Australian Plate is colliding with the Pacific Plate, pushing it down, causing the earth's surface to fold. This collision zone frequently releases pressure from between the two plates, causing earthquakes and often resulting in changes to the landscape. The Wellington region has six principal fault lines three of which are active. The main fault line, the 'Wellington Fault', slices through the region; earthquakes along this fault line has caused the land on the west to rise and the land on the east to sink. It is this movement that is responsible for Wellington's curvaceous hillsides (Maclean). Throughout history the constant movement between the two plates has dramatically changed the nature of Wellington's landscape. The magnitude 8.1 earthquake in 1855 caused the land surrounding Wellington to rise 1-2 metres (Maclean). This earthquake changed several features of Wellington's topography including the drainage of the Te Aro area which provided new opportunities for land use, and also facilitated the draining and the conversion of the in-land dock in Mount Cook (Basin Reserve) to form a dry zone that is now a prominent a sports field. A rise in rock platform between the CBD and Petone facilitated the passage between the two settlements, upon which a motorway and main access route to the city now sits upon (Maclean). 


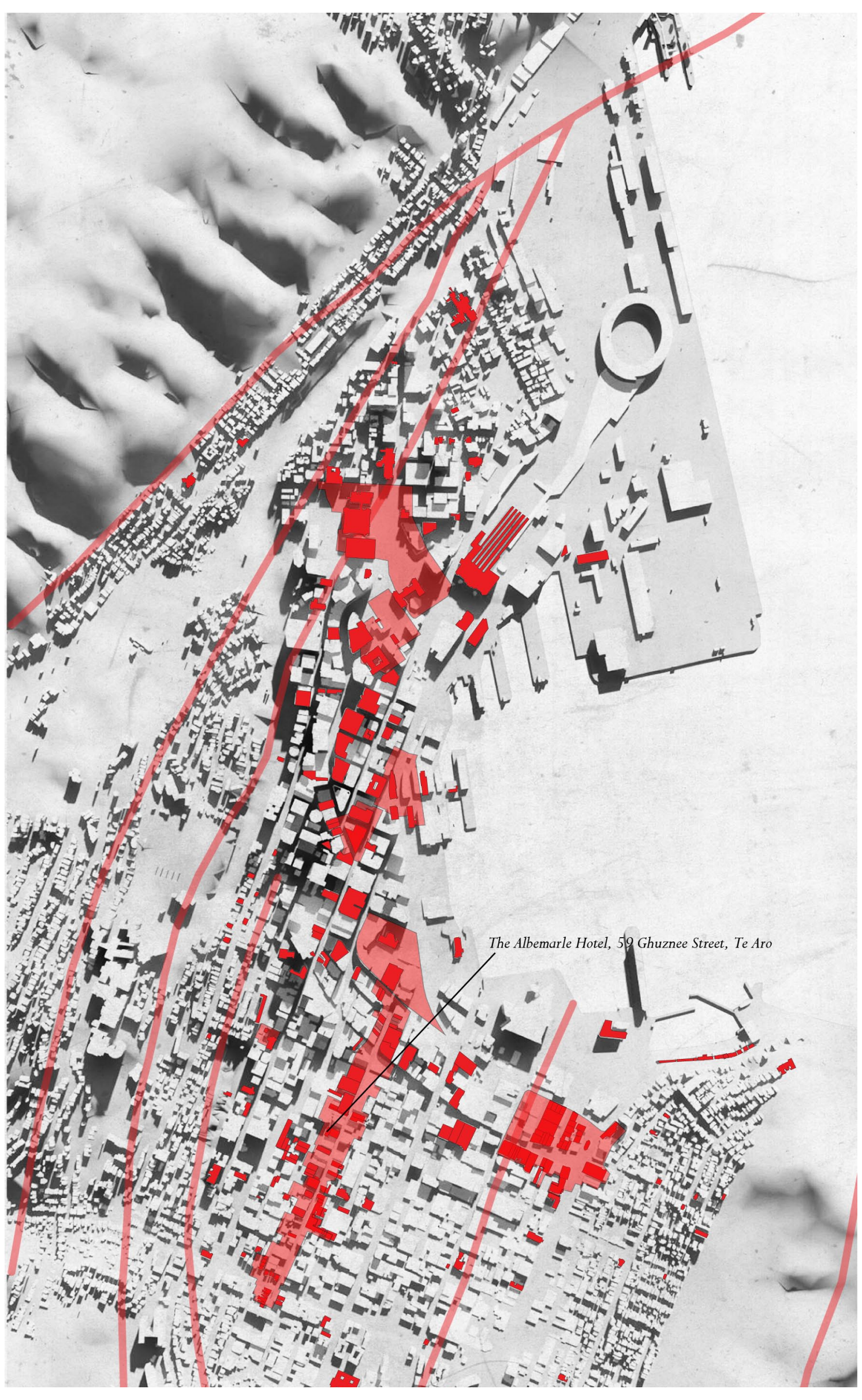

Fig. 37 Wellington's heritage buildings \& heritage areas
Wellington's Heritage Buildings \& Heritage Areas

Wellington is home to a myriad of different heritage buildings and areas; the 150 years of settlement in Wellington has seen Victorian, Edwardian, Art Deco, Modernist and New Zealand vernacular movements reflected in its built form (Wellington City Libraries). The Capital has eight heritage areas and close to 1200 non-residential heritage buildings, the majority of which are currently occupied (McClean and Byron) (See Fig. 37). The number and density of heritage buildings and areas throughout Wellington has become a concern for the Wellington City Council following the 2010-2011 earthquakes in Christchurch, which saw the downfall of a large number of the city's modern and heritage buildings. Wellington with its known and active fault lines is now faced with the issue of protecting its heritage buildings and areas in preparation of an earthquake such as that of Christchurch City (McClean and Byron). Although Wellington missed the full impact of the earthquakes that hit Christchurch in 2010-2011, the repercussions from the events still resonate within Wellington. The previous desirability associated with heritage buildings has changed dramatically; the public is now more reluctant to occupy heritage buildings due to the potential threat of earthquakes. The building code and lateral bracing requirements were increased, and the price of earthquake strengthening increased, resulting in a decline in resale value of heritage places (Schouten, 25.02.12). 


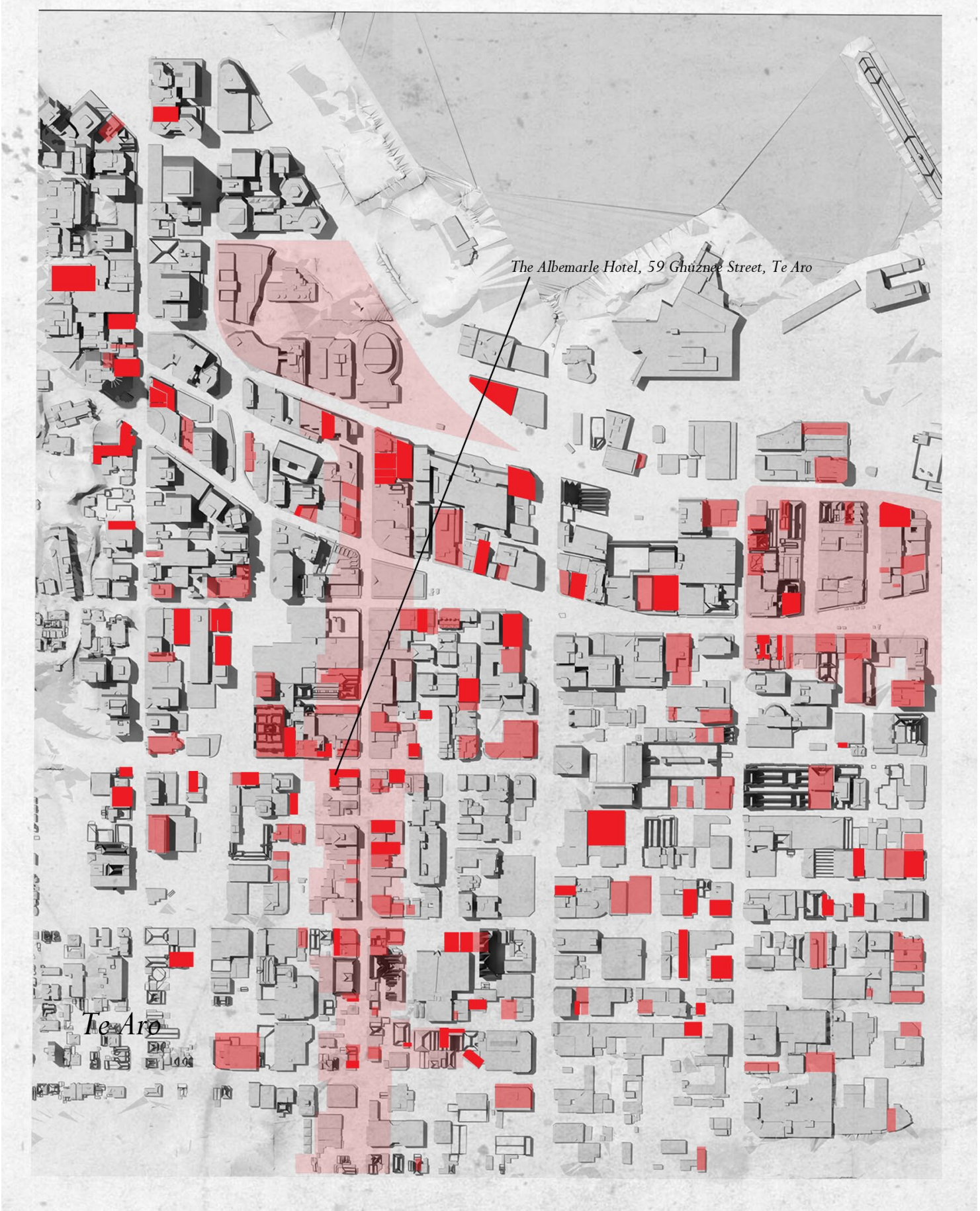

Fig. 38 Te Aro's earthquake prone \& STickered buildings
Te Arós Earthquake Prone \&

STickered Buildings

The New Zealand Government defines earthquake prone (EQP) buildings as having $33 \%$ or less strength than that of the current building code. Under the Wellington City Council's Earthquake Prone Buildings policy of 2009, the Wellington City Council conducted an analysis of 3800 buildings in the Wellington region with the exception of residential houses under two stories. Following the evaluation, one hundred and seventy Section 124 yellow, orange and red stickers have been issued to the owners of EQP buildings within Wellington (See Fig. 38). These identified buildings must be strengthened within 10-20 years (WCC,

'Earthquake-prone Buildings'). The area of Te Aro has many EQP modern and heritage buildings, the owners of which are now faced with the issue of how to strengthen them as a means of meeting the new building code requirements without removing the heritage equalities of the space (WCC, 'Earthquakeprone Buildings').

Yellow Notice

"This is a standard Earthquake-prone Building Notice issued under the Council's Earthquakeprone Building policy and under Section 124(1) (c) of the NZ Building Act. This indicates that the building owner has either 10,15 or 20 years to strengthen the building. The exact time frame will be specified on the notice" (Wellington City Council, 'Earthquake-prone Buildings') (See Fig. 39).

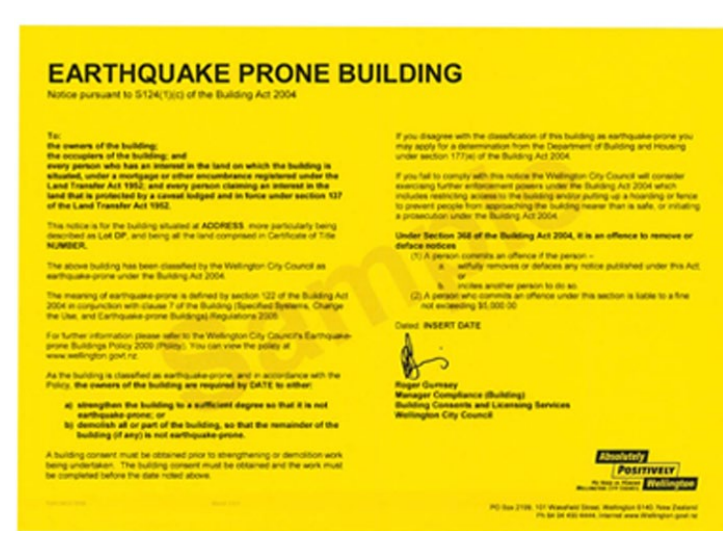

Fig. 39 SECTION I24(I)(B) YFLOW NOTICE

EARTHQUAKE PRONE BUILDING - FINAL NOTICE

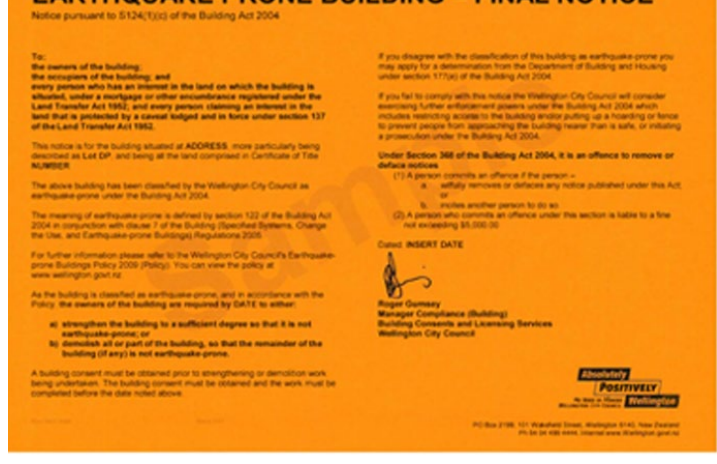

Fig. 4 O SeCtion I24(I) (B) ORANGE NOTICE 
Orange Notice

“An orange 'Final Earthquake-prone Building Notice' is issued where a building owner has failed to comply with the original yellow section 124(1)(c) notice. The owner has however made contact with Council and has been able to show some solid progress towards reaching a solution. The intention of this Notice is to act as a 'final reminder'; it is issued under the Council's Earthquake-prone Buildings policy and Section 124(1)(c) of the NZ Building Act. When orange notices are issued the Council works with the building owner to agree on a series of actions at agreed dates that the build ing owner will take. Should owners fail to meet their requirements, they are issued with a Red Notice” (WCC, 'Earthquake-prone Buildings') (See Fig. 40).

Red Notice

"Comprised of two notices, a red section 124(1) (b) notice prohibits anyone from using or occupying the building (in accordance with Section 128 of the NZ Building Act) and a further red Section 124(1)(c) notice which provides a final date by which the owner must have the building strengthened or demolished. If an owner fails to comply with this notice the Council will consider further action which may include legal action to force the strengthening or demolition of the building" (WCC, 'Earthquake-prone Buildings') (See Fig. $41 \& 42$ ).

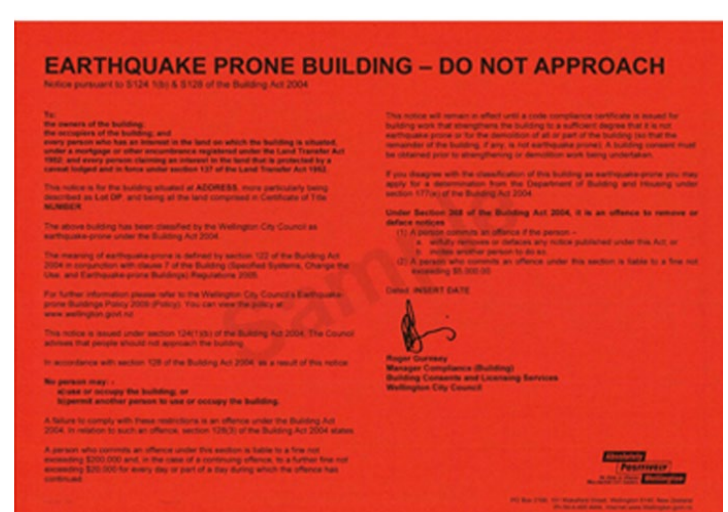

Fig. 4I Section I24 I (B) \& SeCtion I28 Red Notic

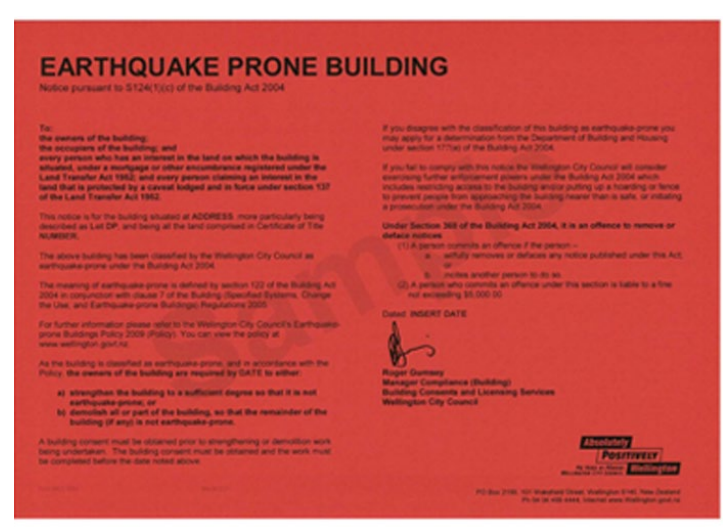

Fig. 42 Section I24(I) (c) Red Notice
The Albemarle was issued with a section 124(1) (b) notice on the 29th of March 2010 requiring the owners to strengthen the building to a sufficient degree so that it is not earthquake prone or forced to be demolished (Wellington City Council, 'Earthquake-prone Buildings'). The Wellington City Council posted the classification notice on the entrance door, and a fee of $\$ 5000.00$ can be incurred for obstructing this from the public view. The notice gave the final date for action as the 29th of March 2012. Since the Section 124(1)(b) classification, the Albemarle has been sold and the new owner is under negotiations with the council to strengthen the historic hotel (Schouten 23 May 2012). The period in which the owners were required to strengthen or demolish the hotel is testament to urgency relating to the pending threat and loss of Wellington's heritage.

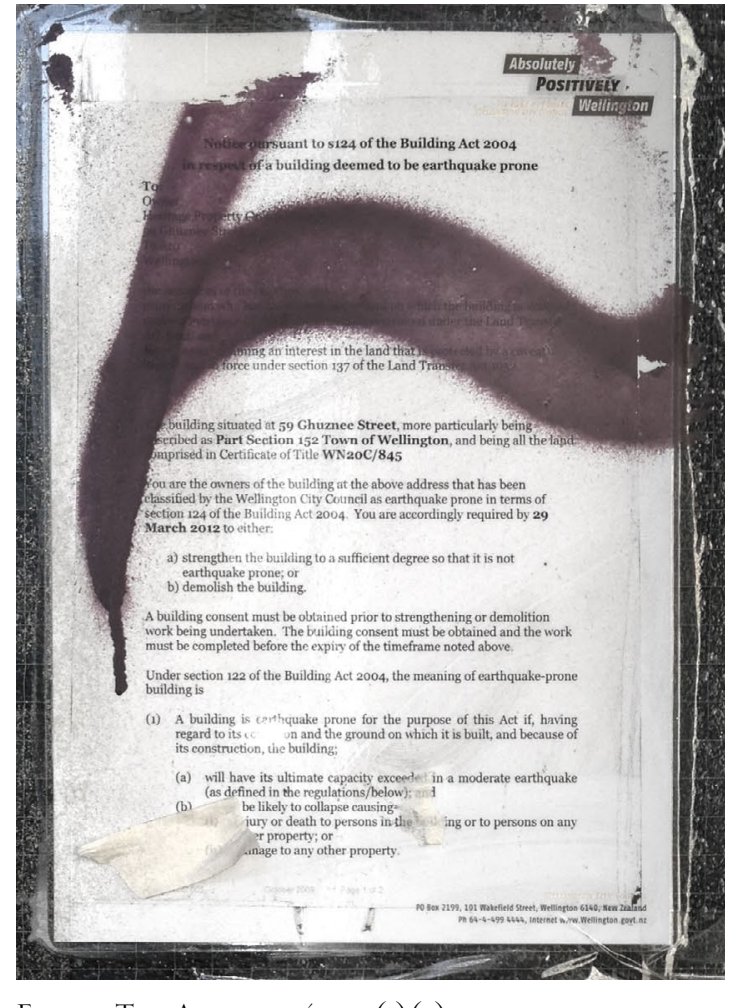

Fig. 43 The Albemarlés's i24(I) (c) notice 


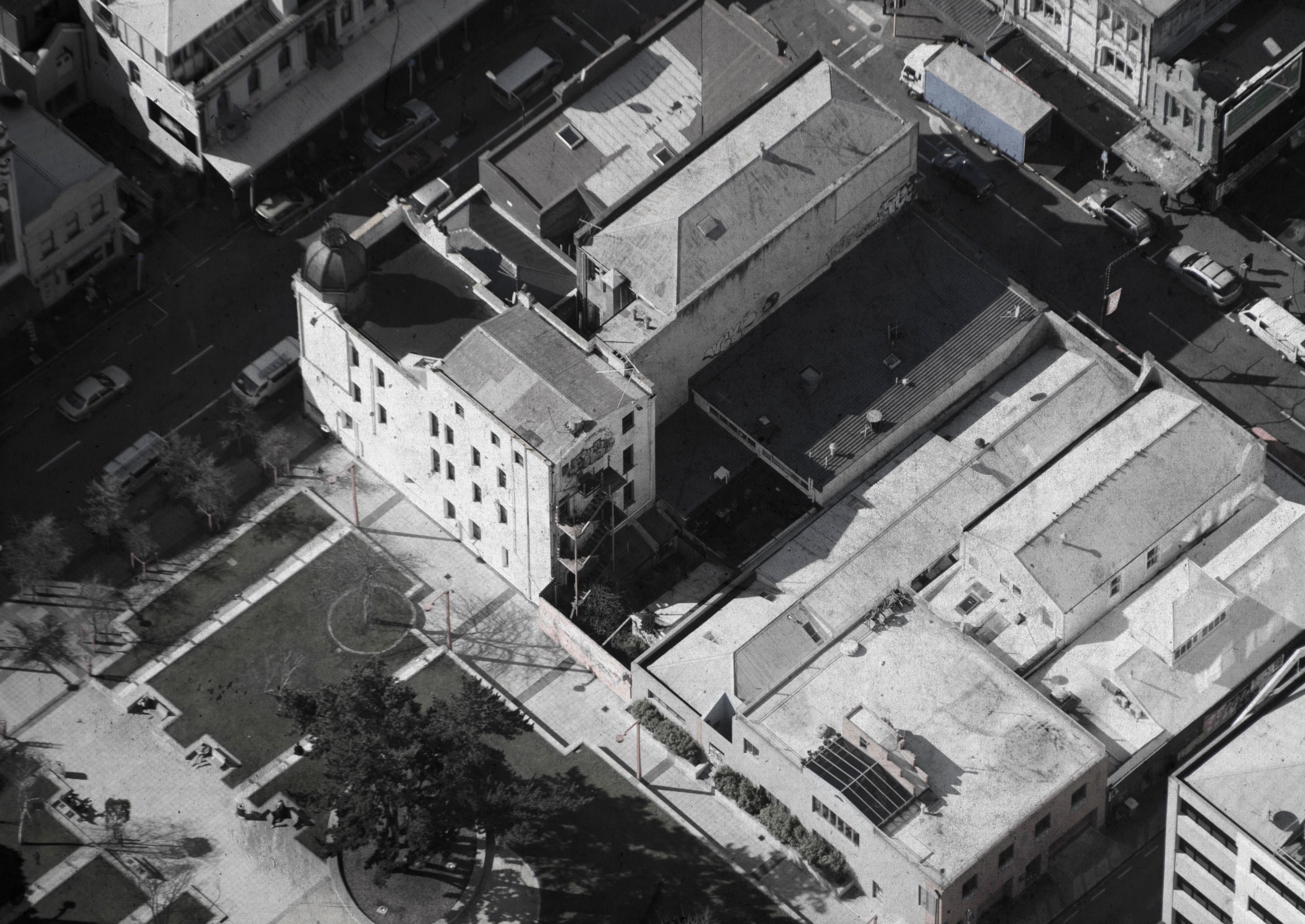


Fig. 44 (PG. 76-77) Arial shot of the Albemarle Hotel \& Glover

Park by Paul Hillier. (2Oi2)

The Vehicle for design

The Albemarle, stickered with a Section 124 notice (See Fig. 45) is faced with the threat of demolition or an extensive structural upgrade in order to survive. The Christchurch earthquakes impacted largely upon the historic hotel as the discussed desirability of heritage sites decreased. Prior to the 2010-2011 earthquakes the hotel was valued as $\$ 1.45$ million.). Following the earthquakes, the Hotel went to auction in early 2012, where property developer Ian Cassels won the auction with his bid for $\$ 650,000$; negotiations began from there to find an agreed price of $\$ 850,000$. The plummet from $\$ 1.45$ million to $\$ 850,000$ is dramatic example of the effect the Christchurch earthquakes have had on Wellington's historic buildings (Schouten 23.05.12).

The Albemarle, originally designed by James Bennie for Broadbent \& Co. in 1905, has seen several changes in its building envelope and has internally witnessed a myriad of programmatic changes from a hotel to a brothel in the 1960 s, to a mineral spa in 1979 , and back to a hotel again. The building once known as "Heaven, Hell and Petticoat Junction" remains a testament to the stories it has witnessed over time, displaying a narrative timeline within the walls and floors of the hotel where snippets of its entended past can be seen (Schouten 23.05.12)

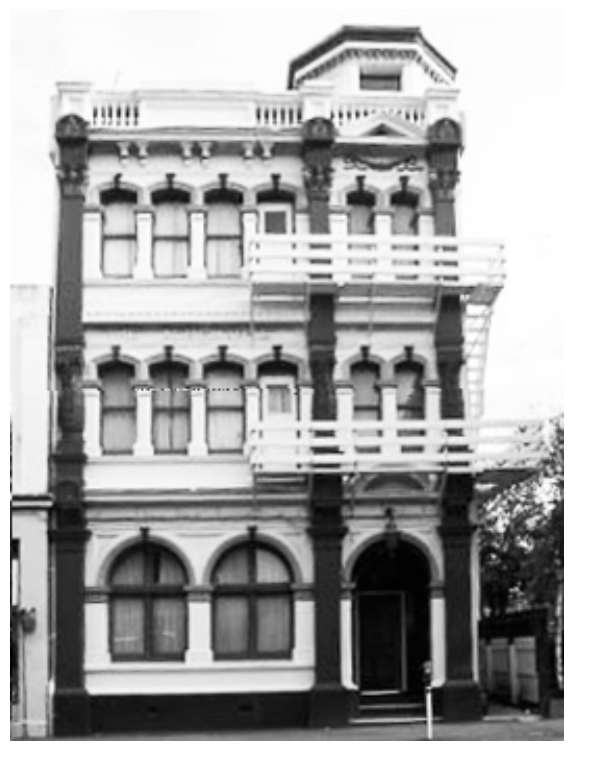

GiG. 45 Albem mrle Hotel after the cupola was remove

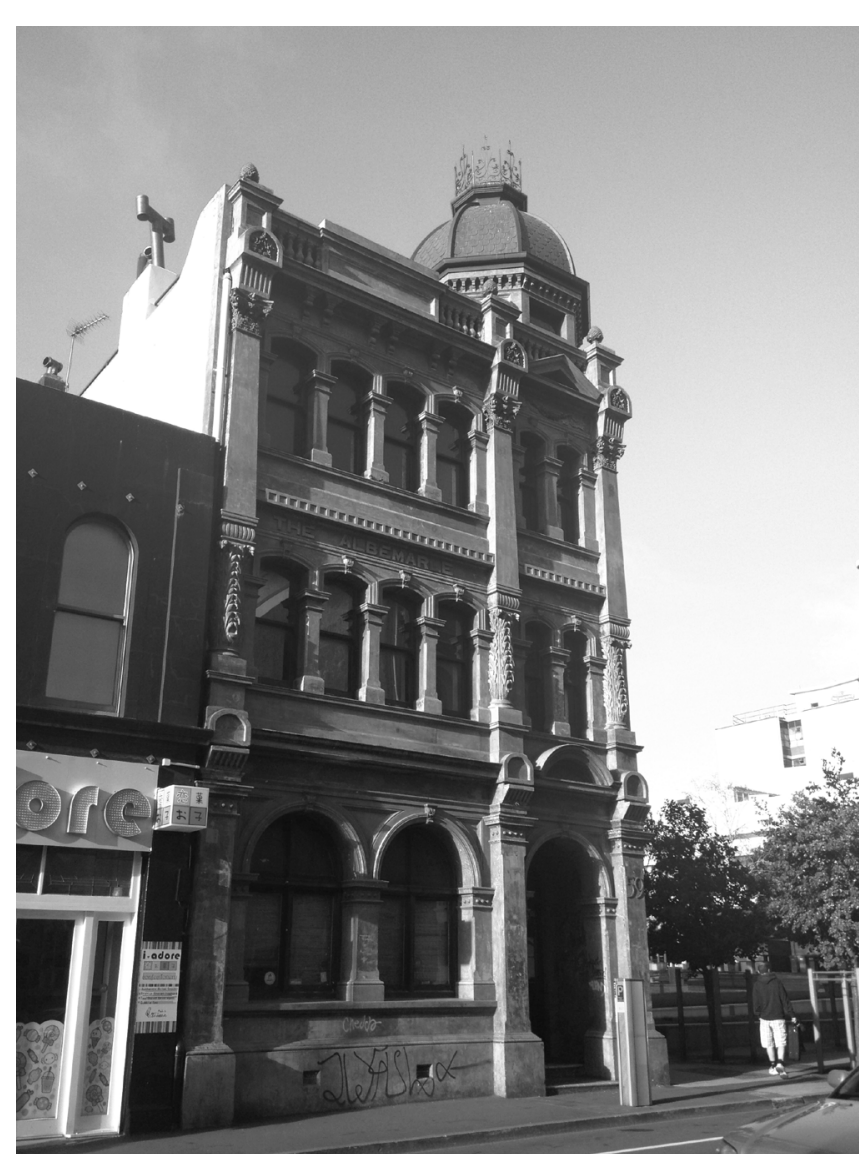

Fig. 46 A
The hotel is a Category II historic building, constructed of load bearing brick masonry on concrete foundations, with timber floors and roof members. The original ornate wroughtiron balcony and veranda have been removed, while the cupola was restored and strengthened by the Heritage Property Group in 2006 (WCC, 'Heritage Inventory -Albemarle Hotel').

The footprint of the hotel is asymmetrical due to a neighbouring building abutting it on the east; James Bennie indented the floor plan by $600 \mathrm{~mm}$ in the central section of the eas façade to allow for a small external light atrium to bring natural light to the east windows. The west property boundary does not follow this same method as it sits along a permanent right of way to allow for service access to the buildings behind the Albemarle, which enabled the west facade to have unobstructed sunlight. Facing a narrow pedestrian service lane, the west façade was left unarticulated without ornamentation. Windows were located wherever they needed to be based on the original interior plans. Adjacent to the pedestrian lane were lots for three additional buildings as a vehicular right of way fronting Ghuznee Street; these lots make up the neighbouring site that is currently Glover Park (See Fig. 47).

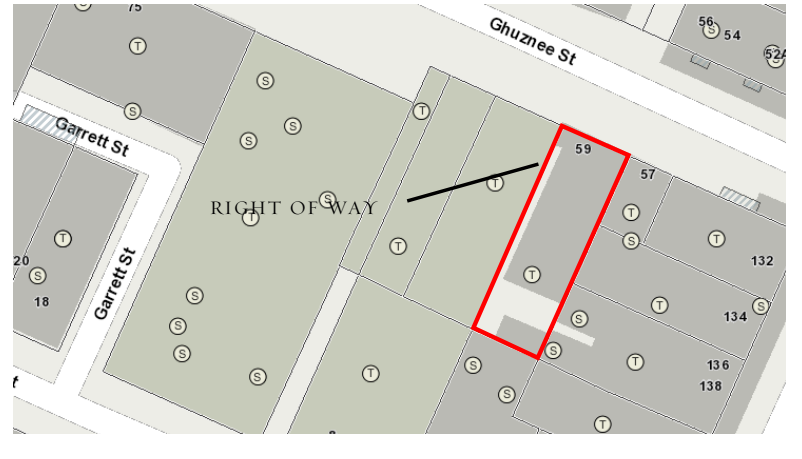

Fig. 47 Albemarle Hotel foot print \& neighbouring right of
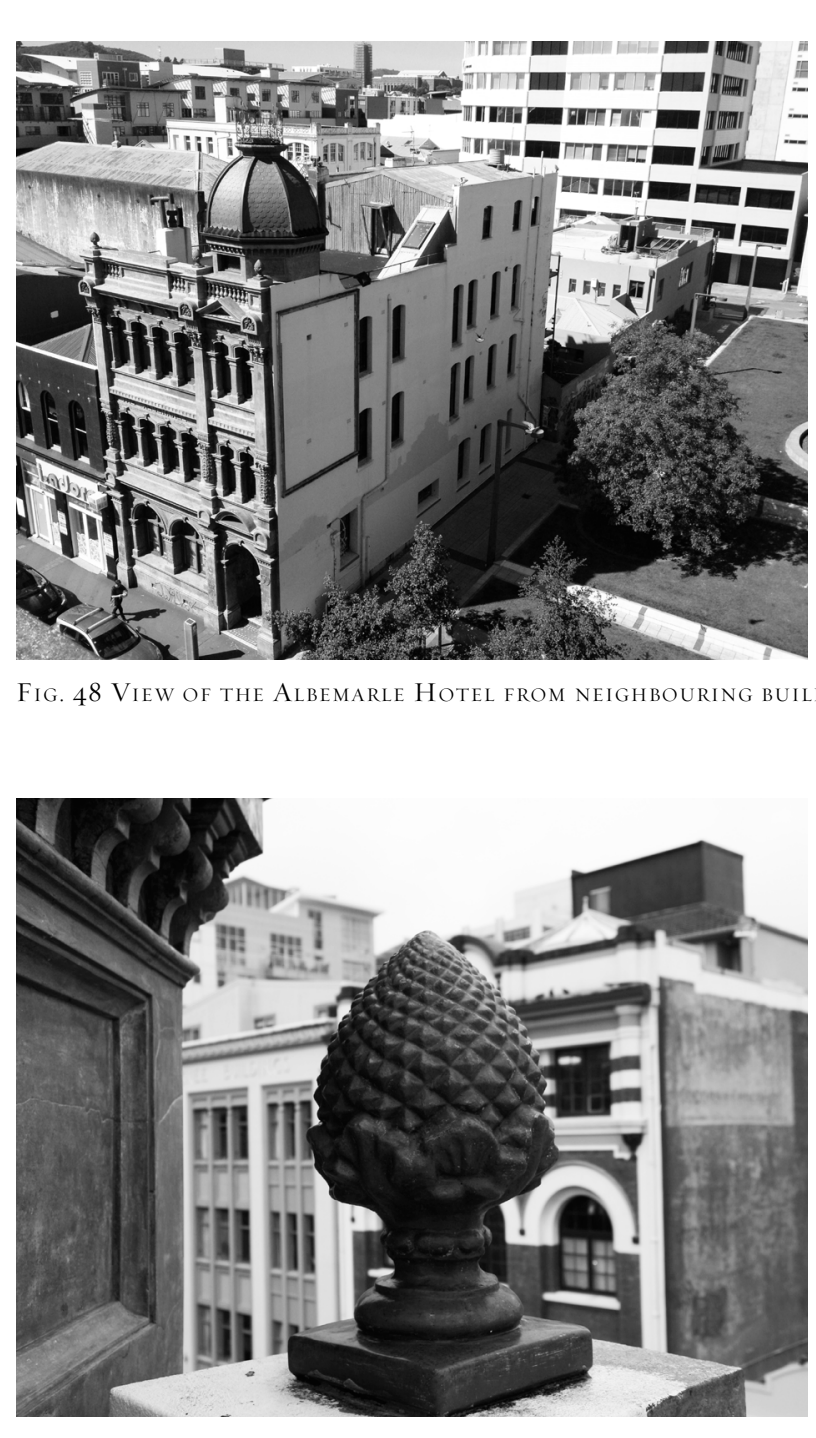

Fig. 49 Pineapple finals. 
At the time of construction the neighbouring Glover park did not exist; the land was used as a car park and prior to that it was occupied by small single-family homes. The Albemarle Hotel was designed as a typical row house building. These row house buildings were built during economic times when there was not much money available, yet there was a desire to emulate the buildings of Europe. As a result, they only economically emulated the front facades, and they often substituted concrete or brick/plaster for actual stone.

The street façade and cupola represent the bulk of the heritage significance for the hotel. The detailed façade is typical of many concrete or stone turn of the century New Zealand urban hotels, emulating neoclassical details typical of London hotel architecture. While built quite economically from concrete rather than stone, the façade incorporates Doric columns on the lower level, quasi-mannerist Ionic columns middle leve and exaggerated Corinthian columns on the top level (See Fig. 51 \& 52). The Albemarle's façade in fact displays a mixture of historic details that were popular at the time, the Renaissance column sequence with mannerist features, the ground floor Doric columns are missing the vertical grooves of a typical Doric column, and incorporate Art Deco dots beneath the capitols. Between the ground floor Doric columns and the first floor Ionic columns, there is a smaller squashed column that separates the two, appearing to support only the floor plate not the whole level. This squashed column pushes the Ionic column up, and the above Corinthian column pushes the Ionic column down so the Ionic column appears squat in comparison to the Doric and Corinthian columns. A true Ionic column typically displays a curved scroll or 'rams head'; however the Albemarle portrays the Ionic scroll by depicting a plant or fern that curls over at the top in a Mannerist style.

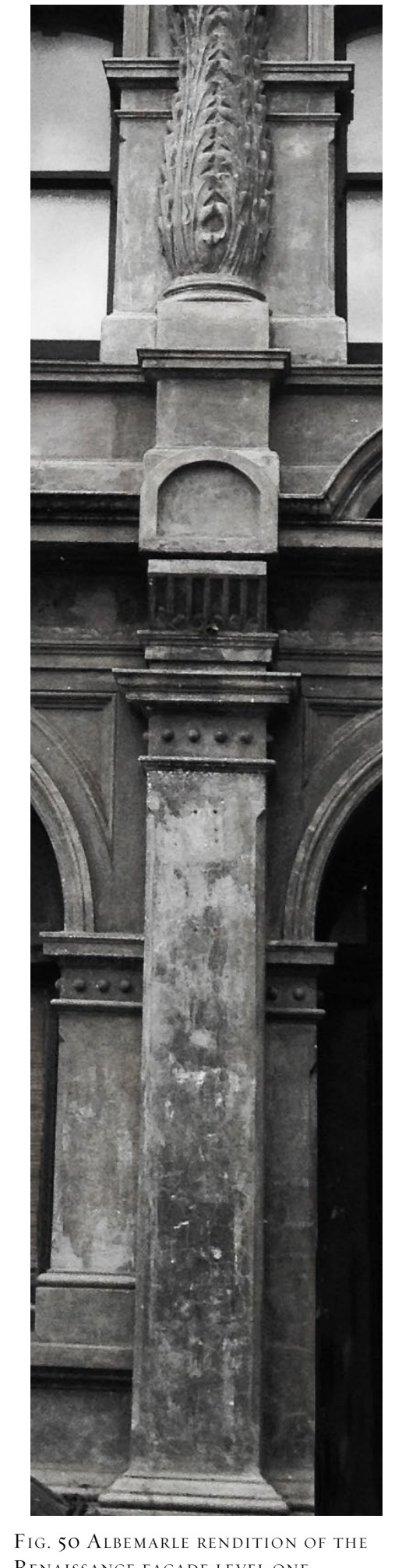

The Corinthian columns are exaggerated with an extra segment inserted above the capitol pushing the whole column down The hotel façade incorporates a pineapple as its decorative finals emulating the 17th and 18th century fixation with the pineapple as a symbol of hospitality (See Fig. 49).

"In the 17th and 18 th century the pineapple, because it was such a rare and exotic fruit, was seen as a symbo of hospitality and welcome. If you gave someone a pineapple you were being really hospitable. Also, sea captains home from trips to the tropics would fix pineapple to the railings of their houses to announce their return and to welcome visitors. Therefore man buildings in London use pineapples as decoration, mainly as finials , such as Ham House, St Paul's Cathedral and Lambeth Bridge" (Despoke)

The Albemarle's historic façade is capped with octagonal tower and the restored copper cupola that sits on the roof (WCC, 'Heritage Inventory -Albemarle Hotel).

The following section 'Layer Four discusses the existing spaces within the Albemarle hotel, and explores how the decaying nature of the hotel is ideally placed to house the program for the regional office of the New Zealand Historic Places Trust.

A further exploration of the types of weathering evident within the Albemarle is explored in the following chapter 'Layer Four: Programmatic explorations'
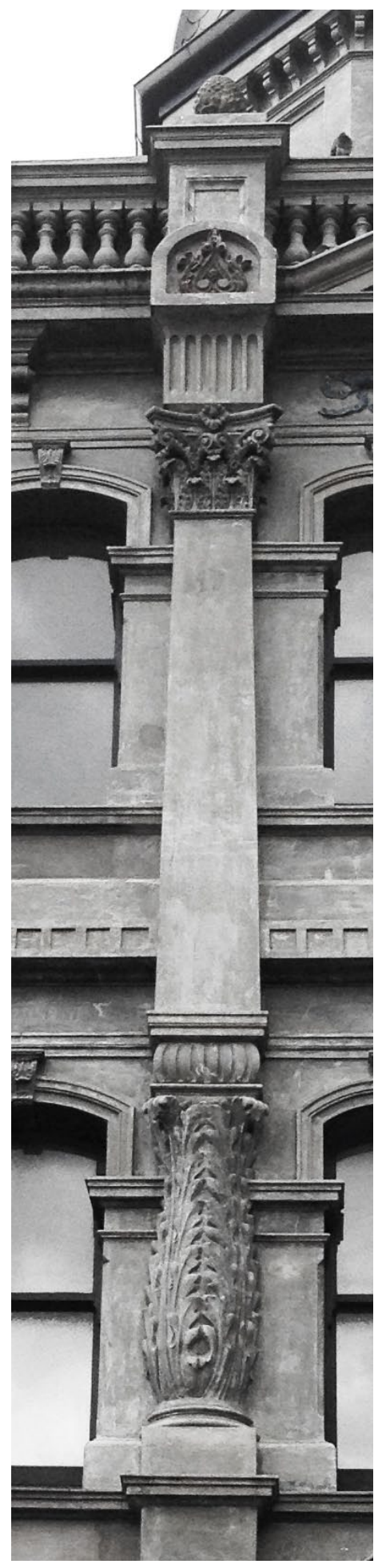

Fig. SI AlabMarle Rendition OF TH THRE 


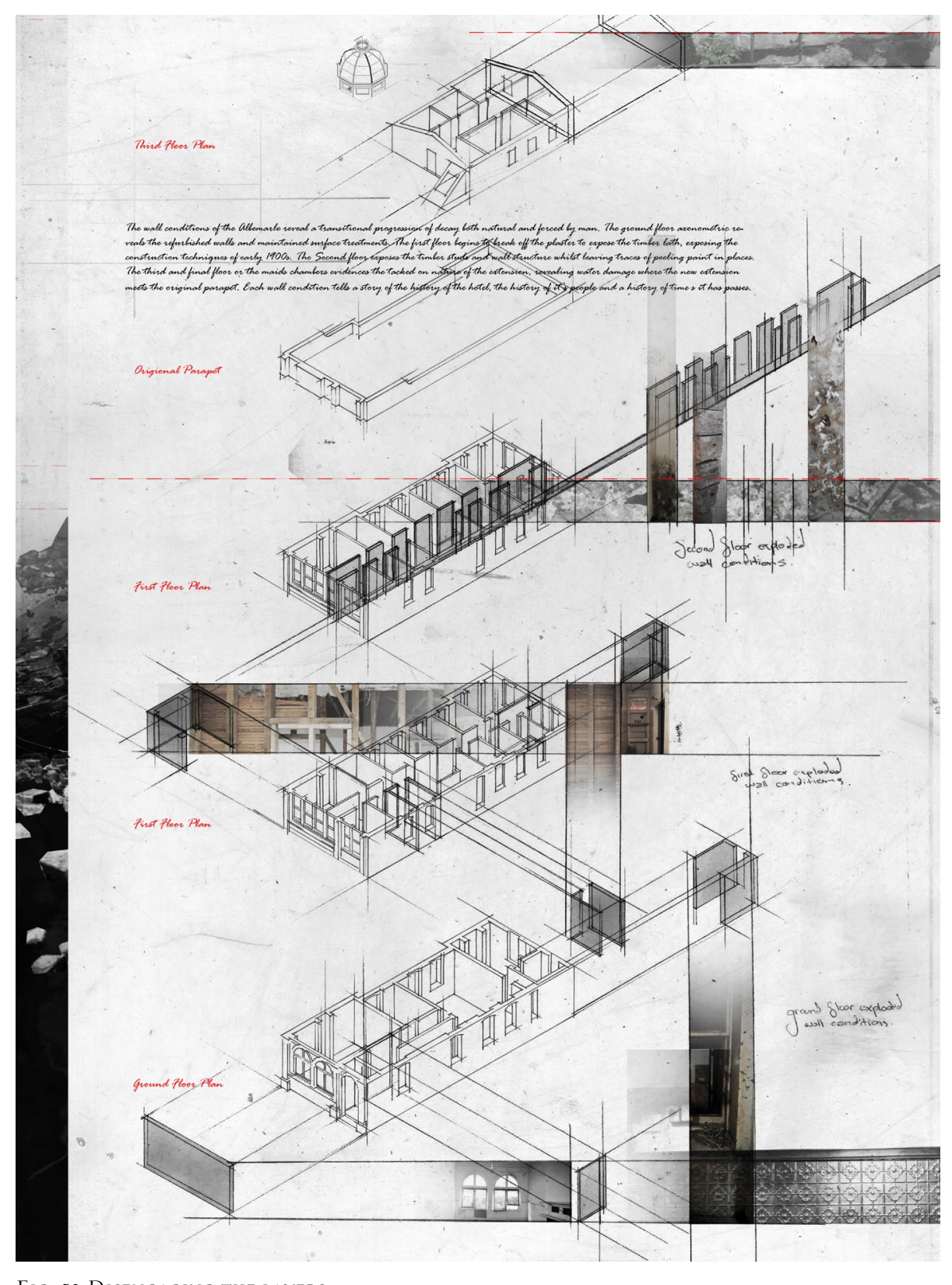

This drawing in Figure 32 explores the existing internal wall conditions within the hotel; the wall conditions especially evidence a large part of the hotel's history. The partially demolished interior timber framed walls reveal the traditional construction methods of lath and plaster, and the rough nature of the wall conditions evidences the on-going destruction of due to partially completed demolitions. The peeling of the paint, exposed aging brick, and scuffs on the walls hint at the different uses the hotel has witnessed, from a hotel to a brothel, to a day spa, and back to a hotel again. The exploded axonometric highlights these wall conditions as something that is beautiful and a quality that should be celebrated rather than covered up. The drawing exposes the wall conditions in the same way that this thesis argues for the display of decaying elements (See Fig. 52).

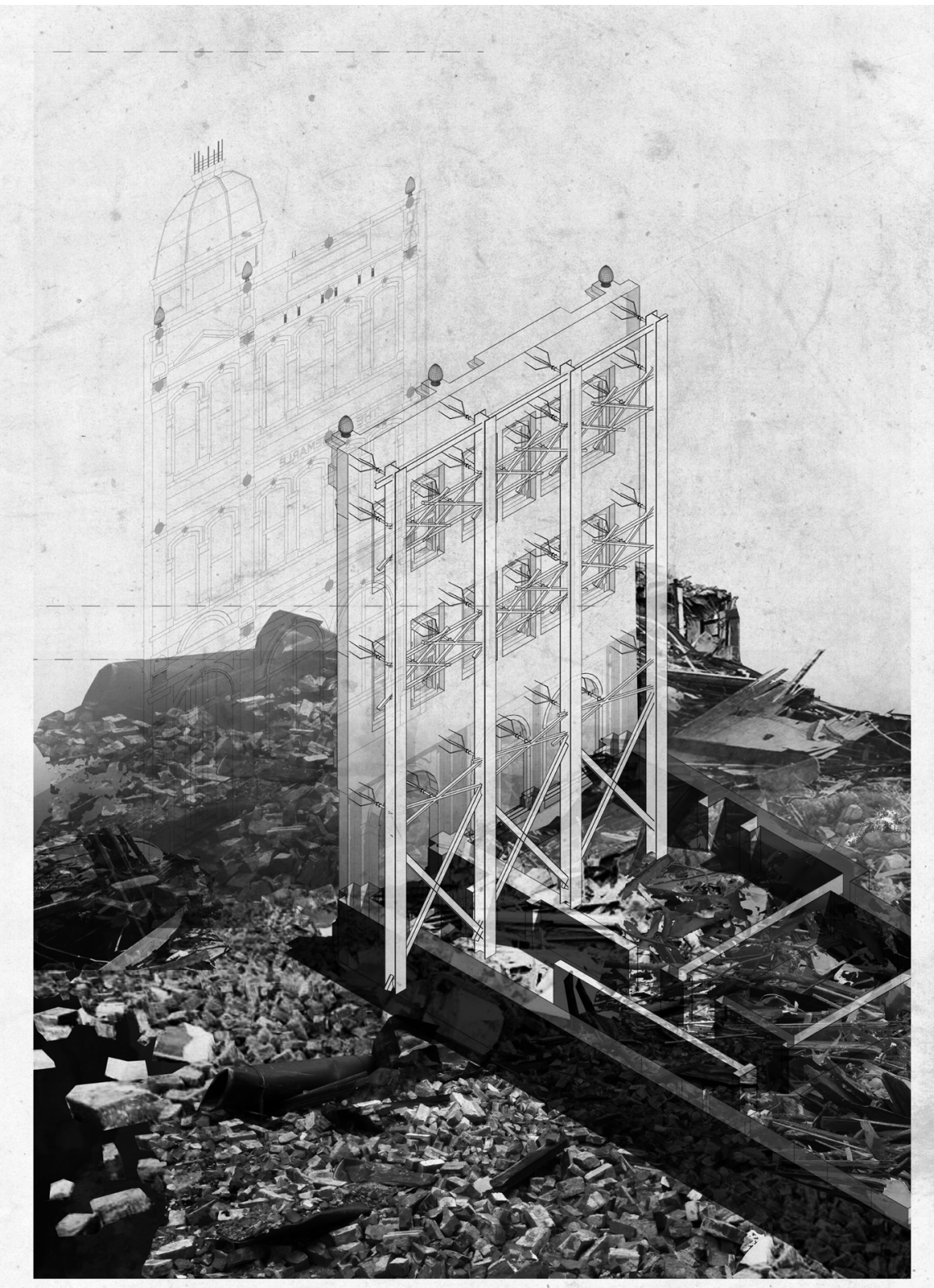

Fig. 53 Protecting the Facade

This image begins to implicate the effects of an earthquake on the Albemarle. The images of the rubble were taken from photographs of damage to similar buildings from the Christchurch earthquake. The image introduces an exploration of the spider tie as a method of tying the façade back to the new structure in order to withstand seismic force. The drawing reiterates the importance of the facade as the only exterior wall to have been articulated by the architect (See Fig. 53).

The following section 'Layer Four' discusses the existing spaces within the Albemarle hotel, and explores how the decaying nature of the hotel is ideally placed to house the program for the regional office of the New Zealand Historic Places Trust. 


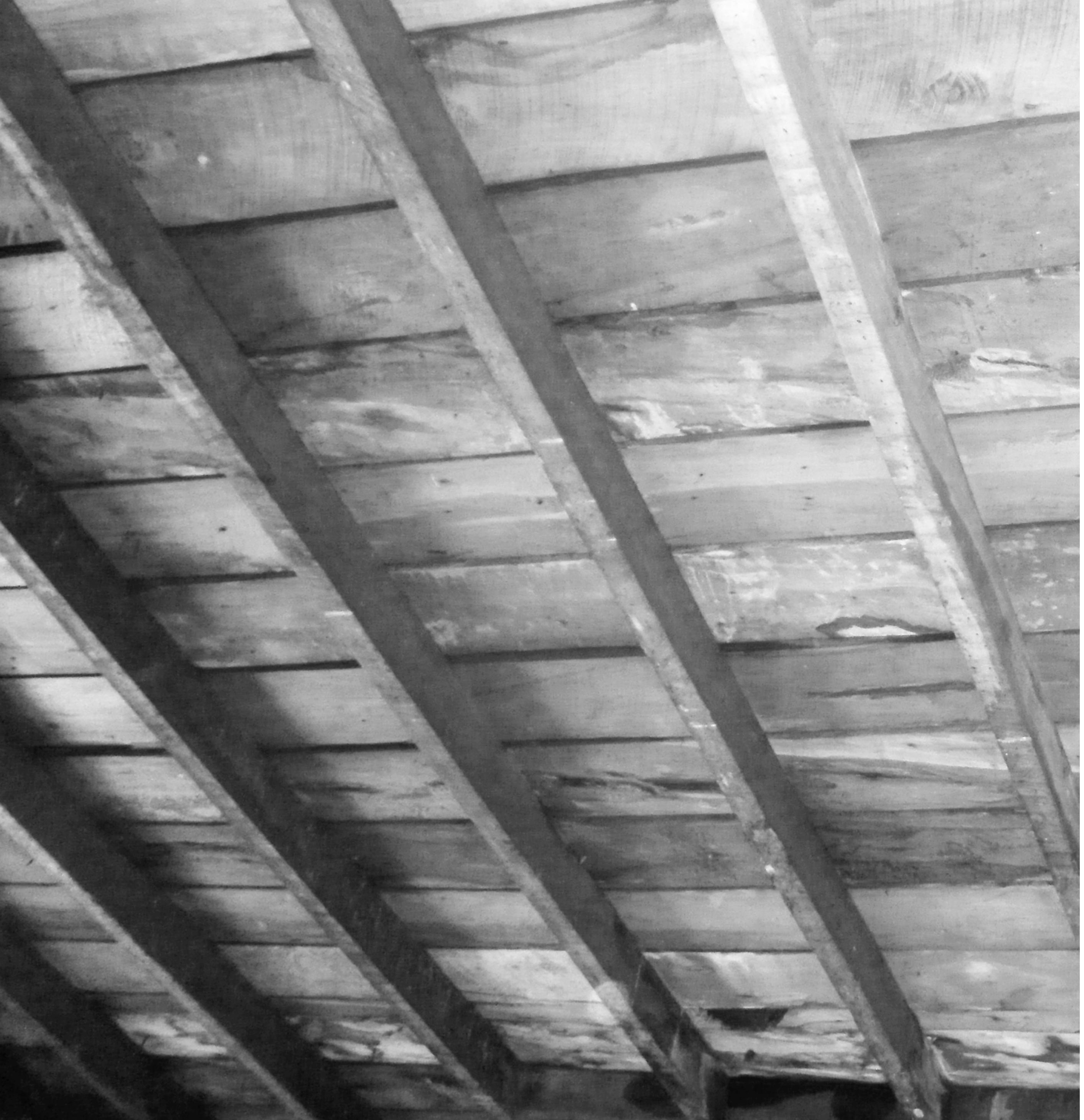

Programmatic

EXPLORATIONS

New Zealand Historic Places Trust

88

Antrim House 1905-2012

Antrim House 2012

Opportunities for the NZHPT

Ground Floor

Opportunities for the NZHPT

Level One

Opportunities for the NZHPT

Level Two

Opportunities for the NZHPT

LevelThree

89

90

97

99

IOI

$\mathrm{IO} 2$ ig. 54 (PG. 84-85) Existing Albemarie Hotel exposed timber ceiling - Level Three 
"FOR NOW HAD COME THAT MOMENT, THAT HESITATION WHEN DAWN TREMBLES AND NIGHT PAUSES, WHEN IF A FEATHER ALIGHT IN THE SCALE IT WILL BE WEIGHED DOWN. ONE FEATHER, AND THE HOUSE, SINKING, FALLING, WOULD HAVE TURNED AND PITCHED DOWNWARDS TO THE DEPTHS OF DARKNESS. IN THE RUINED ROOM, PICNICKERS WOULD HAVE LIT THEIR KETTLES; LOVERS SOUGHT SHELTER THERE, LYING ON THE BARE BOARDS; AND THE SHEPHERD STORED HIS DINNER ON THE BRICKS, AND THE TRAMP SLEPT WITH HIS COAT ROUND HIM TO WARD OFF THE COLD. THEN THE ROOF WOULD HAVE FALLEN; BRIARS AND HEMLOCKS WOULD HAVE BLOTTED OUT PATH, STEP AND WINDOW; WOULD HAVE GROWN, UNEQUALLY BUT LUSTILY OVER THE MOUND, UNTIL SOME TRESPASSER, LOSING HIS WAY, COULD HAVE TOLD ONLY BY A RED-HOT POKER AMONG THE NETTLES, OR A SCRAP OF CHINA IN THE HEMLOCK, THAT HERE ONCE SOME ONE HAD LIVED; THERE HAD BEEN A HOUSE."
$\mathrm{T}$ his section introduces the New Zealand Historic Places Trust (NZHPT) as the chosen program to re-inhabit the Albemarle Hotel. It analyses the existing headquarters of the NZHPT within the Antrim House, evaluating the current spatial configuration and use of space within the historic house This section establishes the inadequacies of the Antrim House for the NZHPT organization, while also highlighting the importance of engaging the public with the functioning of the organization. This section concludes by analyzing the current spatial inefficiencies in the Antrim House, and the opportunities evident within the Albemarle to not only house the regional offices of the NZHPT, but also enhance its ability to evidence its character through its architecture. 


\section{New Zealand Historic Places Trust}

The NZHPT was established by an Act of Parliament in 1954 and became an autonomous Crown Entity under the Crown Entities Act 2004. The NZHPT authority is sanctioned by the Historic Places Act 1993, and it is applied through local district plans (New Zealand Historic PlacesTrust). The national office for the NZHPT is currently housed in the Antrim House at 63 Boulcott Street, where they have a total of 31 staff working between the historic house, stables, conservatory and 15 staff in the neighbouring high-rise office building that functions as the Wellington regional office. While the Albemarle has a smaller gross floor area that is currently available to the NZHPT, the research experiment will test whether the new approach will facilitate a more economic use of space that still meets all the needs of the NZHPT.

The regional office of the NZHPT was chosen as an appropriate program to re-inhabit the historic Albemarle Hotel in order to test the design research imperatives of this thesis through the organization that represents New Zealand's heritage. This thesis argues that the current NZHPT office in Antrim House represents what was described by Jennifer Hill as a false and reproduced heritage; due to its total restoration in 1977 by the Ministry of Works Antrim House was stripped back to its original 1905 condition, removing its ability to evidence its evolving history (NZHPT 'Robert Hannah and his family'). This thesis proposes that the NZHPT Wellington regional office be moved into the historic Albemarle Hotel after it is 'restored' in ways that evidence its rich, and on-going history. Most of Antrim house is not open to the public; located within the Albemarle, however, the NZHPT would have more opportunities to actively engage with the and facilitate the public's understanding of the new attitudes of the NZHPT and the ideas they represent. In this capacity both the public and the NZHPT could witness the aging of the historic hotel.
Antrim House i905-20i2

Antrim House and the surrounding estate is one of the only surviving merchant's homes in the inner city (WCC 'Antrim House'). Set in amongst the surrounding high-rise office blocks of Boulcott Street, Lambton Quay and the Terrance, Antrim House has fully maintained its lush green estate with its neighbouring stables and conservatory. Historic architects, Thomas Turnbull and Sons designed Antrim House (1904) for shoe manufacturer Robert Hannah founder of R. Hannah and Co (NZHPT 'Robert Hannah and his family'). The house with its 18 original rooms displays an example of a typical Edwardian Italianate-style home for wealthy merchants. The family lived in the house until Robert Hannah's death in 1930, at which time the Hannah family leased the house as an exclusive hotel until 1938 when the house was sold but continued as a private bed and breakfast (1938-1949). In 1949 the government acquired the house to be used as a Public Service Hostel until 1977. After becoming concerned for the historic house, the Government agreed that the house would be repaired and reinstated as the headquarters for the national office of the NZHPT. An extensive three year refurbishment was conducted by the Ministry of Works before the NZHPT moved in on the 26th of May 1981(WCC 'Antrim House'). 
Antrim House 2012

The historic house has been returned to its original condition with the exception of the alterations made to the first floor and staircase following a fire in 1940, which saw the ornate finishes replaced with art deco cornices and simplified flush doors (NZHPT 'Robert Hannah and his family').This thesis argues that the constant maintenance of aging buildings is the cosmetic surgery of architecture; the house has become a ghost of its former self, trying too hard to remain young. This thesis argues that age does not diminish beauty but can be considered to enhance it over time. The NZHPT national office occupies the house in a way that seems obligatory. No changes have been made to the house; each separate room has been given an isolated program that denies a holistic plan or function for the organization. Offices and large filing cabinets are crammed into rooms, hiding historic details, without considering how the house might dictate the layout and occupation of each room. Although the NZHPT has operated out of the house since 1988 , it remains a stranger to the house. The NZHPT appears to be intent on maintaining the house to the extent that it is reluctant to engage with it, freezing the house in time, like preserved flower incapable of living out its life, deprived of the ability to share its stories with its visitors

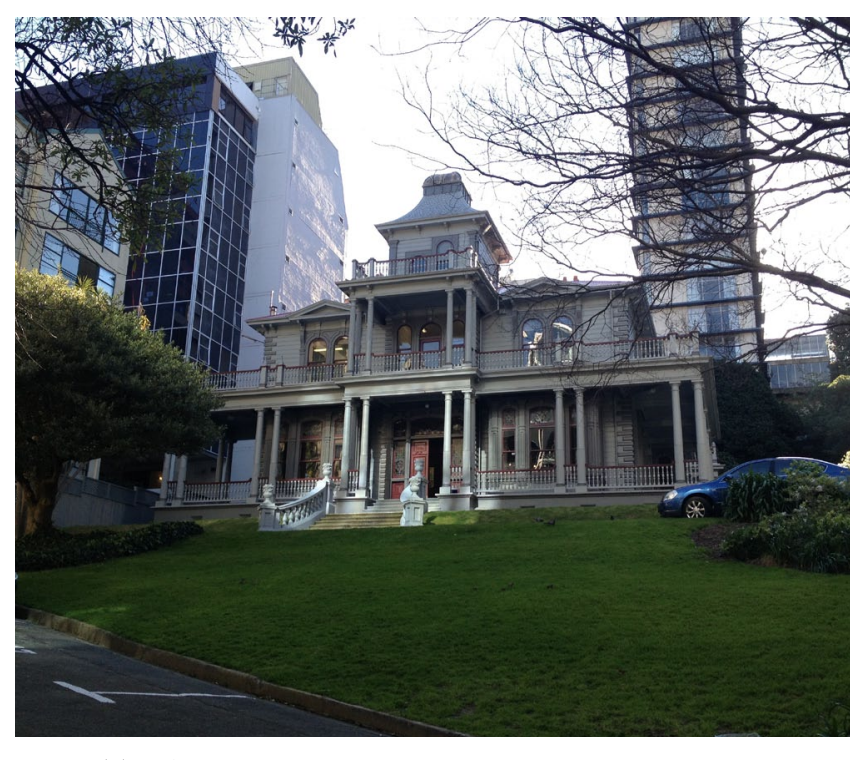

Fig. 55 The Antrim House 2012.

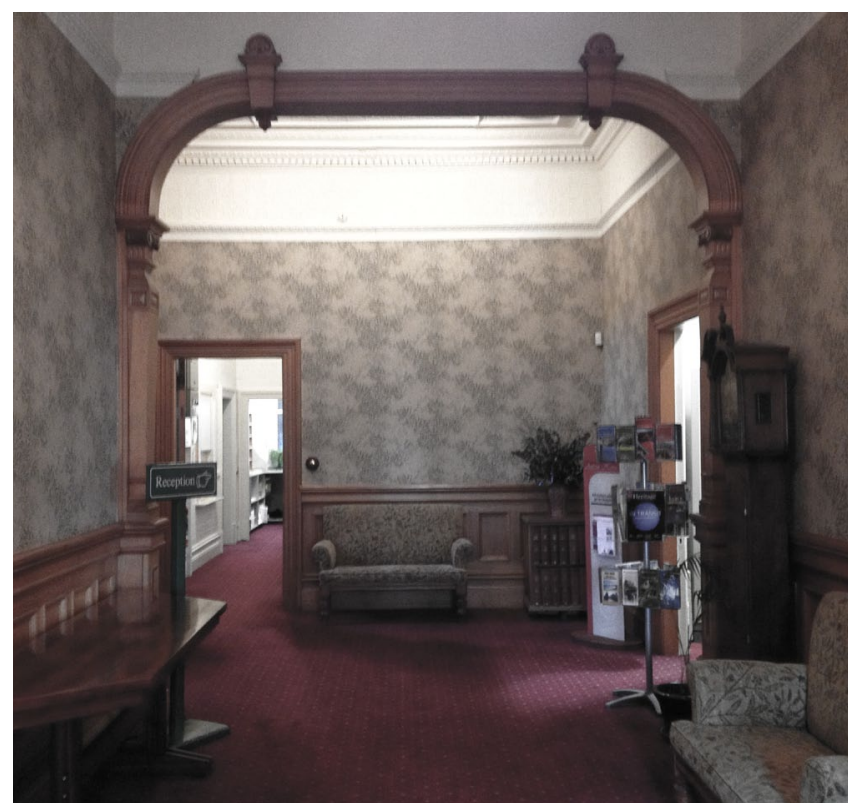

Fig. 56 The Antrim House entrance Lobbr
This reluctance to change or engage with the house has resulted in an extremely inefficient use of space within the house, causing the organization to be spread out over the house, stables, conservatory, and neighbouring office building. The small isolated offices that are separated by walls and rooms do not represent or enable the cooperative nature of the work within the NZHPT. Antrim House remains a private building with only the lobby on the ground floor open to the public. (See Fig. 56 \& 57) This is partly because Antrim House does not have enough space to accommodate the public. Because the original rooms have been maintained, there is only one meeting room with insufficient space for formal or informal meeting areas. This is an example of a historic building originally intended for a program that no longer exists; by placing a new contemporary program inside without reconsidering the interior layout, difficulties occur; and by remaining a private building the NZHPT is further preventing the house from revealing its history to the public.

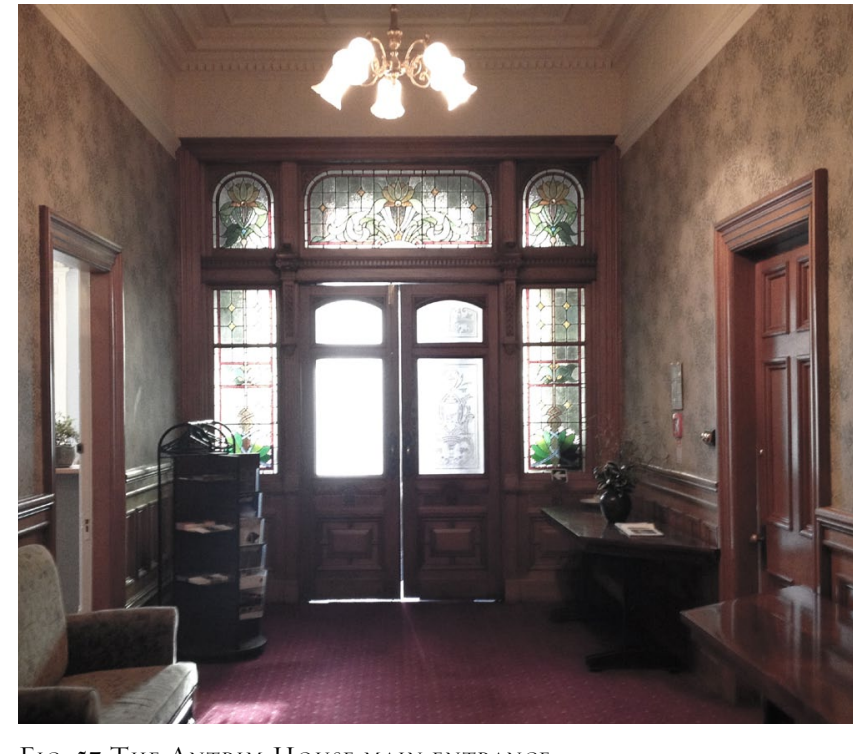

Fig. 57 The Antrim House main entrance 


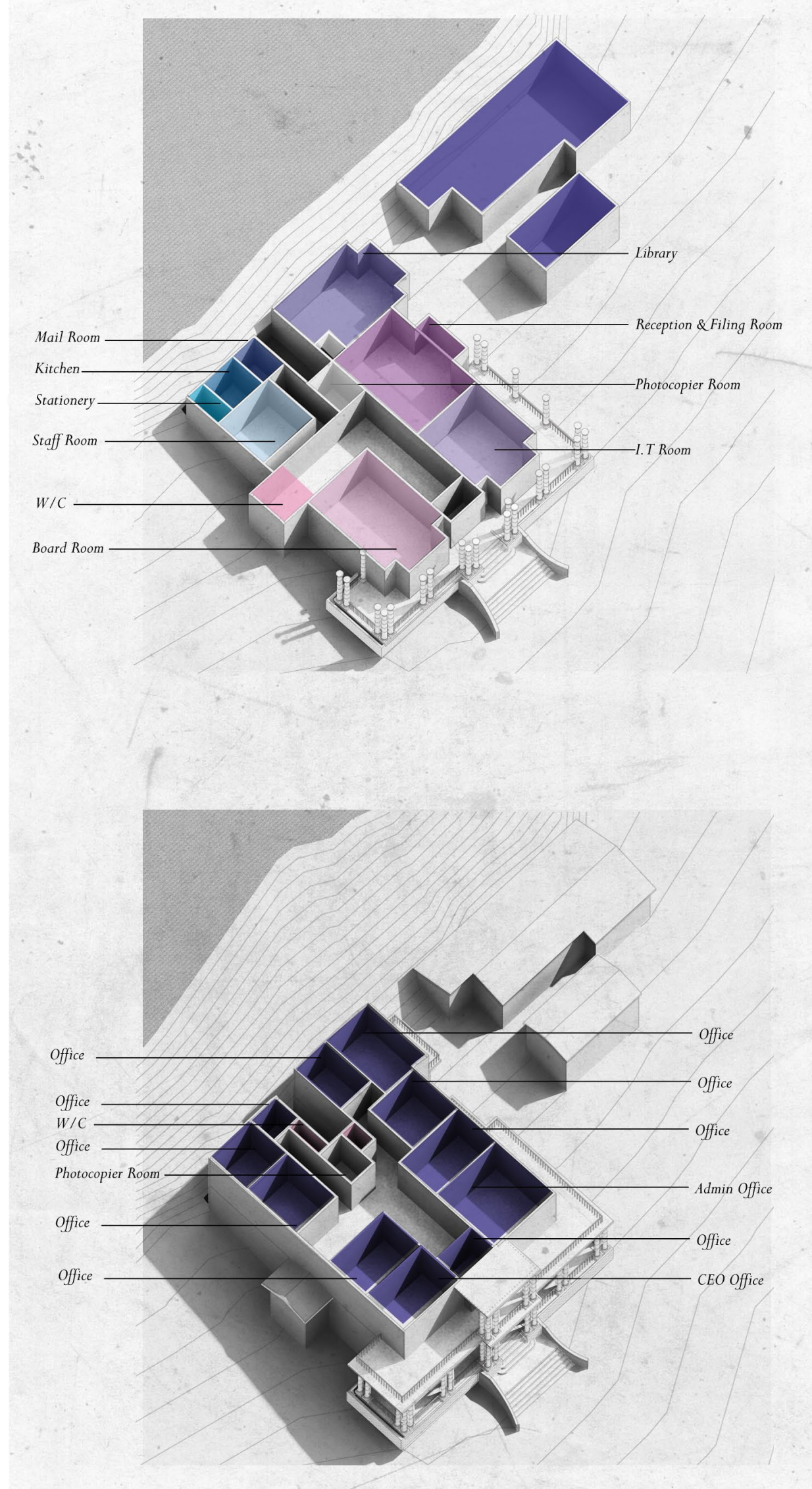

Fig. 58 The Antrim House program analysis
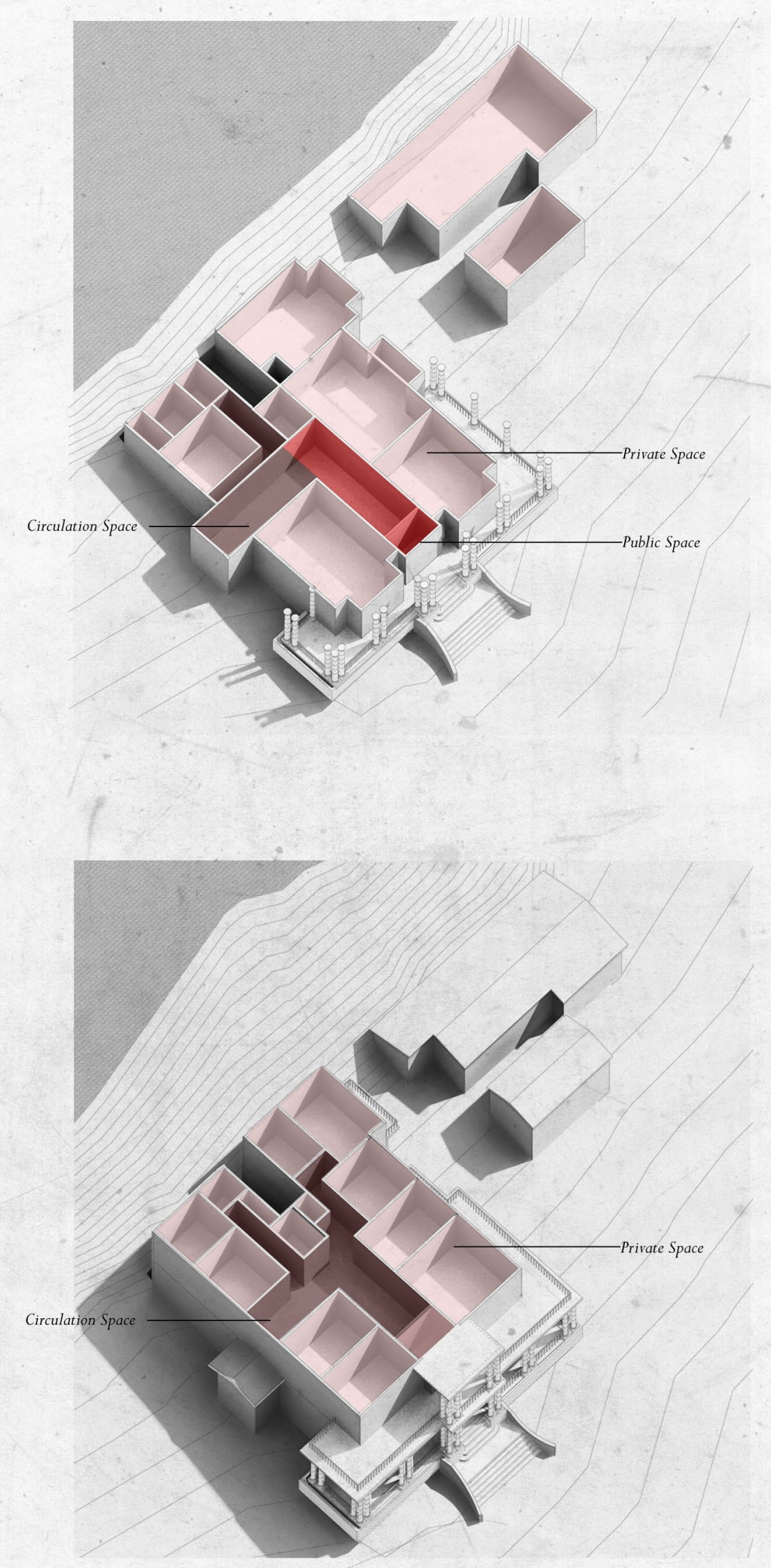

Fig. 59 The Antrim House public \& private space 


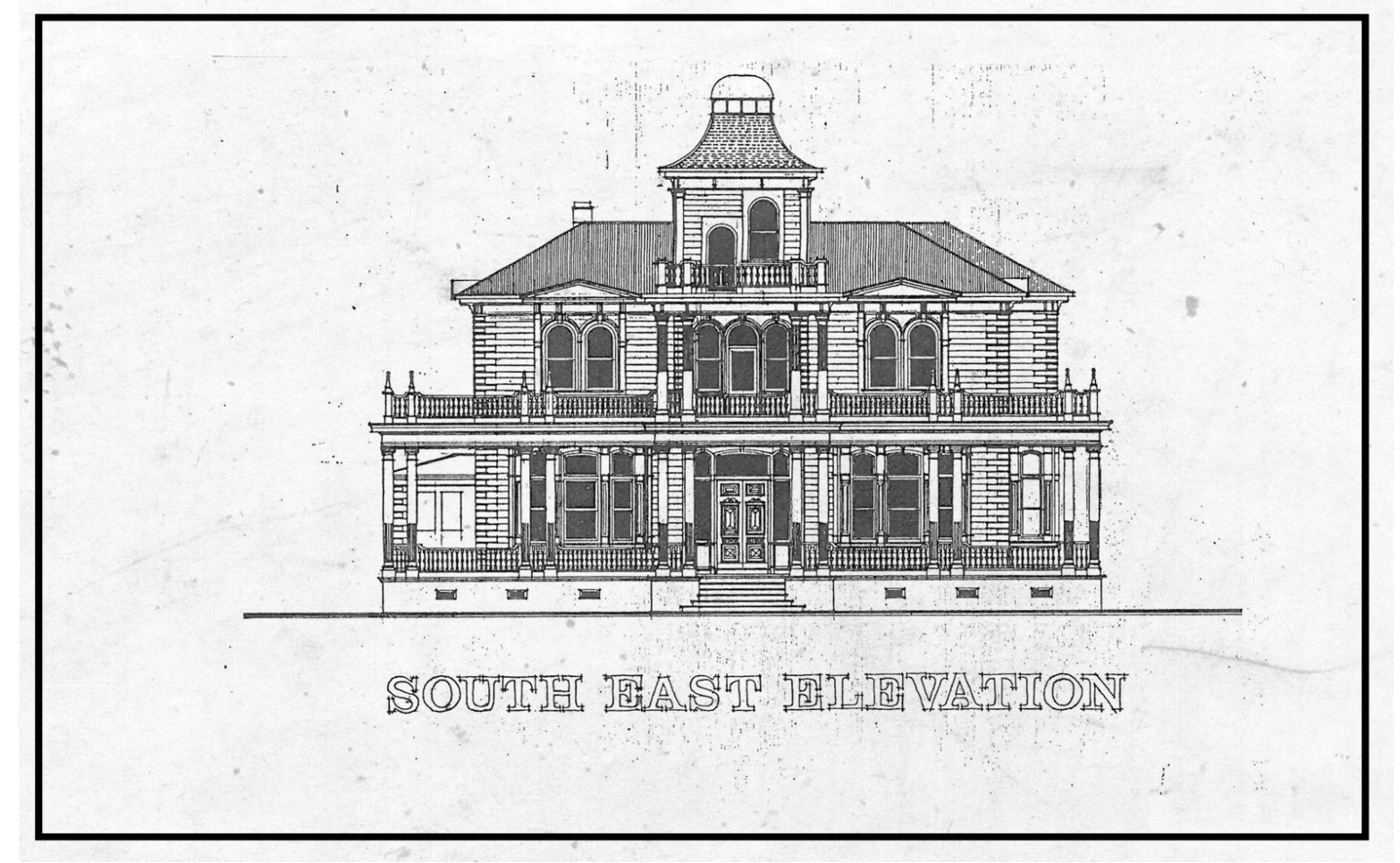

Fig. 60 The Antrim House - original south east elevation

\section{Current Program Analysis}

Offices: $334 \mathrm{~m} 2$

\section{Circulation: $159 \mathrm{~m} 2$}

Admin: $50 \mathrm{~m} 2$

I.T: $45 \mathrm{~m} 2$

Bathrooms: $20 \mathrm{~m} 2$

Storage: 0

Staff and Support Areas: $59 \mathrm{~m} 2$

Library/Archive: $110 \mathrm{~m} 2$

Total area: $777 \mathrm{~m} 2$

\section{Reduced program to regional office}

Offices (20 staff members): $68.5 \mathrm{~m} 2$

Circulation: $86 \mathrm{~m} 2$

Admin: 20m2

I.T: $25 \mathrm{~m} 2$

Bathrooms: $22 \mathrm{~m} 2$

Storage: $15 \mathrm{~m} 2$

Staff and Support Areas: $20 \mathrm{~m} 2$

Library/Archive: $90 \mathrm{~m} 2$

Public Space: $161 \mathrm{~m} 2$

Room for expansion: $200 \mathrm{~m} 2$

Total area: $507.5 \mathrm{~m} 2$

Total area of the Albemarle: $540 \mathrm{~m} 2$

Total area (with room for renovation): $747.5 \mathrm{~m} 2$

Net Land Area of the Albemarle: $251 \mathrm{~m} 2$

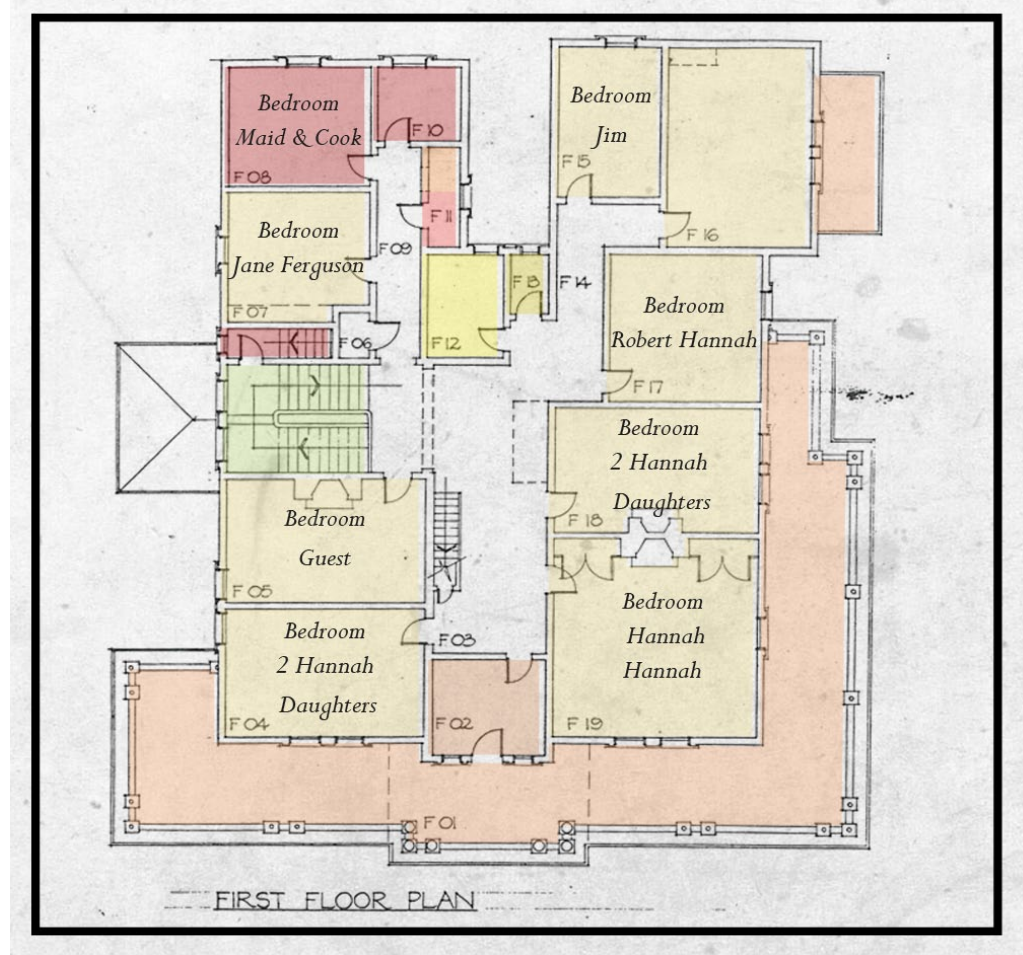

Fig. 6I The Antrim House Level one Spatial analYYIS

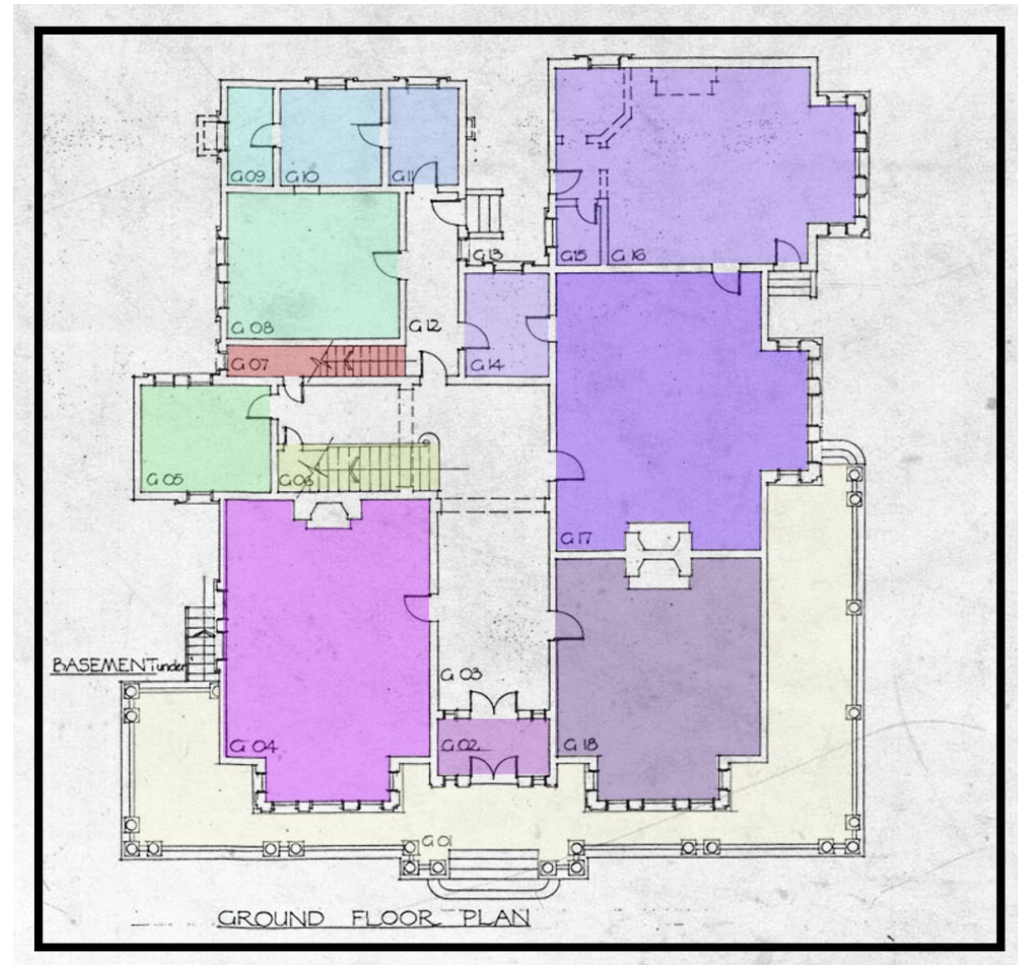

Fig. 62 The Antrim House ground floor spatial analysis

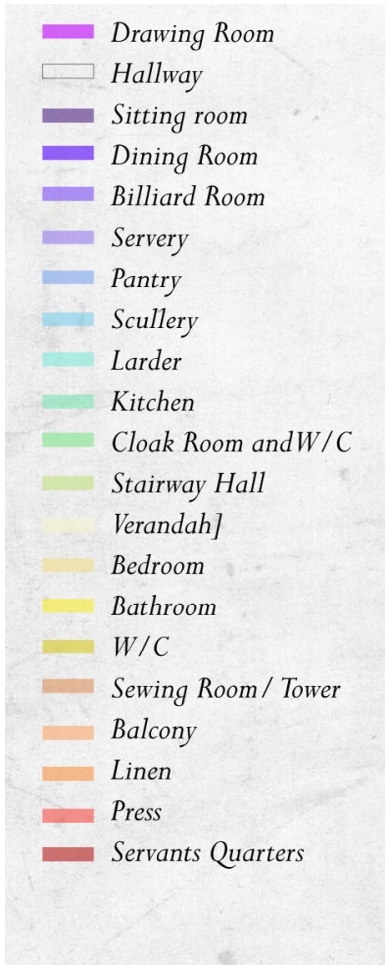

Hallway

Sitting room

Sculler

Serrants Quarters 
$\mathrm{T}$ he photographic journey conducted in this section ascends through the hotel, presenting the argument for the celebration of decay within New Zealand's historic buildings, presenting the areas that fall into the categorical definitions and approaches established previously. This section then explores the opportunities for incorporating the programmatic requirements of the NZHPT within the historic Albemarle Hotel, retaining much of the weathering already evident in the hotel, and assigning functions to spaces according to the needs of the NZHPT.
OpPortunities For the NZHPT-

GROUND FLOOR

The ground floor of the hotel has been moderately maintained with only a few moments of decay visible through the restored finishes. The historic lobby ceiling has been stripped to reveal watermarks and staining on the exposed lath (See Fig.63), the historic timber stair has been stripped and shows multiple layers of paint from different error (See Fig.65) and the front sitting room (See Fig.64), patina can be seen on the embossed copper panelling in the lobby. The ageing of the copper panelling in the lobby suggests that if it were not for the renovation of the ground floor in 2006, oxidization of the copper would also be evident in the restaurant space (See Fig.69), where the panelling is currently painted white.

This thesis argues that in the case of the Albemarle, the ground floor could remain at its current level of refurbishment. It is the most historic in its detailing and reasonably well maintained. The ground floor is an example of a classification C1 space that has 'little or no weathering or decay' and therefore should be 'fully restored to the original historic conditions'. The ground floor could be open to the public, enabling the public to witness both the refurbished and aging aspects of the hotel. The refurbished ground floor rooms show what domestic life was like in 1905, contrasting with the aging elements on upper levels that reveal the lavers of history and on-going transformations witnessed by the hotel over its lifetime.

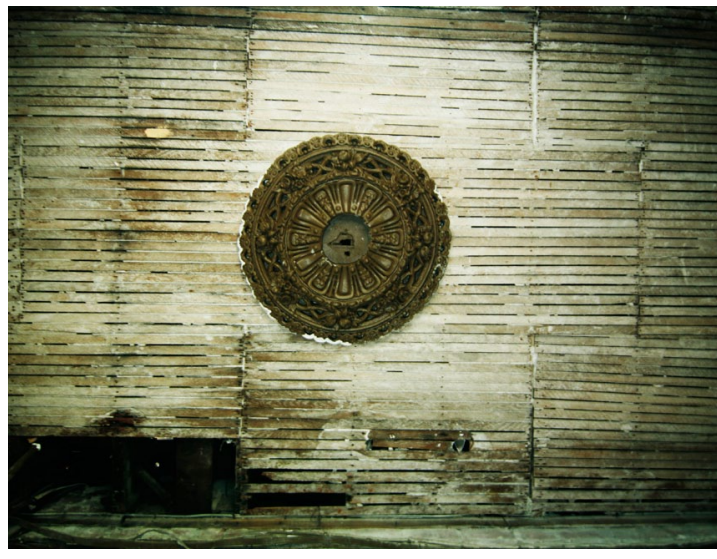

Fig. 63 The Albemarle lobbr Ceiling - ground floor

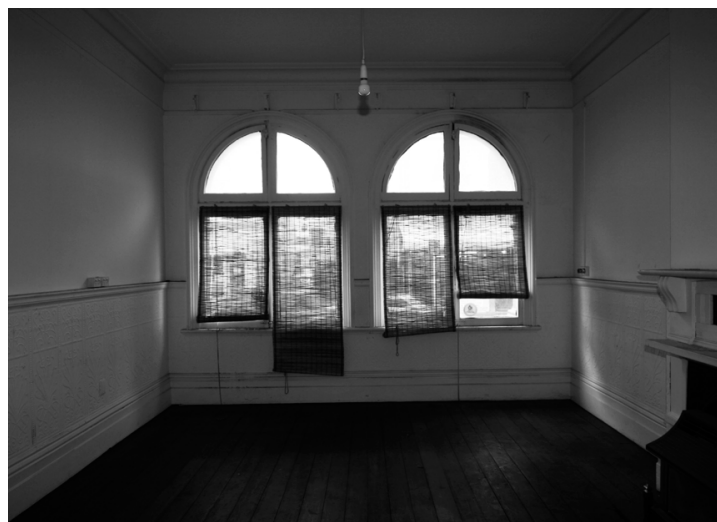

Fig. 64 The AlbeMarle Front SitTing ROOM - GROUND FLOO

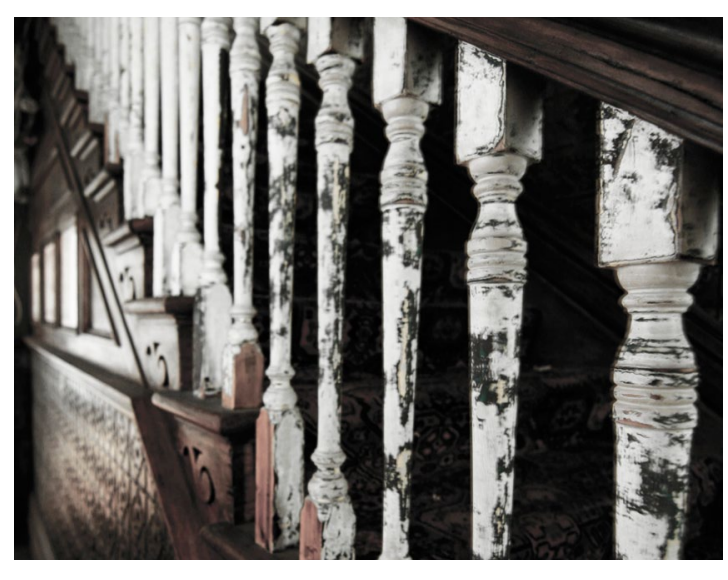


Fig. 66 The Albemarle spatial key - ground floo

Spaces G2 \& G6 have the potential to house a café and open seating spaces for the public, creating a space that functions as an extension of Glover Park for those wishing to sit inside on a rainy day, encouraging a relationship between the people of the park, the people of the cafe and the employees of the NZHPT. The ground level space to the rear of the hotel (G9) could potentially be opened up to the park including the existing outdoor toilet block (G10), providing toilets for the NZHPT and park dwellers alike.

Existing spaces recommended to be maintained as spaces of classification $\mathrm{C} 1$

G1. Lobby

G2. Café Space/ Public Park Extension

G3. Main Access Stair

G4. Fire Place/ Bathroom

G5. Store

G6. Café Space/ Public Park Extension

G7. Kitchen

G8. Outdoor Public Space

G9. Existing Historic toilet block

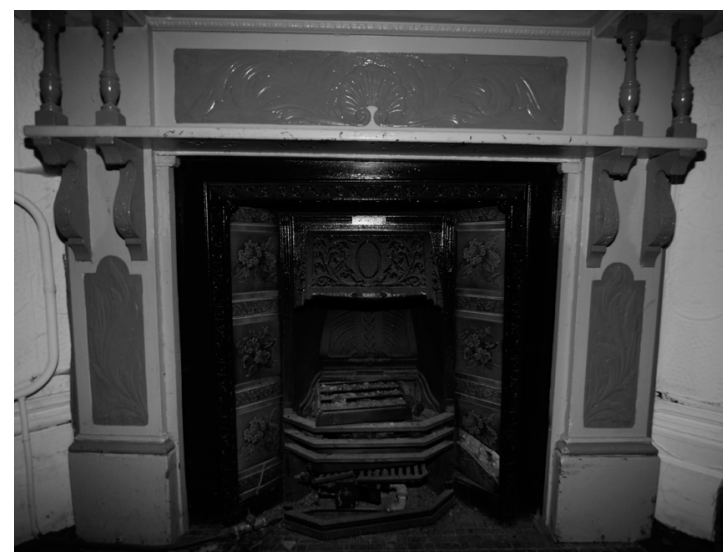

Fig. 67 The Albemarie fireplace - Ground floor

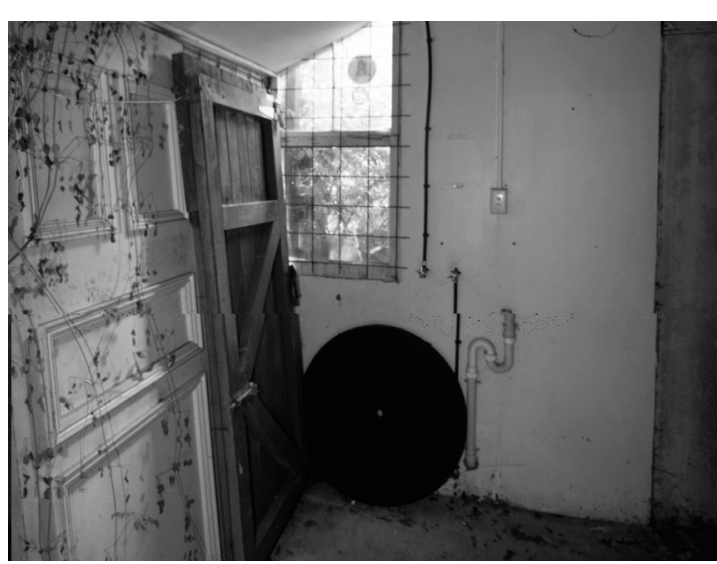

Fig. 68 The Albemarie store room - ground floor

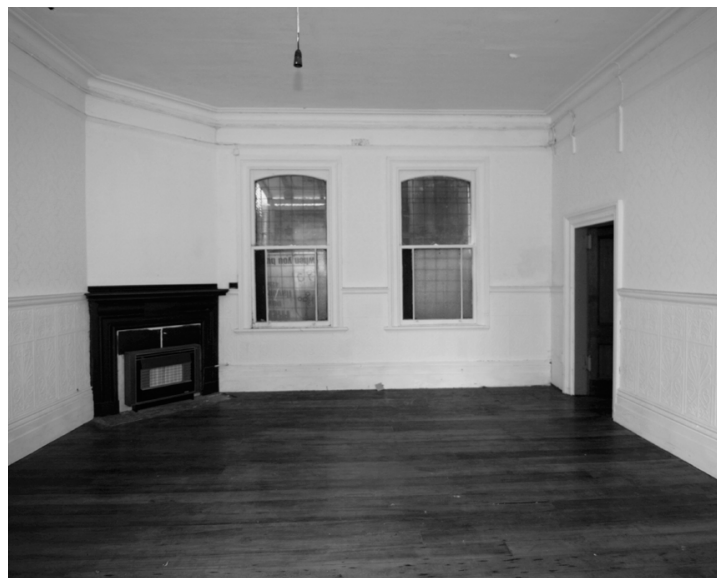

Fig. 69 The Albemarle original restaurant

GROUND FLOOR
OPPORTUNITIES FOR SPACES FOR THE NZHPT-LeVEL ONE

Level One begins to evidence the layers of history within the historic hotel; it evidences the peeling of paint of the hotel days, the shedding wallpaper from the brothel days and water marks from the days when the historic building was a mineral spa; the wall linings and ceiling linings form a timeline of history that the hotel has witnessed.

Levels One and Two are partially demolished, and repairing them to the original condition such as that proposed for the ground floor would be expensive. In accordance with the thesis proposed classification evaluation system, levels 01 and 02 represent classification C2 spaces that should 'retain the transforming layered conditions and integrate historic and new elements', maintaining as much of the weathered conditions possible within the context of returning the levels to a habitable condition.

The large open space shown in Figure 75 has the potential to be a meeting/boardroom for hire by the public or used by the NZHPT office. The 'bedrooms' along the west wall remain partially intact, separated by deteriorating walls without linings, such as that in Figure 70 . The partially demolished walls could function as a visual filter providing some privacy, but retaining the visual connection with the wider office.

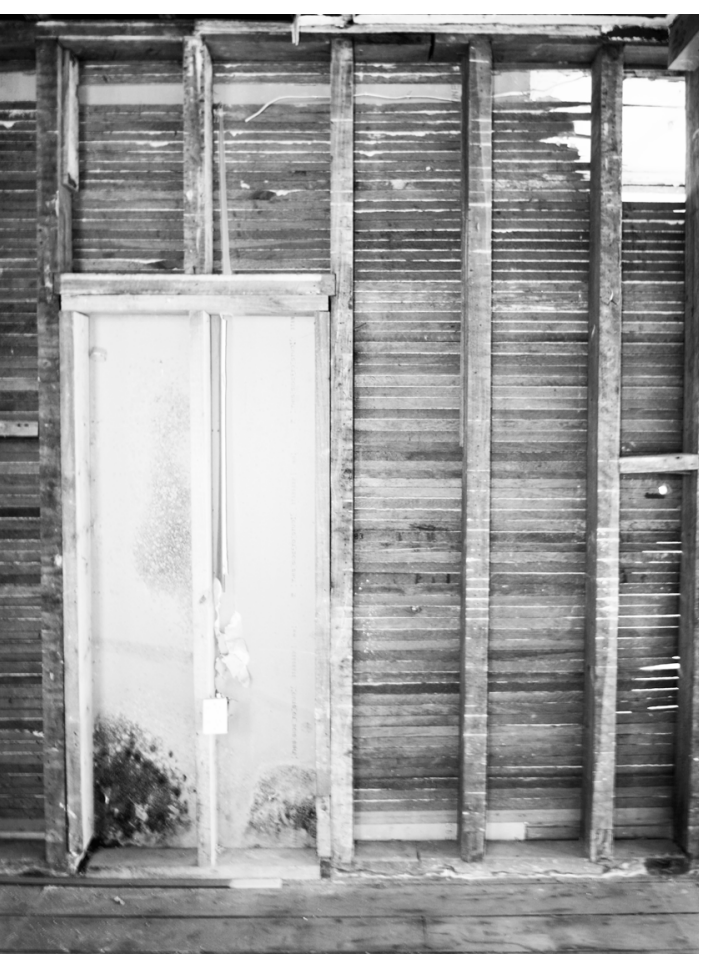

Fig. 70 The Albemarle exposed LAth - Level one

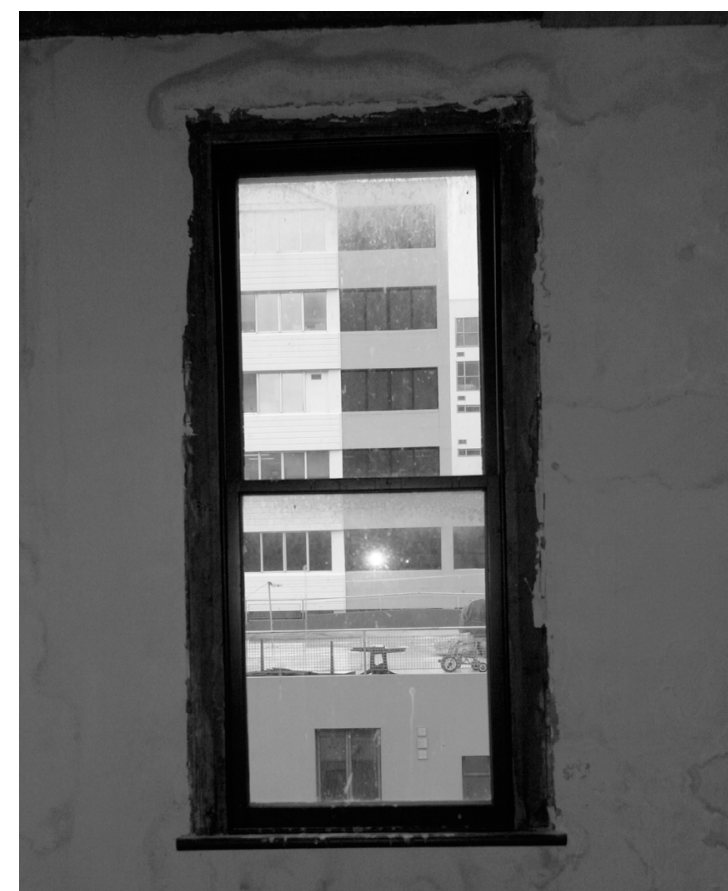

Fig. 7I The Albemarle Water marks - Level one 


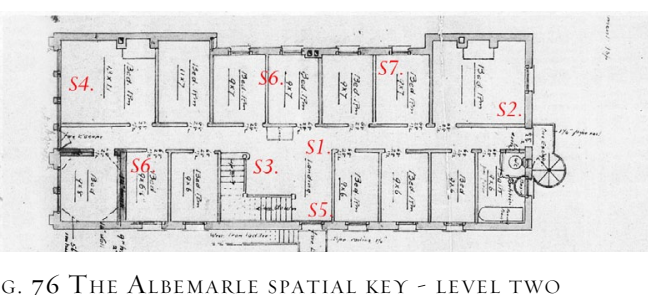

Furthermore, the smaller 'hotel room' size spaces would provide a more efficient use of space for an office than the grand bedrooms of Antrim House The partially demolished and decaying nature of this level enables visitors to understand its history, and the removal of walls potentially allows Level One to function as an open plan office that encourages group work within the office, remedying the isolated nature of the current office layout in the Antrim House The original hallway remains in a partially demolished state; this could provide some spatial separation for the office workers (See Fig. 74).

One of the beautiful aspects of having the ground floor in its original state is that when the surviving furnishings such as the copper light switches (See Fig. 73) are revealed on the half-demolished walls of level One and Two, the occupant can realize what part of the history they come from. The ground floor creates an exciting historic benchmark for the origin, and the upper levels tell the story that follows the historic origin.

F1. Office

F2. Café Space/ Public Park Extension

F3. Office

F4. Circulation

F5. Circulation

F6. Meeting/ Boardroom

F7. Library/ Archive

F8. Open Plan Office Space

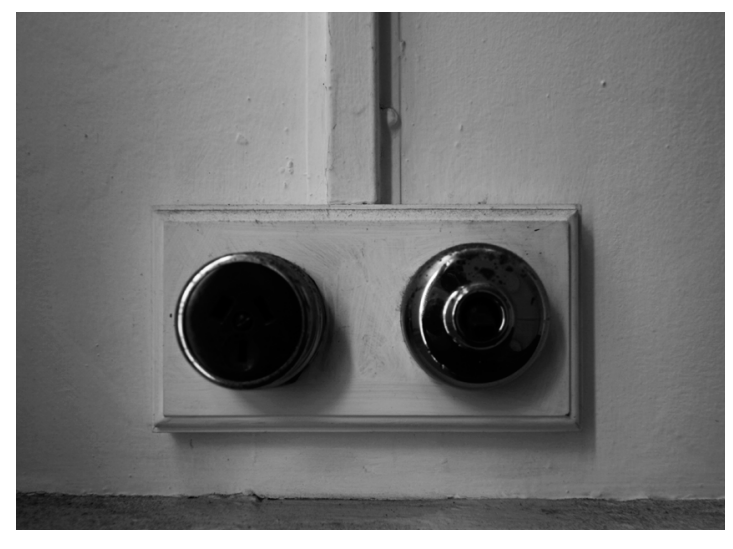

Fig. 73 The Albemarle original copper Light switcheLEVEL ON
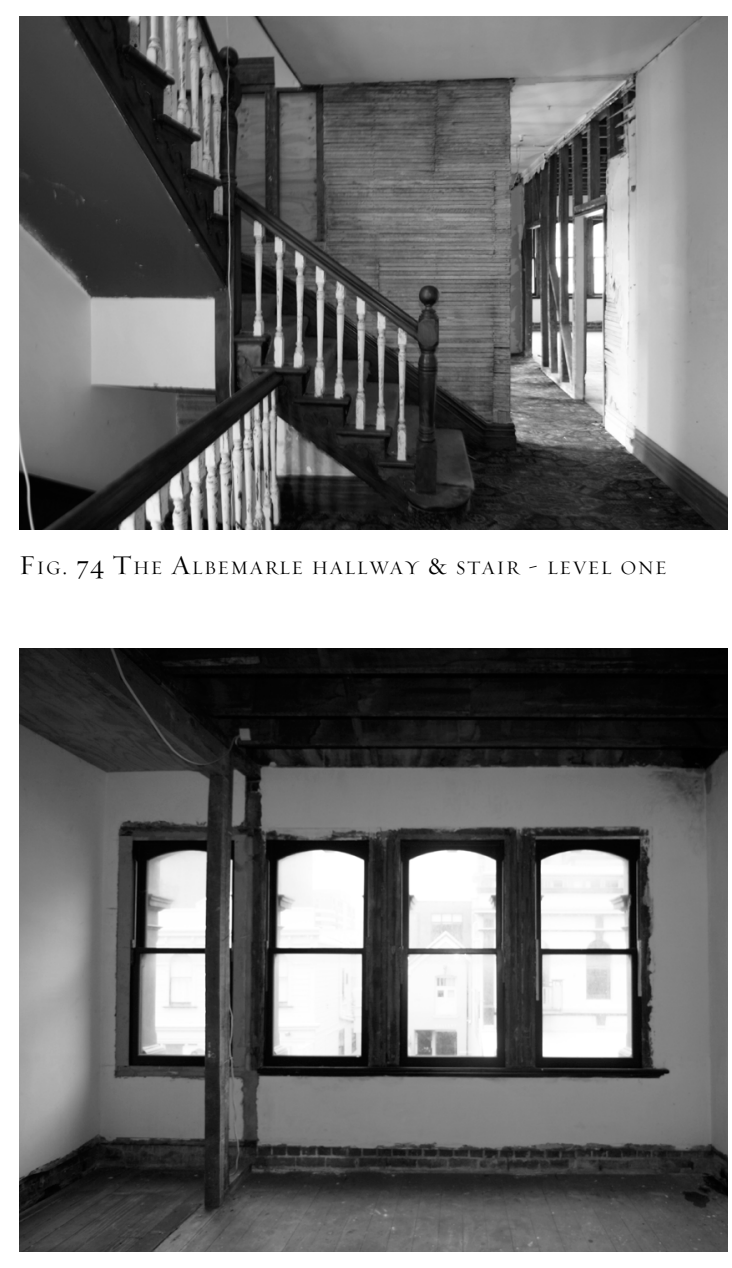

Opportunities for Spaces for the NZHPT - LEVEL TWO

Level Two is also classified by this thesis as a C2 space; the potential spatial layout on this level could be similar to that on the first floor, incorporating open plan office, meeting and staff spaces. The level of decay within the hotel increases on progressively higher floors; the photographs show the drastic change in decay from Levels One to Two, which can be assumed to be a by-product of the third floor extension, or the larger area of decay on this level could be attributed to the mineral spas introduced into the hotel in 1979

One of the advantages of the approach to historic buildings developed by this thesis is that partially missing walls, as aspects of the history of the building, invite more open plan approaches. The current main problem with Antrim House is that it does not offer this option. The approach proposed by this thesis explores spatial definitions not 'privacy' to enable the employees of the NZHPT to engage in an open plan environment that invites both private and group activities. This thesis achieves spatial definitions by: retaining half demolished walls, retaining half demolished ceiling conditions, utilizing the ordering expression of the existing beams, utilizing the ordering expression from the new lateral bracing. The new lateral bracing is implicated in the same spatial resolution as the retention of half demolished walls.

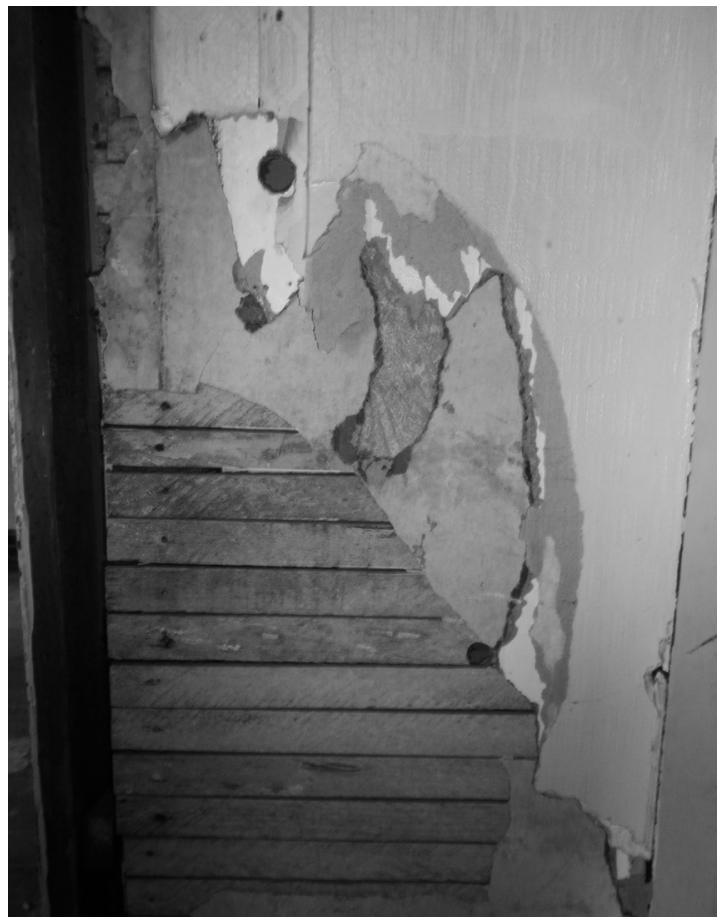

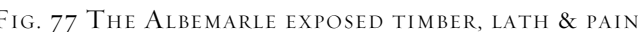
VEL TWO

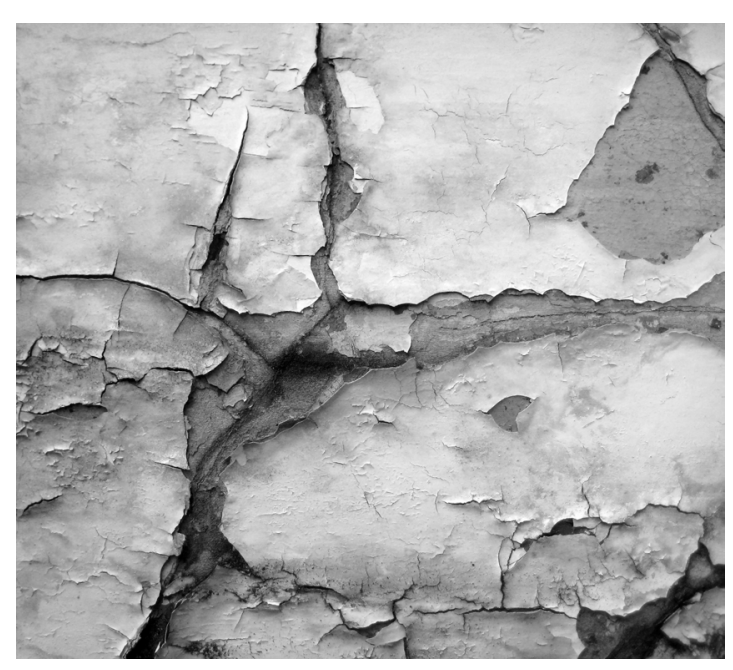

Fig. 78 The Albemarie peeling paint - Level two 


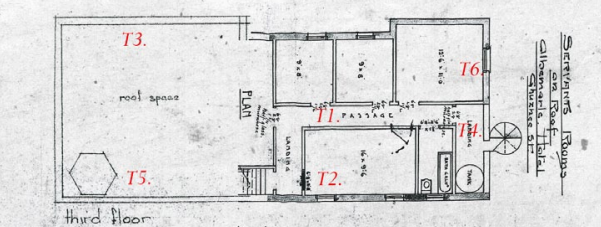

They all act together to invite programming to expand or contract while not losing its spatial identity.

S1. Office

S2. Staff Space

S3. Circulation

S4. Meeting/ Boardroom

S5. Circulation

S6. Office

S7. Storage

Opportunities for Spaces for the NZhPT - Level Three

The roof extension added to the hotel in 1906 (one year after the initial construction was completed) is hidden from below by the thick exterior walls, and as a result many people may not know this space exists on the top of the hotel. Figures 83 \& 84 show the partially demolished walls on the third floor that expose the original parapet embedded within the aging secondary walls. It is through this detail that rainwater has penetrated into the original walls and began to encourage the decay process from the top of the hotel down. The half level opens out to the roof terrace, cupola and views of the neighbouring Glover Park. The rooftop space is considered by this thesis as a classification $\mathrm{C} 3$ space or one that invites the total transformation to a completely new contemporary space because it is severely damaged (and causing further damage below) and has no valuable historic elements of notice. It could be transformed into a completely new contemporary space with potential to function as space for exhibits and functions; the roof is most likely a place an architect would redesign for outdoor use (See Fig. 81).
This thesis considers the rich range of opportunities that are suitable for these varying existing site conditions. The rooftop extension is a space that has the potential to enable a contemporary new use as a part of the hotel's new history, creating a progressive transition from maintained heritage on the ground floor, aging and evidencing of decay as a means of witnessing history on Levels One and Two, and space of new contemporary design on Level Three (rooftop extension).

T1. New Use

T2. New Use

T3. Outdoor Space Over Looking Glover Park

T4. New Use

T5. Cupola

T6. New Use - Water pipes visible in photo

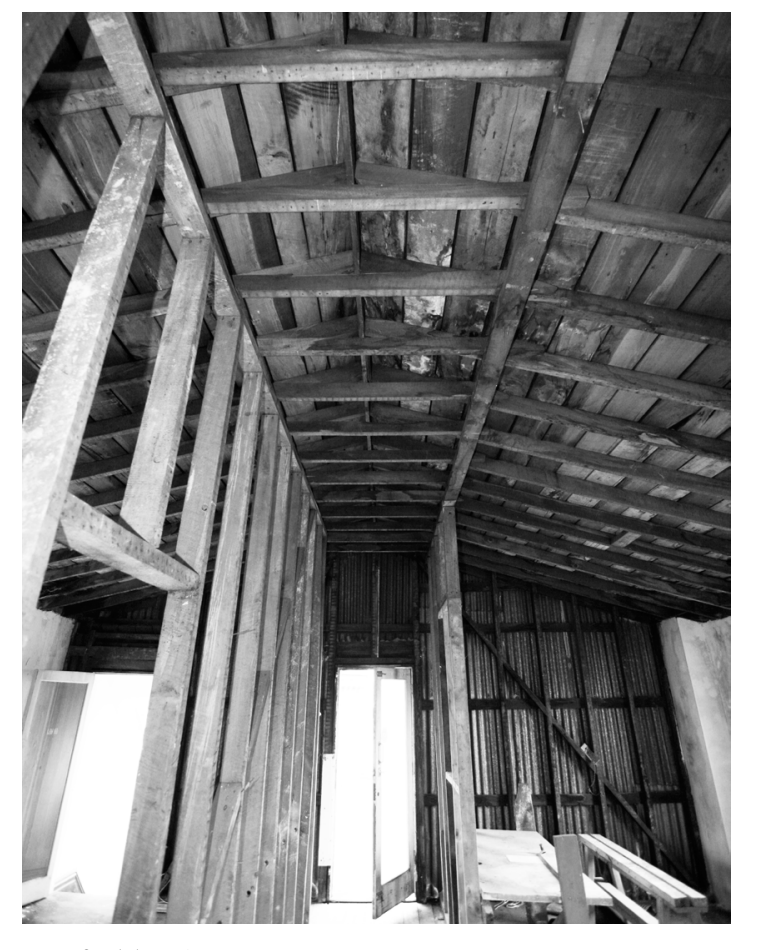

Fig. 80 The Albemarle Exposed timber celung - ifye thre

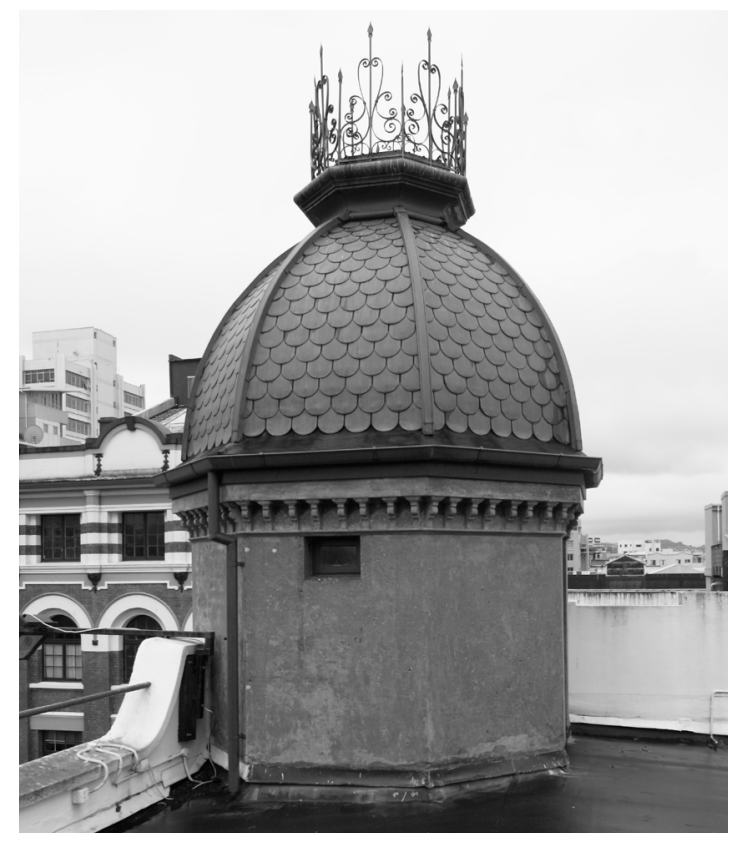


This thesis proposes that the treatment of the historic Albemarle Hotel vary vertically between all levels in accordance with the classification system suggested in 'Layer One'. The concepts explored in the Castelvecchio, where traces of weathering are robust, could be applied to one or two places on the ground level where small traces of weathering can be found (the ground level will remain predominantly maintained); and more vigorously applied to Level One where the weathering is more evident such as that in figure 70 . Techniques observed in the Castelvecchio can be adapted to suit the Albemarle that assist in spatial definition of the open plan office. For example, the insertion of a new raised floor could signify where the historic corridor was previously located, but was removed to facilitate the new open plan office layout for the NZHPT.

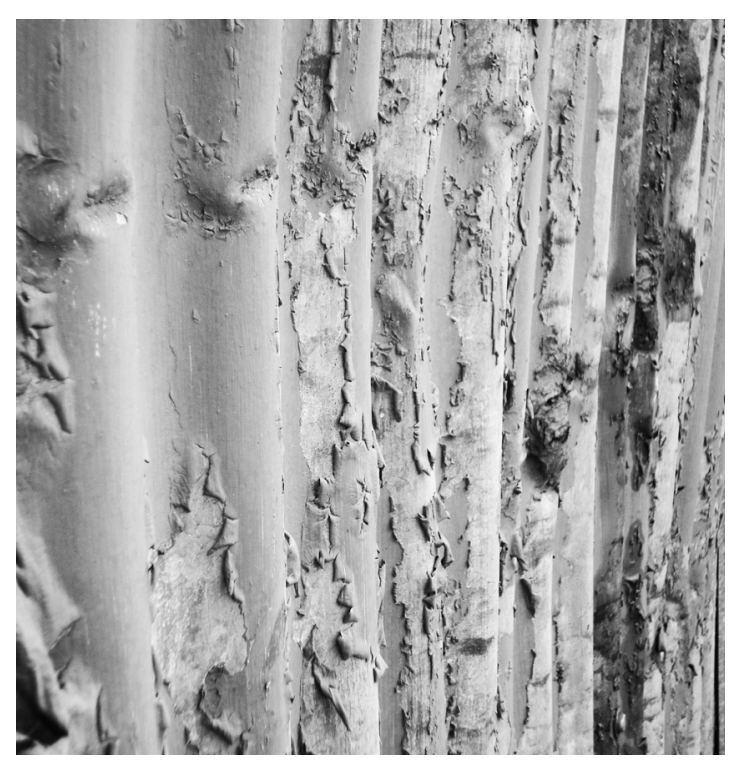

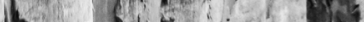

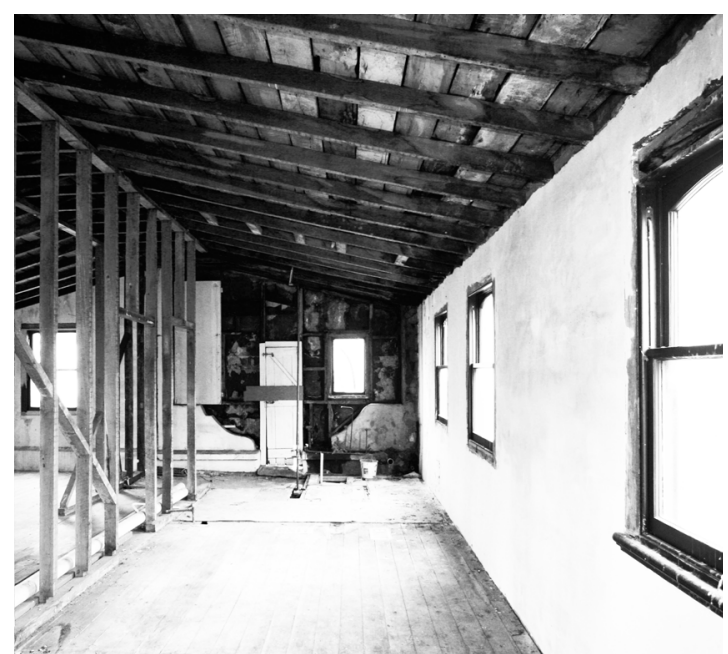

Fig. 83 The Albemarle EXIItTing roof top Space
FIG. 83 THE
FVEL THRE
The concepts explored by the case study: Mint complex, which protects fragile aspects of decay, could be applied to areas shown in figures 49 and 50 on Level One, and more extensively applied to Level Two where the areas of weathering are more extensive (See Fig. 77 \& 78). Again these techniques will be applied in ways that enable spatial definition to occur. On Levels One and Two the structural members splice through the existing historic walls and floors at a regular frequency that creates a rhythmic ordering system from which spatial configurations can be placed within (this is further explored in 'Layer Five' See Fig. 107).

The concepts of the Mint complex appear different on each level; they are applied in a respectful manner on the Ground Level and more obvious penetrations appear as the structural intervention ascends up through the hotel, finally arriving at the third floor level where this thesis proposes a full contemporary transformation the classification $\mathrm{C} 3$ space.

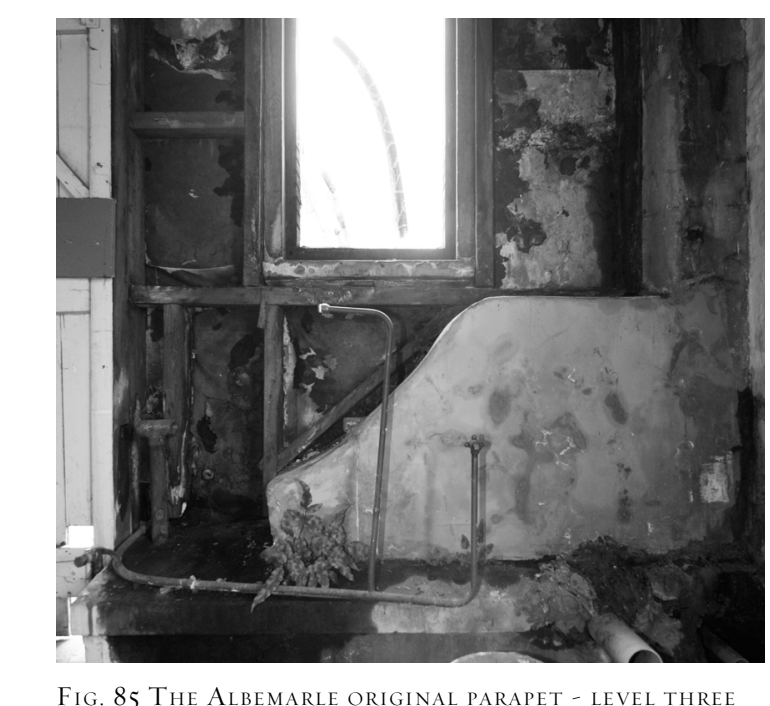

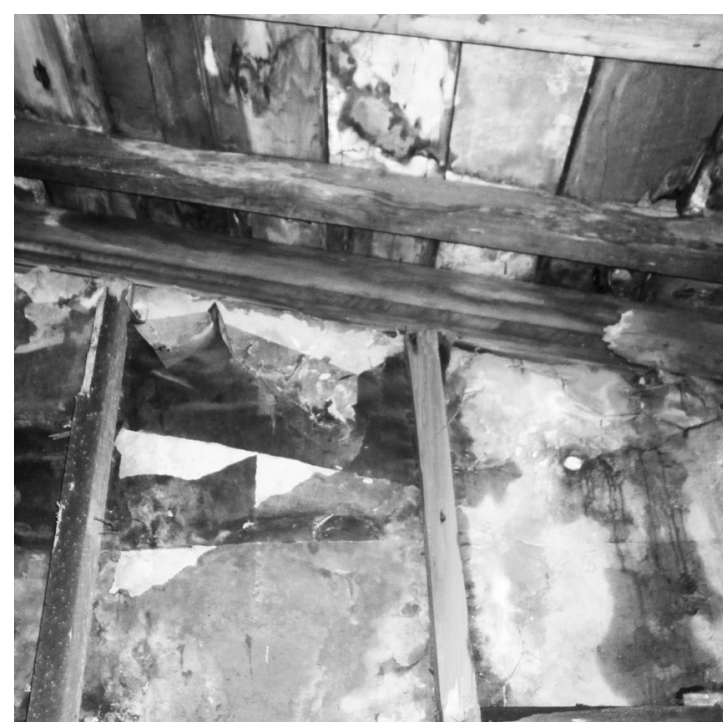

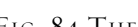

Fig. 85 The Albemarle original parapet - Level Thref 
"SlOWLY AND PAINFULLY, WITH BROOM AND PAIL, MOPPING, SCOURING, Mrs MCNAB, MRS BAST, STAYED THE CORRUPTION AND THE ROT; RESCUED FROM THE POOL OF TIME THAT WAS FAST CLOSING OVER THEM NOW A BASIN, NOW A CUPBOARD; FETCHED UP FROM OBLIVION ALL THE WAVERLEY NOVELS AND A TEA-SET ONE MORNING; IN THE AFTERNOON RESTORED TO SUN AND AIR A BRASS FENDER AND A SET OF STEEL FIRE-IRONS. GEORGE, MRS BASTÍS SON, CAUGHT THE RATS, AND CUT THE GRASS. THEY HAD THE BUILDERS. ATTENDED WITH THE CREAKING OF HINGES AND THE SCREECHING OF BOLTS, THE

SLAMMING AND BANGING OF DAMP-SWOLLEN WOODWORK, SOME RUSTY LABORIOUS BIRTH SEEMED TO BE TAKING PLACE, AS THE WOMEN, STOOPING, RISING, GROANING, SINGING, SLAPPED AND SLAMMED, UPSTAIRS NOW, NOW DOWN IN THE CELLARS. OH, THEY SAID, THE WORK!"
$\mathrm{T}$ his Chapter presents the design research case study experiment explored by this thesis; the research intervention tests new approaches to engaging with New Zealand's 19th and 20th century historic buildings currently under threat from elective demolition or earthquake damage. A new approach is proposed that explores techniques of laterally bracing New Zealand's earthquake prone buildings in ways that become affordable by exposing the structural elements, while also exposing the layers of weathering as a means of evidencing a building's on-going history. This thesis challenges the exposed seismic intervention to act as a space-defining tool that facilitates the incorporation of new contemporary programs, thereby further enabling the historic building to become a viable investment in the 21 st century. 

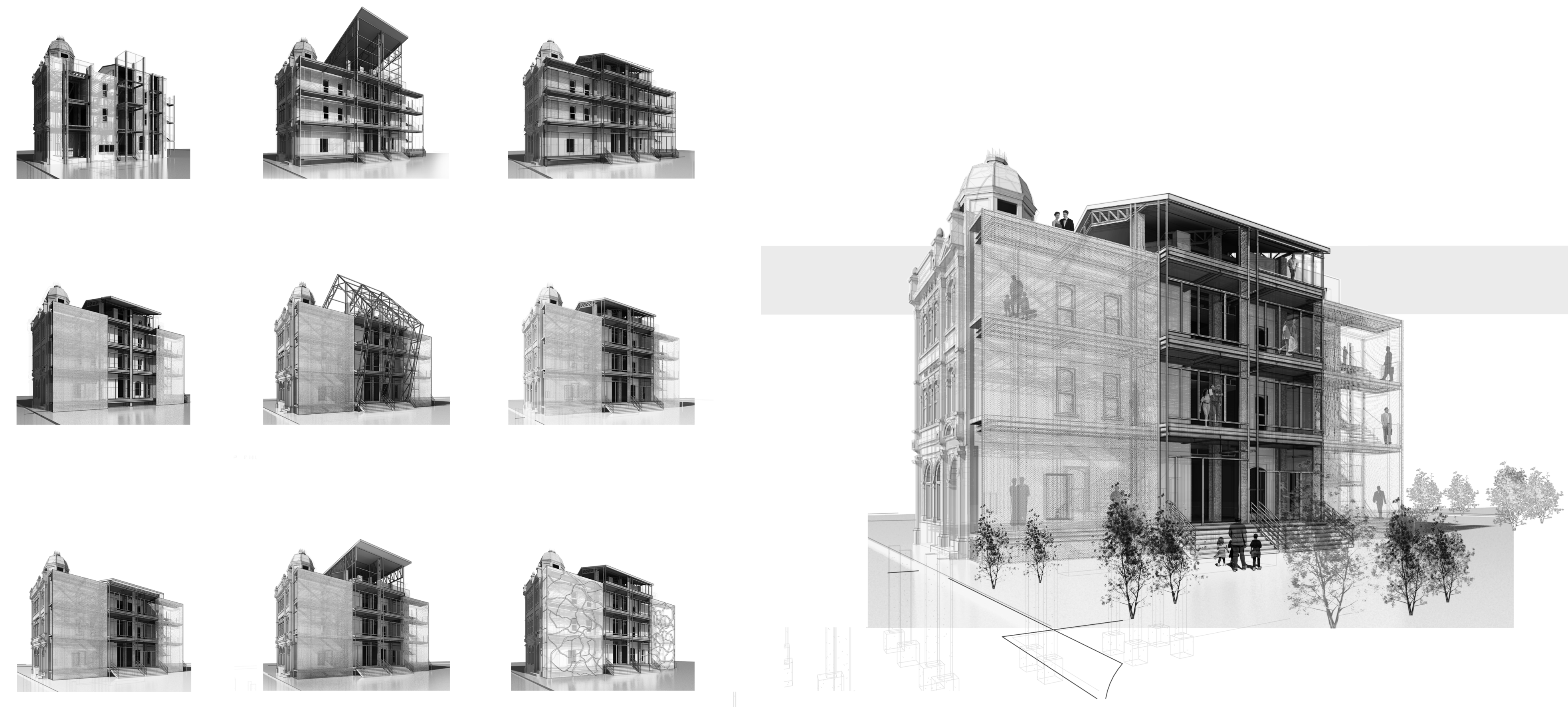
Having identified the urgent requirement to laterally brace the earthquake-prone heritage buildings in New Zealand, a new approach to seismic bracing is proposed; the research intervention explores the application of theories by Scarpa, Kahn, and Miss, along with approaches tested in case studies by Scarpa, Arturo Franco Office, FJMT Architects, Miss and Hamilton. It combines the approaches discussed in 'Layer Two: Assimilating architecture \& installation art' to develop a multifaceted approach to meeting the complex needs of the design research problem. The Albemarle Hotel was selected as the research site because it presents many of the varying conditions of New Zealand's heritage buildings, and it possesses a diversity of spaces and degrees of weathering that allow the testing of the three categories of contemporary 'renovation' identified in the 'Layer One: History, theory \&poetic stratification':

- Maintained original heritage spaces on the ground floor;

- $\quad$ Aging and weathering transformed spaces on levels 01 and 02 that evidence the continual metamorphic development of the hotel throughout history;

- $\quad$ Finally it recognizes level 03 as an area that invites a new contemporary intervention and new use to represent today's architectural expression as a viable representation of tomorrow's history, adding a current layer to the on-going sedimentation process, and validating the Albemarle in the 21 st century.

\section{Seismic Design Evolution}

The sketch designs were initiated following a critical evaluation of the vulnerable Albemarle Hotel, identifying not only the degree and types of weathering within the hotel but also the seismic resisting techniques required to bring the hotel up to the latest building code requirements for lateral bracing, exploring how those conditions can be resolved so that their exposed nature complements both the contemporary and historic materials. This thesis applies the techniques discussed in Charleson's book Seismic Design for Architects to inform the evaluation of the Albemarle's existing seismic resisting strength. The evaluation identified that the hotel has inefficient lateral resisting strength in both the longitudinal and transverse directions; and it has little to no floor diaphragm system that is vital to the transporting of lateral load to the foundations; and the brittle nature of the brick masonry exterior walls (including the heritage façade) has insufficient flexibility and connection strength to resist crumbling in the event of an earthquake. 
In order to improve the seismic strength of the unreinforced masonry walls of the historic Albemarle Hotel, the author embarked on a series of meetings with engineer Sean Gledhill, Technical Director at Aurecon. At these meetings, the architect and engineer discussed the building's proposed use, and considered various techniques currently being employed to strengthen Wellington's unreinforced masonry building stock. The recomended solution to earthquake brace the Albemarle Hotel required lateral stiffness and robust connectivity to the perimeter URM walls to form an appropriate and cost-effective solution. By integrating techniques suggested by Charleson and the informed critique from Gledhill, the structural design experiments took on the viable and practical application of a two-way steel moment resisting frame system. The frames connect to existing vertical elements and allow the floor space to be unimpeded by vertical structure. The frames are spliced up through and re-support the floors, whilst affording good connectivity to the URM walls. These systems enable the historic hotel to effectively transfer lateral loads to the foundations with anchors resisting tension loads, targeting to lift the building's seismic resistance out of the earthquake prone building category.
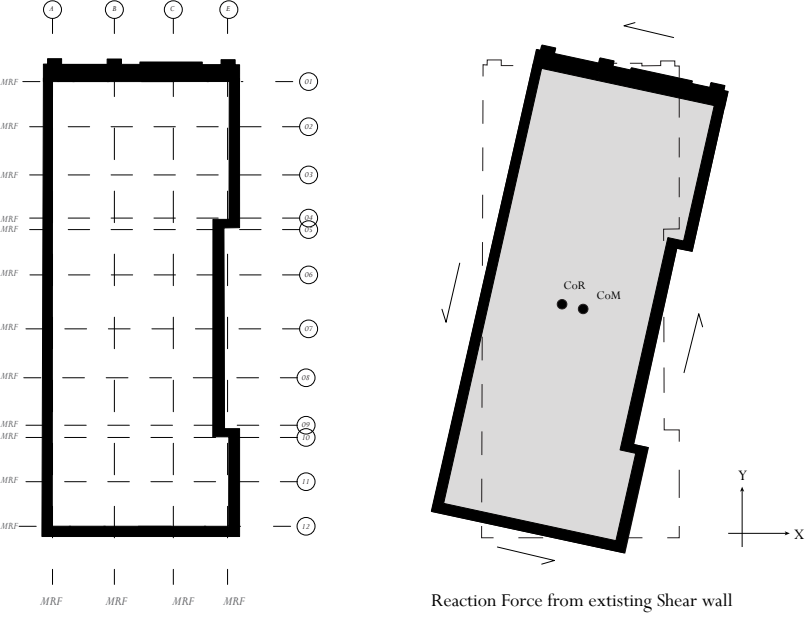

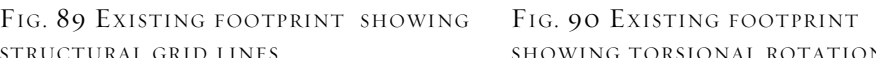

The size and asymmetrical layout of the footprint suggest that four frames be placed along the longitudinal axis and four on the transverse axis; however the design experiment was further developed to employ eight frames along the longitudinal axis and four on the transverse axis; this move was made to reduce the size of the structural members and increase the rhythmic ordering system created by the structural members.

Following exploration of the most efficient moment frame systems (illustrated in Fig 89-94), the design research process further explored non-traditional methods of lateral bracing such as those discussed in Moments of Resistance. The authors explore theoretical projects to discuss alternative applications of exposed structure such as a structural steel skin that is fixed to brick masonry or the application of polished steel ties that take on a decorative aesthetic until their application as seismic resisting elements is required. This theoretical exploration of exposing seismic bracing challenged the moment frame system not only to act as lateral bracing but also to contribute to the historic site in an aesthetic and spatial sense. The design research experiment then looked to the case studies explored in 'Layer Two: Assimilating architecture \& installation art' as a means of further achieving the design imperatives within the site chosen.

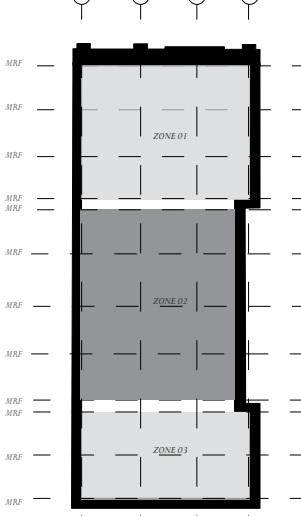

91 EXISTING Footprint SHOWING

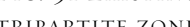

Fig. 92 Existing Footprint SHOWING NEW MOMENT FR
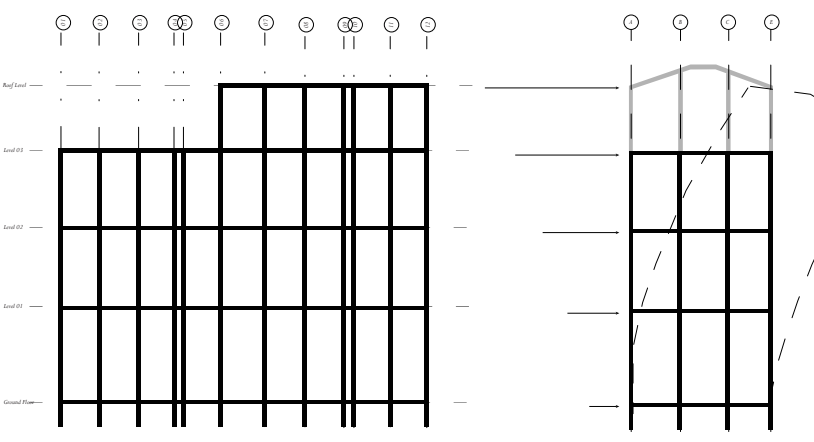

Fig. 93 New moment frame structure Fig. 94 New momen

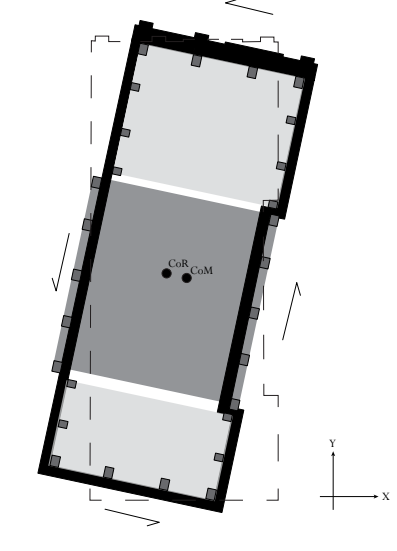




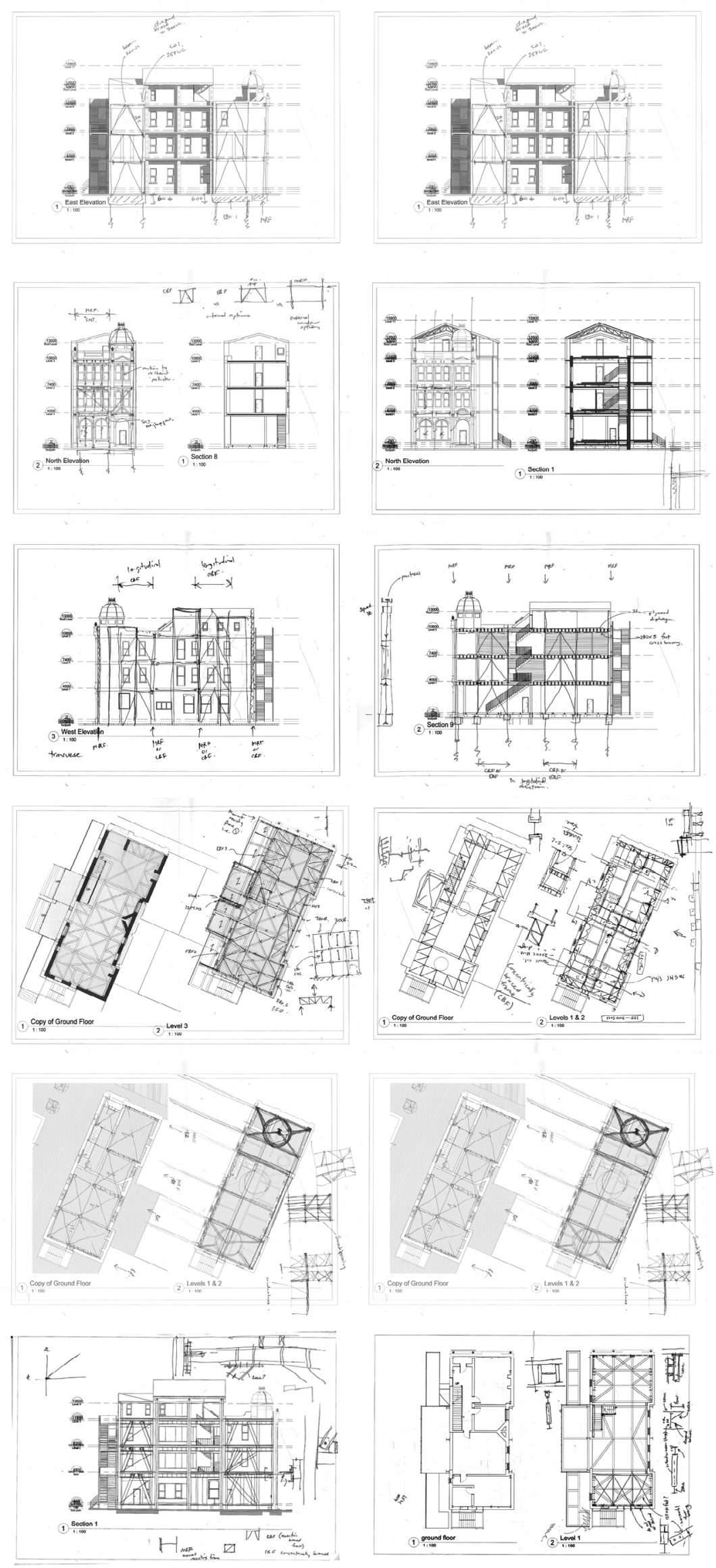

Fig. 95 Drawn Discussions with FNGINERR SEAN GLFDHL
The final moment frame seismic intervention design acknowledges the tripartite nature of the original floor plan, divided into three zones; because the building footprint steps in at the central zone, there is an opportunity in this area to place the columns outside the building envelope. Zone one and three are braced internally and zone two (the central zone) is braced externally. The columns described in the following chapter as tri-flange columns line the north and south facades along gridlines 01 and 12 providing increased stiffness to the vulnerable heritage façade and greater seismic resistance at the two anchors of the historic hotel. These columns are spliced up through the floors to re-support the floors, whilst affording good connectivity to the URM walls. These larger columns are also placed on the exterior of zone two, applying compression to the central zone, and enabling the new west façade intervention to be cantilevered from the external structure. In addition to the vertical elements the moment frame system requires adequate floor diaphragm systems to transfer the lateral load between the vertical elements. The seismic intervention incorporates cruciform beams along all transverse gridlines and flat steel cross bracing shown in Figure 96; this new floor diaphragm system sits below the existing exposed timber floors, enabling the raw timbers to remain as a testament to the hotel's history whilst the contemporary diaphragm will take the lateral load in the event of an earthquake. 


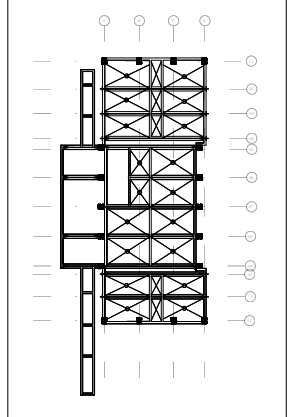

On the roof the moment frame system follows the pitched roof of the 'shed-like' extension sitting between the existing exposed timber roof joists. The research intervention has been designed so that if the roof shed is removed in the future to allow for a new contemporary space, then the remaining moment frame system will emulate the previous roof shape, thereby telling the story of the dilapidated rooftop extension.

The principle design imperatives of the lateral bracing system in this design experiment are to:

- $\quad$ Enhance seismic resistance within the Albemarle Hotel to a suitable level.

- Reduce costs by exposing the system in ways that enhance the imperatives of historic preservation.

- Engage the exposed lateral bracing system as a spatial ordering device to facilitate multiple programmatic or occupational engagements without necessarily dividing spaces into separate rooms.

The design explores the notion that the same instituted ordering system derived from the requirement for lateral bracing can also become an ordering system that invites open plan and semi-enclosed typologies of occupancy, establishing a modular pattern within the interior that both defines space and recognizes the on-going process of decay and weathering as an important part of the history of the Albemarle. The design experiment further explores how theories of layering through a contemporary seismic intervention, as discussed in 'Layer One', can further our engagement with the on-going narrative of the historic hotel.
Fig. 96 Final Bracing Plan

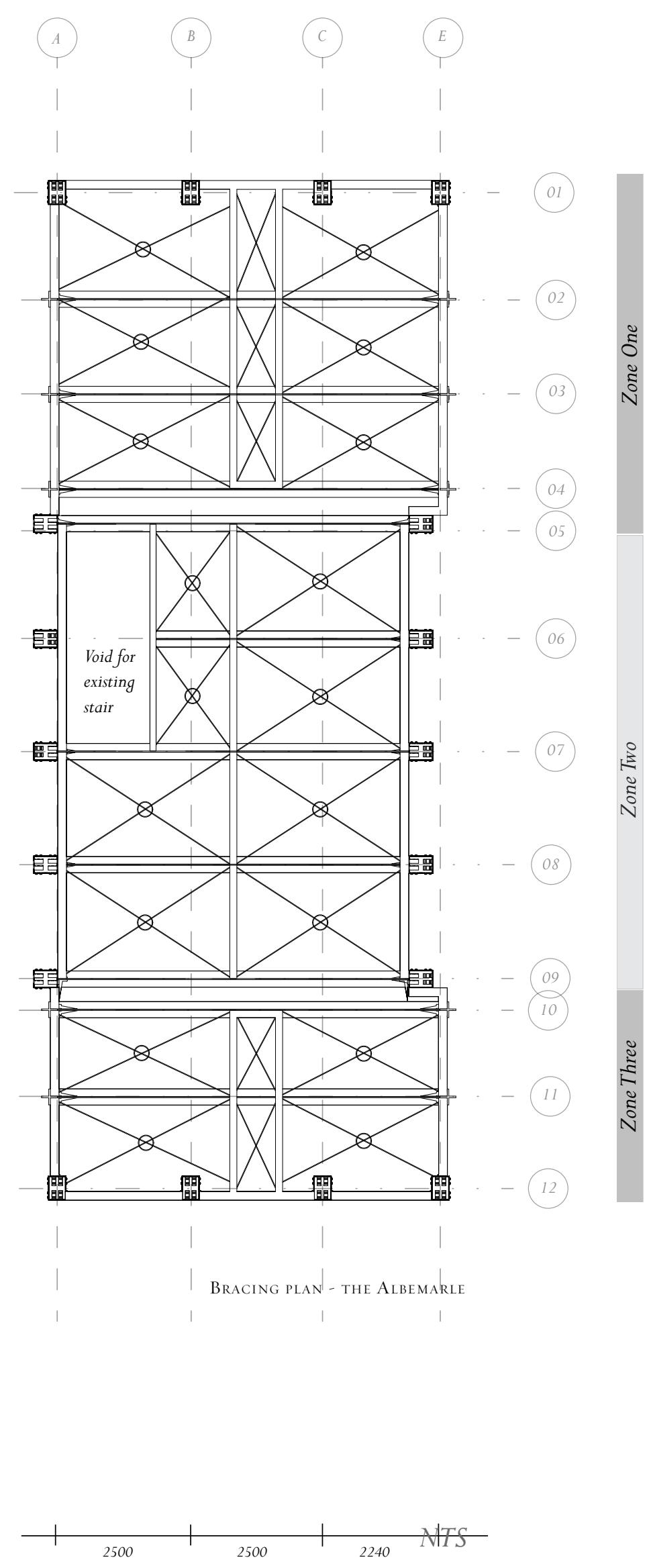




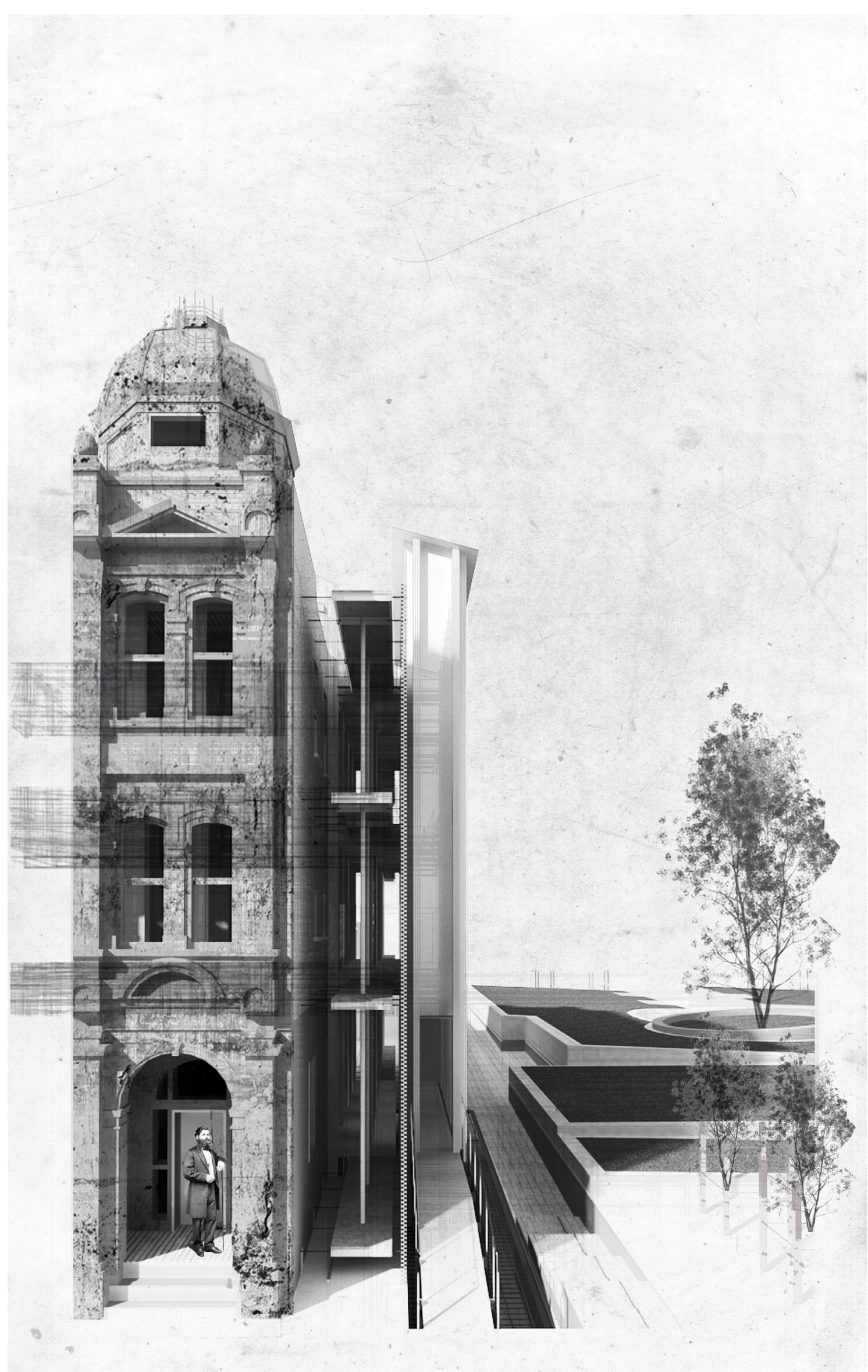

Fig. 97 Perspective view of the contemporary facade \& Albemarle Hotel from Ghuznee Street
The Sister Facade

Having identified a seismic system that seismically braces the historic hotel whilst implicating itself as a contemporary layer that actively participates as one of the exposed layers of history, this thesis then began to explore how the structural intervention might actively and sensitively reveal aspects of the history of the hotel by referencing the story behind the footprint of the hotel. As discussed in 'Layer Three', architect James Bennie designed the asymmetrical footprint of the hotel with an indent along the east façade to allow for sunlight to reach the east windows; this asymmetrical footprint shifts the centre of mass away from the centre of resistance which potentially can cause a higher degree of torsion under earthquake loading. For this reason the new lateral bracing system must also shift at the point where the footprint indents. In order to brace the hotel efficiently, a decision was made to divide the floor plan into three segments. The new design intervention evolved to brace each zone individually, the three zones are then connected using perimeter PFC beams so that the three zones moves as one single system under lateral load; but caters to the unique tripartite nature of the footprint without creating weak points in the system. The central zone is braced from the outside in, and the two end anchor zones are braced internally (See Fig. 92). By placing the moment frame columns for the central zone on the exterior of the west façade, the occupants of the park can witness the division of the hotel into three zones, revealing the unique and quirky nature of the hotel; this also allows the central zone on the ground floor to remain uninterrupted by structural elements.

At this point the design experiment began to explore how the seismic intervention could not only appear on the west façade as a means of reflecting the nature of the indented east façade, but could simultaneously provide a new façade condition to the blighted west façade. 
Due to the development of Glover Park and the exposed nature of the west façade, the Albemarle now has two main facades, the north facade with the ornamental decoration discussed in 'Layer Three', and the west façade with it windows that relate only to the original rooms rather than street aesthetic. The design experiment explored how a new contemporary façade condition might be derived from the requirement for lateral bracing, and how the notion of façade as a spatial edge condition can begin to address some of the complex service issues facing the Albemarle Hotel such as the contemporary requirement for disabled access and a secondary egress stair.

By placing the lateral bracing of the hotel's central zone on the exterior, the seismic intervention facilitates the introduction of a new contemporary façade.

Fig. 98 Perspective view of the contemporary facade from Glover Park
The design research experiment tests Scarpa's notion of stratification by inviting the façade to act as a separate contemporary laver, disengaged from the heritage fabric; the space between the façade and the historic hotel instigates a discourse between the old and the new (See Fig. 98).

The final design of the façade laver is the result of an iterative process (See Fig. 99) that examined the relationship between the hotel and the park, and the relationship between the intervention and the facade including the heritage north façade, the blighted west façade, the west elevation and the roof shed. The resulting contemporary façade treatment opens the central zone of the historic hotel out to the park, providing more natural light to the interior, a visual connection with the park, disabled access, a secondary stair and elevator access to all floors.

Fig. 99 Perspective view of the contemporary facade from Garrett Street

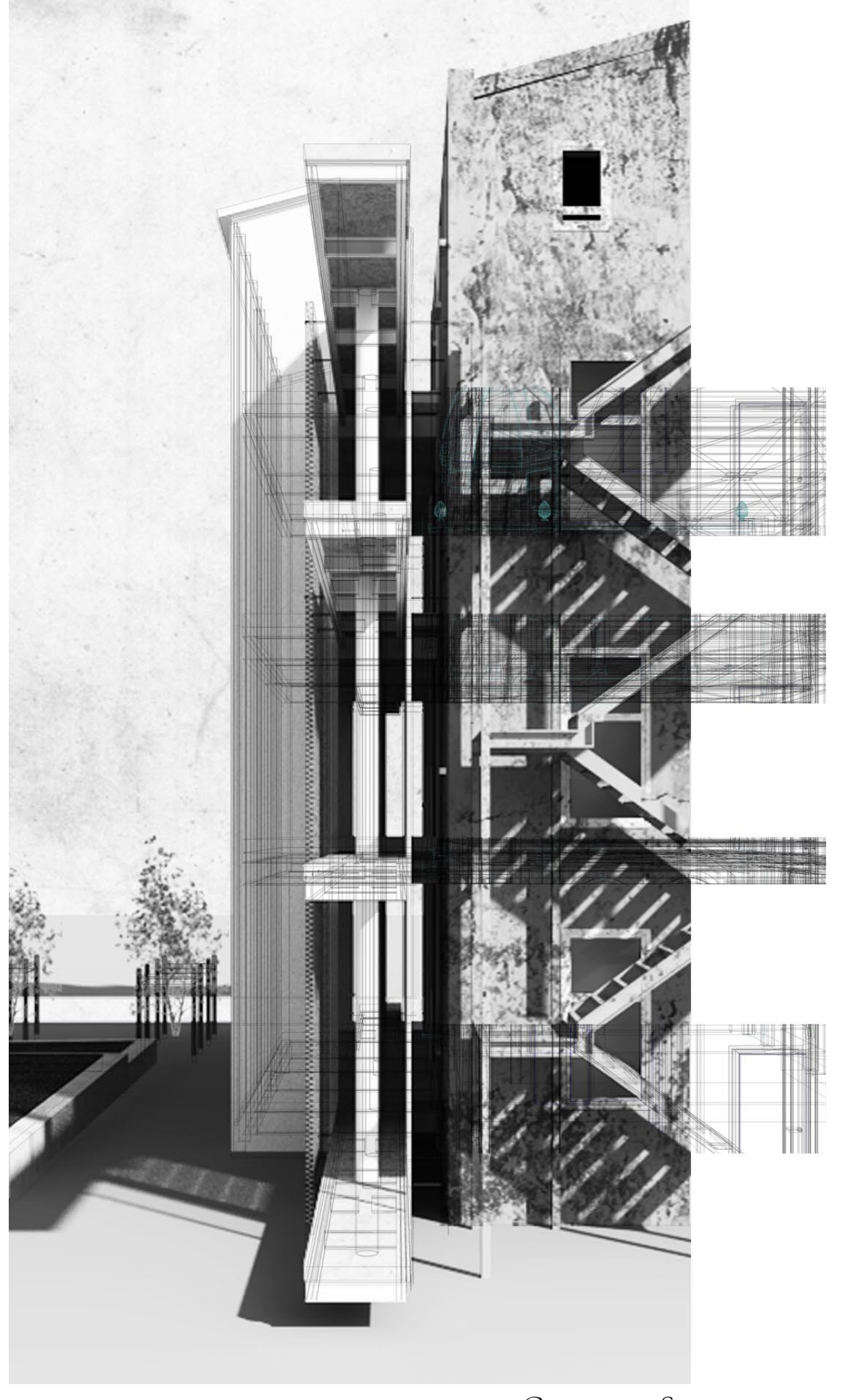

RENEE A. NANKIVELL : TIME PASSES 
The façade mirrors the indented east façade by stepping out where the east façade is recessed, revealing the original historic asymmetrical condition of the hotel to the dwellers of the park. The new façade sits as a new contemporary series of layers disengaged from the historic hotel to allow the intervention to act as a separate element to the existing historic 'row house'. Comprised of a series of layers or planes of glass, mesh and steel the façade intervention filters and distorts the light entering the hotel, creating a distortion of light inspired by Kahn 'wrapping ruins around buildings' in his projects for the U.S. Consulate and Salk Institute. The façade intervention also looks to the work of Mary Miss to implicate her use of materials with varying transparency to define space, layering scenes and partitions as space defining-tools that allow the visitor to enter the façade, not from the centre, but through the space between the layers. The facade also considers Scarpa's method of re-orientation to align the occupant with the rhythm of the layers when transitioning through the façade into the historic hotel.

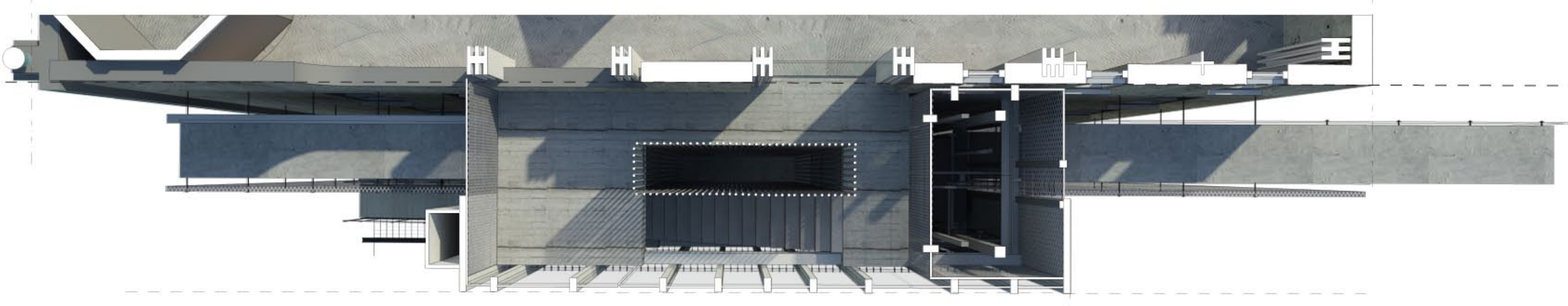

Fig. ioo Perspective plan view of the new facade intervention 


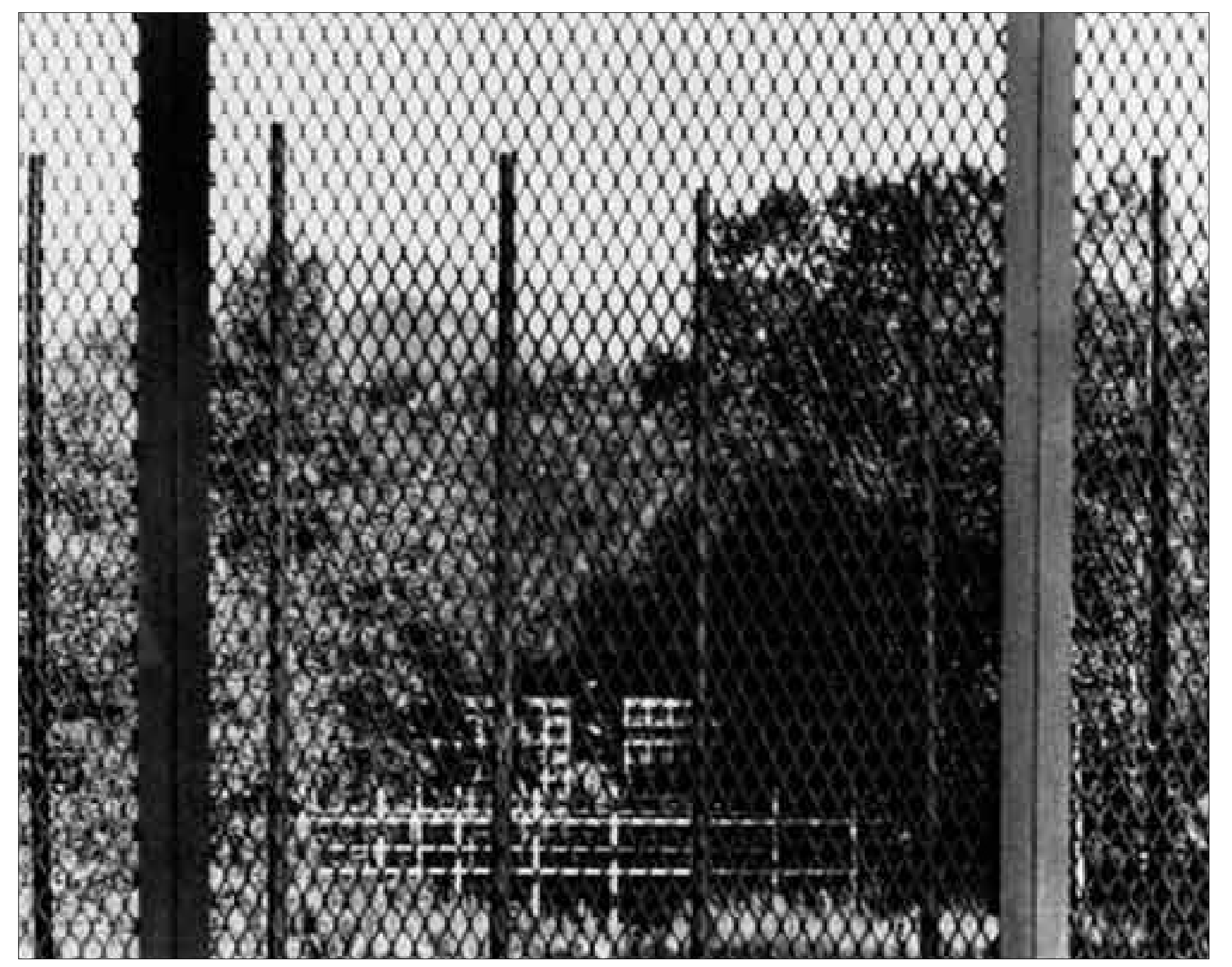

Fig. ioi Veiled Landscape (1979) by Marr Miss

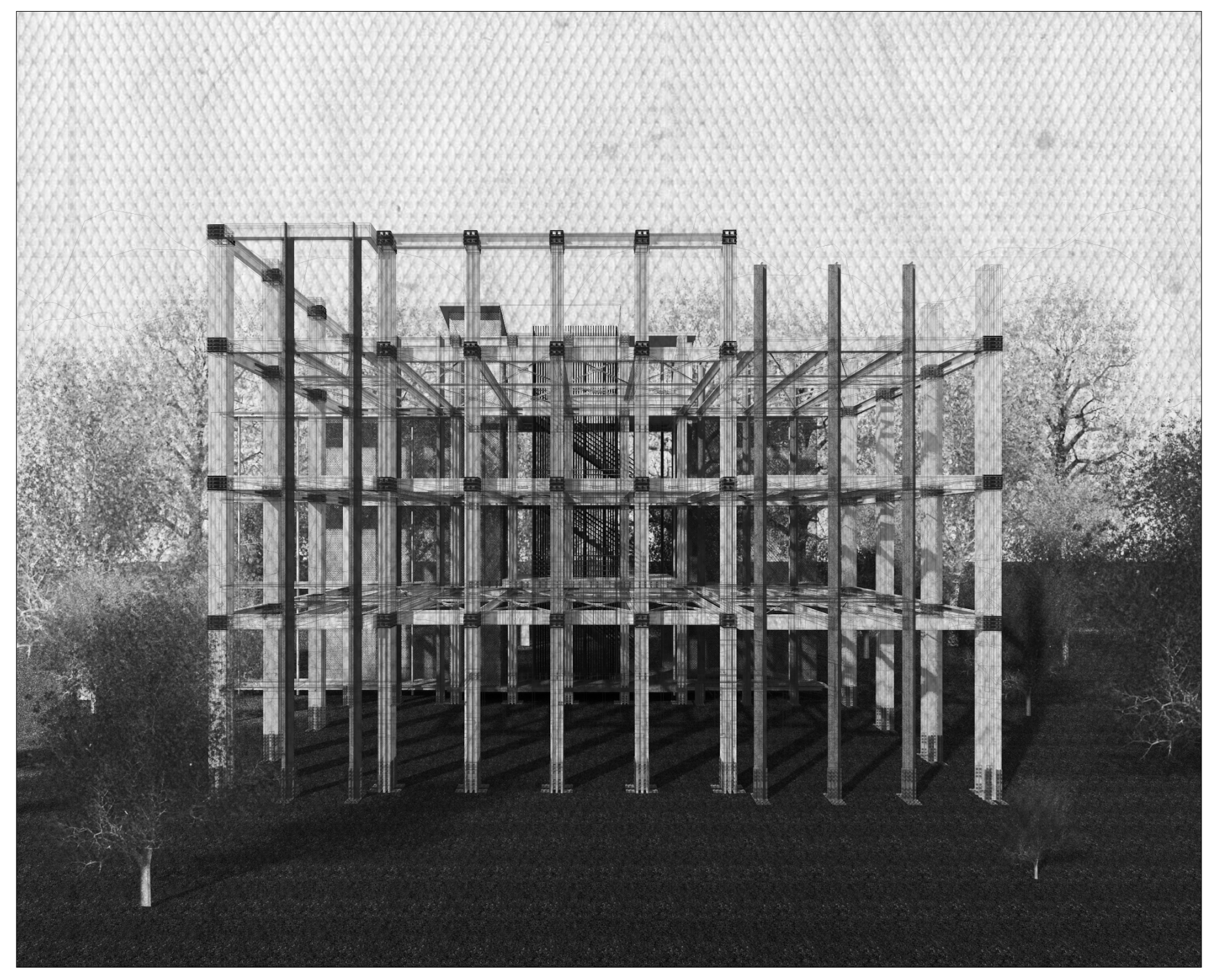

Fig. io2 The contemporary structural intervention presented as a Marr Miss installation 

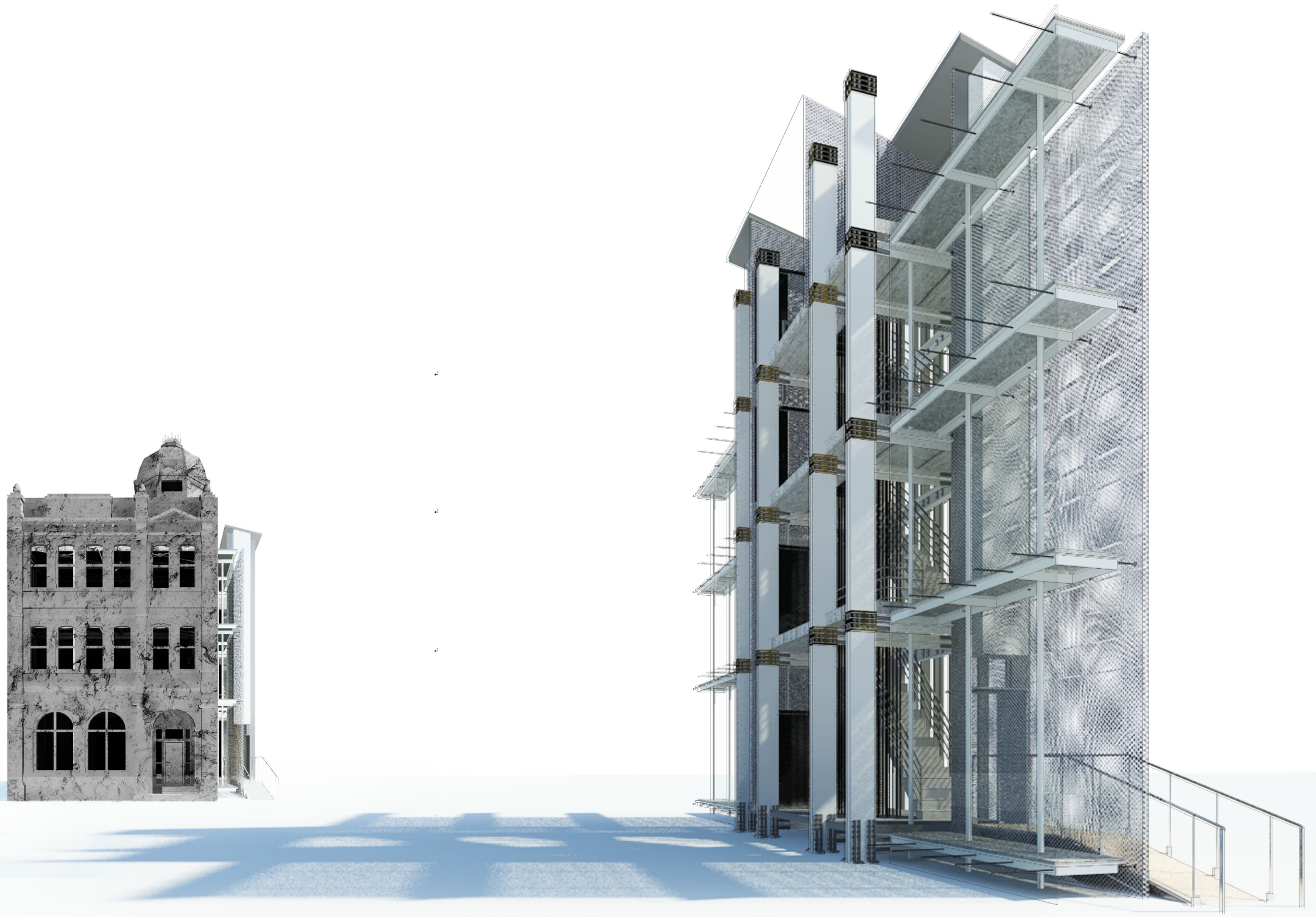


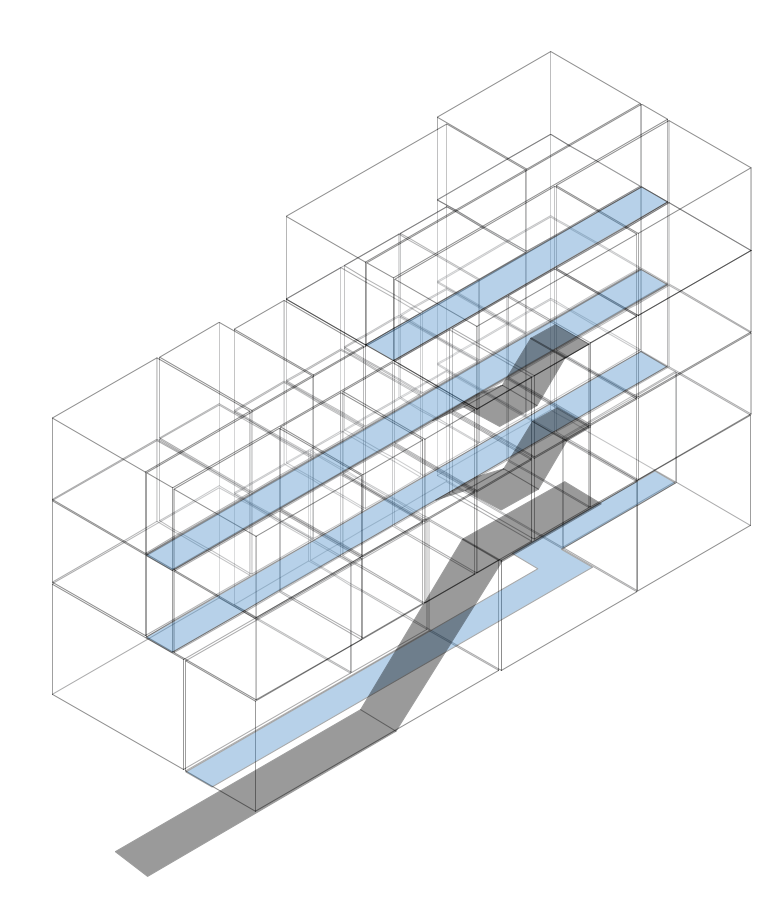

Fig. io4 Existing vertical \& horizontal circulation of the Albemarle Hotel

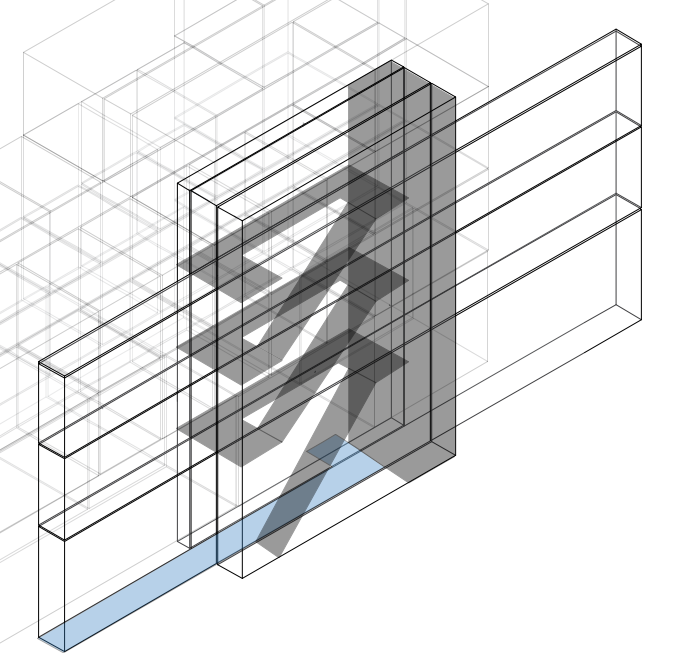

Figure 102 shows the structural intervention and façade design experiment as a Mary Miss exploration, both this thesis and Miss's Veiled Landscape (1979) explore the notion of the façade. Both projects speak of layers and veils that the visitor must transition through to approach the subsequent layer veils, enabling them to witness multiple veils, transforming the experience as the visitor transitions from one veil to the next. The façade investigation explored how a rhythmic structural ordering system and series of veils can implicate spatial ordering and spatial experiences. However, this experiment differs from Miss's explorations since it demands habitability. The design evolved so that the façade was able to take on programmatic functions required to meet building code that historic buildings never anticipated. These new functions now reside within the contemporary veiled façade intervention, including disabled access to all levels, a secondary egress stair, and an elevator.

Figure 104 shows the existing vertical and horizontal circulation for the hotel, with the historic stair in the central zone of the footprint, and the horizontal circulation paths running down the centre of the hotel. Figure 105 shows the contemporary facade and the additional circulation needs it provides for the Hotel. Sitting adjacent to the existing historic timber stair, the new facade provides disabled access to all levels and a secondary egress stair, whilst providing more natural sunlight to the interior. 
BEYOND THE FACADE

The ground floor of the Albemarle displays typical characteristics of a heritage site that this thesis identifies as a classification $\mathrm{C} 1$ space that should continue to be maintained as a means of evidencing its original life in the early 1900s. The material finishes of this level have been well maintained as discussed in the Layer Four'; with little cost or change to the heritage characteristics, the ground floor can be converted into a space for the public such as a café or restaurant. This thesis proposes that the only elements of the structural intervention to be visible on this level are the columns in anchor zones one and three that penetrate through the ceiling and down to the foundations, not unlike the Mint case study where structure passes through historic walls and floors as a means of explaining that the structural elements are not historic. The structure emulates the intention to maintain this level in its current historic state. As mentioned above zone two or the central zone is uninterrupted by these columns as it is braced externally, enabling the façade intervention to penetrate the original restaurant space on the west façade, thereby providing a secondary entrance to the historic space that enables disabled persons to enter and appreciate the beautiful qualities of the heritage hotel.

Levels one and two portray the beautiful elements of weathering that originally stimulated this author's interest in layering and the preservation of layering as a means of evidencing history. The half eroded nature of these two levels did not come from water damage but from a process of renovation that was terminated before completion; levels evidence layers of peeling paint from the brothel on top of wall paper on top of the lath and plaster of the original hotel and the aging brick of the exterior walls. This thesis proposes that these spaces be treated in a similar fashion to the Warehouse 17C and Scarpa's Castelvecchio where the layers of weathering and decay or partial demolition are exposed as beautiful aspects of the heritage site. Robust examples of decay can be evidenced through focus and framing as in the Castelvecchio; more fragile examples can be evidenced behind glass in the Warehouse 17C. Through the implementation of a rhythmic ordering system derived from the structural intervention and techniques observed in 'Layer Two', levels one and two have the potential to organize such programmatic functions as the meeting rooms and office spaces for the NZHPT.
The current progression of weathering increases as the visitor ascends through the hotel's levels. Level three, an addition to the original hotel design, with extensive water damage and no notable heritage characteristics, is identified as a classification C3 space that facilitates the transformation into a contemporary space. This thesis proposes that the east and west walls and roof structure be retained whist the south and north external walls and internal space provide the opportunity for a future architect to develop the space to represent today's architectural layer in the on-going layering of time-related stratification within the hotel. Additionally level three has access to the roof terrace and copper cupola as a space that can be integrated into the rooftop extension.

Through this proposed progression ascending the historic Albemarle hotel, the occupant can experience all three categories of heritage spaces from maintained on the ground floor, to the retention of the transforming layered conditions and the integration of historic and new on levels one and two, and finally the occupant discovers level three as a contemporary space capable of representing today's contemporary architectural expression.

Structural RhYTHM

Seismic Design for Architects suggests that the best possible seismic resisting structure is homogeneous both in the vertical structure and in the mass of the building. Torsion occurs when the centre of resistance ( $\mathrm{CoR})$ is not aligned with the centre of mass (CoM). "When a building twists, the columns furthest away from the CoR suffer serious damage due to excessive torsion-induced horizontal deflections" (Charleson 2008) (See Fig. 90 \& 92). This principle of torsion requires that lateral bracing elements to establish a rhythmic ordering system, placing structural elements at regular intervals throughout the space to resist lateral load effectively. The asymmetrical nature of the Albemarle led to the division of the footprint into three zones each braced individually to provide seismic resistance effectively to each zone and to combat the effect of torsion on the structure. 
This thesis argues that the rhythmic ordering system of moment frames required to laterally brace the Albemarle Hotel provides an opportunity for interior open plan spatial arrangements. It proposes that the programmatic occupancy needs of the NZHPT can be implied by the rhythmic ordering system of the new structure without adding additional new walls. The structural system is divided into three zones, and within those zones bay lines introduce contemporary cruciform beam and tri-flange column junctions enabling spatial divisions to be experienced, and inviting program locations to be established within the bays or across multiple bays. The small $1.8-2 \mathrm{~m}$ structural bays were designed intentionally to allow the size of the structural members to be reduced, resulting in smaller more frequent structural elements that enable a rhythmic ordering system to be developed within the internal space. The rhythmic system facilitates an open plan spatial arrangement system; for example zone one may be used as a meeting room or boardroom space, where gridlines 02 and 03 define the space for the large table. The space defined by gridlines 01 and 02 , and 03 and 04 might define the seating space; such that office workers are aligned with the rhythmic nature of the contemporary structural elements, where the space between gridlines 02 and 03 might hold the meeting table. The rhythmic nature of the contemporary structure is different to the rhythmic nature of the historic beams. The two overlapping rhythmic ordering systems provide more flexibility when considering programmatic planning; functions can either align with the historic or contemporary rhythmic ordering systems. The ability to integrate these two systems not only allows the multiple layering of the tale to be told, but it also allows for far greater flexibility ultimately for the positioning of partitions or spatial divisions; and more importantly it intimates perceived spatial divisions without any walls or partitions.

Figure 107 is a programmatic suggestion of how the rhythmic nature of the contemporary structural intervention might translate Charleson's suggestion of structure as a space-defining tool into pragmatic functional space for the NZHPT regional offices. Figure 107 shows the space defined by gridlines 08 and 09 in the centre zone as potential office space divided by a series of transparent partitions.

Within this space the office workers can witness the layering of both the historic weathering materials and the contemporary structural and space defining elements; the contemporary structural elements act as a spatial divider, facilitating the opportunity for partitions of varying translucency such as those employed by Mary Miss or seen in Warehouse 17C. This image is intended as a suggestive implication of how the internal configuration of the Albemarle might be developed in the future beyond the exploration of this thesis.

The intention of the design research experiment is to facilitate new contemporary programmatic or occupational engagements within the Albemarle that would allow it to progressively transform with new programs and be a viable investment in the 21st century. The design experiment advances the debate for the on-going evidencing of weathering in New Zealand's historic sites. The exposed nature of the new structural system employs a rhythmic lateral bracing system to enable new use and suggests spatial divisions; whilst simultaneously providing a seismic intervention that protects the historic hotel from demolition. This thesis proposes planning experiments such as in figure 107 and 108 that suggest methods of how the structural intervention can enable future architects to configure the space for future users such as the NZHPT offices, drawing on the rhythmic system of structural elements as spatial defining elements.

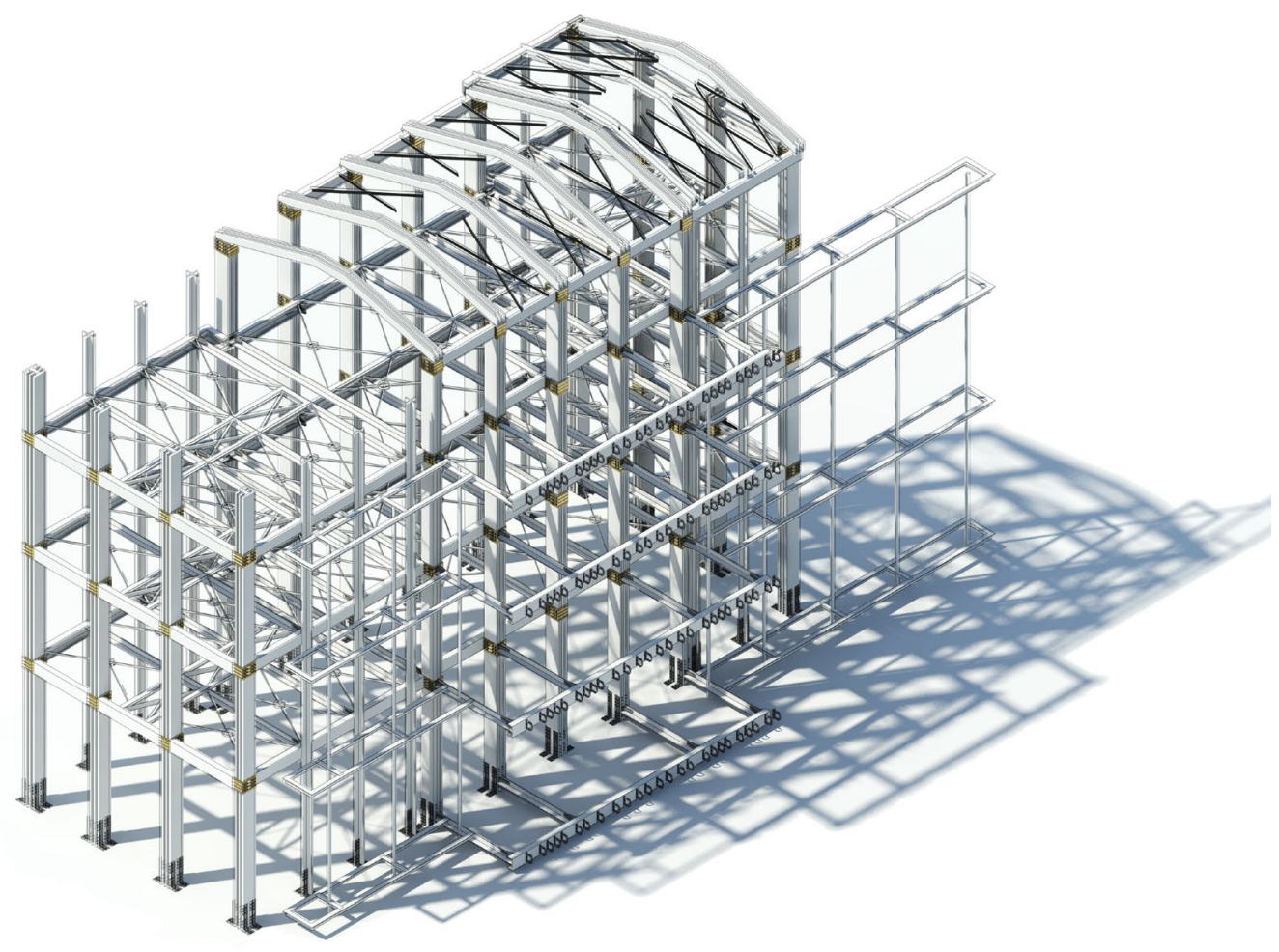

Fig. iog Structural intervention as a rhythmic ordering device 
Contemporary facade intervention

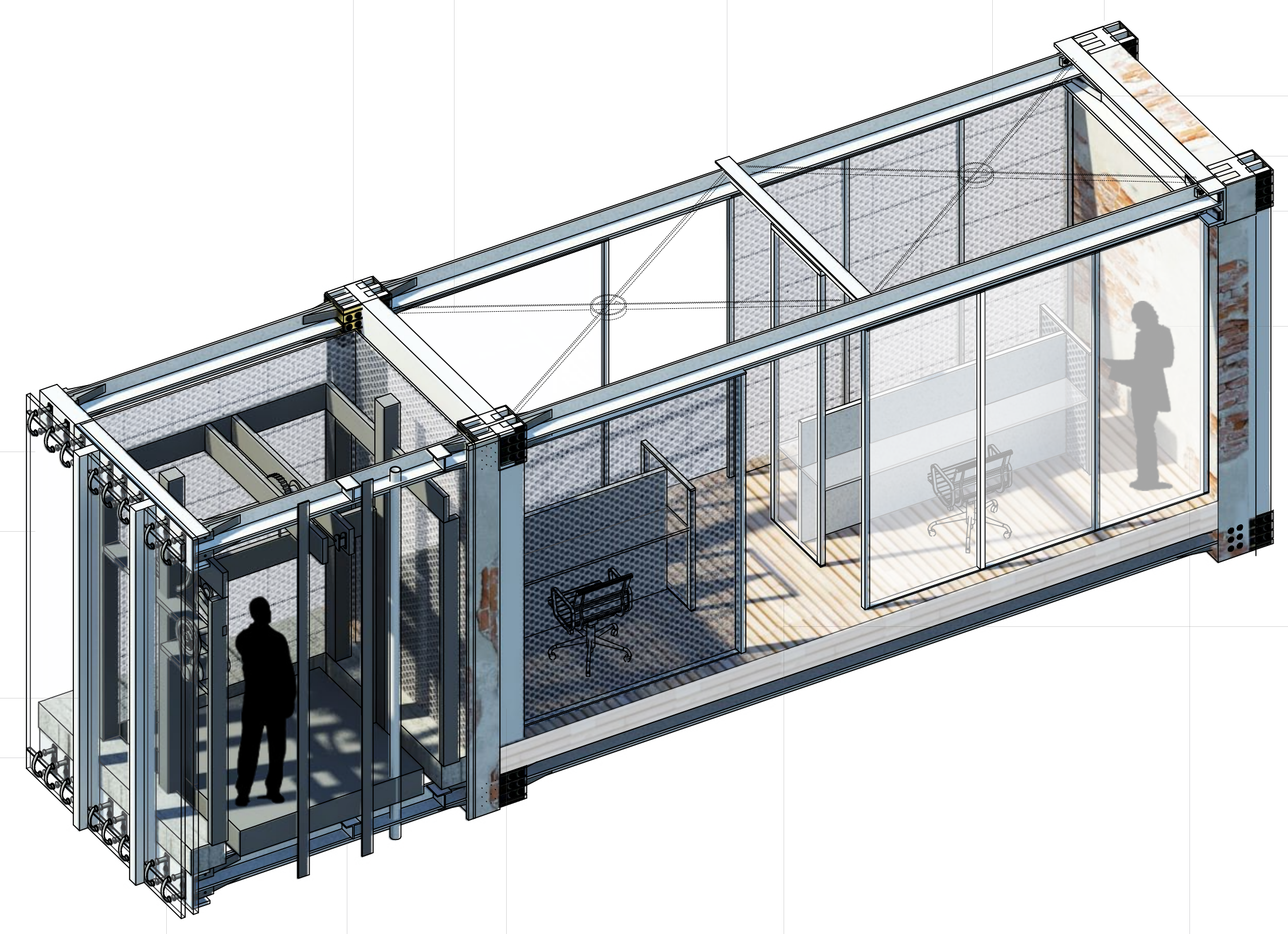

Custom brass tri-flange collar

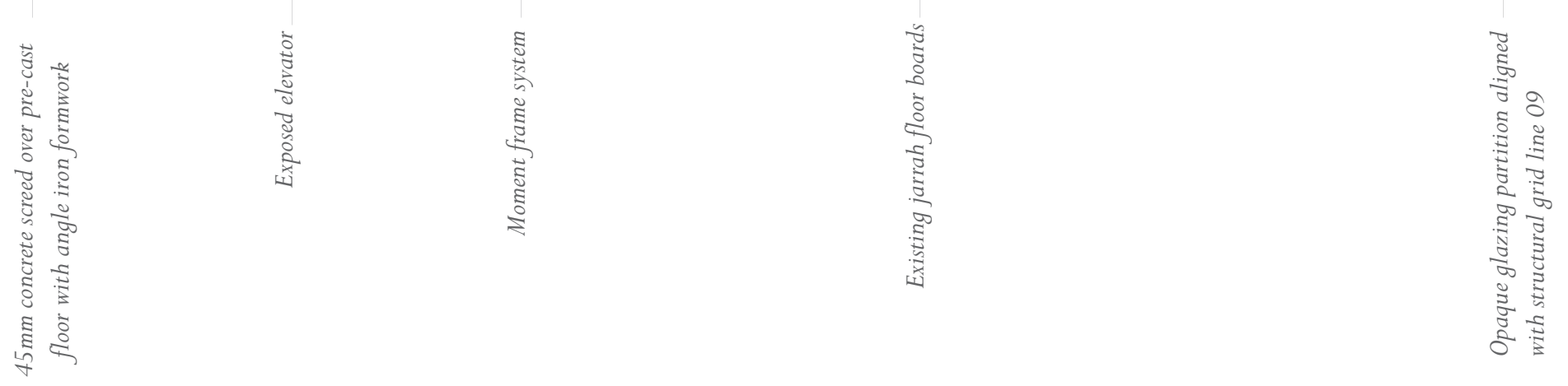




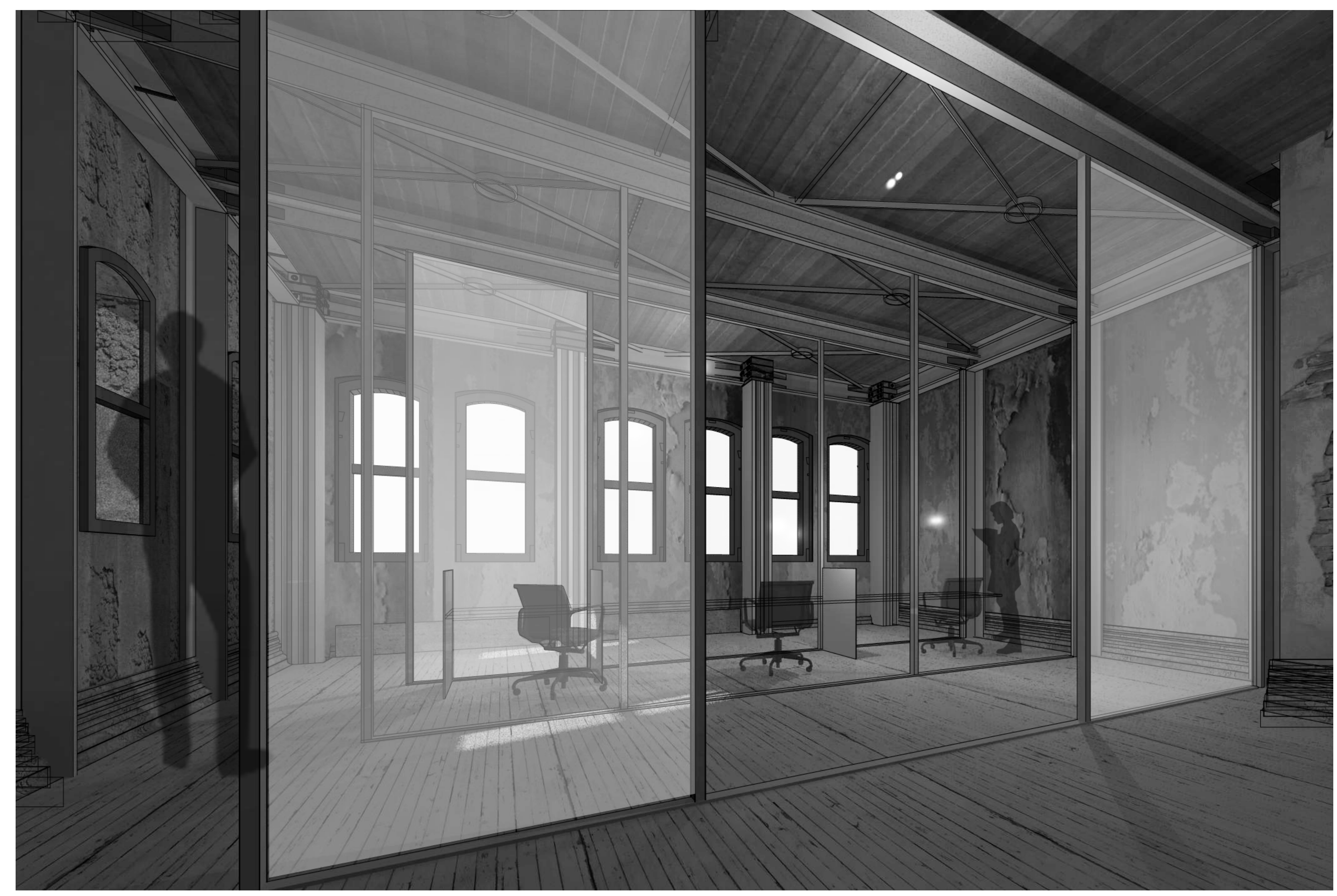


Fig. io9 Facade elevations NTS
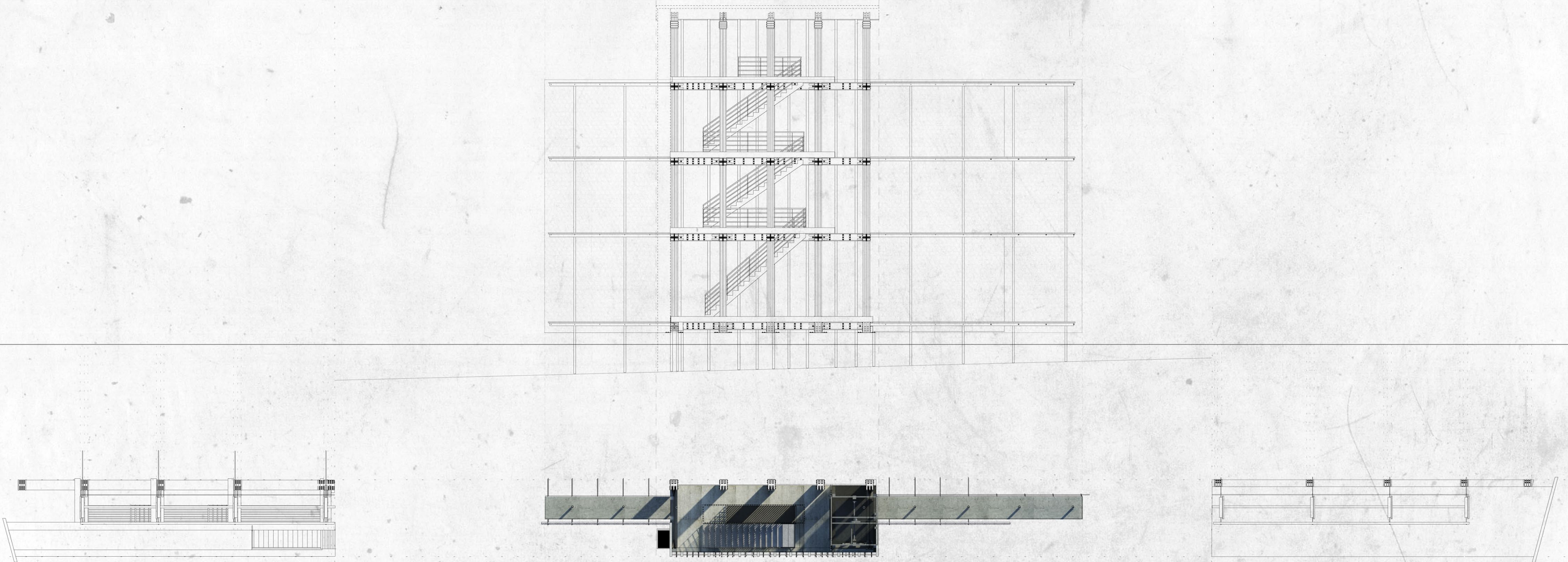

F.

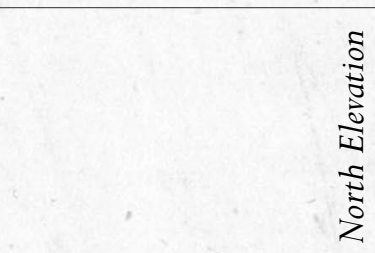

West Elevation
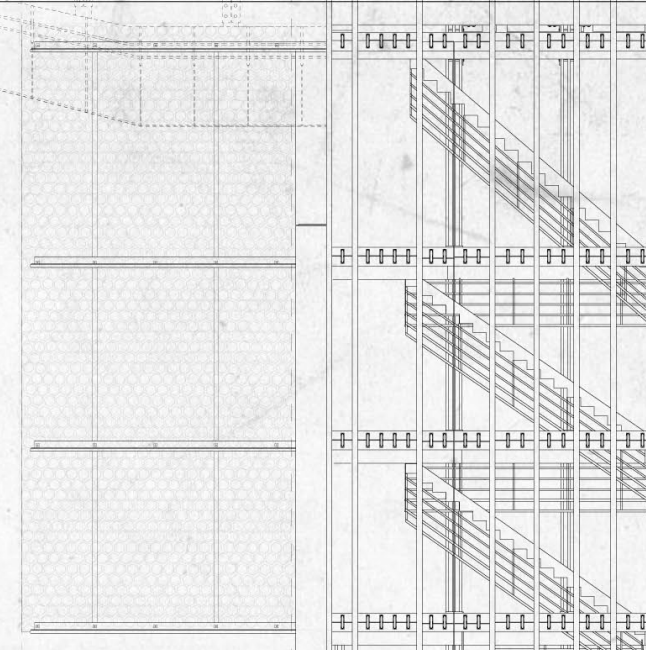

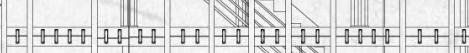

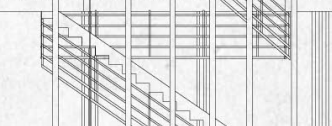

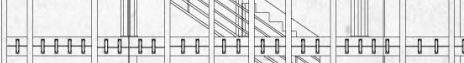

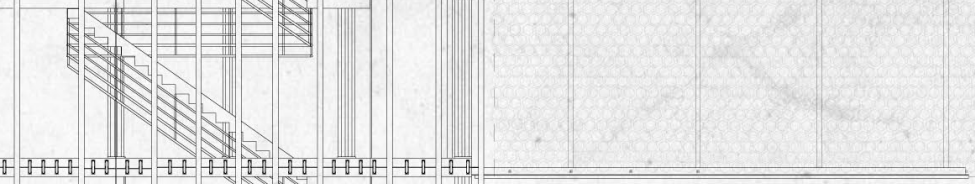

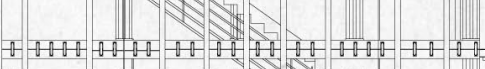

| 


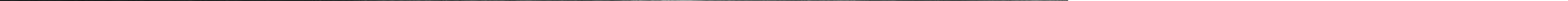


"At LAST, AFTER DAYS OF LABOUR WITHIN, OF CUTTING AND DIGGING WITHOUT,

DUSTERS WERE FLICKED FROM THE

WINDOWS, THE WINDOWS WERE SHUT TO,

KEYS WERE TURNED ALL OVER THE HOUSE;

THE FRONT DOOR WAS BANGED; IT WAS

\section{FINISHED.}

Tn order to prevent the elective demolition of New Zealand's vulnerable 1 heritage sites, this thesis challenges the current approach of completely 'restoring' 19th-20th century historic buildings. This thesis argues that the combined costs of concealed lateral bracing and complete restoration initiatives are often untenable, particularly as these high costs are often used as rationales by developers to argue for the demolition of historic buildings, such as the issues currently facing the Harcourts building. This thesis proposes techniques that structurally reinforce historic buildings while inviting the weathering of a historic building to remain as a testament to its history. As a result of the increased earthquake awareness, 266 of Wellington's heritage buildings are now faced with the ultimatum to introduce lateral bracing to prevent earthquake damage, or face elective demolition. It has become apparent that many owners of heritage sites cannot afford to undertake a significant seismic strengthening project; and as a result New Zealand's heritage may be lost to the forced hand of demolition for fear of potential earthquake damage rather than from the natural disaster itself. This thesis has examined issues now facing New Zealand's heritage buildings, and explores more cost effective responses to lateral bracing and historic restoration including lateral bracing that can be inserted into heritage buildings in ways that reduce the cost of earthquake bracing and ultimately help prevent the demolition of New Zealand's heritage buildings.

\section{Peeling Back}

The complex set of issues facing New Zealand's heritage buildings and the unique nature of each historic site suggest that the degrees of constraints and limitations of this thesis are highly site-specific; this thesis argues that the appropriate response to a heritage site should be based on the weathering conditions and the history that has occurred within each site. This thesis proposes a classification system to clarify the appropriate response to the varying conditions of different zones within New Zealand's heritage buildings, thereby allowing architects to suggest diverse approaches specific to the conditions of the building and the requirements of its new program. 
In the case of the historic Albemarle Hotel several contextual limitations were presented as drivers to address the principal research questions. One limitation investigated was the exposed west façade, which raised the issue of defining a missing elongated side façade for the typical 'row house' building that never required a 'designed' side façade prior to the change in urban fabric. The insertion of such a façade in the traditional sense might be interpreted as damaging the nature of the historic 'row house', yet this façade was never meant to be seen. This unique condition led to the façade exploration inspired by Mary Miss's architectural installations. The façade intervention tackles similar theoretical imperatives as those explored by Mary Miss such as her application of contemporary architectural elements to implicate historical meaning that may be void of nostalgic connotations. The new façade identifies the issue that the original design of the Albemarle never required a aesthetic west façade, whilst simultaneously suggesting that the new façade can be inhabited. Unlike Mary Miss's explorations, the new contemporary façade is further engaged to invite missing service and circulation elements to find a meaningful place within the new intervention in ways that are not contradicting the historic nature of the Albemarle. The design exploration process developed a semi-translucent façade constructed from a series of veils of varying materials and opacities; this thesis proposes that all new contemporary requirements inhabit this new contemporary set of layers. They imply habitable space but also enable the façade to provide a secondary disabled access entrance to the historic hotel as a means of passing through these veils or layers. The new façade allows the visitor to enter the building parallel to the west façade in the same way as the visitor would enter through the original front door or pass down the original right of way. In this way the new façade becomes the neighbouring habitable space that is visually detached from the heritage building, incorporating additional vertical circulation that enables the internal space of the historic hotel to be engaged with a new function such as offices for the NZHPT.

Another limitation arose from the unique nature of the Albemarle's footprint; the indent on the east façade and the right of way along the west façade resulted in an asymmetrical building footprint. The asymmetrical nature of the footprint formed a tripartite configuration that enables the contemporary lateral bracing columns to be placed on the exterior of the building in the central zone, where they support the insertion of the new entrance point and vertical circulation.
The third limitation involved the varying degrees of weathering on each level of the Albemarle which enabled this thesis to explore all three proposed classifications of 'renovation' (from maintenance, to layered evidencing of old and new, to the addition of new contemporary interventions) within a single building. These conditions enabled this thesis to address the fact that most historic buildings are going to have a unique multiplicity of constraints; this thesis addressed this issue by applying approaches that invites adaptability of applications where the conditions within the heritage building also vary. As a result, the Albemarle Hotel takes different approaches on the east and the west façade, horizontally within the tripartite zones, and vertically through the three and a half levels.

The design research exploration considered several case studies with reference to how each issue facing the Albemarle might be addressed, and then proposed a new holistic approach to engaging New Zealand's historic buildings, using a combination of approaches observed in each case study. Each case study was successful on important levels, but none of the case studies addressed all of the issues currently facing Wellington's historic buildings. For example Warehouse $17 \mathrm{C}$ presented decay as a positive aesthetic; however it never engaged the necessity for seismic strengthening elements, but looked to present and protect the fragile areas of decay within the warehouse. The research also applied techniques explored in Scarpa's Casterlvecchio, which presented more robust forms of weathering that did not need protecting but demanded celebration; Scarpa achieved this by disengaging the old and the new within the historic castle. The research then applied techniques observed in the Mint complex to explore how the structure might slice through the existing historic elements; the combination of the two case studies suggests a new approach that both celebrates weathering and enables seismic reinforcing to identify itself within the historic building.

This thesis argues that a cost effective and appropriate architectural response to New Zealand's vulnerable heritage buildings lies in the development of an exposed lateral bracing method that not only answers the legislative requirements for earthquake resistance but simultaneously exposes itself as a contemporary layer of the on-going architectural sedimentation process, invites the beautiful nature of the weathering process within heritage structures to be retained, and develops a rhythmic structural ordering system that can assist in defining open plan spatial divisions for programmatic function such as those required by the NZHPT offices. 
The design experiments demonstrate the argument for a site-specific adaptable approach to New Zealand's heritage buildings, not just a generic model approach; it tests theories of layering and sedimentation as approaches that are able to address the complex set of conditions evident within New Zealand's built heritage. This thesis is intended as an exploration of how vulnerable heritage buildings evidencing varying degrees, types and locations of weathering can be approached. By understanding the nature of these varying conditions, the design research experiment can be applied to other sites; for example, several heritage buildings in Christchurch, including the Christchurch Cathedral, are now missing parts of their original fabric due to earthquake damage and also require lateral bracing techniques in order to be re-inhabited. In such situations the design might explore how a new exposed seismic structural intervention can provide seismic resistance whilst simultaneously defining zones of programmable and habitable space to resolve the missing elements of the heritage building, employing a contemporary layer, derived from the structural intervention to allow the heritage building to become a cost-effective investment and prevent demolition, whilst also telling the story of the missing, damaged, or weathered elements of the historic building.

This thesis explores the very real problems facing New Zealand's 19-20th century buildings that inhabit the 21 st century; it is evident through on-going newspaper publications that building owners in Wellington are confronted by the issues discussed in this thesis. This thesis was explored in order to tackle some of the moral and economic issues faced by heritage building owners; as a contemporary designer this author finds it imperative to work towards creating an identity for today's architectural expression, whilst simultaneously arguing for the protection of New Zealand's architectural forefathers.
In Detail: Looking Berond the Thesis to the Next Steps

To further the exploration of contemporary new approaches to exposed moment frame lateral bracing systems, this thesis also explored alternative designs of moment frames using profile details more sympathetic to the concepts of layering and aspects of historic ornamentation. While these new 'layered' profiles would be too expensive for the current economic climate as custom-fabricated elements, it is argued that if they became mass-produced, they might constitute a viable replacement for the traditional, less sympathetic lateral bracing system. Scarpa's work that deals with similar problems experimented with the relationship of the new and the old at a multiplicity of levels including the joint, the detail and the purpose design of structural profiles that engage with existing structures.

"Scarpa evolved his joints not only as functional connections but also as fetishized celebrations of craft as an end in itself. This sense of 'nearness' to evoke Heidegger's term, was not only expressed through Scarpa's elaboration of the joint but also through patina and colour of delicate surface finishes, demanding highly specialized techniques" (Frampton 331)

These 'alternative column/beam profile' design experiments made a conscious decision not to use standard steel profiles but to explore methods of achieving the same seismic requirements through steel profiles that are elegant, subtle, and sensitive to the historic environment. The resulting steel elements would sit on, beside, under, above, or slice through the walls and floors of the weathering hotel in ways that celebrate the peeling paint and exposed patina, whilst simultaneously validating the structural elements as another layer of history in the on-going evidencing of history within the hotel. 
Standard steel universal columns (UC) in the moment frame were substituted in a design experiment wherein the profile of the steel column is manipulated to resonate with the expression of layering and stratification. The resulting column is comprised of three vertical prongs with a central web to stiffen the column; this move was made so that the column was less obtrusive, appearing as multiple thin layers in two directions rather than a major obstruction in all four directions. Instead of a solid web or flange visitors see three slender vertical elements with a shadow falling between each impact of the columns' presence in the historic hotel. The white powder-coated steel elements identify themselves as contemporary against the weathering hotel (See Fig. 111)

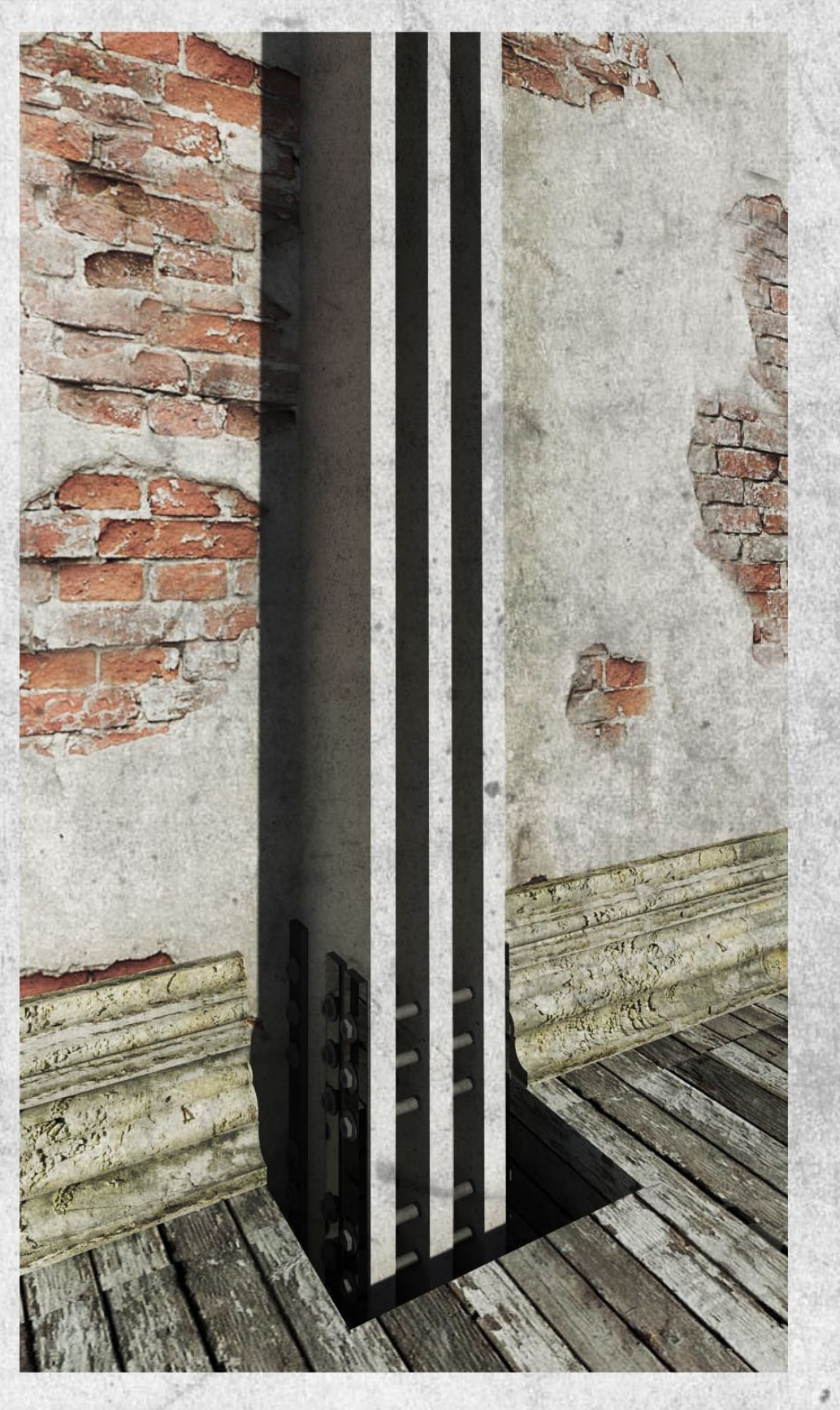

FiG. II Tri-flange Column (See detall sheft IO3)
The three zones of the tripartite hotel footprint could be braced uniquely with the tri-flange columns appearing along the north and south façade and in the central zone to provide the bulk of the seismic resistance, allowing zones one and three to be braced by smaller cruciform columns.

The combination of the triflange and cruciform columns form a two-way moment

frame system within the hotel. Following methods observed in The Mint case study, the beams that provide a floor diaphragm for the moment frame system pass through the existing historic walls where necessary to allow for optimum connection strength.

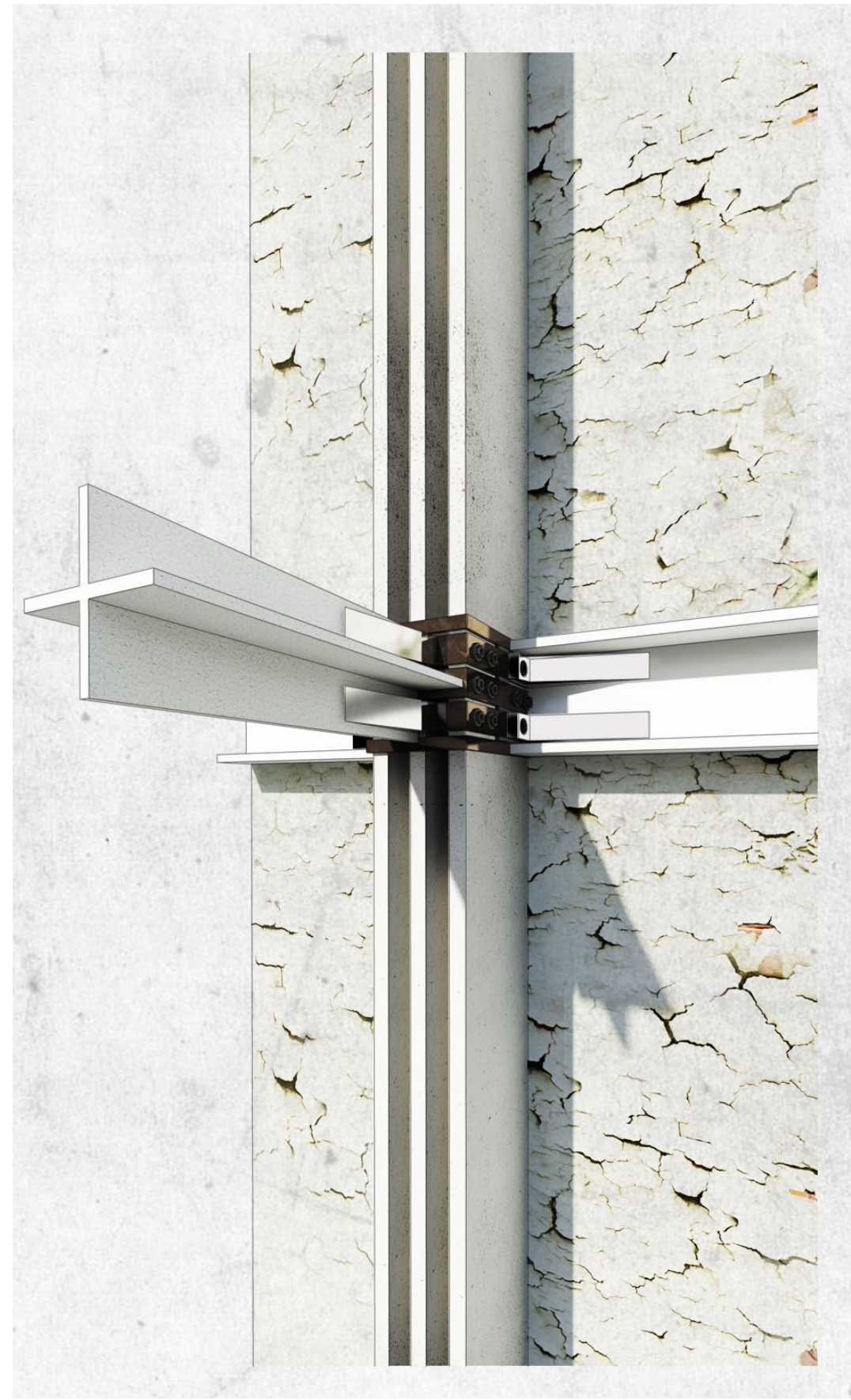


On the Ground Floor these columns penetrate through the existing timber floor and continue down to the foundations to disperse the lateral load; on Levels 1,2 and 3 the timber floor is disengaged from the column, enabling the negative space between the column and the floor to involve the occupant in the appreciation of both the old and the new elements. These exposed columns are the only proposed change to the ground floor as it aligns with the first category of restored heritage space; this thesis proposes that the ground floor continue to be maintained with the exception of the required lateral bracing.

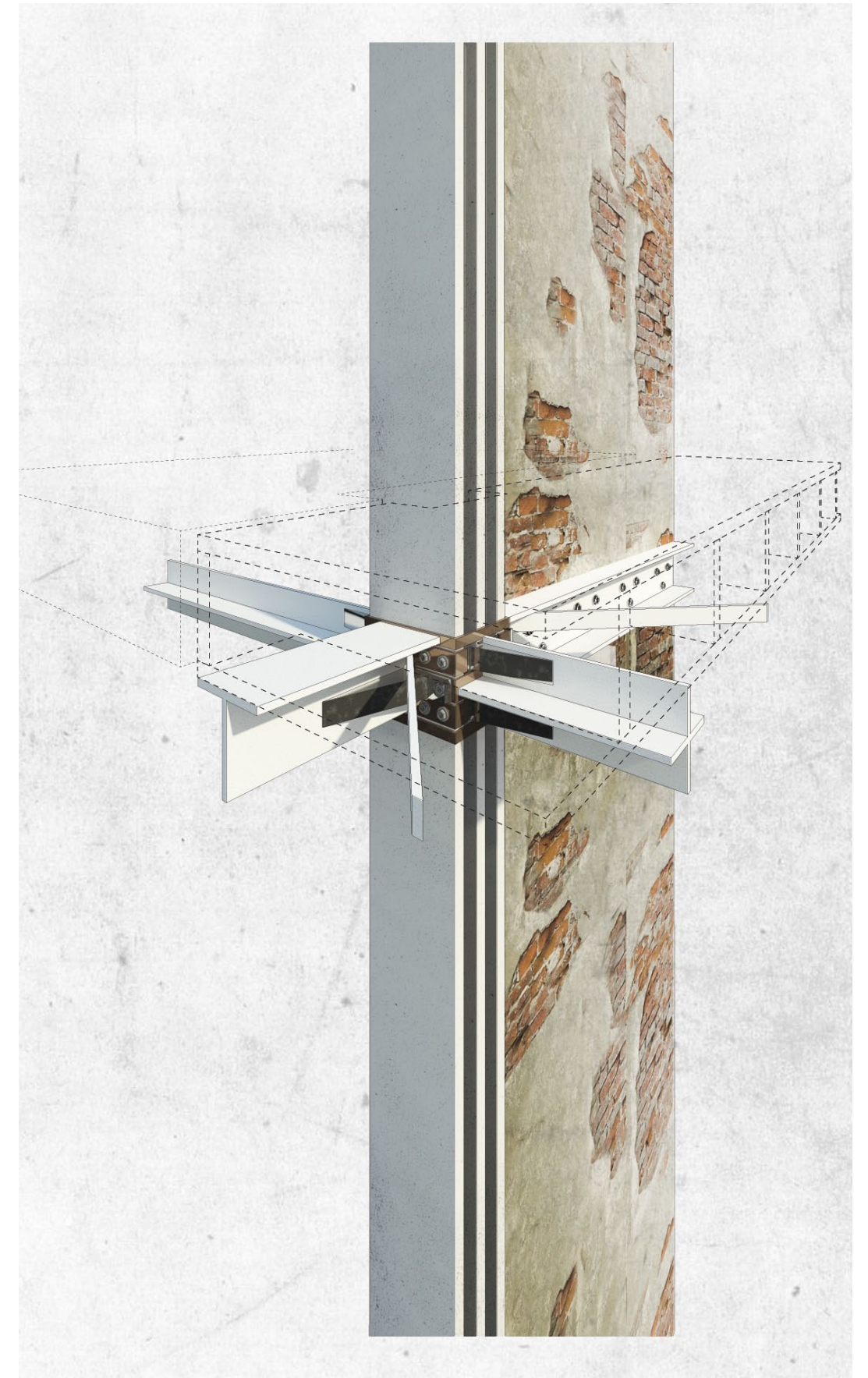

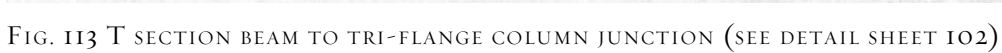

Figure 112, 113 and 114 show the above-mentioned custom design profile of a moment frame, where cruciform beams and a system of cross braces are employed to create floor diaphragms that transfer the lateral load to the columns and down to the foundation. The exposed cruciform beams are also employed to reduce the impact of the structural intervention rather than the obtrusive and bulky nature of concealed beams.

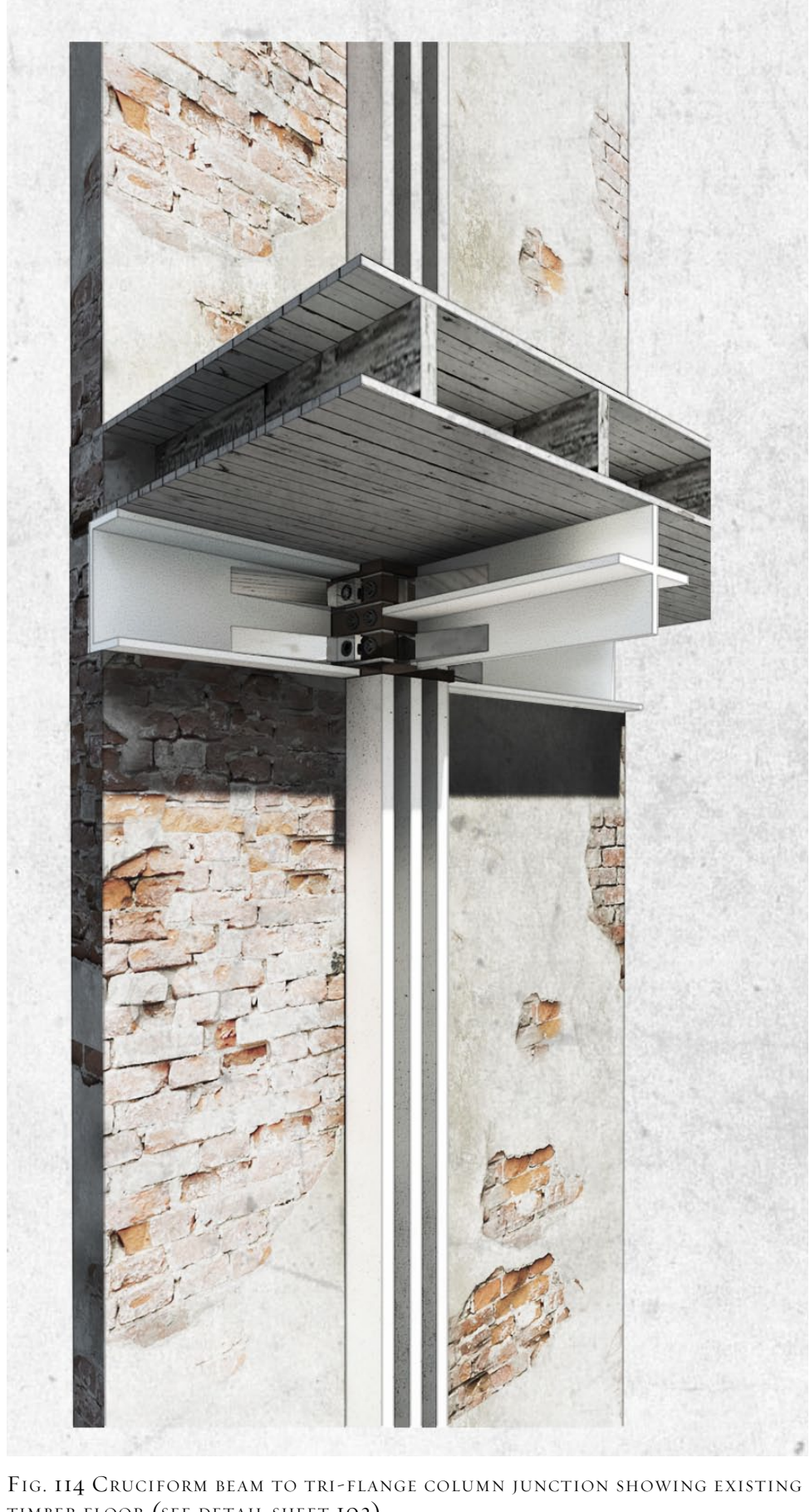

FiG. II4 CRUCIForm BeAm TO TRI-FLA
Timber FLoor (SEe DETAIL SHeET IO2) 
This thesis recognises that the use of purpose designed structural members may be considered as less cost-effective; however as noted previously this thesis argues for a rethinking of traditional approaches to seismic resistance, one that engages with the decaying historic site, sanctifying both the contemporary elements and the decaying structure as positive aesthetics and simultaneously as space defining tools. For this reason this thesis implemented the appearance of the custom structural menbers and employed a standard application (moment frame system) to reduce the cost of this experimentation. This thesis proposes, however, that the explored custom steel sections might eventually become mass-produced in response to historic buildings thereby making the more elegant and subtle steel profiles more cost effective.

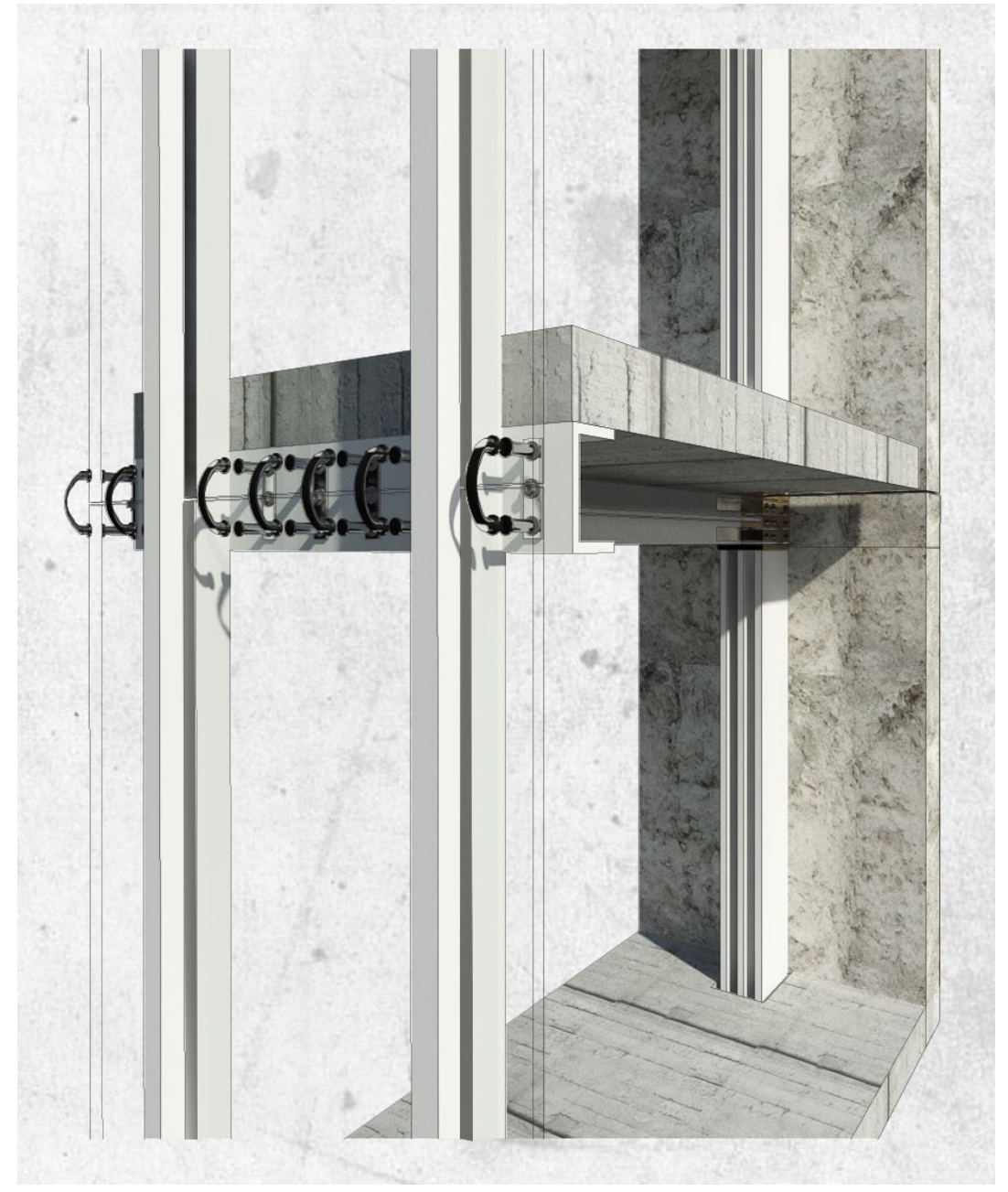

To further advance the feasibility of the design research experiment, this thesis understands that explorations are needed into the insertion or upgrading of the existing heritage foundations. Heritage buildings of different eras require varying approaches to implementing seismic resisting foundations. This thesis chose not to explore this avenue, as its primary focus was solutions involving structural exposure above the ground; however it recognises that to completely reinforce the design research vehicle, new foundations will be required in most cases. There is also an opportunity for further design exploration of the planning experiments discussed in the 'Layer Five: An exploration of contemporary layers' in order to clarify how each space might be occupied by the NZHPT regional office in different configurations.

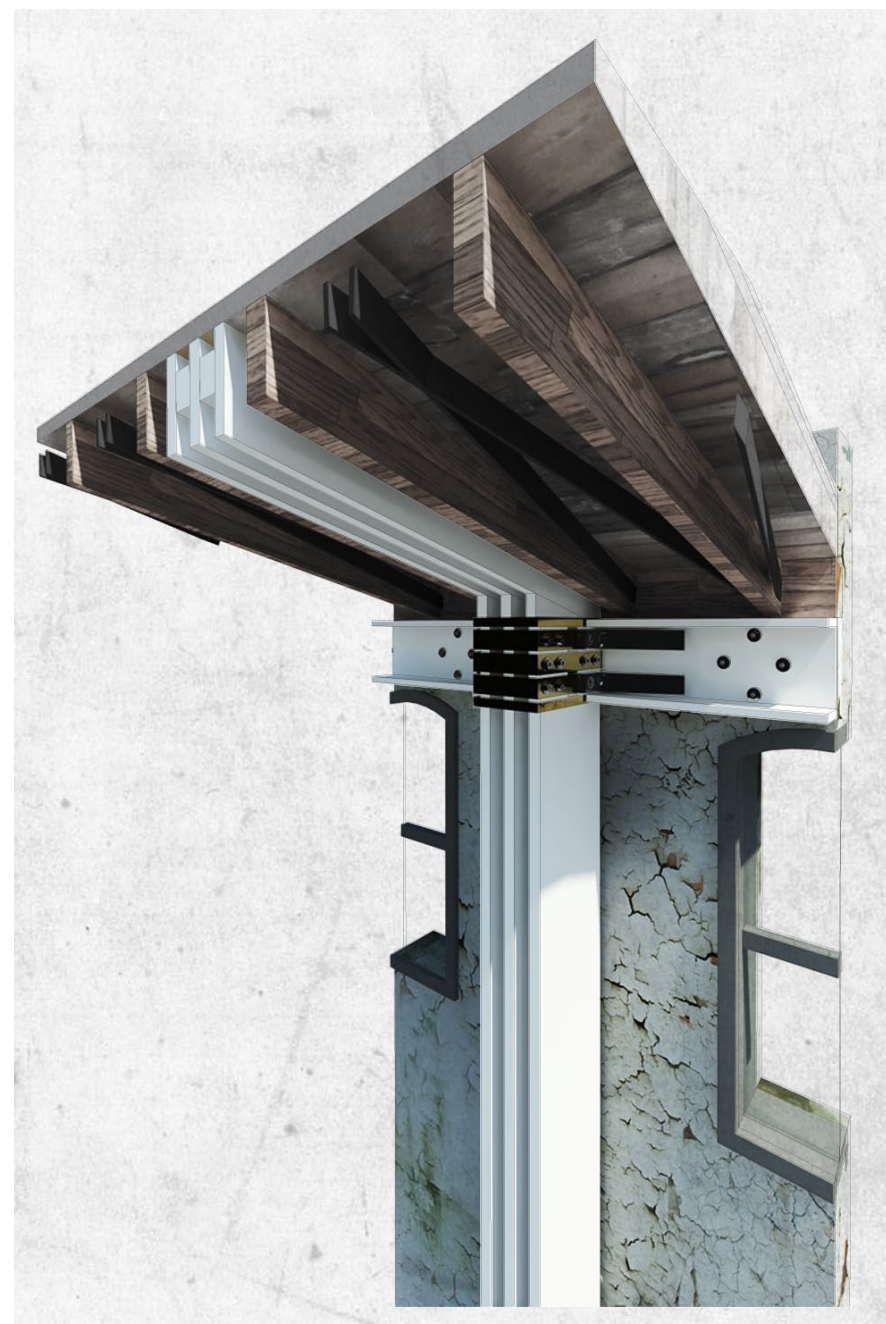

Fig. II6 Existing TIMper RoOF and TPH(SeE Detall SheEt IOI) 
New Zealand's Construction Minister Maurice Williamson has estimated that the cost of raising the building code standard to $67 \%$ world be more than $\$ 12$ billion over the next five years. He is argues that:

"We must ensure the earthquake-prone buildings system strikes an acceptable balance between protecting people from serious harm and managing the huge economic costs of strengthening or removing the most vulnerable buildings" (Rutherford et al.)

It is the hope of this author that following more research in the context of laterally bracing earthquake prone buildings, a new cost-effective approach to New Zealand's heritage buildings will be adopted, that reveals the layered representation of New Zealand's on-going history within our weathering heritage sites- including its contemporary history. The potential for earthquakes is an integral part of New Zealand's history, and one that should be represented in both our contemporary and heritage architectural identity; the cost-effective expression of seismic elements within our heritage buildings ensures the survival of our built heritage for the next generation.

$\frac{\text { Fig. il8 (Pg. I5O-I5i) Detail Sheet ioi Roof details }}{\text { Fig. il9 (PG. I52-I53) Detail Sheet io2 column details oi }}$



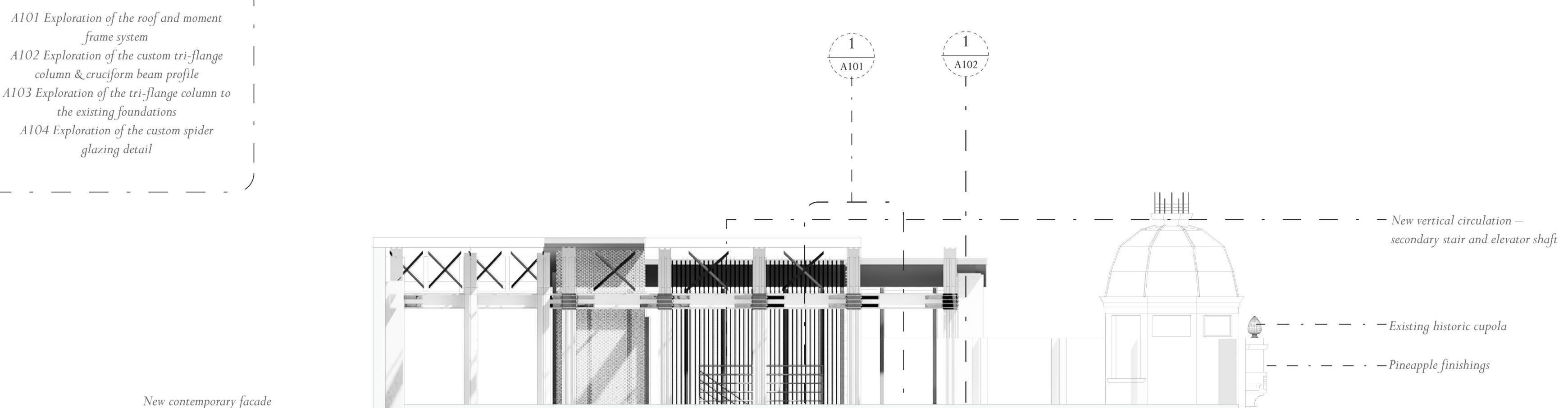

scondary stair and elevator shaft

New contemporary facad
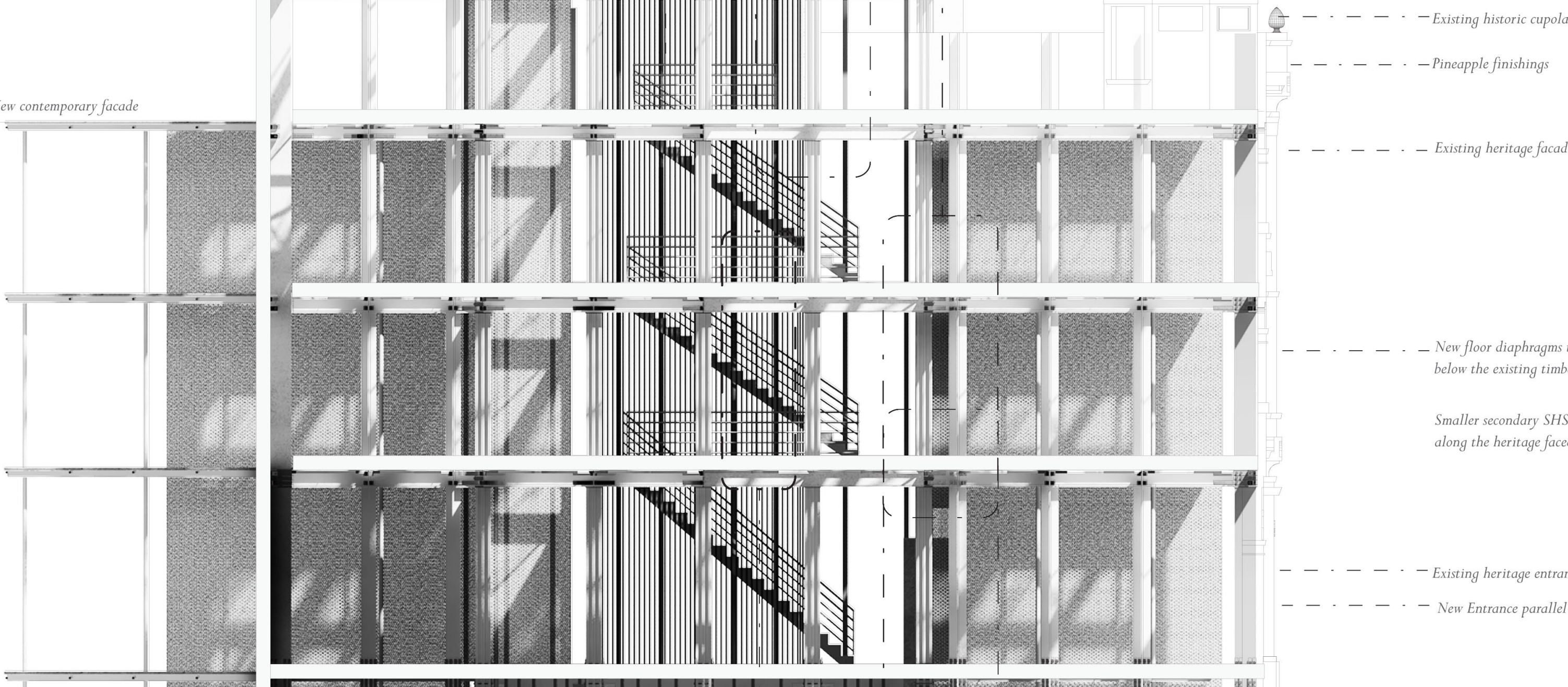
below the existing timber floos

Smaller secondary SHS columı long the heritage faced for additional stiffnes
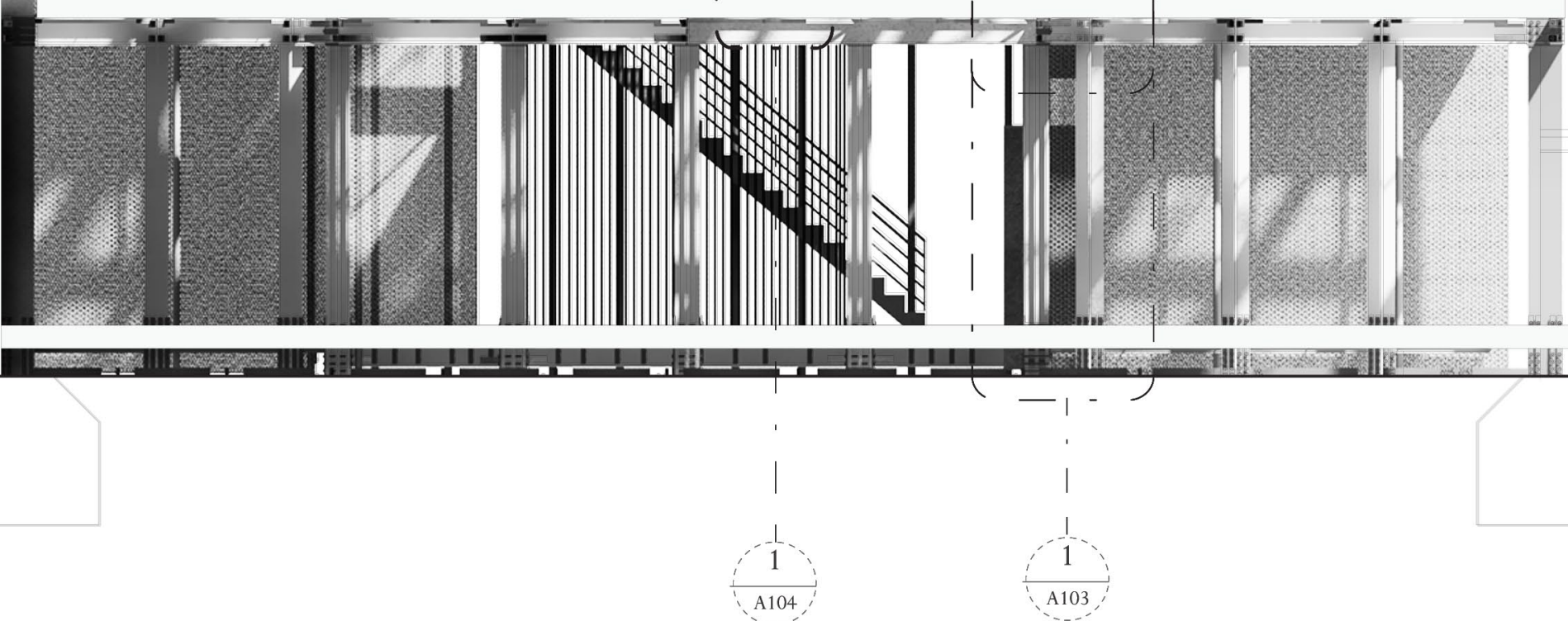

Detail Section A-A Scale 1:100@A3 
Detail 2
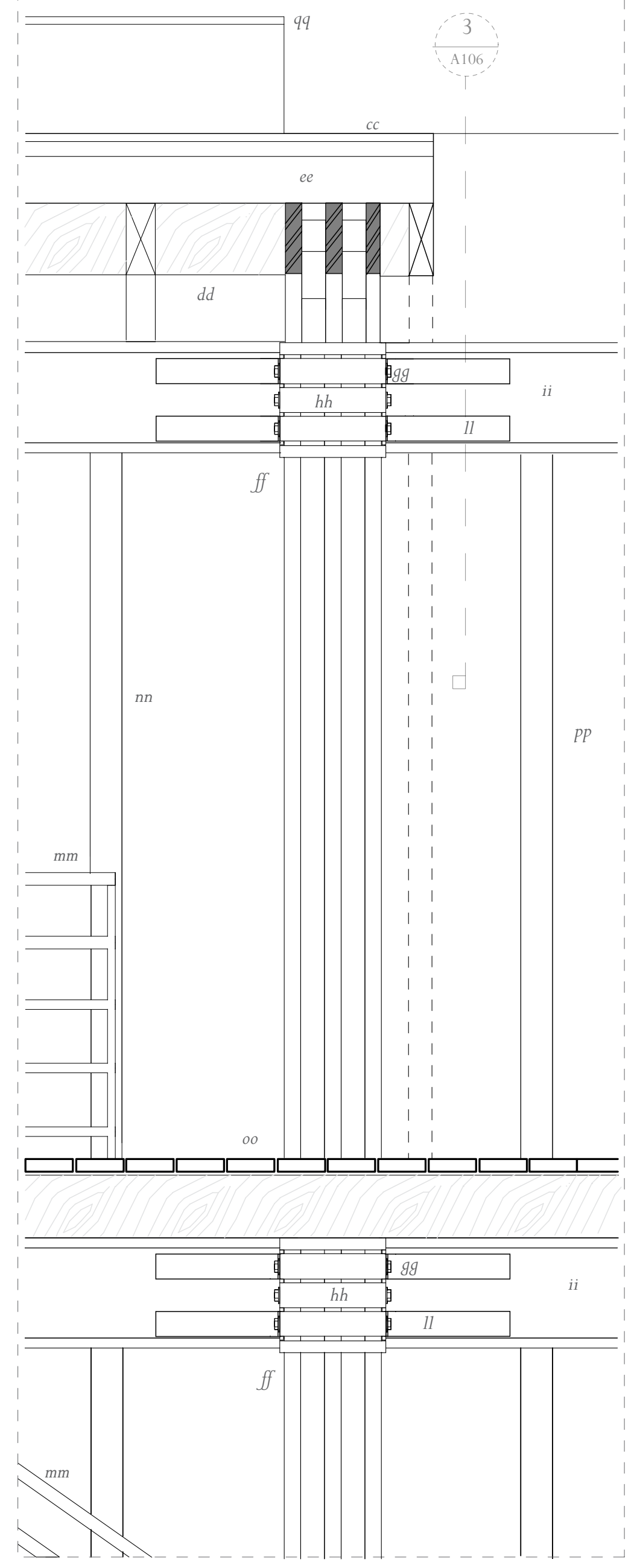

aa Brick cladding on $20 \mathrm{~mm}$ cavity batten on building wrap on new timber framing

Metal flashing to copper guttering and down pipe

Corrugated iron roofing on building wrap o

plywood substrate

Exposed existing timber roof truss

Tri-flange steel roof joist welded to column via

internal web

Tri-flange colum

gg M20 hardware

Brass tri-flange collar

PFC 300x90

Opportunity for a new wall and contemporary space on the third floor

Machine grade steel clips to PFC 300x90

mm $900 \mathrm{~mm}$ polished aluminium pipe handrail

n $50 \times 100$ Vertical aluminium mullion

oo Existing Jarrah bearer joist and floor boards

PP Façade intervention

Faça intervention
대 तn ${ }^{h h}$
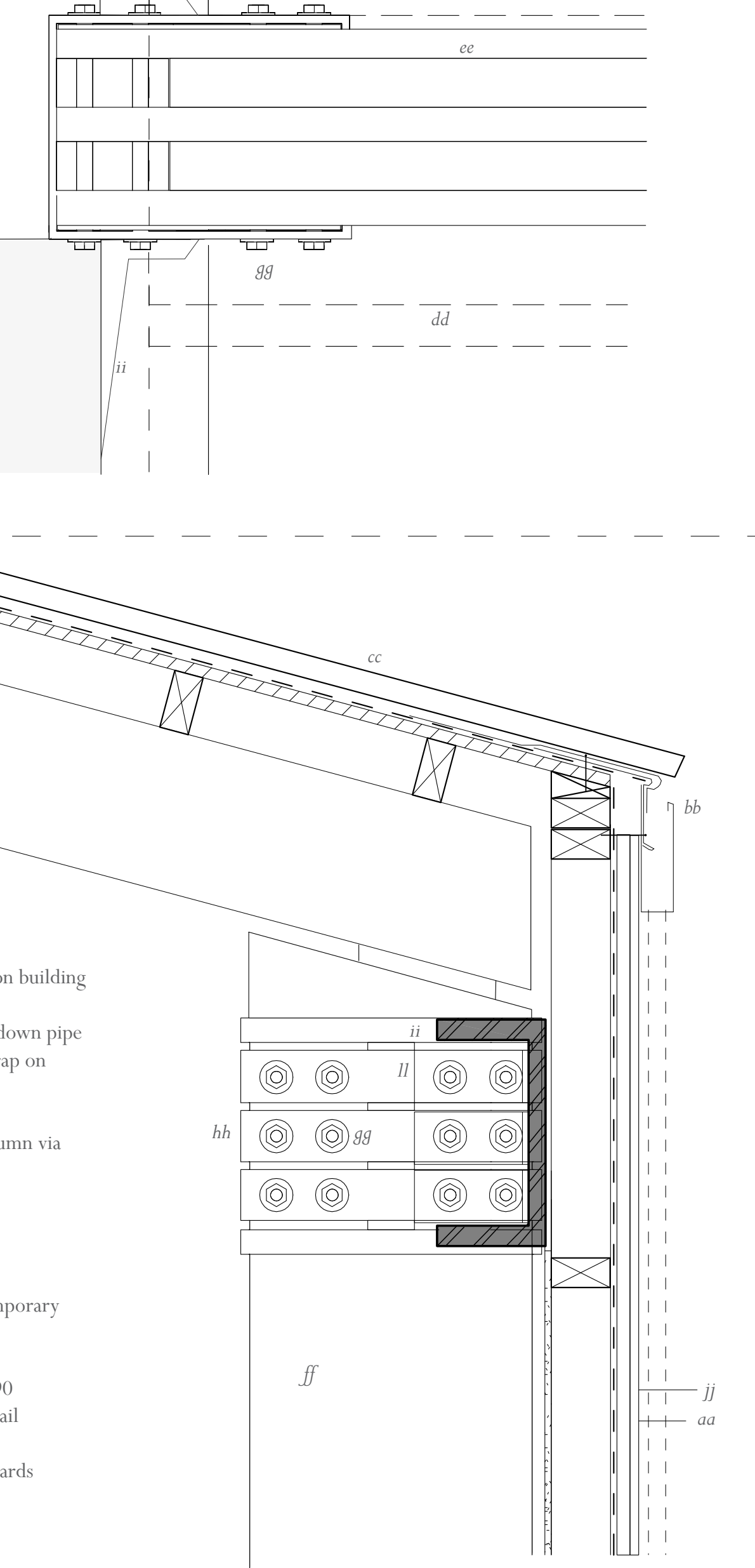

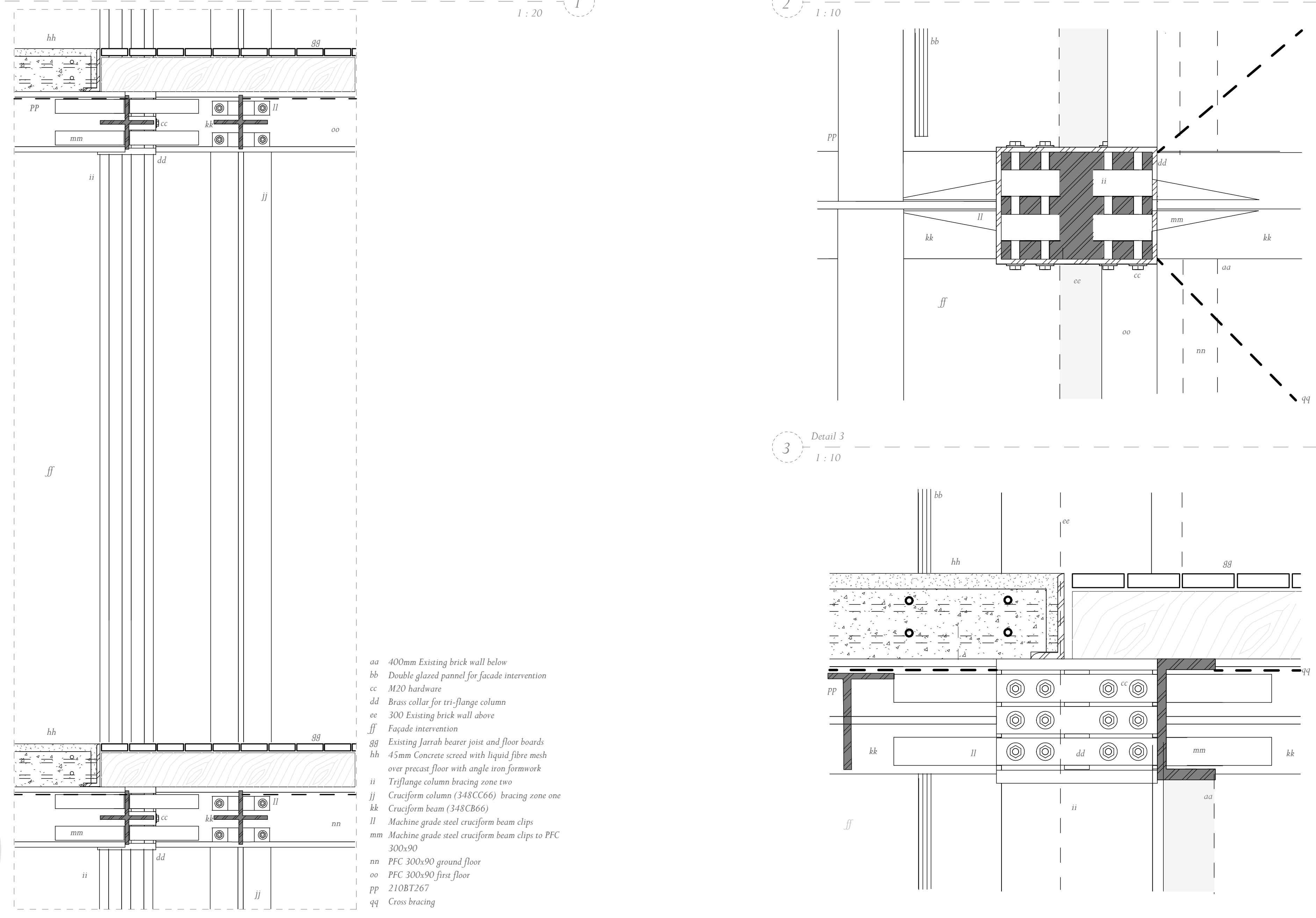

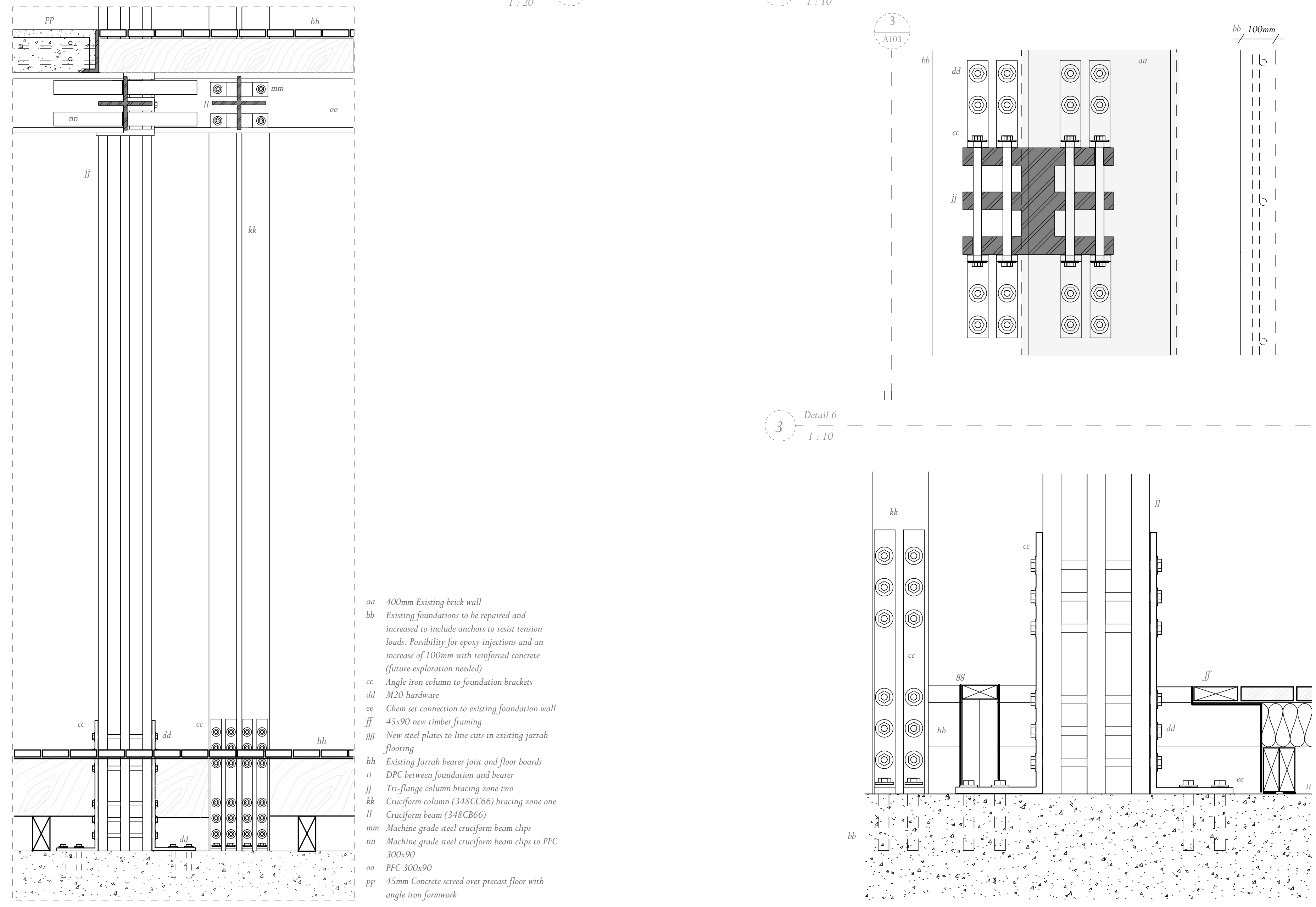

LIST OF REFERENCES

Arturo Franco. 'The Warehouse 17c in Madrid, Spain by Arturo Franco Office'. AECCAFE. 2011. Web. 7 Nov. 2012.

Australia ICOMOS. 'The Burra Charter- The Australian ICOMOC Charter for Places of Cultural Significance'. 1999 : n. pag. Print.

Boniver, Tristan, Collectif Rotor, and Exposition internationale d'architecture. Usus = Usures :

état des lieux $=$ how things stand. Bruxelles: Éditions Communauté française Wallonie-Bruxelles, 2010. Print

Boyarsky, Alvin, and Mary Miss. Mary Miss: Projects 1966-1987. London: Architecural Association, 1987. Print.

Cattanach, A et al. 'Appropriateness of Seismic Strengthening Interventions in Heritage Buildings: A Framework of Appraisal'. 2008. Web. 10 May 2012

CCM Architects. 'Shed 13 CCM Architects'. CCM Architects. Web. 11 Oct. 2012.

Charleson, Andrew. Seismic design for architects : outwitting the quake. Amsterdam; Boston; London: Elsevier/Architectural Press, 2008. Print.

--.. Structure as Architecture a Sourcebook for Architects and Structural Engineers. Oxford: Elsevier, 2005. Web. 11 July 2012

Clare, Lindsay. 'Aesthetic Guidelines and the Design Process'. Take 3 The Double Dimension Heritage and Innovation. Sydney: Red Hill ACT Australia; Royal Australian Institute of Architects, 2004. 145-157. Print.

Department of Building and Housing. 'Earthquake-prone Buildings' . Ministry of Business Innovation \& Employment. Web. 26 Sept. 2012.

Despoke. 'Pineapples on Your Doorstep | Despoke'. 19 June 2012.Web. 13 Nov. 2012.

Dizhur, Dmytro et al. 'Performance of Masonry Buildings and Churches in the 22 February 2011 Christchurch Earthquake'. New Zealand Society for Earthquake Engineering Inc. 44 (2011)

279-296. Print. New Zealand Society for Earthquake Engineering Bulletin.

Easton, Paul. ‘Demolition of Harcourts Building Step Nearer'. The Dominion Post 30 Nov. 2012.

Frampton, Kenneth. Studies in tectonic culture : the poetics of construction in nineteenth and twentieth century architecture. Ed. John Cava. Cambridge, Mass.: MIT Press, 1995. Print.

Gorrie, andrew. 'Stuff.co.nz'. Coffee firm full of beans. 22 July 2009. Web. 11 Oct. 2012.
Guidi, Guido, R. Nicholas Olsberg, and Carlo Scarpa. Carlo Scarpa, architect : intervening with history. Montréal [u.a.]; New York: Canadian Centre For Architecture The Monacelli Press., 1999. Print.

Hill, Jennifer. 'Six Degrees of Intervention'. Take 3 The Double Dimension: Heritage and Innovation. Sydney: Red Hill ACT Australia; Royal Australian Institute of Architects, 2004. 69-85. Print.

Historic Houses Trust of NSW. ‘The Mint'. Historic Houses Trust of NSW. 2012. Web. 30 Sept. 2012

ICOMOS New Zealand. ‘About ICOMOS’. ICOMOS New Zealand. 2007. Web. 11 July 2012.

--. ICOMOS New Zealand Charter for the Conservation of Places of Cultural Heritage Value: Revised 2010. [Auckland, N.Z: ICOMOS New Zealand, 2010. Print.

Jahn, Graham. 'Making Room for Tomorrow's Heritage'. Take 3 The Double Dimension: Heritage and Innovation. Sydney: Royal Australian Institute of Architects, 2004. 196-211. Print.

Larson, Kent, Vincent Scully, and William J. Mitchell. Louis I. Kahn : Unbuilt Masterworks. 1St Edition. The Monacelli Press, 2000. Print.

Maclean, Chris. 'Wellington Region - Creation Stories and Lanscape'. Te Ara Encyclopedia of New Zealand. 3 Mar. 2009. Web. 26 Sept. 2012.

McBride, Kerry. 'Historic Wellington Building Faces Demolition’. The Domion Post 23 Mar. 2012.

---. 'Wrecking Ball Sought for Heritage Building'. The Dominion Post 2 Oct. 2012.

McClean, Robert, and Robert Byron. 'Retrofit and Heritage'. Auckland: New Zealand Historic Places Trust, 2012.1-17. Print.

Mostafavi, Mohsen, and David Leatherbarrow. On weathering : the life of buildings in time

Cambridge, Mass.: MIT Press, 1993. Print.

New Zealand Historic Places Trust. 'History: Robert Hannah and His Family'. Robert Hannah and his family. Web. 3 Oct. 2012

New Zealand Historic Places Trust Pouhere Taonga. 'New Zealand Historic PlacesTrust Pouhere Taonga'. Wellington Harbour Board Shed 13. 2011. Web. 11 Oct. 2012

RomanyWG. Beauty in Decay: Urbex:The Art of Urban Exploration. CarpetBombingCulture, 2010. Print. 
Rutherford, Hamish, Michelle Cooke, and Catherine Harris. 'New Plans for Earthquake Strengthening'. The Dominion Post 7 Dec. 2012.

Schouten, Hank. 'Albemarle Building Spurns Early Suitors'. The Dominion Post. 25 Feb. 2012. Web. 3 Oct. 2012.

---. 'Developer Pays $\$ 820,000$ for Quake-prone Brothel'. The Dominion Post. 23 May 2012.Web. 3 Oct. 2012.

Schultz, Anne-Catrin. Carlo Scarpa - layers. Stuttgart; London: Ed. Menges, 2010. Print. Simon, Joan, and Ann Hamilton. Ann Hamilton. New York: Harry N. Abrams, 2002. Print.

Stevens, Ross Ernest. 'Worn Out or Worn in?: "This Book Is Submitted as a Commentary on Design Research by Composition Undertaken for the Degree of Master of Design [sic]" at Victoria University of Wellington'. 2006 : n. pag. Print.

Taylor, Mark et al. Moments of Resistance. Archadia Press, 2002. Print.

Torrie, Bronwyn. 'Housing Seen as Too Costly for Riddiford Building'. The Dominion Post 15 Oct. 2012

Wellington City Council. 'Earthquake-prone Buildings'. Web. 27 Sept. 2012.

---. 'Heritage Inventory - Heritage Buildings Search'. Albemarle Hotel. Web. 3 Oct. 2012.

---. 'Heritage Inventory - Heritage Buildings Search'. Antrim House. Web. 3 Oct. 2012.

Wellington City Libraries. 'Wellington Architecture'. Heritage > Wellington's Architecture \& Building Heritage. Web. 3 Oct. 2012

Woolf, Virginia. To the lighthouse. New York: Harcourt Brace Jovanovich, 1981. Print.

Zapatka, Christian, and Mary Miss. Mary Miss : making place. New York, NY: Whitney Library of Design, 1997. Print.
LIST OF FIGURES

Fig. 1 (Pg. IV) Vista Este, Campoamor by Andrew More (1998-2002). Source http:/ / www. andrewlmoore.com/photography/cuba/campoamor-vista-este

Fig. 2 (Pg. II) Stratified material conditions. Author's own image (2012).

Fig. 3 (Pg. VI) Identifying the weak points in the west façade. Author's own image (2012).

Fig. 4 (Pg. VIII) Setting the atmosphere with the weathering materials in the Albemarle Hotel. Author's own image (2012).

Fig. 5 (Pg. X) Existing roof top conditions. Author's own image (2012).

Fig. 6 (Pg. XII) Exploring lateral bracing within the Albemarle Hotel without floors and walls. Author's own image (2012).

Fig. 7 (Pg. XVI-1) Existing Albemarle Hotel lobby ceiling - Ground Floor. Author's own image (2012).

LAYER OI

Fig. 8 (Pg. 12-13) Existing Albemarle Hotel historic stair - Ground Floor. Author's own image (2012).

Fig. 9 (Pg. 22) Bresolini’s Building, Wellington. Author's own image (2012).

Fig. 10 (Pg. 22) Bresolini's Building, Wellington. Author's own image (2012).

Fig. 11 (Pg.23) Shed 13, Wellington. (Strengthened 2000). Author's own image (2012)

Fig. 12 (Pg.23) Shed 13 interior, Wellington by Alistar Cox Architects. Source http://www.ccm. co.nz/\#!/projects/heritage/shed-13/

Fig. 13 (Pg. 24) Shed 13, Wellington Strengthening project by CCM Architects \& Ian Bowman. Author's own image (2012).

Fig. 14 (Pg. 32) Classification chart for identifying appropriate approaches to heritage buildings. Author's own image (2012). 
LAYER O2

Fig. 15 (Pg. 40-41) Existing Albemarle Hotel timber lath - Level One. Author's own image (2012).

Fig. 16 (Pg. 45) Castelvecchio interior door portal intervention by Carlo Scarpa (1957-1974)

Source http:/ /blog.buildlllc.com/2008/01/the-architecture-of-observation/

Fig. 17 (Pg. 45) Castelvecchio, Verona courtyard by Carlo Scarpa (1957-1974).Source http:// www.carloscarpa.es/Castelvecchio.html

Fig. 18 (Pg. 45) Castelvecchio Cangrande statue, Verona by Carlo Scarpa (1958-64) Source

http://www.carloscarpa.es/Castelvecchio.html

Fig. 19 (Pg. 47) Warehouse 17C, Madrid by Arturo Franco Office (2006). Source http:// www10. aeccafe.com/blogs/arch-showcase/2011/06/14/the-warehouse-17c-in-madrid-spain-by-arturofranco-office/

Fig. 20 (Pg. 47) Warehouse 17C, Madrid by Arturo Franco Office (2006). Source http:/ / www10. aeccafe.com/blogs/arch-showcase/2011/06/14/the-warehouse-17c-in-madrid-spain-by-arturofranco-office/

Fig. 21 (Pg. 49) The Mint, Sydney (2005).Source http://www.hht.net.au/museums/the_mint

Fig. 22 (Pg. 49) The Mint, Sydney, Sydney (2005). Author's own image (2011).

Fig. 23 (Pg. 49) The Mint, Sydney Sydney (2005). Author's own image (2011).

Fig. 24 (Pg. 51) Untitled by Mary Miss (1976). Photograph by Mary Miss in Mary Miss: Making Place by Christian Zapatka. Pg.49.

Fig. 25 (Pg. 51) Untitled by Mary Miss (1976). Photograph by Mary Miss in Mary Miss: Making Place by Christian Zapatka. Pg.49.

Fig. 26 (Pg. 52) Field Rotation by Mary Miss (1980-81). Photograph by Mary Miss in Mary Miss Making Place by Christian Zapatka. Pg.64

Fig. 27 (Pg. 52) Veiled Landscape by Mary Miss (1980-81). Source http://www.marymiss.com/ index_.html

Fig. 28 (Pg. 53) Capacity of Absorption room one of three by Ann Hamilton (1988). Sourced in Ann Hamilton by Joan Simon. Pg.68

Fig. 29 (Pg. 53) Capacity of Absorption room two of three by Ann Hamilton (1988). Sourced in Ann Hamilton by Joan Simon. Pg.69
Fig. 30 (Pg. 53) Capacity of Absorption room three of three by Ann Hamilton (1988). Sourced in Ann Hamilton by Joan Simon. Pg.70

Fig. 31 (Pg. 54) The Spell by Ann Hamilton (1997). ). Sourced in Ann Hamilton by Joan Simon. Pg. 85

Fig. 32 (Pg. 54) The Spell by Ann Hamilton (1997). Sourced in Ann Hamilton by Joan Simon. Pg. 85

LAYER O3

Fig. 33 (Pg. 56-57) Existing Albemarle Hotel Peeling Paint - LevelThree. Author's own image (2012).

Fig. 34 (Pg. 60) Aerial view of Wellington central. Author's own image (2012).

Fig. 35 (Pg.62) Reclamation of Wellington Harbour. Author's own image (2012).

Fig. 36 (Pg. 64) Wellington's fault lines. Author's own image (2012).

Fig. 37 (Pg. 66) Wellington's Heritage buildings \& heritage areas. Author's own image (2012). Fig. 38 (Pg. 68) Te Aro's earthquake prone \& stickered buildings. Author's own image (2012). Fig. 39 (Pg. 69) Section 124(1)(c) yellow notice. Source http:/ /www.wellington.govt.nz/ services/earthquake/index.html

Fig. 40 (Pg. 69) Section 124(1)(c) orange notice. Source http://www.wellington.govt.nz/ services/earthquake/index.html

Fig. 41 (Pg. 70) Section 124(1)(c) red notice. Source http:/ / www.wellington.govt.nz/services/ earthquake/index.html

Fig. 42 (Pg. 70) Section 124 (1) (b) \& Section 128 red notice. Source http://www.wellington. govt.nz/services/earthquake/index.html

Fig. 43 (Pg. 71) The Albemarle's 124(1)(b) notice. Author's own image (2012).

Fig. 44 (Pg. 72-73) Arial shot of the Albemarle Hotel and Glover Park, Wellington by Paul Hillier. (2012)

Fig. 45 (Pg. 74) Albemarle Hotel after the cupola was removed.

Fig. 46 (Pg. 74) Albemarle Hotel 2012. Author's own image (2012). 
Fig. 47 (Pg. 75) Albemarle Hotel foot print \& neighbouring right of way. Source http://www. wellington.govt.nz/maps/webmaps/webmap/wccmap.html

Fig. 48 (Pg. 75) View of the Albemarle Hotel from neighbouring building. Author's own image (2012).

Fig. 49 (Pg. 75) Pineapple finals. Author's own image (2012).

Fig. 50 (Pg. 76) Albemarle rendition of the Renaissance facade level one. Author's own image (2012).

Fig. 51 (Pg. 77) Albemarle rendition of the Renaissance facade Levels Two \& Three. Author's own image (2012).

Fig. 52 (Pg. 78) Disengaging the layers. Author's own image (2012).

Fig. 53 (Pg. 79) Protecting the Façade. Author's own image (2012).

\section{LAYER O4}

Fig. 54 (Pg. 80-81) Existing Albemarle Hotel exposed timber ceiling - Level Three. Author's own image (2012).

Fig. 55 (Pg. 86) The Antrim House, Wellington. Author's own image (2012)

Fig. 56 (Pg. 86) The Antrim House entrance lobby, Wellington. Author's own image (2012).

Fig. 57 (Pg. 87) The Antrim House main entrance, Wellington. Author's own image (2012).

Fig. 58 (Pg. 88) The Antrim House program analysis. Author's own image (2012).

Fig. 59 (Pg. 89) The Antrim House public \& private space. Author's own image (2012).

Fig. 60 (Pg. 90) The Antrim House original southeast elevation. Author's own image (2012).

Fig. 61 (Pg. 91) The Antrim House Level One spatial analysis. Author's own image (2012).

Fig. 62 (Pg. 91) The Antrim House Ground Floor spatial analysis. Author's own image (2012)

Fig. 63 (Pg. 92) The Albemarle lobby ceiling - Ground Floor. Author's own image (2012).

Fig. 64 (Pg. 92) The Albemarle front sitting room - Ground Floor. Author's own image (2012).

Fig. 65 (Pg. 92) The Albemarle historic stair - Ground Floor. Author's own image (2012).

Fig. 66 (Pg. 93) The Albemarle spatial key - Ground Floor. Author's own image (2012).
Fig. 67 (Pg. 93) The Albemarle fireplace - Ground Floor. Author's own image (2012). Fig. 68 (Pg. 93) The Albemarle store room - Ground Floor. Author's own image (2012). Fig. 69 (Pg. 93) The Albemarle original restaurant - Ground Floor. Author's own image (2012). Fig. 70 (Pg. 94) The Albemarle exposed lath - Level One. Author's own image (2012). Fig. 71 (Pg. 94) The Albemarle water marks - Level One. Author’s own image (2012). Fig. 72 (Pg. 95) The Albemarle spatial key - Level One. Author's own image (2012).

Fig. 73 (Pg. 95) The Albemarle original copper light switches - Level One. Author's own image (2012).

Fig. 74 (Pg. 95) The Albemarle hallway \& stair - Level One. Author's own image (2012). Fig. 75 (Pg. 95) The Albemarle north facing room - Level One. Author's own image (2012). Fig. 76 (Pg. 96) The Albemarle spatial key - Level Two. Author's own image (2012).

Fig. 77 (Pg. 96) The Albemarle exposed timber, lath \& paint - Level Two. Author's own image (2012).

Fig. 78 (Pg. 96) The Albemarle peeling paint - Level Two. Author's own image (2012). Fig. 79 (Pg. 97) The Albemarle spatial key - Level Three. Author's own image (2012).

Fig. 80 (Pg. 97) The Albemarle exposed timber ceiling - Level Three. Author's own image (2012). Fig. 81 (Pg. 97) The Albemarle cooper cupola - Level Three. Author's own image (2012) Fig. 82 (Pg. 98) The Albemarle peeling paint - Level Three. Author's own image (2012). Fig. 83 (Pg. 98) The Albemarle existing roof top space - Level Three. Author's own image (2012). Fig. 84 (Pg. 99) The Albemarle water damaged wall - Level Three. Author's own image (2012). Fig. 85 (Pg. 99) The Albemarle original parapet - Level Three. Author's own image (2012)

\section{LAYER OS}

Fig. 86 (Pg. 100-101) Existing Albemarle peeling paint - Level Two. Author's own image (2012). Fig. 87 (Pg. 102) Design development experiments. Author's own image (2012).

Fig. 88 (Pg. 103) Design development: facade \& roof exploration. Author's own image (2012). 
Fig. 89 (Pg. 107) Existing footprint showing structural grid lines. Author's own image (2012).

Fig. 90 (Pg. 107) Existing footprint showing torsional rotation. Author's own image (2012).

Fig. 91 (Pg. 107) Existing footprint showing tripartite zones. Author's own image (2012).

Fig. 92 (Pg. 107) Existing footprint showing new moment frame torsional rotation. Author's own image (2012).

Fig. 93 (Pg. 107) New moment frame structure. Author's own image (2012).

Fig. 94 (Pg. 107) New moment frame showing lateral movement. Author's own image (2012). Fig. 95 (Pg. 108) Drawn discussions with engineer Sean Gledhill. Author's own image (2012).

Fig. 96 (Pg. 111) Final Bracing Plan. Author's own image (2012).

Fig. 97 (Pg. 112) Perspective view of the contemporary facade \& Albemarle Hotel from Ghuznee Street. Author's own image (2012).

Fig. 98 (Pg. 114) Perspective view of the contemporary facade from Glover Park. Author's own image (2012).

Fig. 99 (Pg. 115) Perspective view of the contemporary facade from Garrett Street. Author's own image (2012).

Fig. 100 (Pg. 116-117) Perspective plan view of the new facade. Author's own image (2012).

Fig. 101 (Pg. 118) Veiled Landscape (1979) by Mary Miss. Author's own image (2012).

Fig. 102 (Pg. 119) The contemporary structural intervention presented as a Mary Miss installation . Author's own image (2012).

Fig. 103 (Pg. 120-121) The contemporary facade intervention. Author's own image (2012).

Fig. 104 (Pg. 122) Existing vertical \& horizontal circulation of the Albemarle Hotel. Author's own image (2012).

Fig. 105 (Pg. 122) New vertical \& horizontal circulation within the contemporary facade. Author's own image (2012)

Fig. 106 (Pg. 125) Structural intervention as a rhythmic ordering device. Author's own image (2012).

Fig. 107 (Pg. 128-129) Programmatic exploration of the rhythmic ordering device. Author's own image (2012).
Fig. 108 (Pg. 130-131) Programmatic exploration of the rhythmic ordering device. Author's own image (2012).

Fig. 109 (Pg. 132-133) Facade elevations NTS. Author's own image (2012).

Peeling back

Fig. 110 (Pg. 134-135) Existing Albemarle water damage - Level Three. Author's own image (2012).

Fig. 111 (Pg. 140) Tri-flange column. Author's own image (2012)

Fig. 112 (Pg.141) Cruciform beam to tri-flange column junction. Author's own image (2012)

Fig. 113 (Pg. 142) T section beam to tri רᄀ-flange column junction. Author's own image (2012).

Fig. 114 (Pg. 143) Cruciform beam to tri-flange column junction showing existing timber floor. Author's own image (2012).

Fig. 115 (Pg. 144) Custom spider glazing detail. Author's own image (2012).

Fig. 116 (Pg. 145) Existing timber roof and tri-flange steel roof joist. Author's own image (2012).

Fig. 117 (Pg. 148-149) Detail Section showing the facade intervention. Author's own image (2012).

Fig. 118 (Pg. 150-151) Detail Sheet 101 Roof details. Author's own image (2012).

Fig. 119 (Pg. 152-153) Detail Sheet 102 column details 01. Author's own image (2012).

Fig. 120 (Pg. 154-155) Detail Sheet 103 column details 02. Author's own image (2012).

Fig. 121 (Pg. 156-157) Detail Sheet 104 glazing details. Author’s own image (2012). 


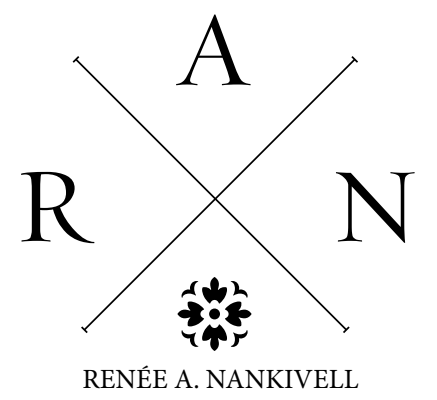

